Coastal Circulation and Water-Column Properties in the War in the Pacific National Historical Park, GuamMeasurements and Modeling of Waves, Currents, Temperature, Salinity, and Turbidity, April-August 2012
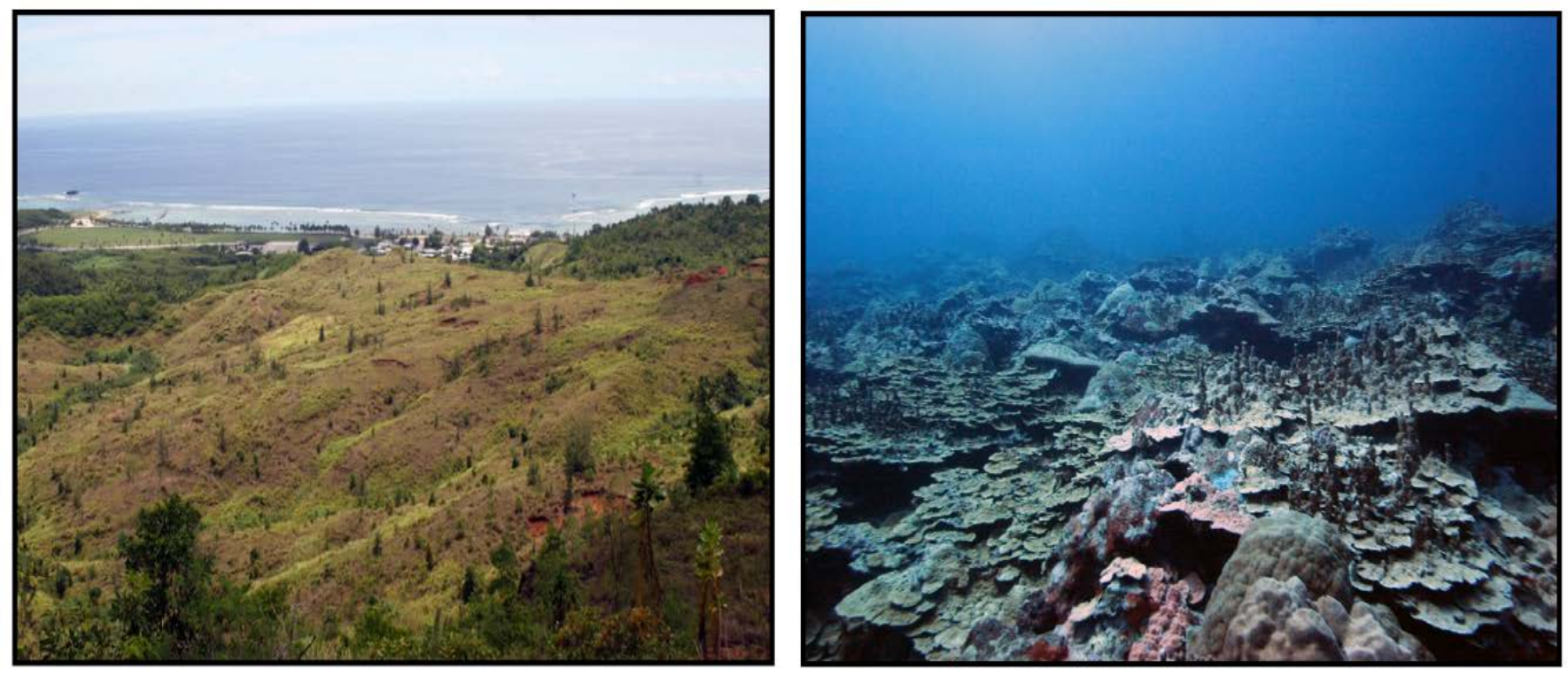

Open-File Report 2014-1130

U.S. Department of the Interior

U.S. Geological Survey 
FRONT COVER: Left: Photograph showing the impact of intentionally set wildfires on the land surface of War in the Pacific National Historical Park. Right: Underwater photograph of some of the healthy coral reefs in War in the Pacific National Historical Park. 


\section{Coastal Circulation and Water-Column Properties in the War in the Pacific National Historical Park, Guam- Measurements and Modeling of Waves, Currents, Temperature, Salinity, and Turbidity, April-August 2012}

By Curt D. Storlazzi, Olivia M. Cheriton, Jamie M.R. Lescinski, and Joshua B. Logan

Open-File Report 2014-1130

U.S. Department of the Interior

U.S. Geological Survey 


\section{U.S. Department of the Interior \\ SALLY JEWELL, Secretary}

U.S. Geological Survey
Suzette M. Kimball, Acting Director

U.S. Geological Survey, Reston, Virginia: 2014

For product and ordering information: World Wide Web: http://www.usgs.gov/pubprod

Telephone: 1-888-ASK-USGS

For more information on the USGS-the Federal source for science about the Earth, its natural and living resources, natural hazards, and the environment:

World Wide Web: http://www.usgs.gov

Telephone: 1-888-ASK-USGS

Any use of trade, product, or firm names is for descriptive purposes only and does not imply endorsement by the U.S. Government.

Suggested citation:

Storlazzi, C.D., Cheriton, O.M., Lescinski, J.M.R., and Logan, J.B., 2014, Coastal circulation and water-column properties in the War in the Pacific National Historical Park, Guam-Measurements and modeling of waves, currents, temperature, salinity, and turbidity, April-August 2012: U.S. Geological Survey Open-File Report 20141130, 104 p., http://dx.doi.org/10.3133/ofr20141130.

Although this information product, for the most part, is in the public domain, it also may contain copyrighted materials as noted in the text. Permission to reproduce copyrighted items must be secured from the copyright owner.

ISSN 2331-1258 (online) 


\section{Contents}

Abstract

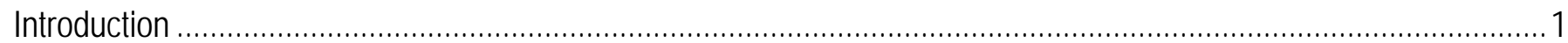

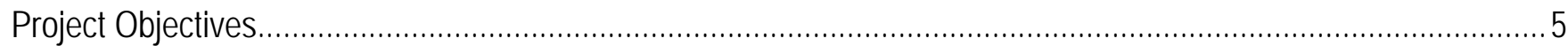

Study Area

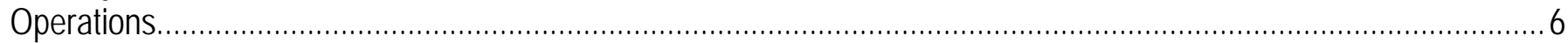

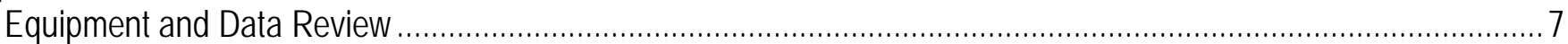

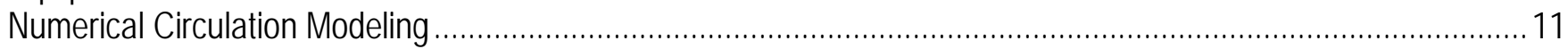

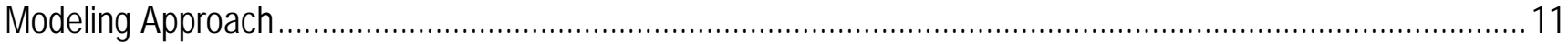

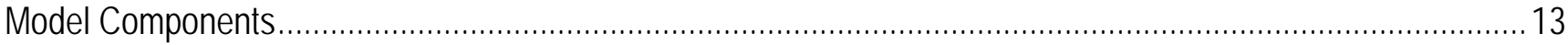

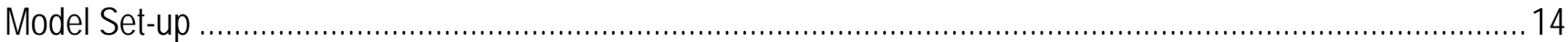

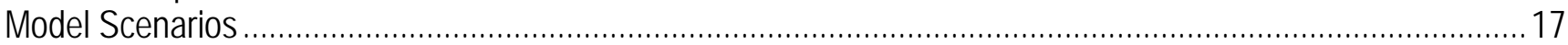

Research Platform and Field Operations........................................................................................... 18

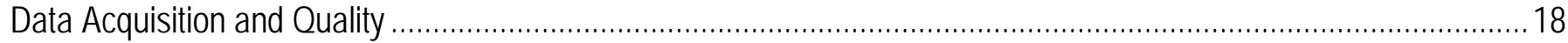

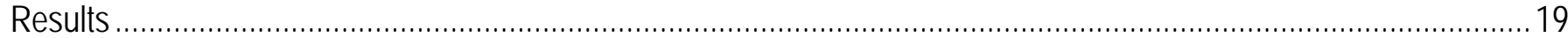

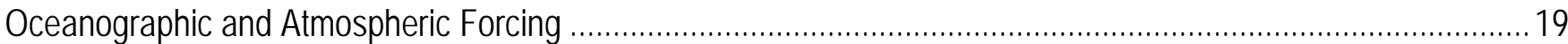

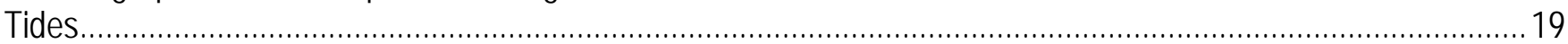

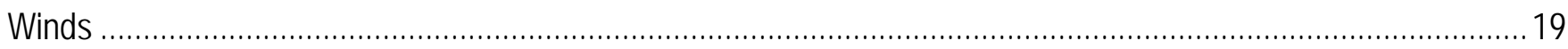

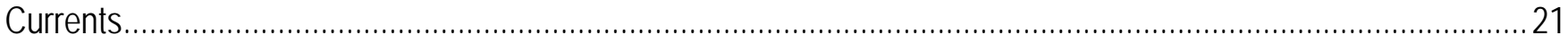

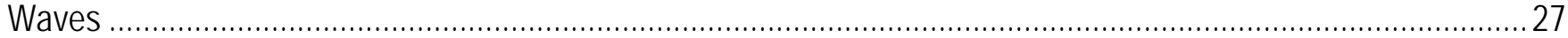

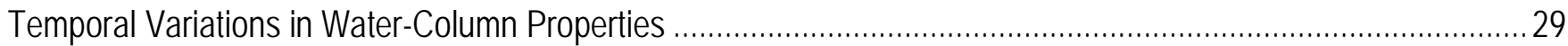

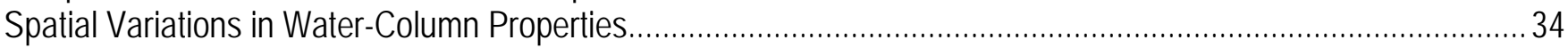

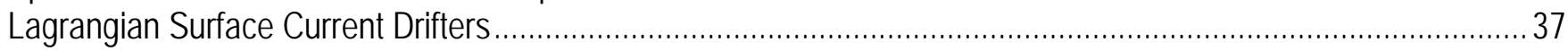

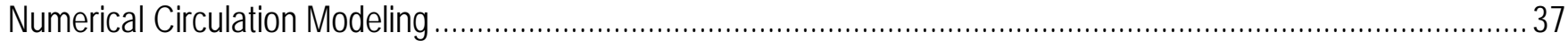

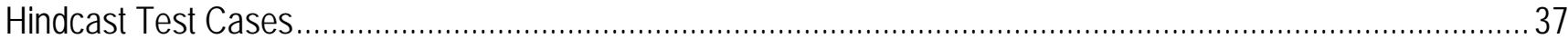

Modeled Tide, Wind, and Wave Scenarios ................................................................................... 39

Modeled Dispersal Patterns along Western Guam .............................................................................51

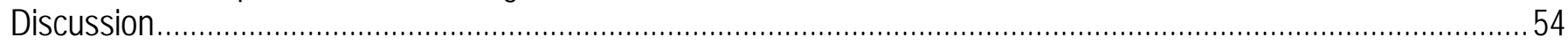

Spatial and Temporal Variability in Circulation Patterns and Water-Column Properties .........................................54

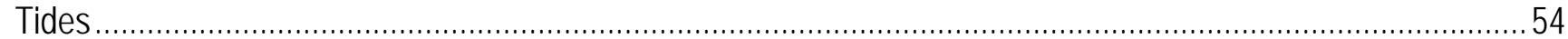

Winds

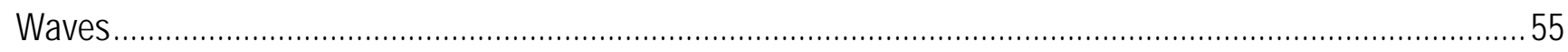

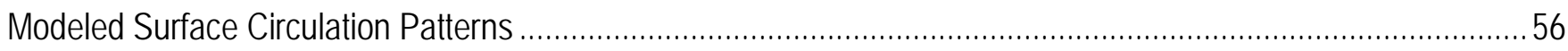

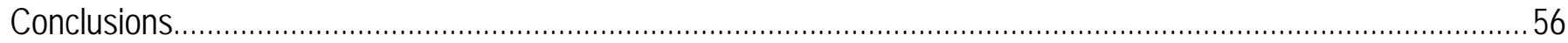

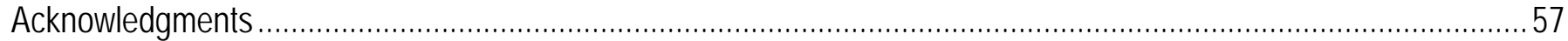

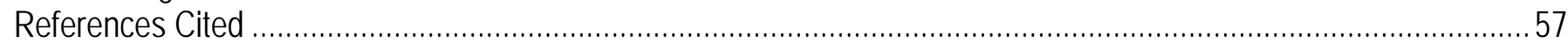

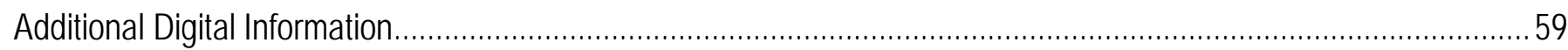

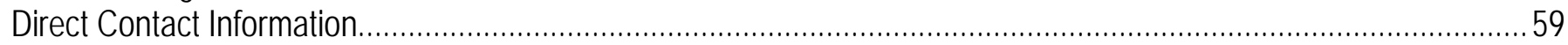

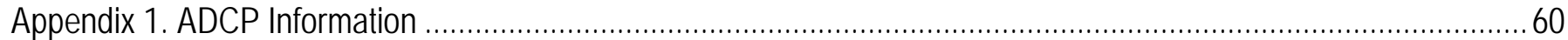

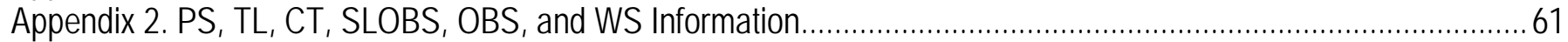

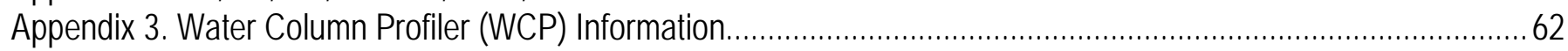

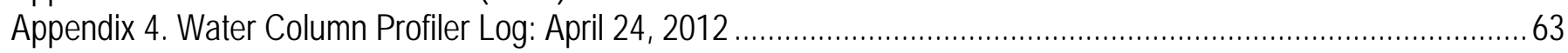

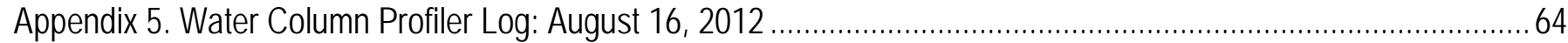

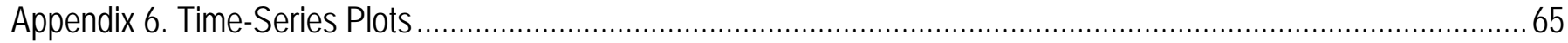

Appendix 7. Maps Showing Variations of Water-Column Properties................................................................. 77

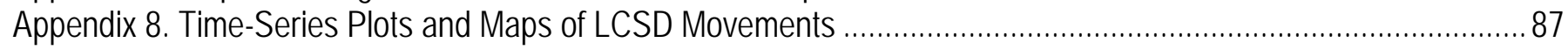

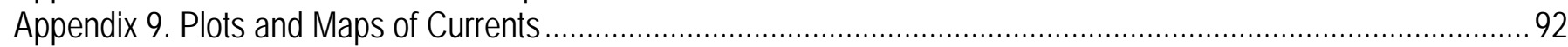

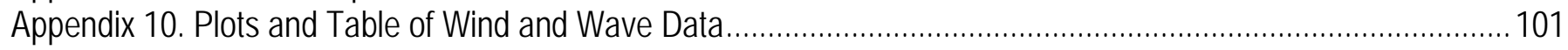




\section{Figures}

1. Map of Guam showing the island's topography and locations of places discussed in the text.................. 3

2. Map of west-central Guam showing locations of instrument packages in Asan and Agat Bays ................ 4

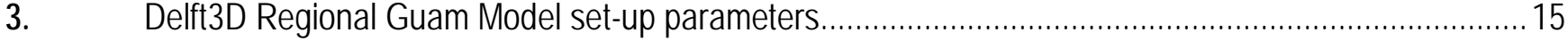

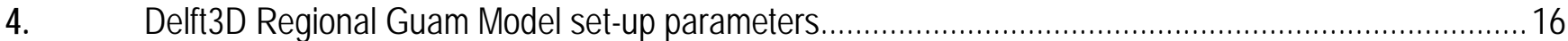

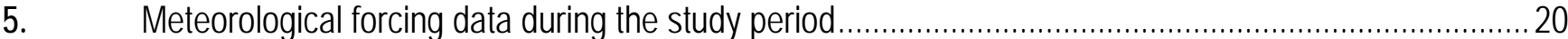

6. Principle axis ellipses and mean near-surface current speeds and directions under tidal forcing ...........22

7. $\quad$ Principle axis ellipses and mean near-bed current speeds and directions under tidal forcing ..................23

8. Mean near-surface and near-bed current speeds and directions during conditions dominated by northeasterly winds

9. Mean near-surface and near-bed current speeds and directions during conditions dominated by variable winds

10. Mean near-surface and near-bed current speeds and directions during conditions dominated by large

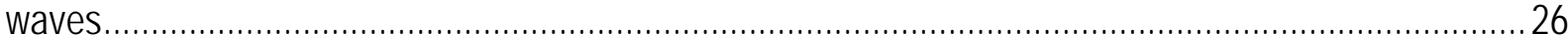

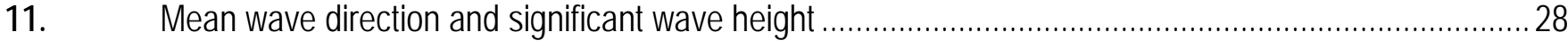

12. Tide, temperature, and salinity for the shallow and deep sites....................................................... 30

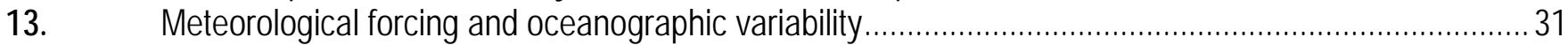

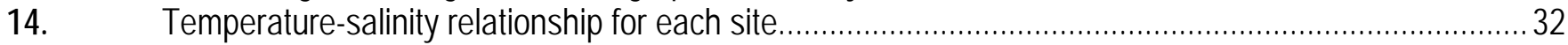

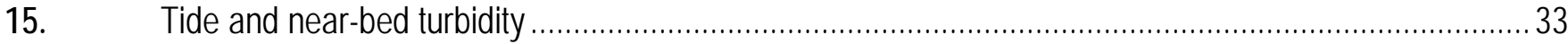

16. Temperature and salinity profiler measurements from April and August surveys .................................. 35

17. Optical backscatter, light transmission, and chlorophyll concentration profiler measurements from April and August surveys .................................................................................................... 36

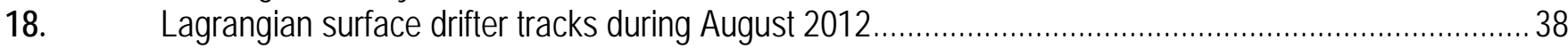

19. Map of average near-surface current speeds over mean tidal forcing ................................................ 40

20. Map of average near-surface current speeds over mean tidal forcing and winds out of the north ........... 41

21. Map of average near-surface current speeds over mean tidal forcing and winds out of the northwest... 42

22. Map of average near-surface current speeds over mean tidal forcing and winds out of the west...........43

23. Map of average near-surface current speeds over mean tidal forcing and winds out of the southwest .. 44

24. Map of average near-surface current speeds over mean tidal forcing and winds out of the south.......... 45

25. Map of average near-surface current speeds over mean tidal forcing and waves out of the north .......... 46

26. Map of average near-surface current speeds over mean tidal forcing and waves out of the northwest.. 47

27. Map of average near-surface current speeds over mean tidal forcing and waves out of the west .......... 48

28. Map of average near-surface current speeds over mean tidal forcing and waves out of the southwest . 49

29. Map of average near-surface current speeds over mean tidal forcing and waves out of the south.........50

30. Map showing modeled surface particle dispersal for release locations on coral reefs north of Apra Harbor

31. Map showing modeled surface particle dispersal for release locations on coral reefs in and south of

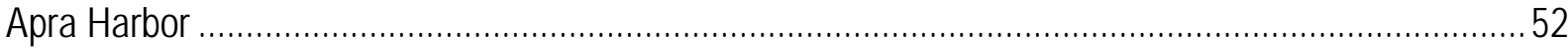

32. Map showing modeled surface particle dispersal for release locations north of Apra Harbor ..................53

33. Map showing modeled surface particle dispersal for release locations on coral reefs in and south of Apra Harbor 


\section{Tables}

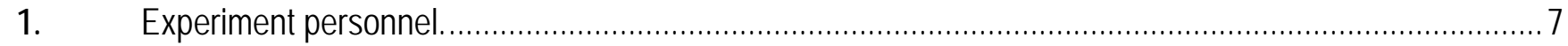

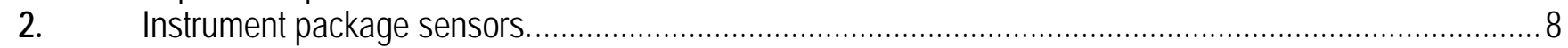

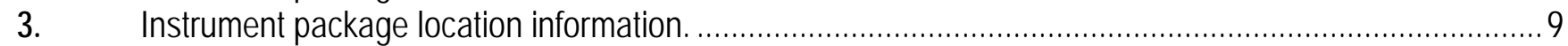

4. Water column profiler cast location and depth information. ................................................................. 10

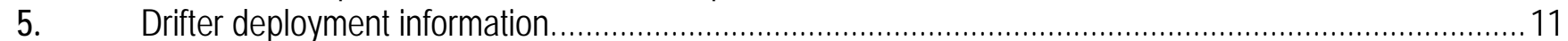

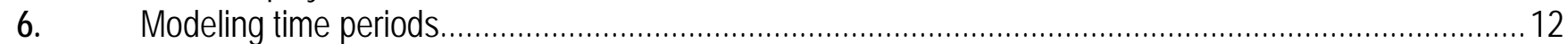

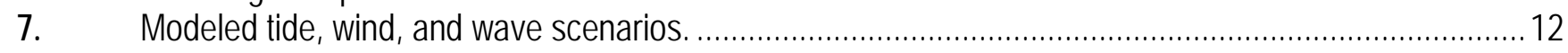

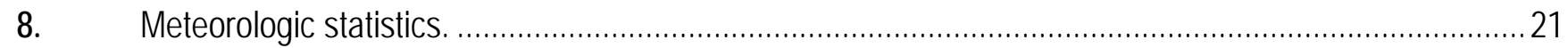

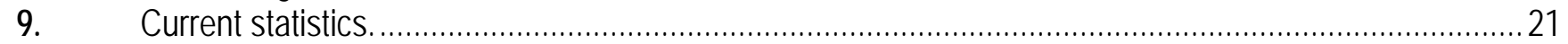

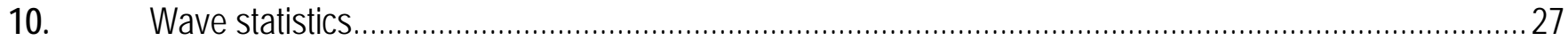

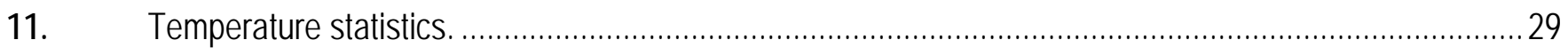

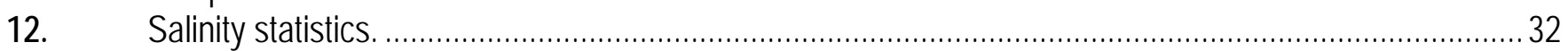

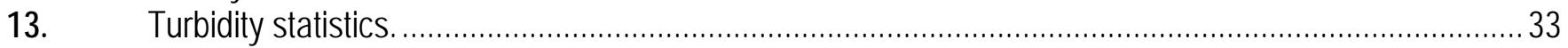




\title{
Coastal Circulation and Water-Column Properties in the War in the Pacific National Historical Park, Guam- Measurements and Modeling of Waves, Currents, Temperature, Salinity, and Turbidity, April-August 2012
}

\author{
By Curt D. Storlazzi ${ }^{1}$, Olivia M. Cheriton¹, Jamie M.R. Lescinski², and Joshua B. Logan¹
}

\begin{abstract}
The U.S. Geological Survey (USGS) Pacific Coastal and Marine Science Center (PCMSC) initiated an investigation in the National Park Service's (NPS) War in the Pacific National Historical Park (WAPA) to provide baseline scientific information on coastal circulation and water-column properties along west-central Guam, focusing on WAPA's Agat Unit, as it relates to the transport and settlement of coral larvae, fish, and other marine organisms. The oceanographic data and numerical circulation modeling results from this study demonstrate that circulation in Agat Bay was strongly driven by winds and waves at longer ( $>1$ day) timescales and by the tides at shorter ( $<1$ day) timescales; near-surface currents in deep water were primarily controlled by the winds, whereas currents on the shallow reef flats were dominated by wave-driven motions. Water-column properties exhibited strong seasonality coupled to the shift from the trade wind to the non-trade wind season. During the dry tradewind season, waters were cooler and more saline. When the winds shifted to a more variable pattern, waters warmed and became less saline because of a combination of increased thermal insolation from lack of wind forcing and higher rainfall. Turbidity was relatively low in Agat Bay and was similar to levels measured elsewhere along west-central Guam. The numerical circulation modeling results provide insight into the potential paths of buoyant material released from a series of locations along west-central Guam under summer non-trade wind forcing conditions that characterize coral spawning events. This information may be useful in evaluating the potential zones of influence/impact resulting from transport by surface currents of material released from these select locations.
\end{abstract}

\section{Introduction}

The flow of water in and around coral reefs affects a number of physical, chemical, and biologic processes and factors that influence the health and sustainability of coral reef ecosystems. These range from the residence time of sediment and contaminants to nutrient uptake and larval retention and dispersal. As currents approach a coast, they diverge to flow around reef structures, causing strong horizontal and vertical shear. This can result in either the rapid advection of material in localized jets, or the retention of material in eddies that form in the lee of bathymetric features. The high complexity and diversity, both within and between reefs, and the limited number of field measurements have limited our

\footnotetext{
${ }^{1}$ U.S. Geological Survey.

2 Deltares, Delft, The Netherlands.
} 
understanding of the nature of flow and the resulting flux of physical, chemical, and biologic material in these fragile ecosystems.

Sediment, nutrients, and other pollutants from a variety of land-based activities adversely affect many coral reef ecosystems in the United States and around the world. These pollutants are transported in surface water runoff, groundwater seepage, and atmospheric fallout into coastal waters, and there is compelling evidence that the sources have increased globally as a result of human-induced changes to watersheds. Significant changes in the drainage basins due to agriculture, feral ungulate grazing, fires, and urbanization have, in turn, altered the character and volume of land-based pollution released to coral reefs. Terrigenous sediment runoff (and the associated nutrients and contaminants often absorbed onto it) and deposition on coral reefs are recognized to negatively affect coral health by blocking light and inhibiting photosynthesis, directly smothering and abrading coral, and triggering increases in macroalgae. Thus, for effective reef management, it is essential to monitor the impacts of these landbased activities on reef health and ecology by conducting studies that combine information on watershed, surface water flow, and groundwater flow with information on the transport and fate of sediment and other pollutants in the reef environment.

Two of the main anthropogenic activities along west-central Guam's coastline that may affect the region's coral reef ecosystems are pollution and coastal land use and development, as discussed in the review by Porter and others (2005). The pollution threats include point sources, such as municipal wastewater discharges (Northern District, Hagatna, Naval Station Guam/Agat-Santa Rita Waste Water Treatment Plants), cooling water (Tanguisson Steam and Cabras Power Plants), and numerous storm water, ballast water, and tank bottom draw outfalls; nonpoint sources include septic systems, urban runoff, illegal dumping, and groundwater discharges. Poor land-use practices include development without the use of runoff management measures, increased areal extent of impervious surfaces and decreased extent of vegetative barriers, and recreational off-road vehicle use. Furthermore, feral ungulates and illegal wildfires remove protective vegetative cover and generally result in increased soil erosion. Although anthropogenic point sources have been reduced in many areas by better management practices, nonpoint sources have either stayed constant or increased. Between 1975 and 1999, it is estimated that Guam lost more than one-quarter of its tree cover, and the occurrences of more than 750 wildfires each year have resulted in a greater proportion of badlands and other erosion-prone land surfaces with high erosion rates (Forestry and Soil Resources Division, 1999).

Approximately 2.25 square kilometers $\left(\mathrm{km}^{2}\right)$ of Agat Bay, west-central Guam, lies within the National Park Service's (NPS) War in the Pacific National Historical Park's (WAPA) Agat Unit (fig. 1). The bay is the sink for material coming out of the Agat watershed. Anthropogenic modifications of the watersheds adjacent to Agat Bay, which include intentionally set wildfires, construction, and agriculture (Minton, 2005), are believed to have increased over the past 25 years (National Resource Conservation Service, 1996). These land-use practices result in accelerated erosion by removing grasses and small trees that stabilize the soil. Even modest rains on Guam cause sediment plumes to be discharged from many rivers to coastal waters, including the rivers in Asan and Agat (Minton and others, 2007). In addition, typhoons pass close enough to Guam every 2-3 years to cause heavy precipitation ( $>2$ $\mathrm{cm} /$ hour) on the island, rapidly flushing unstabilized soil down to the coast and onto WAPA's nearshore reefs (Porter and others, 2005).

Observations by Minton and others (2007) indicate that this terrestrial sediment discharge to the coastal waters has resulted in sedimentation, eutrophication, and pollution that have affected WAPA's coral reef ecosystems. These authors have further shown that the input of terrestrial sediment to the park's nearshore waters is greater during the wet season (July-December), which is of serious concern because this is also the time of peak coral spawning and larval settlement (Richmond and Hunter, 1990). Quantitative information on the coastal processes that control sediment, larval, nutrient, and contaminant residence time and advection through the bay's fringing reef systems is needed to better manage the WAPA's marine resources. 


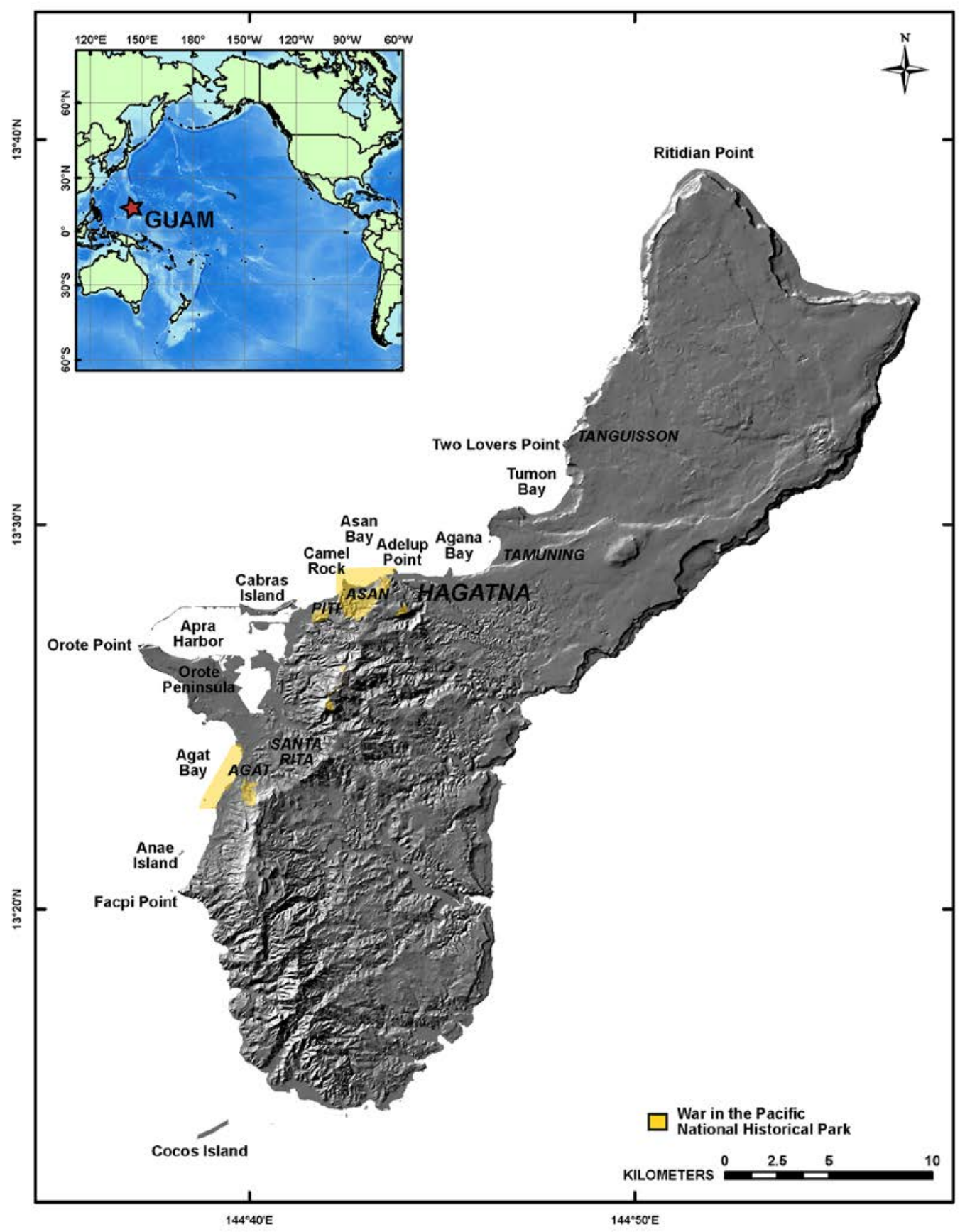

Figure 1. Shaded-relief map of Guam showing the island's topography and locations of places discussed in the text.

The U.S. Geological Survey (USGS) Pacific Coastal and Marine Science Center (PCMSC) recently completed an investigation of coastal circulation and water-column properties along westcentral Guam, primarily focusing on WAPA's Asan Unit to the north (fig. 2; Storlazzi and others, 2009; Storlazzi and others, 2013). In 2012, the USGS-PCMSC initiated an additional investigation to provide baseline scientific information on coastal circulation and water-column properties along west-central Guam, focusing on WAPA's Agat Unit (fig. 2), as it relates to the transport and settlement of coral larvae, fish, and other marine organisms. This work also supports the U.S. Coral Reef Task Force's (USCRTF) goal of investigating the impact of land-based pollution on corals reefs, as well as the 
resilience of and recruitment to these reefs. Furthermore, the data collected during this experiment will provide NPS and the Guam Environmental Protection Agency (EPA) with quantitative baseline data for possible future measurements made during the planned large-scale expansion of the U.S. military installation at Apra Harbor, which separates WAPA’s Agat and Asan Units.

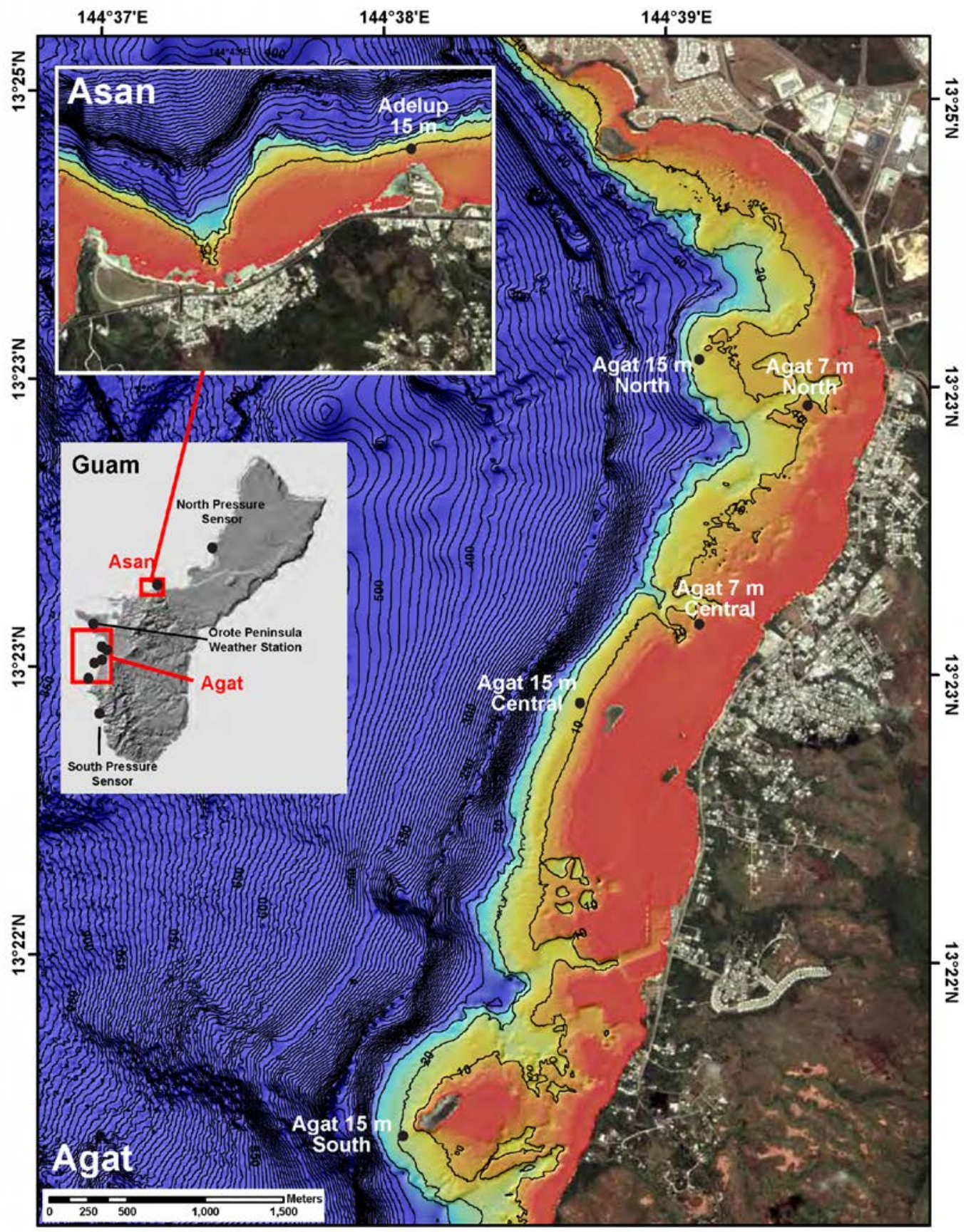

Figure 2. Map of west-central Guam showing locations of instrument packages in Asan and Agat Bays. Bathymetric contour interval 10 meters. 


\section{Project Objectives}

In 2012, USGS and NPS researchers began a collaborative study to determine coastal circulation patterns and their influence on sediment, larval, nutrient, and contaminant flux along west-central Guam and, specifically, in WAPA's Agat Unit and its coral reef ecosystem. To meet these objectives, flow and water-column properties along west-central Guam and in WAPA's Agat Unit were investigated using a suite of meteorologic and oceanographic instrument packages, satellite-tracked ocean surface current drifters, and a physics-based numerical circulation model. The continuous measurements of winds, rainfall, waves, currents, tides, and water properties (temperature, salinity, and turbidity) from these instrument deployments, along with the deployment of satellite-tracked Lagrangian Surface Current Drifters (LSCDs), provide information on nearshore circulation and the variability in these hydrodynamic properties within WAPA's Agat Unit. These observational and model data complement ongoing and future water-quality research efforts along west-central Guam and in WAPA and will provide baseline information of the hydrodynamic and oceanographic regime for the marine portion of WAPA's Agat Unit.

The field experiment consisted of continuous collection of meteorologic and oceanographic data in WAPA from April through August 2012. Deltares and the USGS initiated the development of a threedimensional, physics-based, numerical hydrodynamic (tides, waves, and currents) model of west-central Guam's marine waters. The goals of these efforts were to provide baseline scientific information on circulation, water-column properties, and their influence on the movement of sediment, larvae, nutrients, and contaminants through the waters of west-central Guam and WAPA. In order to do this, the USGS and NPS set out to do the following:

a) Measure wind speed, wind direction, rainfall, and barometric pressure to: (1) provide baseline information to NPS and others; (2) address forcing of oceanographic data; and (3) provide boundary conditions for a 3-dimensional, hydrodynamic numerical model for west-central Guam's waters.

b) Measure wave heights, wave periods, wave directions, current speeds, current directions, temperature, salinity, and turbidity to: (1) provide baseline information to NPS and others; and (2) provide boundary conditions and calibration information for a 3-dimensional, hydrodynamic numerical model for west-central Guam’s waters.

c) Deploy satellite-tracked Lagrangian Surface Current Drifters during a period of coral spawning in the summer.

d) Develop a three-dimensional, physics-based, numerical hydrodynamic (tides, waves, and currents) model of west-central Guam's waters.

e) Determine the influence of oceanographic and meteorologic forcing on flow patterns, watercolumn properties, and the resulting transport of material (sediment, larvae, nutrients, and contaminants) for different sets of forcing conditions.

\section{Study Area}

This study was conducted along the west-central coast of the island of Guam, Mariana Islands, U.S.A. (fig. 1). Guam lies between lat $13.2^{\circ} \mathrm{N}$ and $13.7^{\circ} \mathrm{N}$ and between long $144.6^{\circ} \mathrm{E}$ and $145.0^{\circ} \mathrm{E}$ and has an area of $541 \mathrm{~km}^{2}$. It is the southernmost island in the Mariana Islands and is the largest and most heavily populated island in Micronesia. The northern part of the island is a forested coralline limestone plateau rising more than $260 \mathrm{~m}$ above sea level, while the southern part is primarily highly erodible volcanic terrain with peaks as high as $406 \mathrm{~m}$ that are covered in forest and grassland. A coral reef surrounds most of the island, except where rivers discharge into bays. The island's population is most 
dense in the northern and central regions. Guam is described by the Pacific Islands Global Climate Observing System (2012) as having a tropical marine climate, with an average annual rainfall of 2,260 $\mathrm{mm}$, ranging from 2,000 $\mathrm{mm}$ to more than 3,300 $\mathrm{mm}$ (Lander and Guard, 2003). The wet season runs from July through November ( 70 percent of annual rainfall), with the remaining months constituting the dry season ( $\sim 30$ percent of annual rainfall). On longer time scales, rainfall is correlated with the El Nino-Southern Oscillation (ENSO) phenomenon; the period from the end of an ENSO year through the year following ENSO tends to be very dry. The greatest frequency of typhoons occurs between October and November; however, they can form throughout the year. On average, three tropical storms and one typhoon pass within $330 \mathrm{~km}$ of Guam each year.

U.S. Army Corps of Engineers (USACE) Wave Information Studies (WIS) wind and wave hindcast data for west-central Guam (Coastal Hydraulic Laboratory, 2012) for the period of 1981-2004 show the dominance of the northeast trade winds on the general wind and wave climate for the study area. Winds are predominantly out of the east-northeast at speeds of approximately $12 \mathrm{~m} / \mathrm{s}$; similarly, waves are primarily out of the east-northeast and have mean heights on the order of $2 \mathrm{~m}$. Although the mean wind and wave climate is dominated by the northeast trade winds, the influence of typhoons passing close to Guam is evident in the directional distribution of high-speed winds and large waves. Their frequency of occurrence is low, but the directions of the fastest wind speeds and largest waves are more uniformly distributed than the means dominated by the trade winds, with the fastest wind speeds and largest waves coming out of the south and southwest. The tides along west-central Guam are described by the Center for Operational Oceanographic Products and Services (2012) as mixed microtidal and semidiurnal, with two uneven high tides and low tides each day; the mean tidal range is $0.49 \mathrm{~m}$ and the diurnal tidal range is $0.72 \mathrm{~m}$. Mean sea levels are generally highest $(+6.4 \mathrm{~mm})$ during July and lowest (-6.9 mm) during December (Pacific Islands Global Climate Observing System, 2012).

The seafloor in WAPA's Agat and Asan Units was mapped by the National Oceanic and Atmospheric Administration's (NOAA) National Center for Coastal Ocean Science (2005) as predominantly a coral pavement with limited aggregate reef. By their definition, the habitat consists of a macroalgae-covered (10 to $<50$ percent) reef flat, macroalgae-covered (50 to $<90$ percent) reef crest, coral-covered (10 to $<50$ percent) fore reef, and turf-covered (10 to $<50$ percent) upper insular shelf with interspersed patches of unconsolidated sediment.

\section{Operations}

This section provides information about the personnel, equipment, and field operations used during the study. Table 1 gives a list of personnel involved in the experiment and tables $2-4$ provide complete listings of instrument and deployment information. Five instrument suites were deployed to provide an integrated understanding of circulation and sediment dynamics in WAPA's coastal waters: terrestrial instruments, bottom- and mooring-mounted oceanographic instruments, spatial hydrographic surveys, and satellite-tracked Lagrangian ocean surface current drifters.

To provide meteorologic forcing information, terrestrial sensors were used in conjunction with a weather station. The weather station was erected on a large, unobstructed field on the Orote Peninsula between WAPA's Agat and Asan Units (see fig. 1), and it recorded hourly measurements of wind speed and direction, barometric pressure, air temperature, and rainfall. The bottom-mounted oceanographic instruments were deployed along the 7-m and 15-m isobaths in WAPA's Agat and Asan Units (fig. 2). These bottom-mounted instrument packages included near-bed temperature/salinity and optical backscatter sensors, along with upward-looking acoustic Doppler current profilers (ADCPs), which made measurements of current speed, current direction, and acoustic backscatter throughout the water column. Additionally, within the Agat area, two moorings were placed at the North and Central 15-m sites (fig. 2) adjacent to the bottom-mounted instrument packages. These moorings collected nearsurface measurements of temperature, salinity, and turbidity, as well as temperature throughout the 
water column. Two pressure sensors were deployed upcoast and downcoast of WAPA to provide water level boundary conditions for a three-dimensional, physics-based, numerical hydrodynamic (tides, waves, and currents) model for west-central Guam's waters. All of the measurements were on the insular shelf in water depths less than $15 \mathrm{~m}$.

Table 1. Experiment personnel.

[USGS, U.S. Geological Survey; Deltares, Dutch Institute for Delta Technology; NPS, National Park Service]

\begin{tabular}{|l|l|l|}
\hline \multicolumn{1}{|c|}{ Person } & \multicolumn{1}{|c|}{ Affiliation } \\
\hline Curt Storlazzi & USGS & Chief scientist, diver \\
Olivia Cheriton & USGS & Oceanographer \\
Jamie Lescinski & Deltares & Numerical modeler \\
Tom Reiss & USGS & Geographer, dive safety officer \\
Joshua Logan & USGS & Instrument specialist \\
Andrew Stevens & USGS & Instrument specialist \\
Kathy Presto & USGS & Instrument specialist \\
Kurt Rosenberger & USGS & Biologic Resource Division specialist, diver \\
Justin Mills & NPS & Biologic Resource Division specialist, diver \\
Amanda deVillers & Resource Division Manager \\
Mike Gawel & NPS & Vessel captain \\
Todd Genereux & F/V Heavy Metal & Vessel captain \\
Chris Williams & F/V Heavy Metal & Vessel captain \\
Monique Genereux & F/V Heavy Metal & \\
\hline
\end{tabular}

In addition to these fixed, bottom-mounted, time-series measurements, repetitive spatial surveys of water-column properties (variations in water temperature, salinity, turbidity, light transmission, and fluorescence with depth) were made at a number of stations approximately every kilometer from Two Lover's Point at the northern end of Tumon Bay south to Facpi Point (see fig. 1). These data were used to provide greater spatial context to the in situ, bottom-mounted, time-series measurements. Satellitetracked Lagrangian Surface Current Drifters were deployed during coral spawning over selected coral reefs in WAPA's Agat and Asan Units to understand the pathways coral larvae would take following spawning during the summer months.

\section{Equipment and Data Review}

Acoustic Doppler Current Profilers. - Three upward-looking acoustic Doppler current profilers (ADCP) were mounted on MiniPROBEs along the 15-m isobath in Agat and Asan Bays (fig. 2) and used to measure current velocity at $180.5-\mathrm{m}$ bins from $1.7 \mathrm{~m}$ above the seafloor up to the surface for 900 s every $20 \mathrm{~min}$. These instruments also recorded directional wave data, collecting 1,024 measurements at a rate of $2 \mathrm{~Hz}$ every hour to allow calculation of tides (m), significant wave height (m), dominant wave period (s), mean wave direction ( ${ }^{\circ}$ True), and directional spread $\left({ }^{\circ}\right)$. Two additional upward-looking ADCPs mounted on MiniPROBEs were deployed at a depth of $7 \mathrm{~m}$ in small sand patches in Asan Bay's reefs. These shallower ADCPs sampled current velocity at 20 0.5-m bins from $0.83 \mathrm{~m}$ above the seafloor up to the surface for $800 \mathrm{~s}$ every $20 \mathrm{~min}$. Directional wave data from the 7-m ADCPs were also recorded every hour. Acoustic backscatter data $(\mathrm{dB})$ collected from the ADCPs for the current measurements also provide information on the particulates in the water column and can be used as a qualitative measurement of turbidity (Deines, 1999). The sensor locations are listed in tables 2 and 3 ; complete sensor and processing information is listed in appendix 1. 
Table 2. Instrument package sensors.

\begin{tabular}{|c|c|c|}
\hline Site Name & $\begin{array}{c}\text { Depth } \\
\text { [m] }\end{array}$ & Sensors \\
\hline North Pressure Sensor & 5 & Onset HOBO temperature and pressure sensor \\
\hline \multirow[t]{2}{*}{ Adelup Point } & 11 & RD Instruments $600 \mathrm{kHz}$ Workhorse Monitor acoustic Doppler current profiler \\
\hline & 10 & Aquatec 200-TY self-logging optical backscatter sensor \\
\hline \multirow[t]{5}{*}{ Agat 15-m North Mooring } & 1 & Seabird SBE-37SM Microcat conductivity-temperature sensor \\
\hline & 1 & Aquatec 210-TYT self-logging optical backscatter sensor \\
\hline & 5 & Onset HOBO temperature logger \\
\hline & 10 & Onset HOBO temperature logger \\
\hline & 15 & Onset HOBO temperature logger \\
\hline \multirow[t]{3}{*}{ Agat 15-m North MiniProbe } & 14 & RD Instruments $600 \mathrm{kHz}$ Workhorse Monitor acoustic Doppler current profiler \\
\hline & 13 & Aquatec 210-TYT self-logging optical backscatter sensor \\
\hline & 14 & Seabird SBE-37SM Microcat conductivity-temperature sensor \\
\hline \multirow[t]{3}{*}{ Agat 7-m North MiniProbe } & 6 & Nortek 2 MHz Aquadopp acoustic Doppler current profiler \\
\hline & 6 & Seabird SBE-37SM Microcat conductivity-temperature sensor \\
\hline & 5 & Seapoint turbidity sensor \\
\hline \multirow[t]{5}{*}{ Agat 15-m Central Mooring } & 1 & Seabird SBE-37SM Microcat conductivity-temperature sensor \\
\hline & 1 & Aquatec 210-TYT self-logging optical backscatter sensor \\
\hline & 5 & Onset HOBO temperature logger \\
\hline & 10 & Onset HOBO temperature logger \\
\hline & 15 & Onset HOBO temperature logger \\
\hline \multirow[t]{3}{*}{ Agat 15-m Central MiniProbe } & 14 & RD Instruments $600 \mathrm{kHz}$ Workhorse Monitor acoustic Doppler current profiler \\
\hline & 13 & Aquatec 210-TYT self-logging optical backscatter sensor \\
\hline & 14 & Seabird SBE-37SM Microcat conductivity-temperature sensor \\
\hline \multirow[t]{3}{*}{ Agat 7-m Central MiniProbe } & 6 & Nortek $2 \mathrm{MHz}$ Aquadopp acoustic Doppler current profiler \\
\hline & 6 & Seabird SBE-37SM Microcat conductivity-temperature sensor \\
\hline & 5 & Seapoint turbidity sensor \\
\hline \multirow[t]{2}{*}{ Agat 15-m South MiniProbe } & 14 & Nortek $600 \mathrm{kHz}$ acoustic wave and current profiler \\
\hline & 13 & Aquatec 200-TY self-logging optical backscatter sensor \\
\hline South Pressure Sensor & 2 & Onset HOBO temperature and pressure sensor \\
\hline Weather Station & - & NovaLynx WS-16N-A weather station \\
\hline Terrestrial Camera System & - & USGS Terrestrial Imaging System \\
\hline
\end{tabular}


Table 3. Instrument package location information.

\begin{tabular}{|l|c|c|}
\hline \multicolumn{1}{|c|}{ Site name } & $\begin{array}{c}\text { Latitude } \\
\text { [decimal degrees N] }\end{array}$ & $\begin{array}{c}\text { Longitude } \\
\text { [decimal degrees E] }\end{array}$ \\
\hline Adelup 15-m Point MiniProbe & 13.48297 & 144.72889 \\
Agat 15-m North Mooring & 13.40202 & 144.65217 \\
Agat 15-m North MiniProbe & 13.40161 & 144.65857 \\
Agat 7-m North MiniProbe & 13.39925 & 144.64464 \\
Agat 15-m Central Mooring & 13.38217 & 144.64547 \\
Agat 15-m Central MiniProbe & 13.38190 & 144.65242 \\
Agat 7-m Central MiniProbe & 13.38648 & 144.63505 \\
Agat 15-m South MiniProbe & 13.35695 & 144.64015 \\
Weather Station & 13.43037 & 144.80133 \\
Pressure Sensor North & 13.53607 & 144.65227 \\
Pressure Sensor South & 13.31335 & \\
\hline
\end{tabular}

Conductivity and Temperature Sensors.-Six conductivity and temperature (CT) sensors collected and averaged four samples every 5 min to measure water temperature $\left({ }^{\circ} \mathrm{C}\right)$ and conductivity $(\mathrm{S} / \mathrm{m})$, from which salinity using the (dimensionless) Practical Salinity Units (PSU) was calculated. The rapid sampling rate was chosen in order to resolve any transient freshwater plumes that were advected past the instruments. The sensor locations are listed in tables 2 and 3; complete sensor and processing information is listed in appendix 2.

Temperature Loggers. - Six temperature loggers (TL) collected water temperature $\left({ }^{\circ} \mathrm{C}\right)$ measurements every 5 min at different depths throughout the water column at the Agat 15-m North and Central moorings. Three TLs were on each of the moorings. Data from these loggers provided information on the vertical thermal structure and stratification in the Agat study area. The TL depths and locations are listed in tables 2 and 3; and detailed logger and processing information is in appendix 2.

Turbidity Sensors.-CSix self-logging optical backscatter sensors (SLOBS) collected eight samples every 5 min to measure turbidity in Nephelometric Turbidity Units (NTU). Two additional optical backscatter sensors (OBS) that were logged externally by the ADCPs were placed on the 7-m MiniProbes. The SLOBSs and OBSs on the MiniPROBEs were mounted above the ADCPs in order for the turbidity data to be correlated with co-located ADCP acoustic backscatter data as discussed below. The sensor locations are listed in tables 2 and 3; complete sensor information is listed in appendix 2.

Pressure Sensors.-Two pressure sensors (PS) collected water level data (mbar) every 5 min. One PS was deployed off Two Lover's Point at the northern end of Tumon Bay and the other PS was deployed off Fouha Point, to the south of the Agat area and Facpi Point (see fig. 2), to provide water level boundary conditions for the three-dimensional, physics-based hydrodynamic numerical model for west-central Guam's waters. The sensor locations are listed in tables 2 and 3; complete sensor and processing information is listed in appendix 2.

Weather Station.-Meteorologic data were acquired by a self-contained weather station (WS) installed $2.5 \mathrm{~m}$ above ground in a large, unobstructed field on the Orote Peninsula between WAPA's Agat and Asan Units (fig. 2). The WS recorded hourly measurements of barometric pressure (mb), air temperature $\left({ }^{\circ} \mathrm{C}\right)$, precipitation $(\mathrm{mm})$, as well as wind speed $(\mathrm{m} / \mathrm{s})$ and direction ( ${ }^{\circ}$ True). The instrument's location is listed in tables 2 and 3; complete sensor information is listed in appendix 2.

Water-Column Profiler.-Surveys of water-column properties (WCP) were made using a conductivity/temperature/depth profiler with optical backscatter, transmissometer, and chlorophyll (fluorescence) sensors to collect vertical profiles of water temperature $\left({ }^{\circ} \mathrm{C}\right)$, salinity (PSU), light transmission (m), optical backscatter (NTU), and fluorescence $\left(\mathrm{mg} / \mathrm{m}^{3}\right)$. Information on the locations and depths of the profiler casts is listed in table 4; complete sensor information and individual cast 
acquisition logs are given in appendixes 3-5. The profile surveys were conducted between Two Lover's Point and Facpi Point and were repeated during the two different seasons-April (dry) and August (wet).

Table 4. Water column profiler cast location and depth information.

\begin{tabular}{|c|c|c|c|}
\hline Location & $\begin{array}{c}\text { Latitude } \\
\text { [decimal degrees } \mathrm{N} \text { ] }\end{array}$ & $\begin{array}{c}\text { Longitude } \\
\text { [decimal degrees E] }\end{array}$ & $\begin{array}{c}\text { Depth } \\
{[\mathrm{m}]}\end{array}$ \\
\hline Two Lovers Point & 13.53676 & 144.80072 & 26.6 \\
\hline Tumon Bay & 13.51401 & 144.79655 & 12.6 \\
\hline Oka Peninsula & 13.50745 & 144.77468 & 17.1 \\
\hline Alupang Cove & 13.48847 & 144.76433 & 14.1 \\
\hline Outfall & 13.48458 & 144.74806 & 12.4 \\
\hline Adelup Point & 13.48310 & 144.72851 & 18.9 \\
\hline Asan Cut & 13.47847 & 144.71503 & 33.1 \\
\hline Camel Rock & 13.48148 & 144.70441 & 13.4 \\
\hline Piti Bomb Holes & 13.47201 & 144.69146 & 17.1 \\
\hline Breakwater & 13.46704 & 144.66377 & 12.6 \\
\hline Magundes Channel & 13.46947 & 144.63993 & 12.9 \\
\hline Western Shoals & 13.45251 & 144.65388 & 15.1 \\
\hline Gab Gab Beach & 13.45127 & 144.64429 & 38.9 \\
\hline Kilo Wharf & 13.45135 & 144.63302 & 41.1 \\
\hline Apra Harbor Entrance & 13.45299 & 144.62153 & 28.1 \\
\hline South Orote Point & 13.44522 & 144.61834 & 24.6 \\
\hline Blue Hole & 13.43634 & 144.62622 & 23.6 \\
\hline Shark Pit & 13.42106 & 144.63915 & 26.4 \\
\hline Neye Island & 13.41624 & 144.64472 & 12.1 \\
\hline Dadi Beach & 13.41010 & 144.65232 & 10.9 \\
\hline Apaca Pt & 13.40529 & 144.65702 & 16.1 \\
\hline Agat Bay & 13.40059 & 144.65172 & 25.6 \\
\hline Agat Cemetery & 13.38904 & 144.64961 & 21.6 \\
\hline Alutom Island & 13.38172 & 144.64528 & 13.6 \\
\hline Agat Harbor Entrance & 13.36799 & 144.64225 & 11.4 \\
\hline Anae Island & 13.35789 & 144.63576 & 15.1 \\
\hline Facpi Point & 13.34222 & 144.63090 & 18.6 \\
\hline Taelayag Beach & 13.35068 & 144.63704 & 42.6 \\
\hline
\end{tabular}

Lagrangian Surface Current Drifters. - Satellite-tracked Lagrangian Surface Current Drifters (LSCDs) equipped with Differential Global Positioning System (DGPS) were deployed each night during coral spawning (August 10-12, 2012; 2012 Year Day 223-225) to track the surface currents, internally logging their location every minute and transmitting their positions to satellites every 5 min. At least two LSCDs were released each night, one above the Adelup 15-m site at the eastern side of Asan Bay, and the second above the Agat 15-m Central site (see fig. 2). When available, two drifters, one placed at a depth centered around $1.0 \mathrm{~m}$ below sea level and the other placed at a depth centered around $0.10 \mathrm{~m}$ below sea level, were released at the same location to determine if there was significant vertical shear close to the sea surface. The LSCDs were recovered the following day by small boat, 
refurbished, and prepared for release the following evening. Details of each drifter deployment, including locations, times, distances, and velocities, are shown in table 5.

Table 5. Drifter deployment information.

[ChST, Chamorro Standard Time]

\begin{tabular}{|l|c|c|c|c|c|c|c|c|c|}
\hline $\begin{array}{c}\text { Date } \\
\text { [2012 Year } \\
\text { Day] }\end{array}$ & $\begin{array}{c}\text { Drifter } \\
\text { ID } \\
\text { numbers }\end{array}$ & $\begin{array}{c}\text { Deploy } \\
\text { location }\end{array}$ & $\begin{array}{c}\text { Drogue } \\
\text { depth } \\
\text { [m] }\end{array}$ & $\begin{array}{c}\text { Deploy } \\
\text { time } \\
\text { [ChST] }\end{array}$ & $\begin{array}{c}\text { Total } \\
\text { time } \\
{[\mathrm{h}: \mathrm{m}]}\end{array}$ & $\begin{array}{c}\text { Total } \\
\text { distance } \\
{[\mathrm{km}]}\end{array}$ & $\begin{array}{c}\text { Net } \\
\text { distance } \\
{[\mathrm{km}]}\end{array}$ & $\begin{array}{c}\text { Net } \\
\text { direction } \\
{\left[{ }^{\circ}\right]}\end{array}$ & $\begin{array}{c}\text { Maximum } \\
\text { velocity } \\
{[\mathrm{m} / \mathbf{s}]}\end{array}$ \\
\hline 10 August & 006 & Asan & 0.1 & $21: 05$ & $18: 45$ & 9.6 & 5.6 & 318 \\
[225] & 010 & Asan & 1.0 & $21: 05$ & $11: 40$ & 1.2 & 0.6 & 231 \\
& 005 & Agat & 0.1 & $21: 05$ & $18: 15$ & 9.6 & 5.8 & 331 \\
& 007 & Agat & 1.0 & $21: 05$ & $18: 05$ & 7.6 & 3.6 & 318 & 0.4 \\
\hline 11 August & 006 & Asan & 0.1 & $22: 10$ & $10: 45$ & 3.7 & 1.5 & 69 & 0.2 \\
[226] & 005 & Agat & 0.1 & $22: 05$ & $15: 25$ & 5.7 & 3.0 & 8 & 0.2 \\
& 007 & Agat & 1.0 & $22: 05$ & $15: 10$ & 6.8 & 2.3 & 300 & 0.3 \\
\hline 12 August & 006 & Asan & 0.1 & $23: 05$ & $16: 15$ & 4.8 & 3.0 & 40 & 0.2 \\
[227] & 010 & Asan & 1.0 & $23: 05$ & $16: 30$ & 4.5 & 3.4 & 67 & 0.2 \\
& 005 & Agat & 0.1 & $23: 10$ & $16: 00$ & 7.4 & 0.7 & 257 & 0.4 \\
\hline
\end{tabular}

Miscellaneous Data Sources.-Navigation equipment for deployment, recovery, and survey operations included hand-held Global Positioning System (GPS) units equipped with Wide Area Augmentation System (WAAS) and a computer with positioning and mapping software. The positioning and mapping software enabled real-time GPS position data to be combined with images of previously collected high-resolution Scanning Hydrographic Operational Airborne Lidar Survey (SHOALS) colorcoded lidar, shaded-relief bathymetry, 5-m isobaths, and aerial photographs of terrestrial portions of the maps. Additional meteorologic data from the Andersen Air Force Base weather station were obtained through the NOAA National Climatic Data Center (NCDC; http://www.ncdc.noaa.gov).

\section{Numerical Circulation Modeling}

\section{Modeling Approach}

A Delft3D coupled three-dimensional, wave-current numerical circulation model for west-central Guam was constructed to examine the effects of waves, winds, and tides on circulation and buoyant transport around WAPA. This circulation model was developed for use in fate and transport studies as well as other operational coastal modeling applications for the U.S. National Parks.

The model was built using both the 2007-2008 and the 2012 WAPA field experiment data (table 6 lists specific time periods) for model calibration and validation. Because the 2007-2008 record (Storlazzi and others, 2009; Storlazzi and others, 2013) covers both the summer (non-trade wind) period and the winter (trade wind) period, it serves as a good test of the predictive capabilities of the developed model train and parameter settings. While the 2007-2008 data were used for model validation, the 2012 field experiment data were used for model calibration. In addition to these hindcast modeling scenarios, a suite of modeling sensitivity test cases was run to gain insight into the hydrodynamics under (1) tides, (2) tides plus winds, and (3) tides plus waves. The wind and wave conditions are bulk statistical conditions based upon analyses of the NOAA National Data Buoy Center (NDBC; http://www.ndbc.noaa.gov/) meteorological stations and wave buoy off Ritidian Point at the north end of Guam. The full suite of sensitivity test cases is listed in table 7. 
Table 6. Modeling time periods.

\begin{tabular}{|l|c|c|}
\hline \multicolumn{1}{|c|}{ Run ID } & Year & Time Period (Year Day) \\
\hline Summer2007 & 2007 & 8 August-25 August (221-238) \\
Winter2007 & 2007 & 26 December-15 January (360-380) \\
Summer2012 & 2012 & 25 July-16 August (205-228) \\
\hline
\end{tabular}

Table 7. Modeled tide, wind, and wave scenarios.

[NA, not applicable]

\begin{tabular}{|c|c|c|c|c|}
\hline Processes & $\begin{array}{c}\text { Direction } \\
\text { [direction "from"] }\end{array}$ & Wind Speed [m/s] & Significant Wave Height [m] & Peak Wave Period [s] \\
\hline Tide & NA & NA & NA & NA \\
\hline \multirow{15}{*}{ Tide + Wind } & \multirow{3}{*}{ North } & 5 & NA & NA \\
\hline & & 10 & NA & NA \\
\hline & & 15 & NA & NA \\
\hline & \multirow{3}{*}{ Northwest } & 5 & NA & NA \\
\hline & & 10 & NA & NA \\
\hline & & 15 & NA & NA \\
\hline & \multirow{3}{*}{ West } & 5 & NA & NA \\
\hline & & 10 & NA & NA \\
\hline & & 15 & NA & NA \\
\hline & \multirow{3}{*}{ Southwest } & 5 & NA & NA \\
\hline & & 10 & NA & NA \\
\hline & & 15 & NA & NA \\
\hline & \multirow{3}{*}{ South } & 5 & NA & NA \\
\hline & & 10 & NA & NA \\
\hline & & 15 & NA & NA \\
\hline \multirow{12}{*}{ Tide + Wave } & \multirow{2}{*}{ North } & NA & 0.5 & 9.2 \\
\hline & & NA & 1.5 & 10.2 \\
\hline & Northwest & NA & 0.5 & 9.2 \\
\hline & \multirow{3}{*}{ West } & NA & 0.5 & 9.2 \\
\hline & & NA & 1.5 & 10.2 \\
\hline & & NA & 2.5 & 9.9 \\
\hline & \multirow{3}{*}{ Southwest } & NA & 0.5 & 9.2 \\
\hline & & NA & 1.5 & 10.2 \\
\hline & & NA & 2.5 & 9.9 \\
\hline & \multirow{3}{*}{ South } & NA & 0.5 & 9.2 \\
\hline & & NA & 1.5 & 10.2 \\
\hline & & NA & 2.5 & 9.9 \\
\hline
\end{tabular}




\section{Model Components}

Global Ocean Model.-The HYbrid Coordinate Ocean Model (HYCOM, http://hycom.org/) is a three-dimensional, data-assimilative, hybrid isopycnal-sigma-pressure coordinate system ocean model that is run operationally. The hybrid system uses different vertical coordinate systems for different ocean regions: (1) isopycnal-following in open ocean domains, (2) terrain-following in shallow coastal regions, and (3) z-level (depth-based) coordinates in the mixed layer and (or) unstratified seas. This conditional vertical system extends the applicable geographic range of traditional isopycnic coordinate circulation models toward shallow coastal seas. For this study, two HYCOM + NCODA Global 1/12 Analysis experiments were obtained: (1) April 2007-September 2008 and (2) January 2011-August 2013. For these two datasets, computations were carried out on a Mercator grid between lat $78^{\circ} \mathrm{S}$ and $47^{\circ} \mathrm{N}\left(1 / 12^{\circ}\right.$ equatorial resolution), with horizontal dimensions of 4,500 x 3,298 points, resulting in an average resolution of approximately $7 \mathrm{~km}$; the vertical axes of the grid had 32 vertical layers.

Tides.-The Oregon State University TOPEX/Poseidon global inverse solution (TPXO; http://volkov.oce.orst.edu/tides/global.html) was used to provide tidal forcing. It is a global tide model that uses the Laplace Tidal Equations and incorporates along-track averaged satellite altimetry data (Egbert and others, 1994; Egbert and Erofeeva, 2002). TPXO uses a global grid with $0.25^{\circ}$ resolution, on which the resulting tides are computed as complex amplitudes of the Earth-relative, sea-surface elevations for 13 harmonic tidal constituents.

Waves.-For the western Guam regional model presented herein, wave outputs from the Simulating WAves Nearshore (SWAN) model were obtained from the Pacific Islands Ocean Observing System (PacIOOS, http://oos.soest.hawaii.edu/pacioos/) for the 2007-2008 summer and winter periods of interest (table 6). These SWAN runs used boundary conditions from the WAVEWATCH-III Mariana Islands Regional Wave Model using peak parameters. WAVEWATCH-III (Tolman, 2009) is a global wave model that was developed by NOAA's National Centers for Environmental Prediction (NCEP). SWAN is a high-resolution wave model that effectively captures shallow water effects and also resolves nearshore coastal dynamics such as refracting, shoaling, and island shadowing. The third generation SWAN wave processor (Delft3D Version 5.01.00.2163) integrates wave effects, such as enhanced bed shear stresses and wave-induced current forcing due to wave breaking, into flow simulations. The SWAN model is based on discrete spectral action balance equations, computing the evolution of random, short-crested waves (Holthuijsen and others, 1993; Booij and others, 1999; Ris and others, 1999). It includes physical processes such as the generation of waves by wind, dissipation due to whitecapping, bottom friction, depth-induced breaking, and nonlinear quadruplet and triad wave-wave interactions. Wave propagation, growth, and decay are solved periodically on subsets of the flow grid.

DELFT3D.-Delft3D-Flow (version 5.01.00.2163) forms the core of the model system and simulates water motion due to tidal and meteorologic forcing by solving the unsteady shallow-water equations that consist of the continuity equation, the horizontal momentum equations, and the transport equation under the shallow water and Boussinesq assumptions. Vertical accelerations are assumed to be minor compared to gravitational acceleration (shallow water assumption), thus reducing the vertical momentum equation to the hydrostatic pressure relation. By specifying boundary conditions for bed roughness (quadratic friction law), free surface (wind stress), lateral boundaries (water level, currents, salinity, and water temperature), and closed boundaries with free-slip conditions at the seabed, the equations can be solved on a staggered grid by using an Alternating Direction Implicit method (Stelling 1984; Leendertse, 1987, Deltares, 2011).

Particle Tracking.-MDRIFT is a Matlab-based particle-tracking program that tracks particles for a certain amount of time as they are transported by the surface currents (for coral-larval dispersal this is typically a few days), after which they are removed from the simulation. Alternatively, to simulate the active settling of coral larvae on a reef system, the particles may be removed once they reach water depths less than a user-specified limit. Particle diffusion processes are included by adding a random 
disturbance to the current velocity fields. To examine particle trajectories in the western Guam study area, this program was run with the time- and space-varying surface velocity fields from the Delft3DFlow hydrodynamic model using the locations and transport rates of in situ LCSD releases.

\section{Model Set-up}

Grid schematization for any numerical model is a tradeoff between computational time and processes to be modeled. Grid resolution and time step should be sufficient to capture the phenomena of interest, but still allow efficient and accurate computations. For Guam it is important to capture both the large-scale oceanic circulation and the local (wave-dominated) nearshore flow. Therefore, two models were constructed (1) the Regional Guam Model, and (2) the Western Guam Model, which was nested within the larger Regional Guam Model. Each of these models consists of the Delft3D-flow and Delft3D-wave modules.

Regional Guam Model.-The Regional Guam Model is a coupled Delft3D-FLOW and Delft3DWAVE model. The Delft3D-FLOW component is a three-dimensional, rectangular gridded model consisting of 40 vertical Z-layers and a horizontal domain that is $81 \mathrm{x} 81 \mathrm{~km}$ with 1-km grid resolution (fig. 3). In order to include large-scale oceanic circulation effects, this model was forced using the threedimensional HYCOM Global Ocean model output (horizontal current velocities, water level, water temperature, and salinity).Tidal data from the TPXO global model of ocean tides, which were interpolated to the Regional Guam Model boundaries, were also included in the time-series forcing files. A time step of 1 min was used to ensure stable computations. The 40-layer grid schematisation is essential to capture the oceanic circulations. The K- $\varepsilon$ model was used as turbulence closure model with values of $10 \mathrm{~m}^{2} / \mathrm{s}$ for the horizontal eddy viscosity and diffusivity, and $1 \times 10^{-6} \mathrm{~m}^{2} / \mathrm{s}$ for the background values. Surface heat fluxes were not included in the model. The bed stress is modeled as a quadratic friction based on the magnitude of the Eulerian velocity in the first layer above the bed using the default 2D-Chézy coefficient $\left(65 \mathrm{~m}^{1 / 2} / \mathrm{s}\right)$.

Western Guam Model.-The Western Guam Model has a three-dimensional, curvilinear domain with 450 grid cells running cross-shore and 118 grid cells running alongshore (fig. 4). The grid cell resolution ranges from $50 \mathrm{~m}$ to upwards of $450 \mathrm{~m}$. The northern and southern extents of the domain are roughly co-aligned with the 2012 deployment locations of the pressure sensors. This model has 20 vertical z-layers, with 1-m resolution at the surface and decreasing resolution with depth, and uses a 15-s time step. The water level, temperature, salinity, and horizontal current velocity boundary conditions were supplied by the Regional Guam Model, using the Delft3D nesting procedure. On the free surface, wind is implemented as a spatially uniform shear stress, based on the wind data available from the nearby USGS weather station, and included in the momentum equations. Wind-speed-dependent drag coefficients are defined as 0.00063 at $0 \mathrm{~m} / \mathrm{s}$ and 0.00723 at $30 \mathrm{~m} / \mathrm{s}$. For consistency, similar settings were used in the large-scale and small-scale model except for bed shear stress. On the reef flat, selecting the correct bed stress is critical for the representation of the flow. Here a constant Manning value of 0.02 provided best results.

The Delft3D modeling system was developed for use on low-slope coastlines. By default it therefore uses a sigma vertical layer system. In sigma convention each vertical grid cell is a percentage of the water depth. Such convention is efficient in shallow seas and allows for high grid resolution in the nearshore (where most of the flow and sediment transport occurs) and larger grids offshore. In areas with a large depth variation, such as Guam, sigma layers would result in an unacceptable jump in vertical grid resolution at the reef crest, with small layers on the reef, but large grids offshore. With a zlayer convention as applied in this study this is avoided; grid cells have a constant (fixed) size throughout the domain. 
A

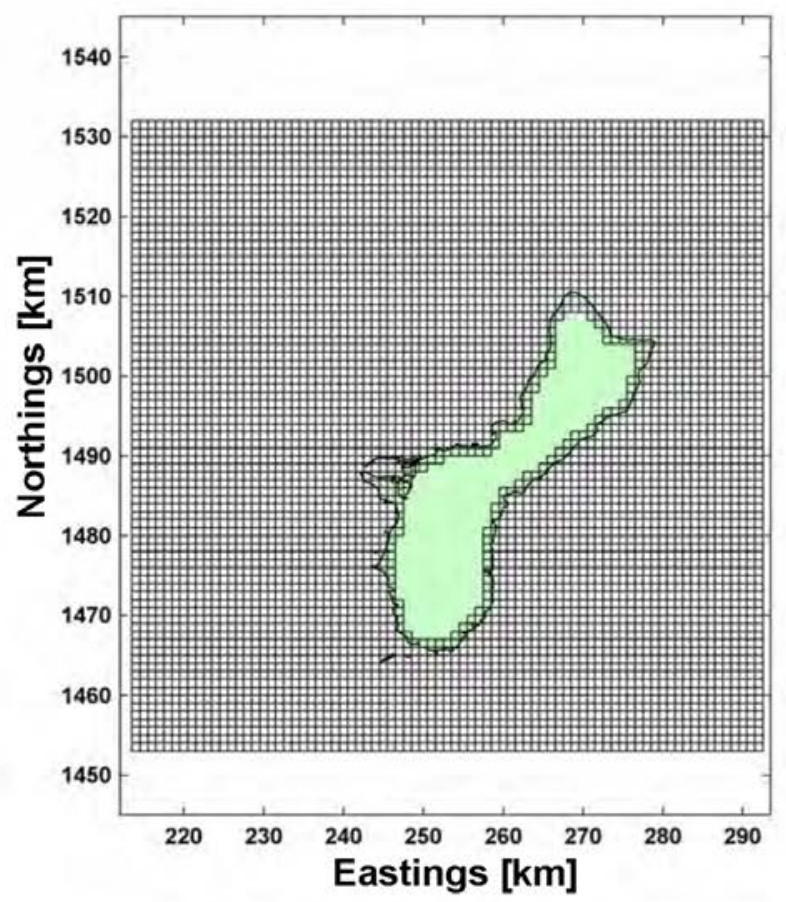

$B$

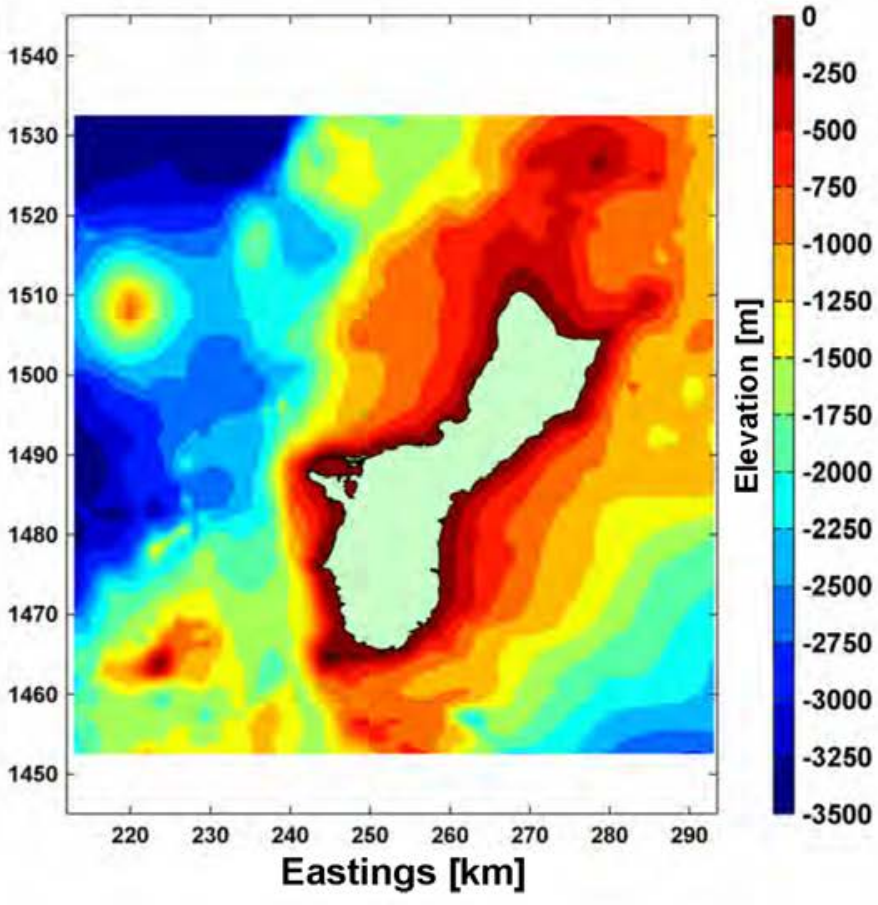

C

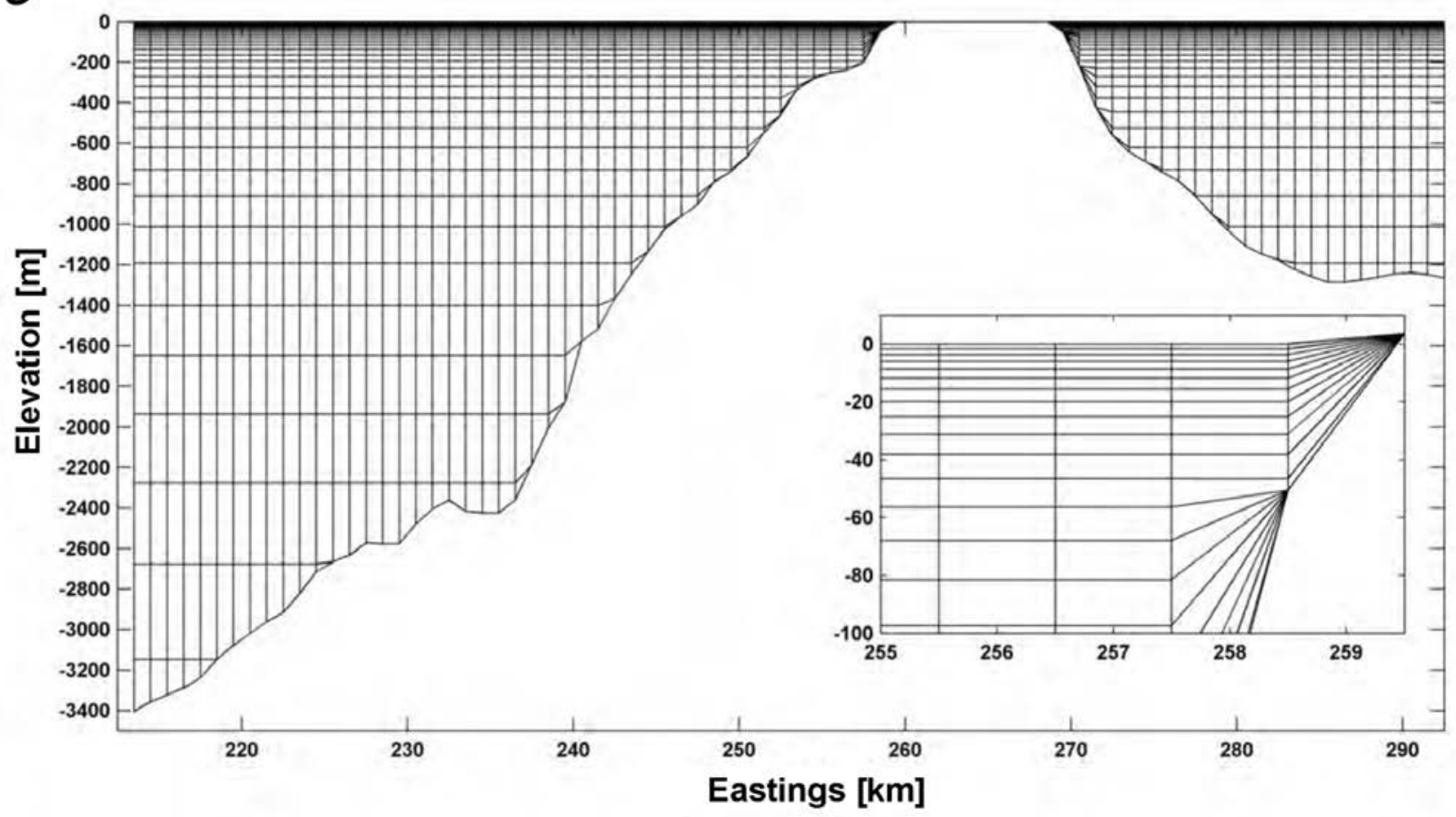

Figure 3. Delft3D Regional Guam Model flow grid $(A)$, bathymetry $(B)$, and vertical model layers with water depth (C). 
A

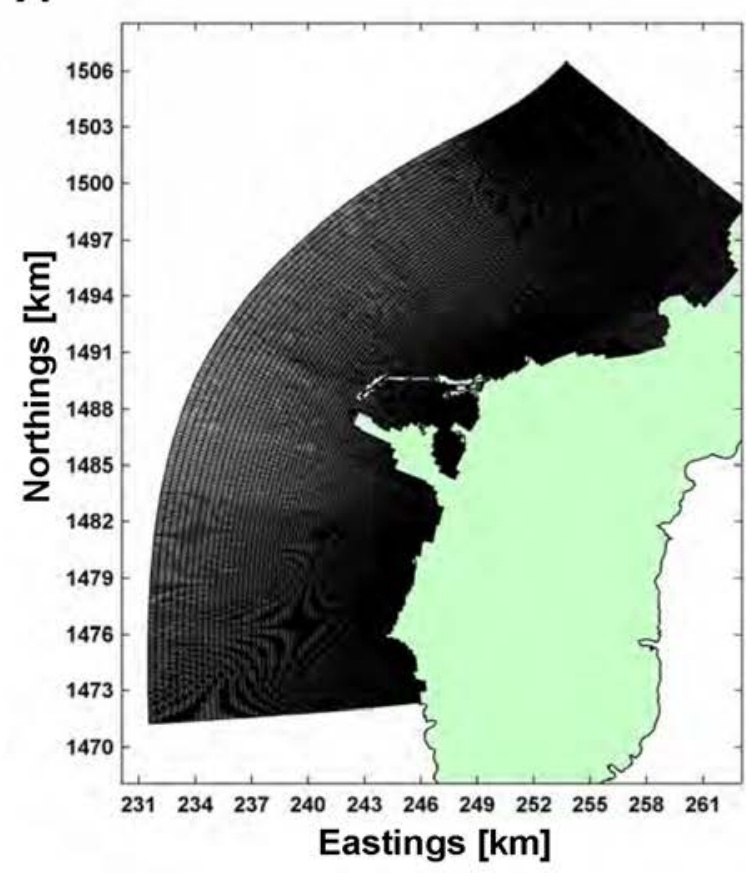

$B$

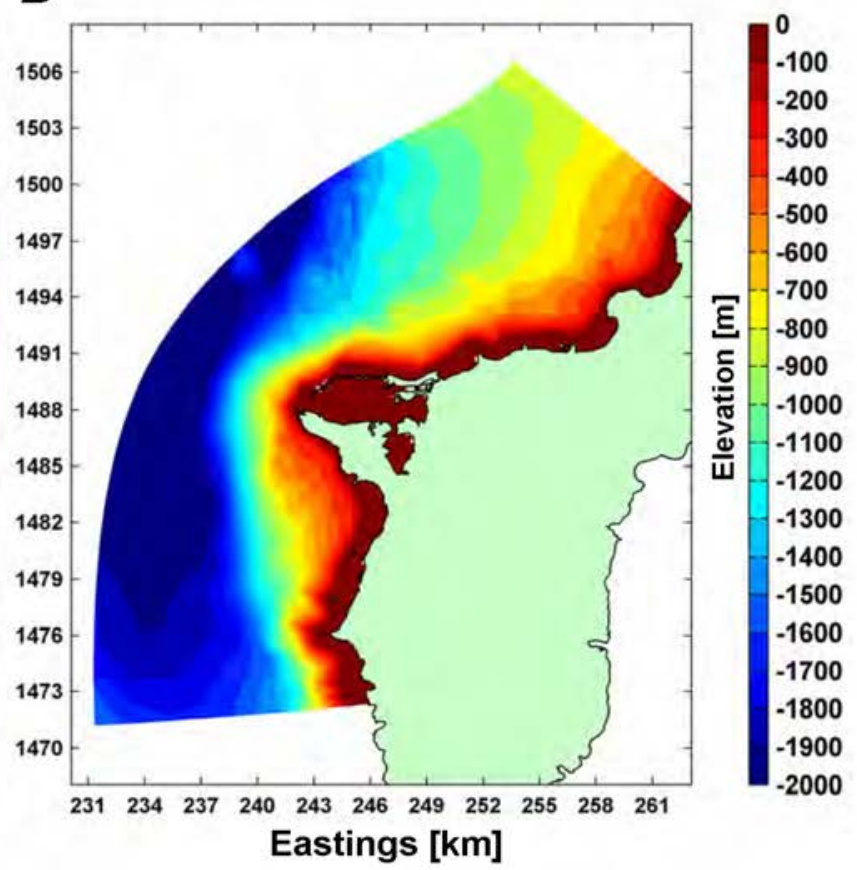

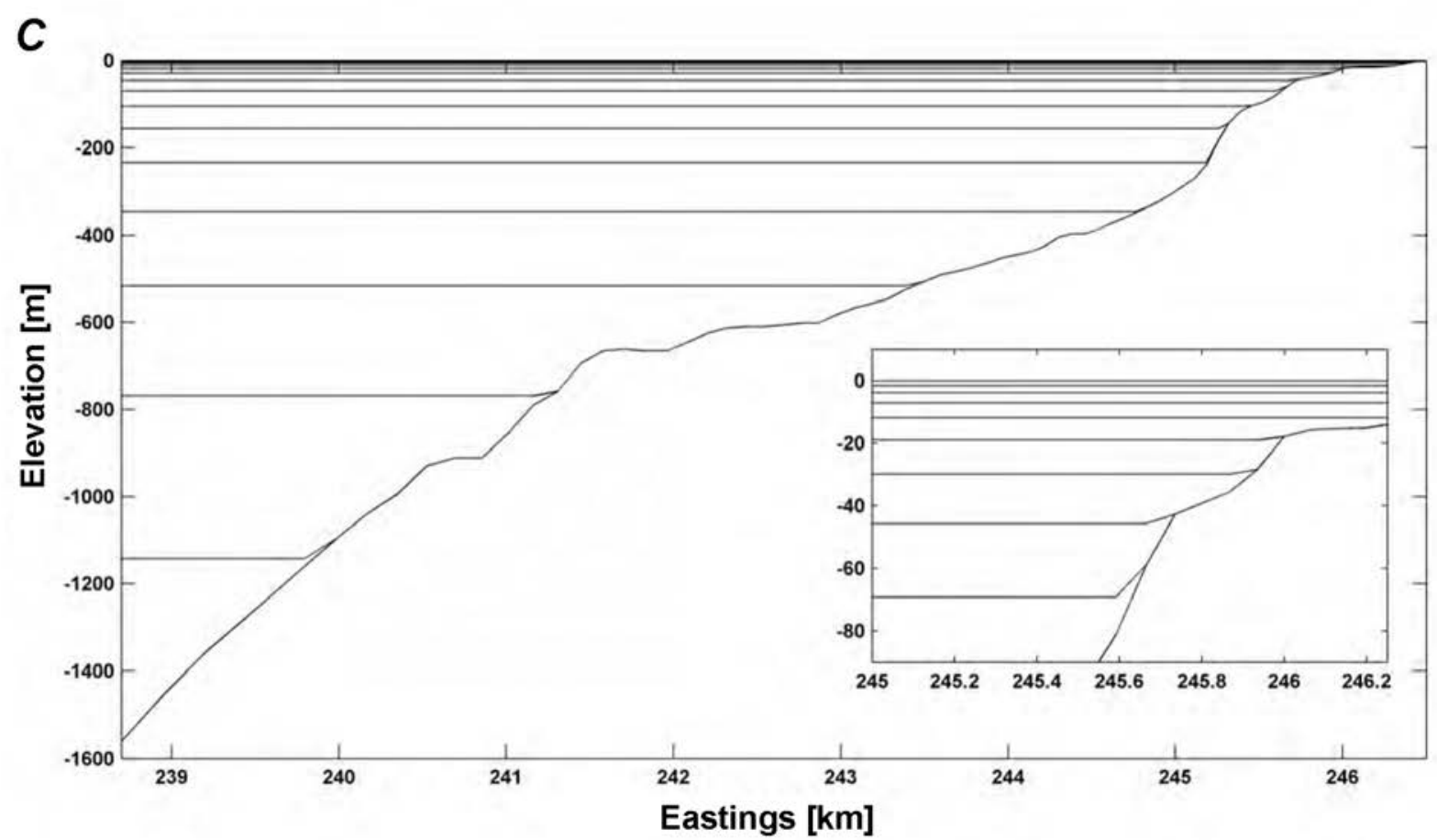

Figure 4. Delft3D Western Guam Model flow grid $(A)$, bathymetry $(B)$, and vertical model layers with water depth (C). 
For both the Regional Guam model and Western Guam model, wave simulations were performed using the SWAN wave model. Both wave models use the flow grid as spatial domain. The Regional model was run in stand-alone mode. In the wave model, default settings were set for the directional space (full circle with 36 directions) and for frequency space $(0.05 \mathrm{~Hz}-1 \mathrm{~Hz})$. Wave forces are based on the wave energy dissipation rate. Depth-induced breaking was computed by the Battjes and Jansen breaker model with default values (Alpha $=1$, Gamma $=0.8$ ). Bottom friction was computed with the Jonswap formulation with $0.067 \mathrm{~m}^{2} \mathrm{~s}^{-3}$ coefficient. Diffraction, whitecapping, nonlinear triad interactions and wave setup were not included in the computations. Default accuracy criteria for convergence were applied.

The Western Guam model uses the computed water levels, flow velocities, and wind fields from the Regional flow model and is forced by the computed wave spectra from the Regional wave model. The default settings for the spectral resolution used were similar to those used for the Regional model. The wave forces are based on the radiation stresses. Processes included are: depth-induced breaking, bottom friction, wind growth, and whitecapping (Komen formulation) with similar settings to the Regional model. Each set of 60-min wave results was coupled to the flow model.

Bathymetry data for both models were obtained by desampling (down to $50 \mathrm{~m}$ ) NOAA's National Geophysical Data Center (NGDC) bathymetric dataset, which has approximately 10-m resolution (Chamberlin, 2008). Gaps in the bathymetric data were filled using data from the General Bathymetric Chart of the Oceans (GEBCO; Intergovernmental Oceanographic Commission and International Hydrographic Organization, 2003). The bathymetry was referenced to mean sea level (MSL) according to the NOAA Apra Harbor Water Level Station (Center for Operational Oceanographic Products and Services, 2012).

\section{Model Scenarios}

A suite of model runs was conducted to gain insight into the horizontal flow regime under various forcing conditions: (1) tides only, (2) tides plus winds, and (3) tides plus waves. The full suite of modeled tide, wind, and wave scenarios are listed in table 7. For all the modeled scenarios, the Western Guam model was run using astronomical tidal constituents for forcing at the boundaries for the time period from 25 July to 16 August 2012.

A systematic series of wind conditions were chosen to be modeled: winds coming from the north, northwest, west, southwest, and south, at speeds of 5, 10 and $15 \mathrm{~m} / \mathrm{s}$. Wind speeds of $20 \mathrm{~m} / \mathrm{s}$ were considered as well, but these conditions caused instability in the model and were subsequently discarded. These wind speeds were chosen based on the available 2009-2011 wind speeds recorded at the NOAA National Data Buoy Center (NDBC) buoys in Pago Bay on the east coast of Guam and Apra Harbor on the west coast (NDBC Stations PGBP7 and APRP7, respectively; appendix 10.1, 10.2).

The modeled wave scenarios use wave directions of out of the north, northwest, west, southwest, and south, with wave heights of $0.5,1.5$, and $2.5 \mathrm{~m}$. These wave heights were identified using the directional wave data from the NOAA buoy at Ritidian Point (NDBC Station 52202), which were available for the period of October-December 2012. Measured significant wave heights ranged from 0.5 to $4.5 \mathrm{~m}$ and the peak periods range from 4 to $18 \mathrm{~s}$ (appendix 10.3, 10.4). As with the high wind scenarios, the model developed instabilities when offshore wave heights were larger than $2.5 \mathrm{~m}$. Additionally, the model also suffered from instabilities at smaller wave heights for northerly (heights $>2.0 \mathrm{~m}$ ) and northwesterly (heights $>1.0 \mathrm{~m}$ ) waves. These instabilities resulted from the combined development of strong currents and large water level changes in the region north of Apra Harbor. As a result, only model scenarios with wave heights of 0.5 and $1.5 \mathrm{~m}$ are presented for northerly waves, and only scenarios with wave heights of $0.5 \mathrm{~m}$ are presented for northwesterly waves. 


\section{Research Platform and Field Operations}

The instrument deployments and recoveries were conducted using the F/V Heavy Metal. Vessel operations, including mobilization and demobilization, were based out of Agat Marina. The port quarterdeck was adapted for instrument deployment and recovery operations, which included the use of an electric winch and an overhead davit. The instruments were deployed by attaching a removable bridle to the instrument package with a connecting line through the davit and down to the winch. The instruments were lowered to within a few meters of the seafloor, where scuba divers attached a lift bag and detached the lifting line. The divers then moved the instrument package into position for anchoring. The water-column profiler casts were conducted by hand from the same vessel. The driver's station was outfitted with a laptop computer and GPS-enabled navigation system to provide the vessel captain with a graphic display of position information, speed, heading, and distance to the next location.

\section{Data Acquisition and Quality}

Data were acquired for 114 days during the period from 23 April 2012 through 14 August 2012 (2012 Year Days [YD] 114-227). More than 1,406,000 data points were recorded by the ADCPs, CTs, TLs, SLOBSs, PSs, and WS; more than 61,000 data points were recorded by the water-column profiler. The raw data were archived and copies of the data were postprocessed for analysis.

The ADCP, CT, TL, PS, and weather station data generally appeared to be of high quality. In addition, the water-column profiler data were very high in quality, although the near-bed optical backscatter data often displayed spikes due to interaction of the optical beam with the seabed. The acoustic surface tracking (AST) function of the ADCP at the Agat 15-m South site was unusable because of an error in programming the instrument. However, wave parameters were obtained by using the "PUV" method (using pressure, and the two velocity components, U and V) — the same method used with the other current profilers.

The Agat 15-m Central mooring was found with the mooring float severed and the mooring line on the seafloor; the temperature data indicate that this occurred sometime between YD 150 and 157, so the data from this mooring following YD 150 (May 29) were removed from the record and not included in the analyses. In addition, it appears that some of the salinity measurements were fouled by sediment or other material getting lodged in the conductivity chamber of the CT sensor. The low salinity spikes occurring during large wave events were most likely caused by sediment fouling; however, it is not possible to determine this definitively. Consequently, large salinity fluctuations occurring over short time scales are not considered in the analyses, though the data are shown in the figures.

Lastly, turbidity data are not available from three of the MiniProbe sites because of wiper malfunctions that started approximately 40-50 days into the deployment, which resulted in the optical backscatter sensor windows becoming fouled, either by biological growth or sediment deposition. These wiper failures occurred on the SLOBS and OBS sensors at the two Agat 7-m sites and the Agat 15-m South site. As a result, the data from these three sites were not incorporated into the analyses herein.

In order to determine the contributions of different forcing mechanisms to flow patterns, the current data were constrained to periods when just the forcing mechanism of interest was dominant. For example, in order to identify the influence of winds (large waves) on flow patterns, a period of time was identified without concurrent large waves (strong winds) and low-pass filtered with a cutoff of $36 \mathrm{~h}$ in order to remove tidal components. To identify the contribution of tides to circulation patterns, a period of time without trade winds or large waves was selected and then 10-28-h band-pass filtered. 


\section{Results}

This section reviews the data collected by the instruments during the deployments, field surveys, and modeling and addresses the significance of the findings to better understand the oceanographic conditions in the study area.

\section{Oceanographic and Atmospheric Forcing}

The study period from April through August 2012 included parts of both the trade wind season that normally runs from December through June, and the wet, rainy season that normally runs from July through November. The winds recorded at Andersen Air Force Base on the northeastern tip of Guam and those recorded by the Orote Peninsula WS both show a similar pattern (fig. 5). For the first week of the study ( YD 114-122), winds were relatively weak and consistently out of the northeast. The transition to the wet season was marked by a series of rain events lasting from YD 127 to 157 (6 May-5 June; fig. 5). More than 90 percent of the total rainfall for the study period occurred during this 30-day window, with the majority of this rainfall occurring during two short periods: YD 143.0-143.5 (22 May 00:00-12:00, $34 \mathrm{~mm}$ ) and YD 148.6-149.7 (27 May 14:00-28 May 17:00, $17 \mathrm{~mm}$ ). During this rainy period, and throughout the remainder of the study period, winds were more variable and most commonly directed out of the south or southeast. For the entire record, the hourly precipitation ranged from 0.0 to $13.3 \mathrm{~mm}$, with a mean rainfall \pm 1 standard deviation of $0.05 \pm 0.40 \mathrm{~mm}$ (table 8). Both wind speed and air temperature exhibited large diurnal fluctuations. Air temperature ranged from a low of 22.4 to a high of $33.8^{\circ} \mathrm{C}$, with a mean temperature \pm 1 standard deviation of $27.4 \pm 2.5^{\circ} \mathrm{C}$. After the series of rain events, the mean daily air temperature decreased slightly, because of lower daily highs (fig. 5).

\section{Tides}

The study period encompassed seven complete spring-neap tidal cycles. The tides near Agat are microtidal, mixed, and semidiurnal, with two uneven high tides and two uneven low tides per day; thus, the tides change at a frequency of just over every 6 hours (fig. 5). The mean daily tidal range was approximately $0.54 \mathrm{~m}$, while the minimum and maximum daily tidal ranges were 0.36 and $1.01 \mathrm{~m}$ during neap and spring tides, respectively. The highest high tide was $+0.38 \mathrm{~m}$ and the lowest low tide was $-0.63 \mathrm{~m}$.

\section{Winds}

The hourly winds speeds at the Orote Peninsula WS ranged from 0.00 to $6.56 \mathrm{~m} / \mathrm{s}$, with a mean speed \pm 1 standard deviation of $1.68 \pm 1.32 \mathrm{~m} / \mathrm{s}$ (fig. 5, table 8). The winds at this site exhibited strong diurnal patterns, with the strongest winds in the afternoon and the weakest winds in the evening and early morning. Up until the shift to the wet season (on YD 122), the mean wind velocity was $1.86 \mathrm{~m} / \mathrm{s}$ out of the northeast ( $64^{\circ}$ from true north). The strongest gusts occurred during the series of rain events (YD 127-157), with peak wind gusts reaching $15 \mathrm{~m} / \mathrm{s}$ and coming from the south ( $175^{\circ}$ from true north). After the shift to the wet season, winds were variable, with a mean wind velocity of $1.67 \mathrm{~m} / \mathrm{s}$ coming out of the east-southeast ( $99^{\circ}$ from true north). 
$\boldsymbol{A}$

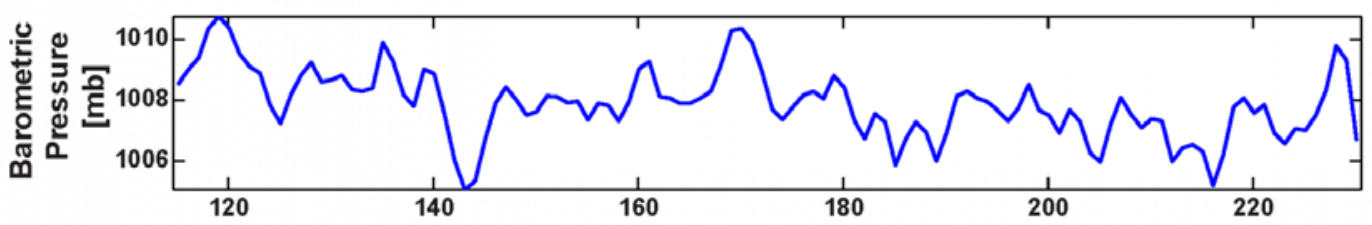

B

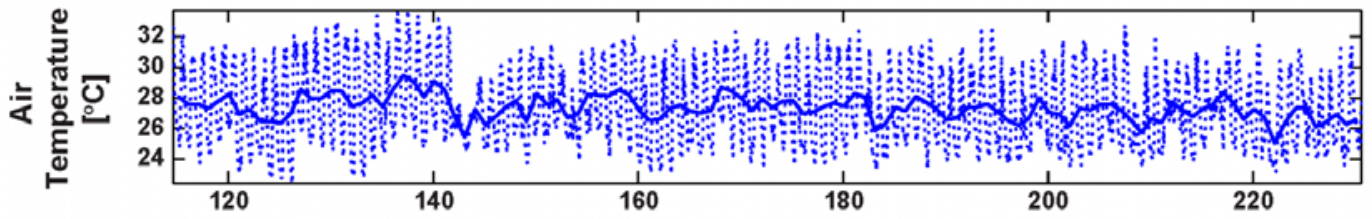

C

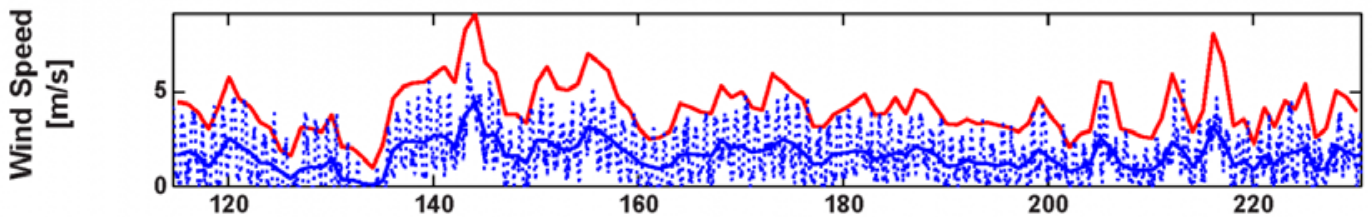

D

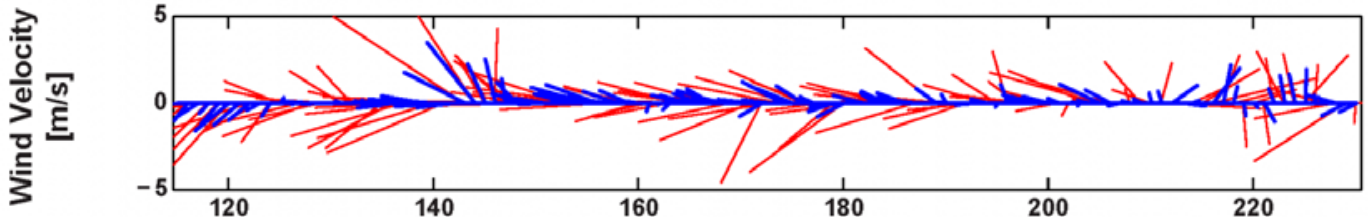

$E$

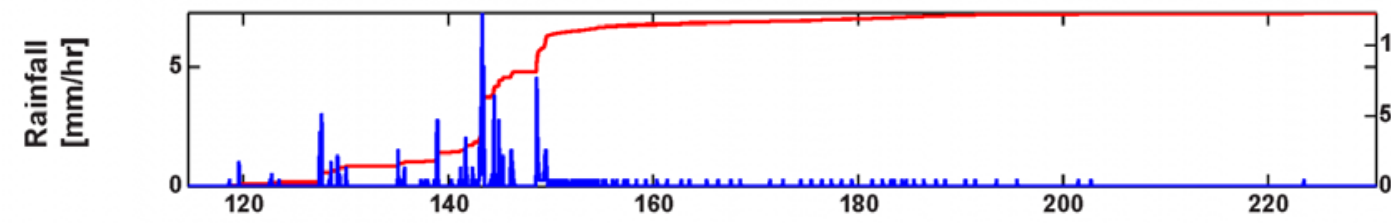

$F$

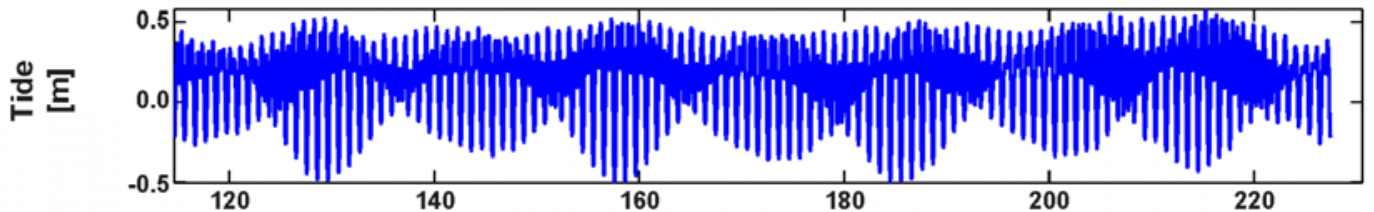

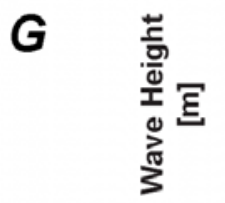

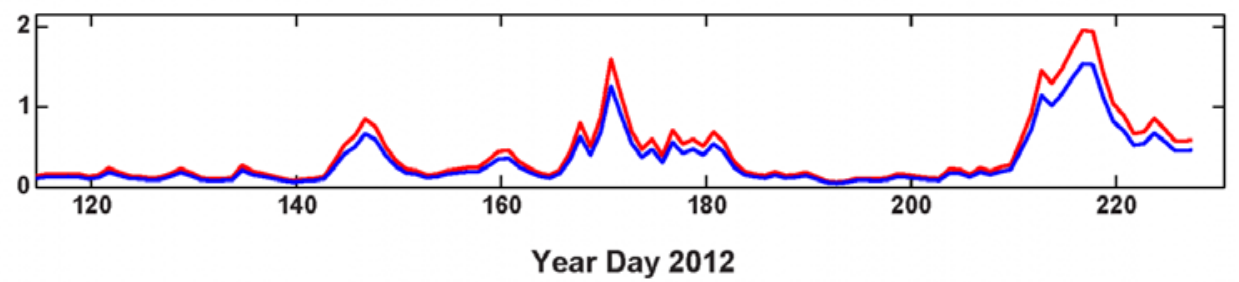

Figure 5. Time-series plots of meteorological forcing data during the study period. $A$, Barometric pressure, in millibars. B, Air temperature, in degrees Celsius. C, Wind speed, in meters per second, with hourly (dashed blue), daily-averaged (solid blue) and maximum daily (solid red) speeds from the Orote Peninsula weather station (WS). D, Daily-averaged wind velocity, with direction in compass orientation and speed in meters per second, for both Andersen Air Force Base (red) and the WS (blue). E, Hourly (blue) and cumulative (red) rainfall, in millimeters, from the WS. F, Tidal height, in meters. G, Significant (blue) and maximum (red) wave height, in meters, from the Agat 15-m North MiniProbe. 
Table 8. Meteorologic statistics.

[SD, standard deviation; mb, millibar; all values were calculated for 2012 Year Days 114-227; wind direction is "coming from"]

\begin{tabular}{|l|l|c|c|}
\hline \multicolumn{1}{|c|}{ Site name } & Mean \pm 1 SD & Minimum & Maximum \\
\hline Sea level barometric pressure $[\mathrm{mb}]$ & $1007.9 \pm 1.6$ & 1003.6 & 1012.5 \\
Air temperature $\left[{ }^{\circ} \mathrm{C}\right]$ & $27.4 \pm 2.5$ & 22.4 & 33.8 \\
Precipitation $[\mathrm{mm} / \mathrm{hr}]$ & $0.05 \pm 0.40$ & 0 & 13.25 \\
Wind speed $[\mathrm{m} / \mathrm{s}]$ & $1.68 \pm 1.31$ & 0 & 6.56 \\
Wind direction $\left[{ }^{\circ}\right]$ & $97 \pm 47$ & 0 & 360 \\
\hline
\end{tabular}

\section{Currents}

The mean surface and near-bed current velocities for each MiniProbe site are listed in table 9. Currents in the Agat study area were strongest at the 15-m sites and slowest at the shallower 7-m sites. In general, current magnitudes increased during the second half of the study, when winds were more variable and larger waves impinged on the coast. At each site, currents were tidally driven and unidirectional throughout the water column, with current speeds greatest at the surface and decreasing with depth. At the Agat 15-m Central and North sites, flows were roughly along-isobath, with flood tides directed to the north and ebb tides to the south (figs. 6-7). Currents at the Agat 7-m sites exhibited more cross-shore flow. At all sites, subtidal currents (tidal forcing removed) were very slow. In Agat Bay, surface subtidal currents were directed to the north at the 15-m sites and offshore at the 7-m sites under both northeasterly and variable winds (figs. 8-9). This northward flow in the subtidal currents changed only during large wave events, which caused offshore surface flow at the 15-m sites and onshore flow at the 7-m sites (fig. 10).

The southernmost MiniProbe (Agat 15-m South) recorded the greatest current speeds, with 15 percent of surface currents exceeding $0.3 \mathrm{~m} / \mathrm{s}$, and across-shore (east-west) velocities occasionally reaching $0.4 \mathrm{~m} / \mathrm{s}$, particularly in the second half of the study (see appendix 6.7). However, the flow patterns at this site were most likely intensified by its proximity to Anae Island (figs. 1, 5). Currents were also moderately strong at the Agat 15-m North MiniProbe, with 15 percent of measured surface currents exceeding $0.2 \mathrm{~m} / \mathrm{s}$ during the study period. Flows were weakest at the Adelup Point, Agat 15-m Central, and the two Agat 7-m sites (appendix 6, table 9).

Table 9. Current statistics.

[Current direction is "going to"; minimum speed recorded at each site was $0.00 \mathrm{~m} / \mathrm{s}$ ]

\begin{tabular}{|c|c|c|c|c|}
\hline Site name & $\begin{array}{l}\text { Depth } \\
{[\mathrm{m}]}\end{array}$ & $\begin{array}{c}\text { Mean speed } \pm 1 \text { SD } \\
{[\mathrm{m} / \mathrm{s}]}\end{array}$ & $\begin{array}{c}\text { Mean direction } \\
{\left[{ }^{\circ} \text { True }\right]}\end{array}$ & Maximum speed [m/s] \\
\hline \multirow[t]{2}{*}{ Adelup 15-m Point MiniProbe } & 2.6 & $0.07 \pm 0.05$ & $12^{\circ}$ & 0.35 \\
\hline & 8.6 & $0.05 \pm 0.03$ & $53^{\circ}$ & 0.24 \\
\hline \multirow[t]{2}{*}{ Agat 15-m North MiniProbe } & 3.8 & $0.11 \pm 0.08$ & $33^{\circ}$ & 0.48 \\
\hline & 11.8 & $0.07 \pm 0.04$ & $14^{\circ}$ & 0.29 \\
\hline \multirow[t]{2}{*}{ Agat 7-m North MiniProbe } & 2.1 & $0.04 \pm 0.03$ & $329^{\circ}$ & 0.24 \\
\hline & 6.6 & $0.02 \pm 0.01$ & $11^{\circ}$ & 0.12 \\
\hline \multirow[t]{2}{*}{ Agat 15-m Central MiniProbe } & 3.3 & $0.06 \pm 0.04$ & $19^{\circ}$ & 0.31 \\
\hline & 11.3 & $0.04 \pm 0.03$ & $23^{\circ}$ & 0.17 \\
\hline \multirow[t]{2}{*}{ Agat 7-m Central MiniProbe } & 1.9 & $0.03 \pm 0.02$ & $359^{\circ}$ & 0.18 \\
\hline & 5.0 & $0.02 \pm 0.01$ & $21^{\circ}$ & 0.09 \\
\hline \multirow[t]{2}{*}{ Agat 15-m South MiniProbe } & 3.6 & $0.17 \pm 0.11$ & $240^{\circ}$ & 0.82 \\
\hline & 11.6 & $0.13 \pm 0.08$ & $10^{\circ}$ & 0.59 \\
\hline
\end{tabular}




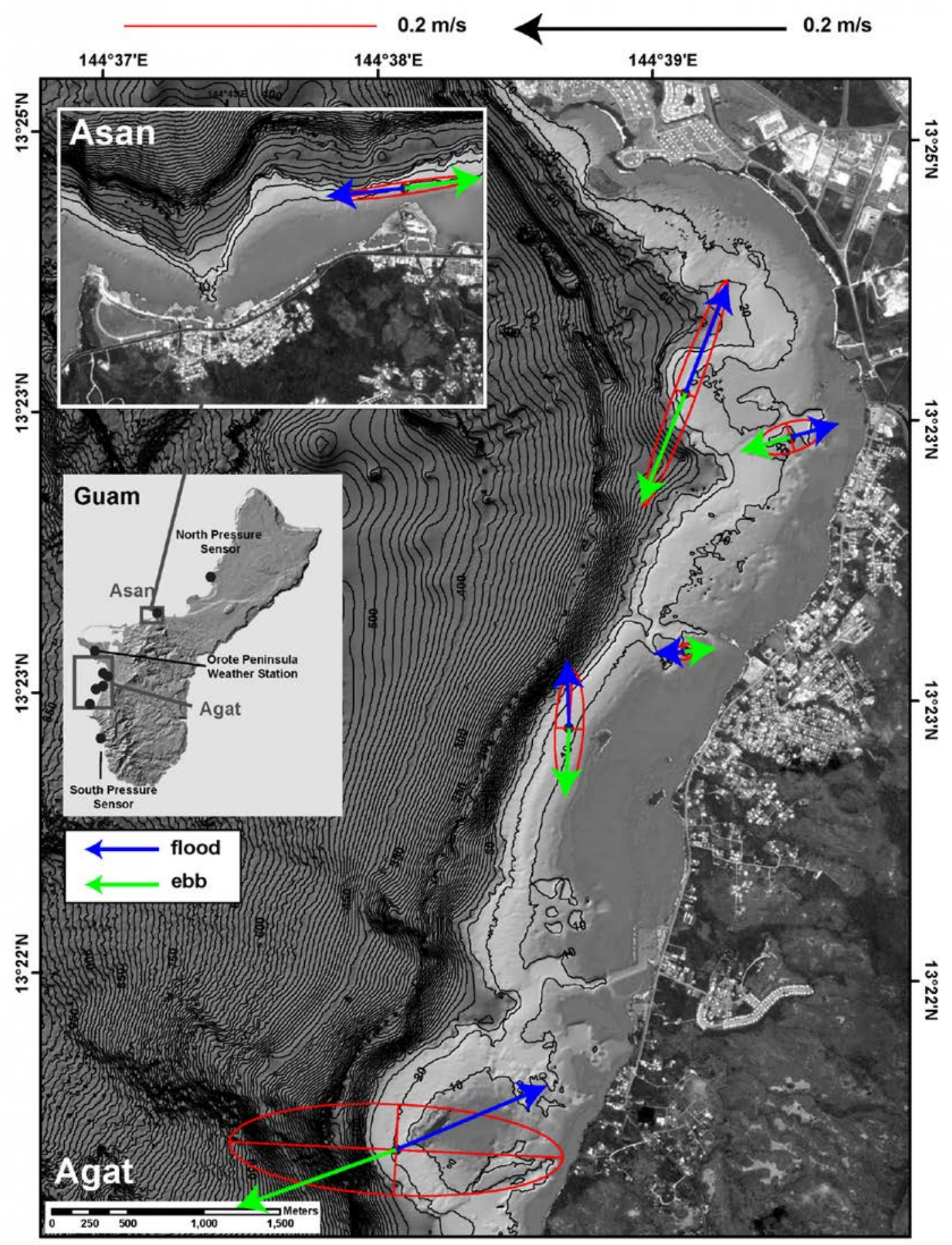

Figure 6. Map showing the mean (blue and green arrows) and variability (red ellipses) of near-surface current directions, in compass orientation, and speeds, in meters per second, during flood (blue) and ebb (green) tides during the 2012 experiment. Bathymetric contour interval 10 meters. 


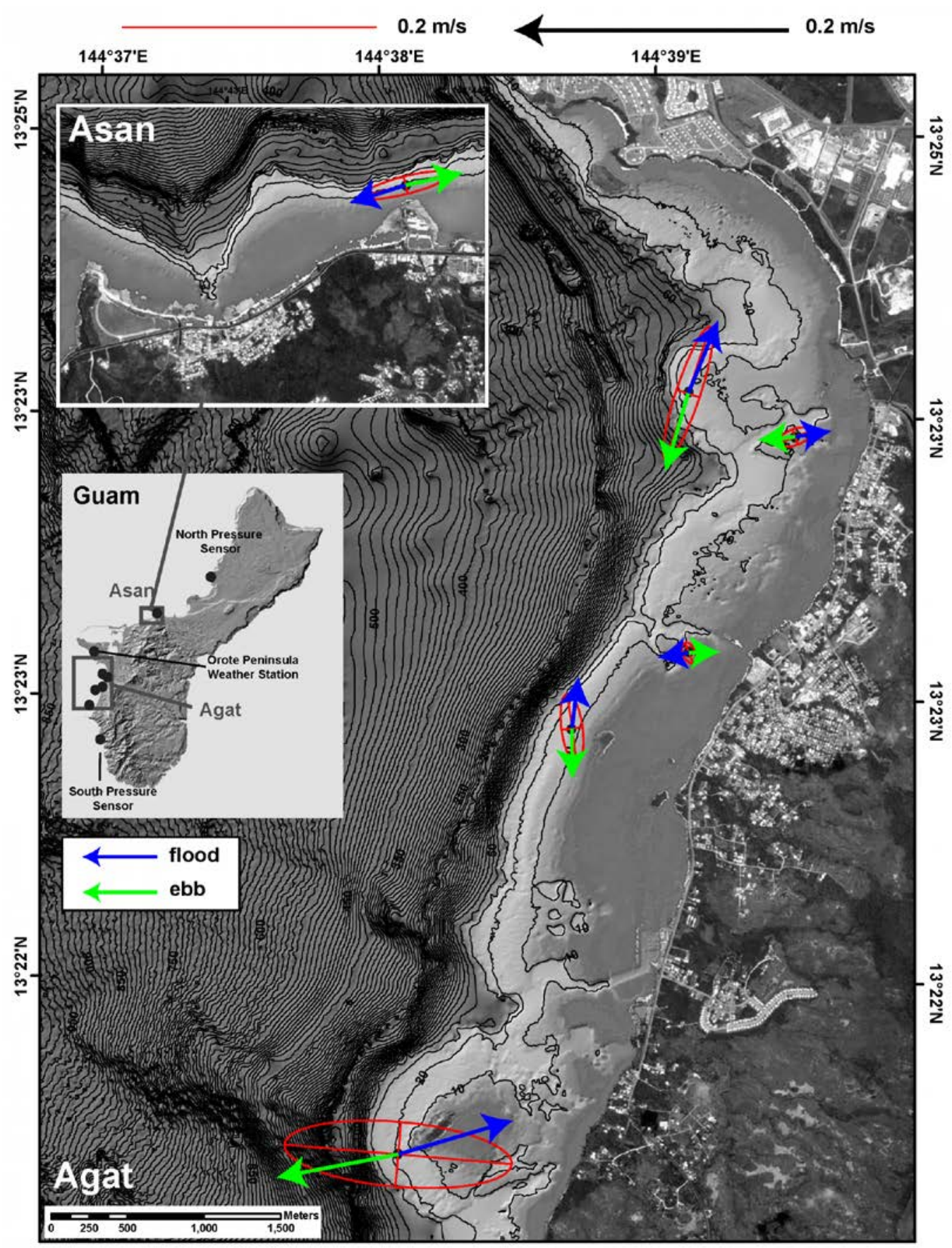

Figure 7. Map showing the mean (blue and green arrows) and variability (red ellipses) of near-bed current directions, in compass orientation, and speeds, in meters per second, during flood (blue) and ebb (green) tides during the 2012 experiment. Bathymetric contour interval 10 meters. 


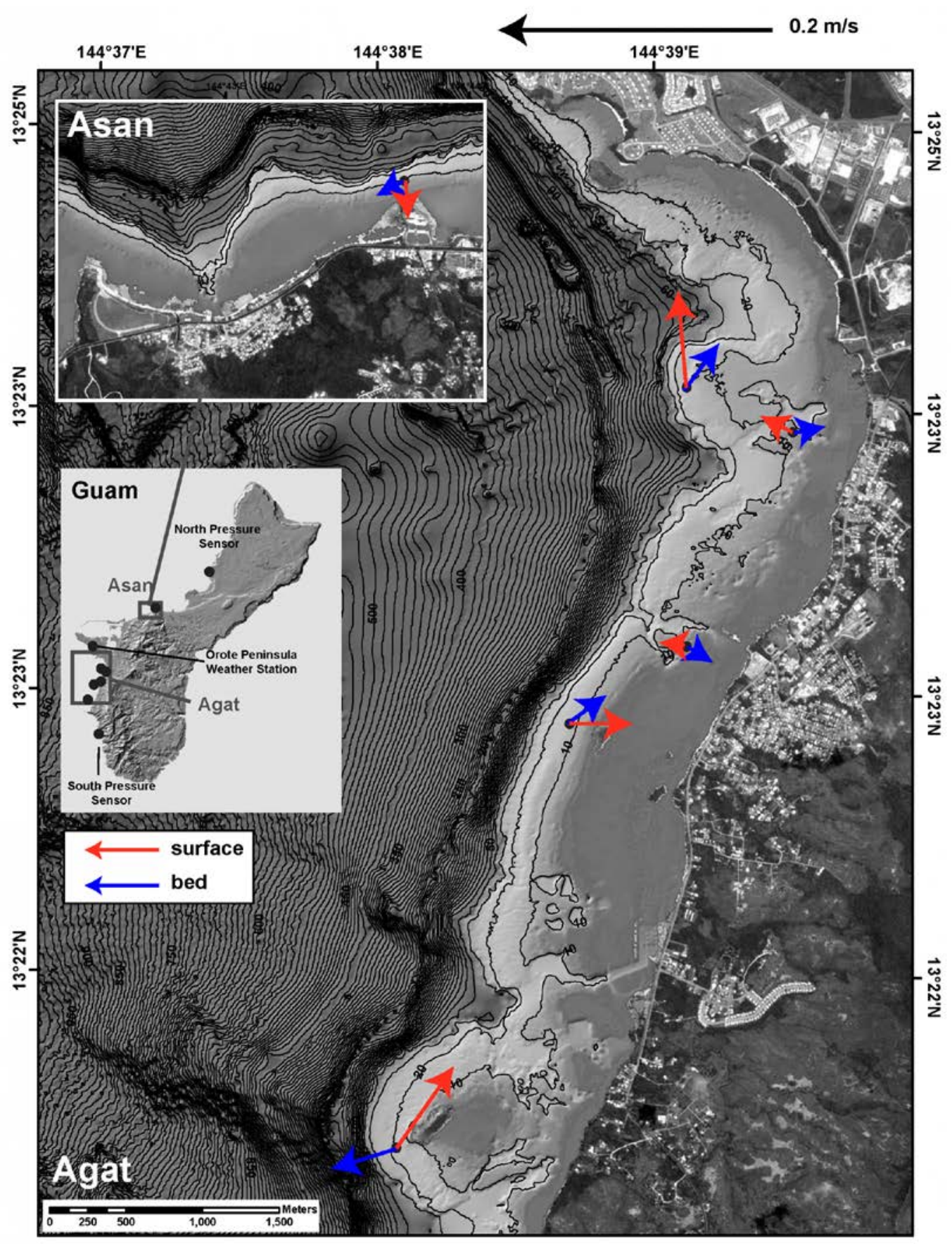

Figure 8. Map showing the mean near-surface (red) and near-bed (blue) current directions, in compass orientation, and speeds, in meters per second, during conditions dominated by northeasterly winds (2012 Year Day 114-122). Bathymetric contour interval 10 meters. 


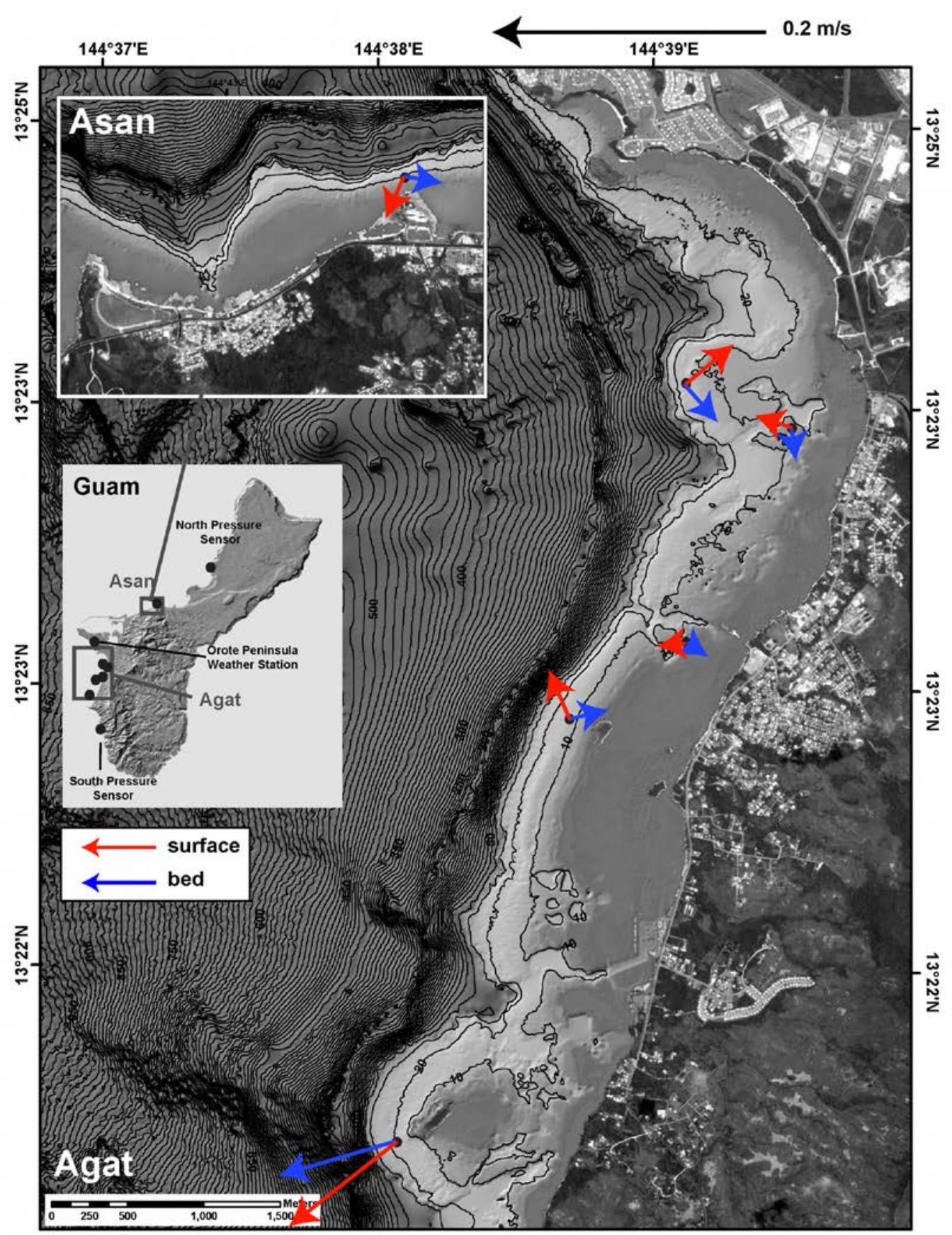

Figure 9. Map showing the mean near-surface (red) and near-bed (blue) current directions, in compass orientation, and speeds, in meters per second, during conditions dominated by variable winds and small waves (2012 Year Day 185-207). Bathymetric contour interval 10 meters. 


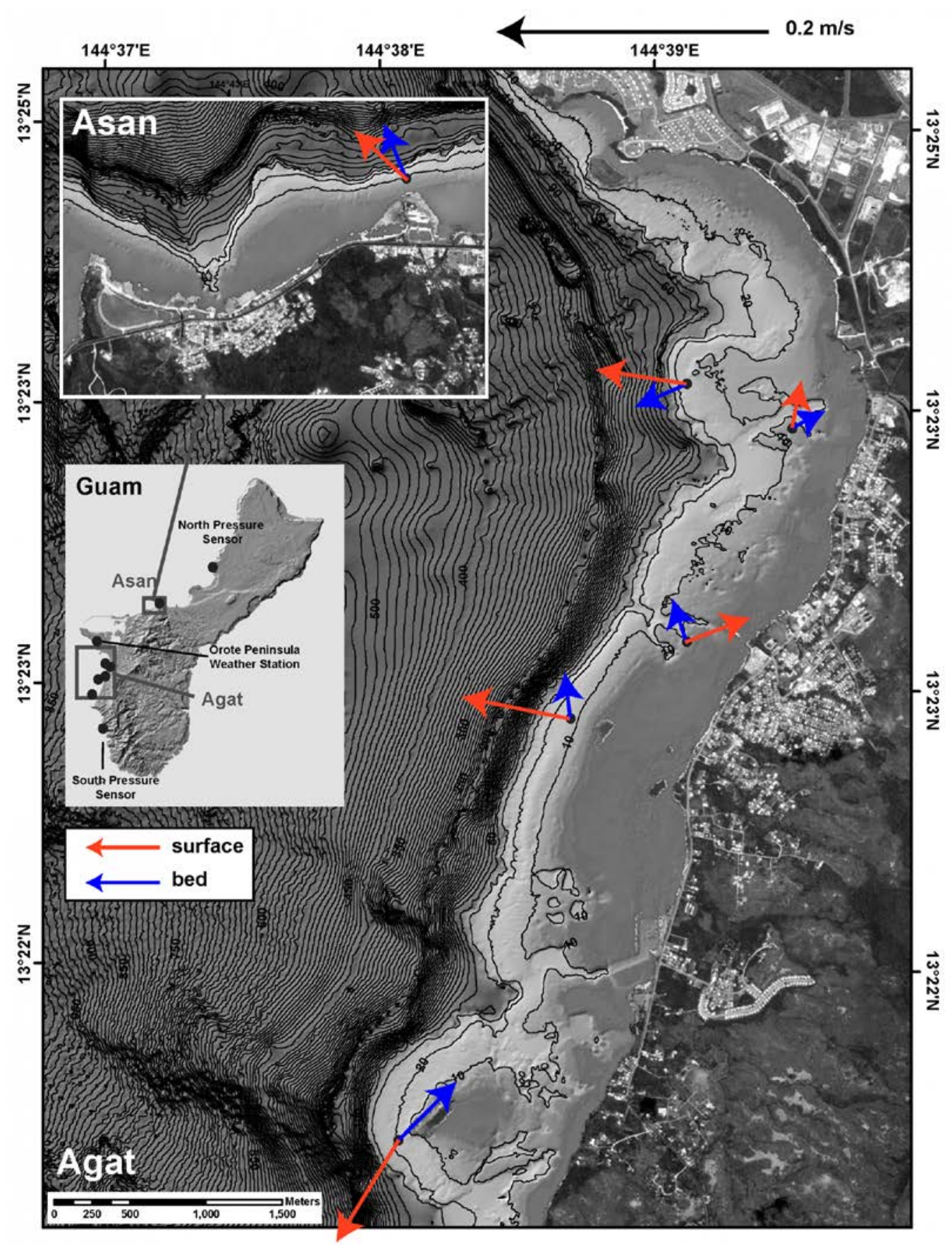

Figure 10. Map showing the mean near-surface (red) and near-bed (blue) current directions, in compass orientation, and speeds, in meters per second, during conditions dominated by large waves (2012 Year Day 212-220). Bathymetric contour interval 10 meters. 


\section{Waves}

The waves in the Agat study area during the course of the experiment are shown in figures 5 and 11, and statistics for each site are listed in table 10. The two shallowest sites recorded the maximum and minimum significant wave heights, with Agat 7-m South experiencing the smallest waves (mean 0.24 $\mathrm{m}$ ), and Agat 7-m North experiencing the largest (mean $0.48 \mathrm{~m}$; maximum $3.2 \mathrm{~m}$ ). The mean significant height for the Agat 15-m sites was $0.4 \mathrm{~m}$ (table 10). Dominant wave periods ranged from 1.4 to $14.8 \mathrm{~s}$, with a mean dominant period \pm 1 standard deviation of $8.2 \pm 1.9 \mathrm{~s}$. The mean wave direction for the Agat sites ranged from $271^{\circ}$ to $297^{\circ}$ from true north (waves out of the west-northwest). A large wave event occurred from YD 212 to 220 (30 July-7 August). During this event, wave heights at all the Agat sites (except the Agat 7-m Central site) exceeded $1.5 \mathrm{~m}$. These large waves had periods of approximately 10 $\mathrm{s}$, came out of the west-northwest, and were associated with strong winds out of the south.

Table 10. Wave statistics.

[SD, standard deviation; wave direction is "coming from”]

\begin{tabular}{|c|c|c|c|c|}
\hline Site name & Parameter & Mean \pm 1 SD & Minimum & Maximum \\
\hline \multirow[t]{3}{*}{ Adelup 15-m Point MiniProbe } & Height [m] & $0.32 \pm 0.19$ & 0.06 & 1.28 \\
\hline & Period [s] & $9.56 \pm 1.79$ & 1.40 & 14.8 \\
\hline & Direction $\left[{ }^{\circ}\right]$ & $352 \pm 18$ & 0 & 360 \\
\hline \multirow[t]{3}{*}{ Agat 15-m North MiniProbe } & Height [m] & $0.44 \pm 0.40$ & 0.03 & 2.47 \\
\hline & Period [s] & $8.17 \pm 2.32$ & 2.00 & 27.70 \\
\hline & Direction $\left[^{\circ}\right]$ & $284 \pm 29$ & 0 & 357 \\
\hline \multirow[t]{3}{*}{ Agat 7-m North MiniProbe } & Height [m] & $0.48 \pm 0.41$ & 0.10 & 3.20 \\
\hline & Period [s] & $8.45 \pm 1.72$ & 3.10 & 13.02 \\
\hline & Direction $\left[{ }^{\circ}\right]$ & $297 \pm 19$ & 225 & 347 \\
\hline \multirow[t]{3}{*}{ Agat 15-m Central MiniProbe } & Height [m] & $0.33 \pm 0.33$ & 0.00 & 2.04 \\
\hline & Period $[\mathrm{s}]$ & $8.50 \pm 2.30$ & 0.00 & 27.70 \\
\hline & Direction $\left[{ }^{\circ}\right]$ & $272 \pm 26$ & 6 & 355 \\
\hline \multirow[t]{3}{*}{ Agat 7-m Central MiniProbe } & Height [m] & $0.24 \pm 0.17$ & 0.08 & 1.13 \\
\hline & Period [s] & $5.57 \pm 2.11$ & 2.68 & 13.27 \\
\hline & Direction $\left[{ }^{\circ}\right]$ & $297 \pm 20$ & 0 & 359 \\
\hline \multirow[t]{3}{*}{ Agat 15-m South MiniProbe } & Height [m] & $0.44 \pm 0.38$ & 0.09 & 3.15 \\
\hline & Period [s] & $8.89 \pm 1.42$ & 5.26 & 13.83 \\
\hline & Direction [] & $277 \pm 45$ & 0 & 360 \\
\hline
\end{tabular}




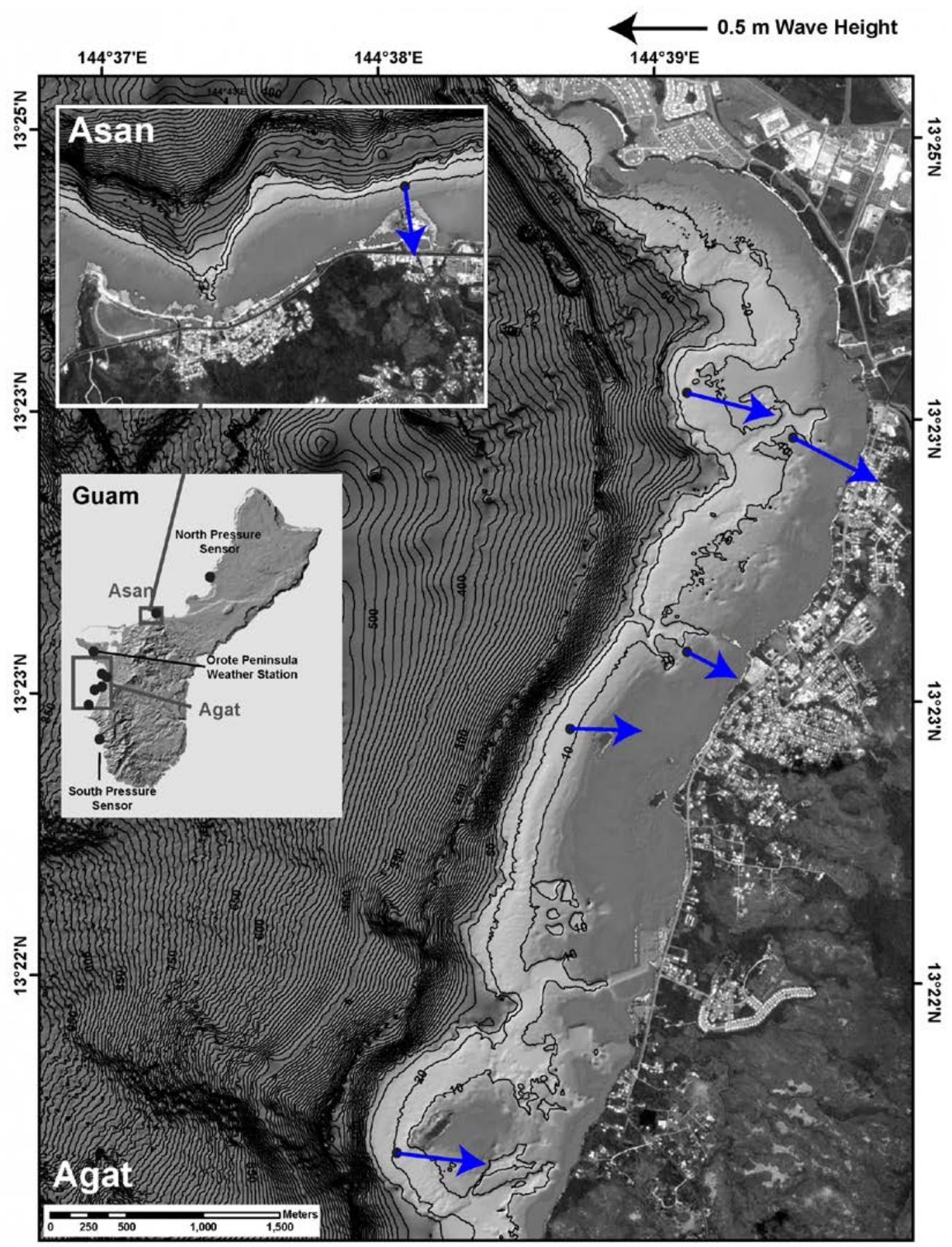

Figure 11. Map showing the mean wave direction, in compass orientation, and magnitude of significant wave height, in meters, from the entire study period. Bathymetric contour interval 10 meters. 


\section{Temporal Variations in Water-Column Properties}

The water-column properties that were measured by the moored temperature loggers, CTs, OBS, and SLOBS included variations in temperature $\left({ }^{\circ} \mathrm{C}\right)$, salinity (PSU), and turbidity (NTU). The watercolumn properties that were measured by the CTD/OBS profiler included variations in temperature $\left({ }^{\circ} \mathrm{C}\right)$, salinity (PSU), turbidity (NTU), and chlorophyll (mg/m³) with depth.

Temperature.-Near-bed water temperatures at the mooring sites ranged between 27.87 and $30.84{ }^{\circ} \mathrm{C}$, with a mean temperature \pm 1 standard deviation of $29.46 \pm 0.45^{\circ} \mathrm{C}$ (table 11 ). The shallow Agat 7-m South MiniProbe recorded both the maximum and minimum water temperatures during the deployment; this site also exhibited the greatest daily fluctuations in temperature, with near-bottom waters typically warming approximately $0.5^{\circ} \mathrm{C}$ between the early morning and afternoon. The Agat 15$\mathrm{m}$ North mooring temperature also showed a strong response to daily heating. After the transition to the wet season (on YD 122) with its more variable winds, temperatures at all sites were, on average, approximately $1.2^{\circ} \mathrm{C}$ warmer (fig. 12). The range of near-bed temperatures across the sites was very small throughout the entire study, though a few periods of slightly larger temperature ranges (as much as $\sim 0.4^{\circ} \mathrm{C}$ ) occurred and these coincided with wind shifts (fig. 13). Temperature was also fairly uniform with depth, resulting in generally low thermal stratification throughout the study period (fig. 13).

Table 11. Temperature statistics.

[Only data from Year Days 114.5 to 150 are used for Agat Central 15-m mooring]

\begin{tabular}{|l|c|c|c|c|}
\hline \multicolumn{1}{|c|}{ Site name } & $\begin{array}{c}\text { Depth } \\
{[\mathrm{m}]}\end{array}$ & $\begin{array}{c}\text { Mean } \pm 1 \text { SD } \\
{\left[{ }^{\circ} \mathrm{C}\right]}\end{array}$ & $\begin{array}{c}\text { Minimum } \\
{\left[{ }^{\circ} \mathrm{C}\right]}\end{array}$ & $\begin{array}{c}\text { Maximum } \\
{\left[{ }^{\circ} \mathrm{C}\right]}\end{array}$ \\
\hline Agat 15-m North Mooring & 14 & $29.6 \pm 0.4$ & 28.2 & 30.5 \\
Agat 15-m North MiniProbe & 13 & $29.5 \pm 0.4$ & 28.0 & 30.0 \\
Agat 7-m North MiniProbe & 7 & $29.5 \pm 0.4$ & 28.2 & 30.5 \\
Agat 15-m Central Mooring* & 14 & $29.2 \pm 0.5$ & 28.2 & 30.4 \\
Agat 15-m Central MiniProbe & 13 & $29.5 \pm 0.4$ & 28.0 & 30.3 \\
Agat 7-m Central MiniProbe & 5 & $29.5 \pm 0.5$ & 27.9 & 30.8 \\
\hline
\end{tabular}

Salinity.-Near-bed salinity in Agat Bay ranged between 26.40 and 34.89 (PSU), with a mean salinity \pm 1 standard deviation of $34.34 \pm 0.22$ (PSU; table 12). After the seasonal shift on YD 122, all sites experienced a gradual decline in daily-averaged salinity (fig. 12). This decline started around YD 152 (31 May) and resulted in a mean drop of 0.61 (PSU). During this latter part of the study, while the water was becoming less saline, the range of near-bed salinities across the Agat sites was steadily increasing, from less than 0.2 to nearly 1.0 (PSU; fig. 13). At the 15-m sites, salinity tended to decrease during neap tides and increase during spring tide periods. Salinity was also highly variable during large wave events, though it's unclear if this is a result of a real salinity fluctuation or increased fouling of the CT sensor salinity chambers. Daily-averaged values of salinity, shown in the temperature-salinity diagrams in figure 14, reveal the large fluctuations in salinity that occurred following the big rain event that peaked approximately YD 150 (29 May). 
$\boldsymbol{A}$

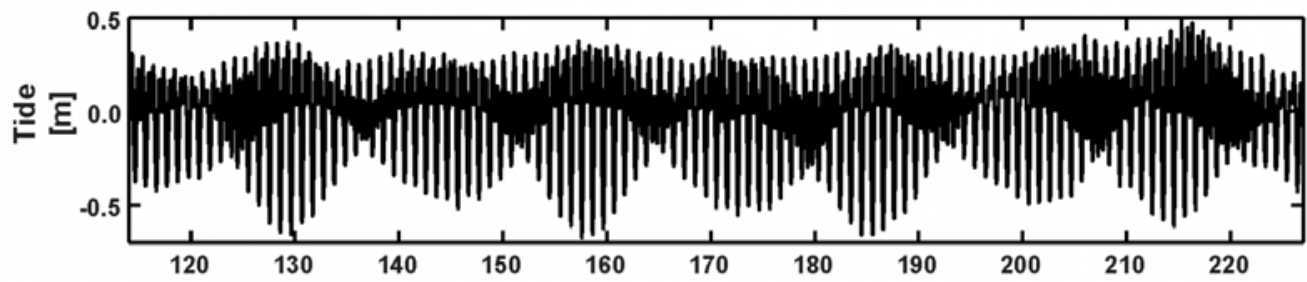

$B$

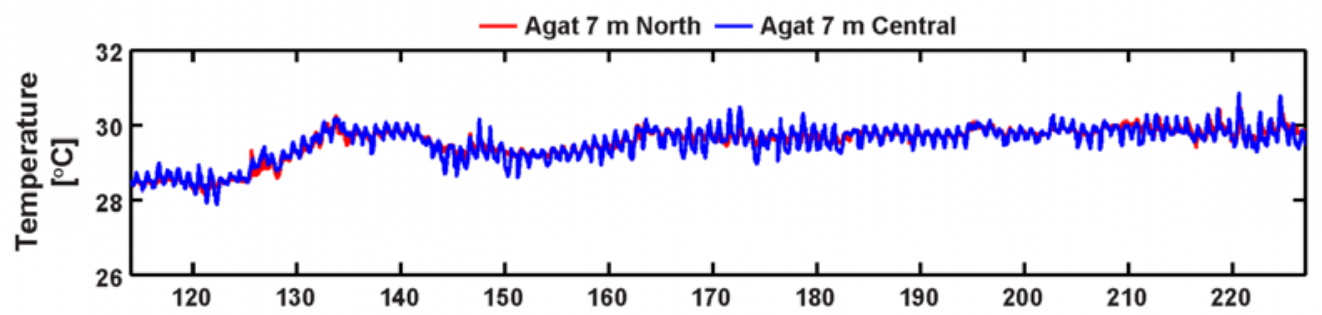

C

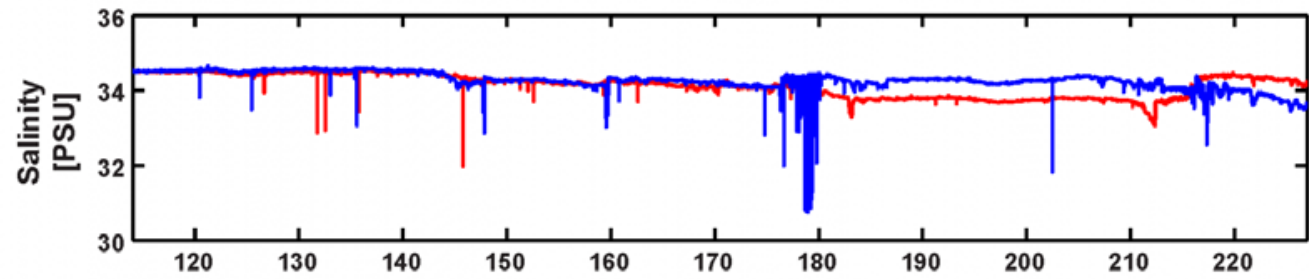

$D$

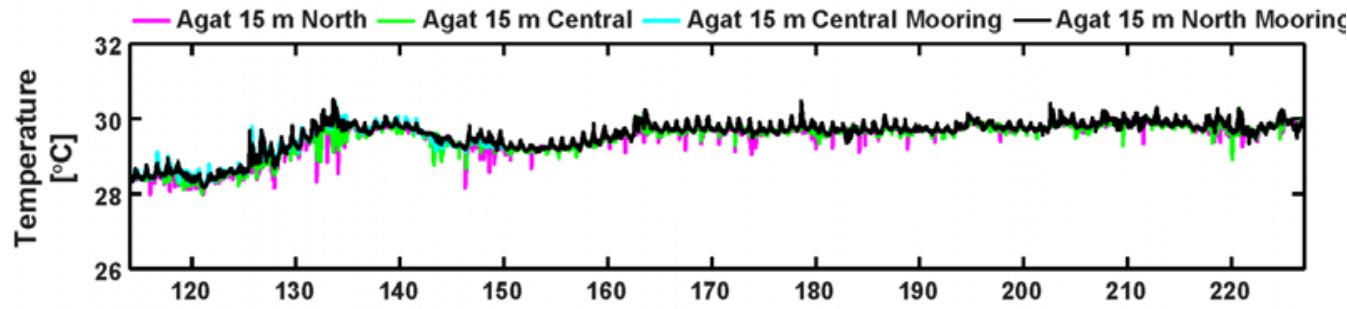

E

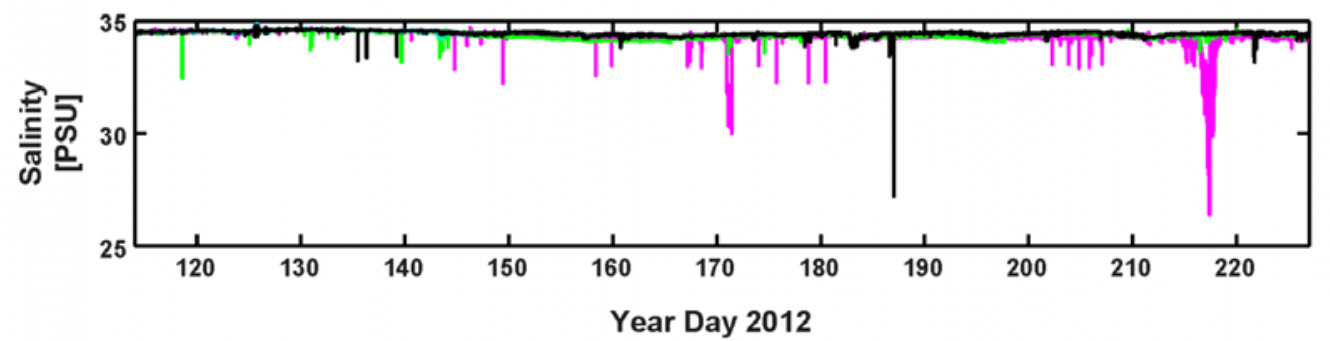

Figure 12. Time-series plots of tidal height $(A)$, in meters, temperature $(B, D)$, in degrees Celsius, and salinity $(C$, $E)$, using the Practical Salinity Units, for the shallow and deep sites. 


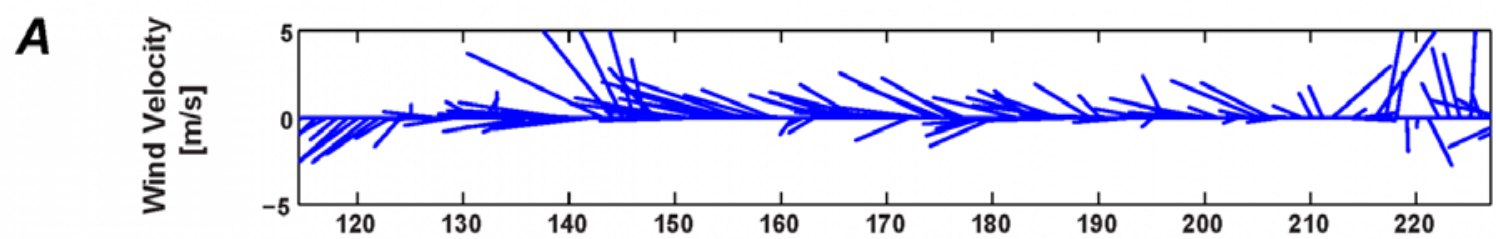

$B$

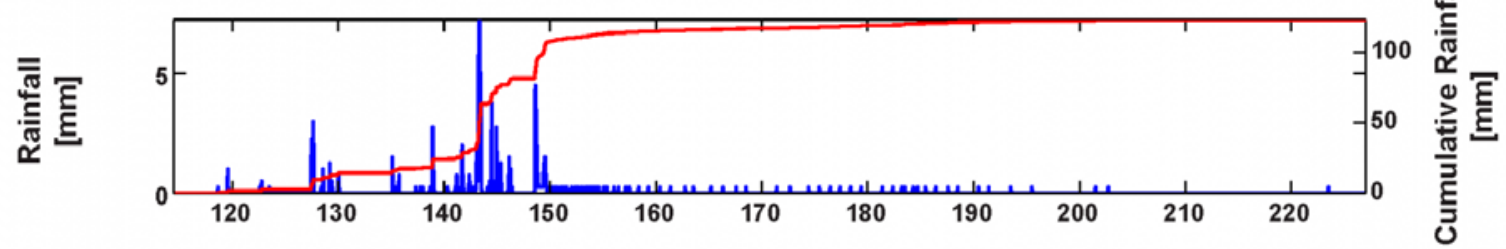

C

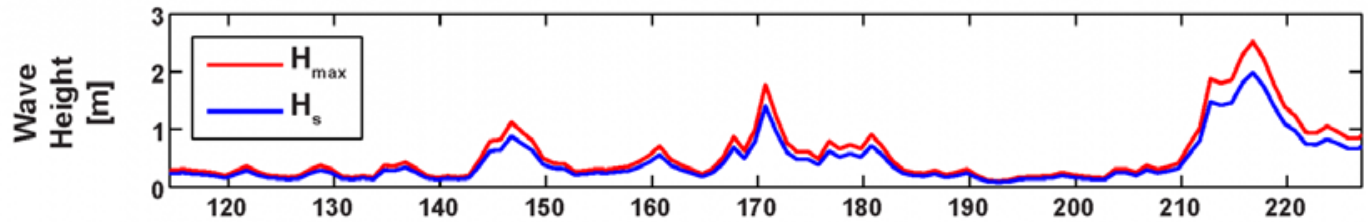

D

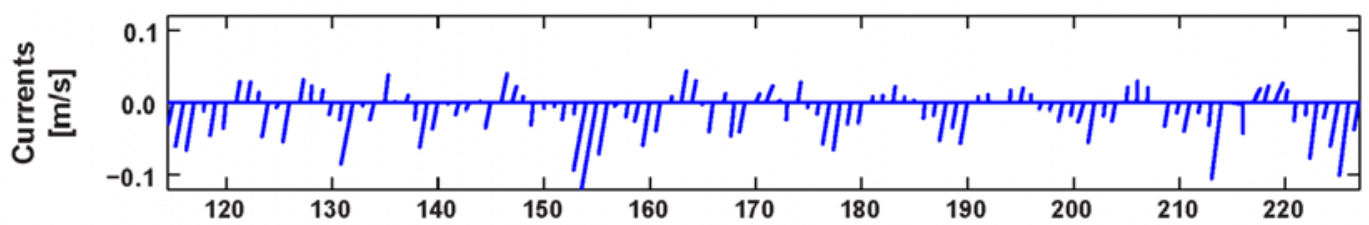

E

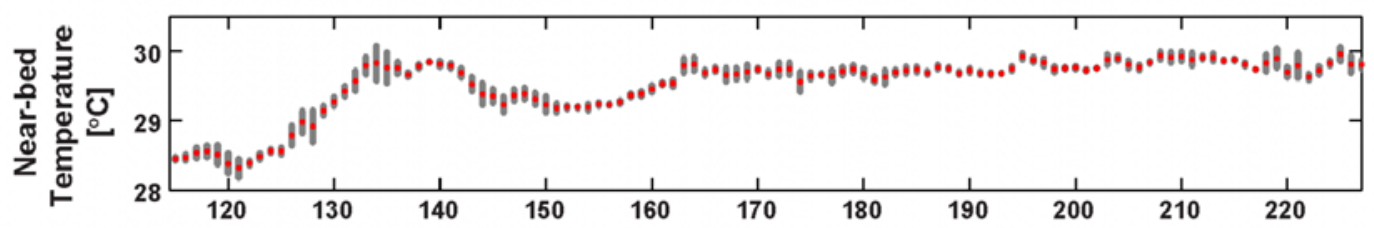

$\boldsymbol{F}$

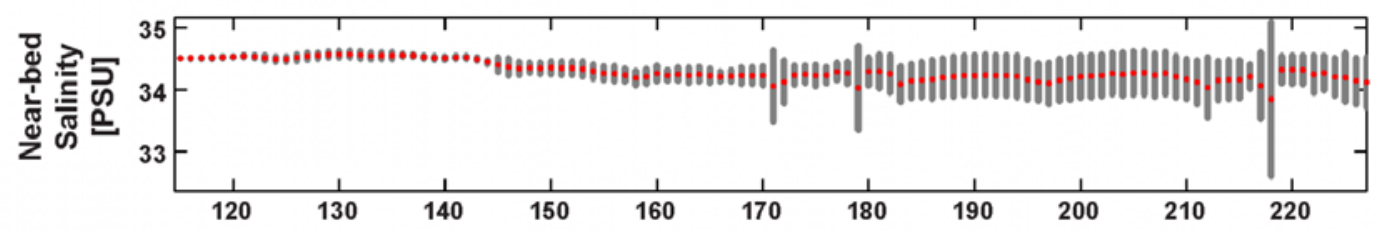

G

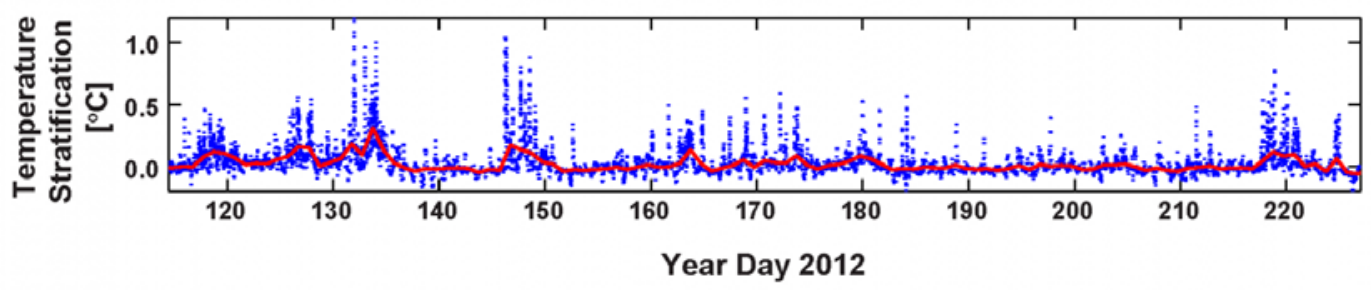

Figure 13. Time-series plots of meteorological forcing from the Orote Peninsula weather station and variability in currents and water-column properties from the Agat 15-m North MiniProbe. A, Daily-averaged wind, with direction in compass orientation and speed in meters per second. $B$, Hourly (blue) and cumulative (red) rainfall, in millimeters. $C$, Significant (blue) and maximum (red) wave height, in meters. D, Daily depth-averaged current velocities, with direction in compass orientation and speed in meters per second. $E$, Daily-averaged near-bed temperature (red dots) and daily temperature range (gray bars), in degrees Celsius. $F$, Daily-averaged near-bed salinity (red dots) and daily salinity range (gray bars), using the Practical Salinity Units. G, Difference between surface and near-bed temperatures, in degrees Celsius, at the Agat 15-m North Mooring for both 5-min (blue dashed) and daily-averaged (solid red) values. 
Table 12. Salinity statistics.

[SD, standard deviation; PSU, Practical Salinity Units; only data from 2012 Year Days 114.5 to 150.0 are presented for Agat Central 15-m mooring because of vessel damage to mooring]

\begin{tabular}{|l|c|c|c|c|}
\hline \multicolumn{1}{|c|}{ Site name } & $\begin{array}{c}\text { Depth } \\
{[\mathrm{m}]}\end{array}$ & $\begin{array}{c}\text { Mean } \pm \text { 1SD } \\
{[\text { PSU] }}\end{array}$ & $\begin{array}{c}\text { Minimum } \\
{[\mathrm{PSU}]}\end{array}$ & $\begin{array}{c}\text { Maximum } \\
{[\text { PSU] }}\end{array}$ \\
\hline Agat 15-m North Mooring & 14 & $34.45 \pm 0.10$ & 27.22 & 34.79 \\
Agat 15-m North MiniProbe & 13 & $34.31 \pm 0.43$ & 26.40 & 34.70 \\
Agat 7-m North MiniProbe & 7 & $34.13 \pm 0.30$ & 31.98 & 34.56 \\
Agat 15-m Central Mooring* & 14 & $34.53 \pm 0.05$ & 34.23 & 34.89 \\
Agat 15-m Central MiniProbe & 13 & $34.36 \pm 0.14$ & 32.45 & 34.67 \\
Agat 7-m Central MiniProbe & 5 & $34.26 \pm 0.27$ & 30.74 & 34.66 \\
\hline
\end{tabular}
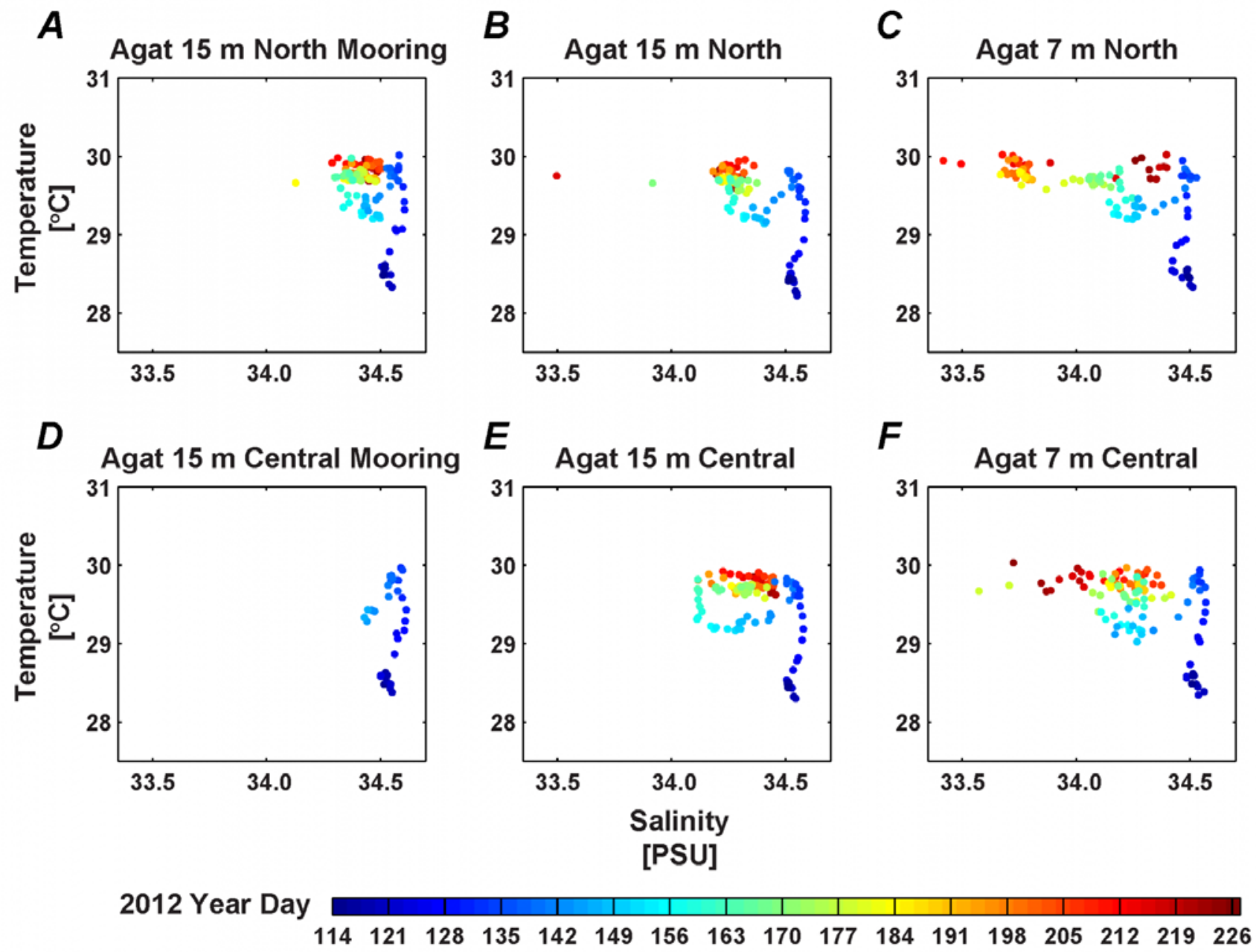

Figure 14. Scatter plots of temperature, in degrees Celsius, versus salinity, using the Practical Salinity Units, showing their relationship for each site $(A-F)$ using daily-averaged values. Color-coding is by 2012 Year Day. 
Turbidity.-Concurrent, reliable turbidity data were recorded for five of the sites: Adelup Point, the two Agat 15-m North platforms, and the two Agat 15-m Central platforms. The optical sensors at these sites operated for the entire study period with the exception of Agat 15-m Central mooring, which sank after YD 150. In general, turbidity was very low at all five sites throughout the study period (fig. 14). At the Agat sites, turbidity ranged from 0.00 to 3.38 NTU, with a mean turbidity \pm 1 standard deviation of $0.13 \pm 0.15 \mathrm{NTU}$ (table 13), while the Adelup site had a turbidity range of 0.00 to 3.24 NTU, with a mean of $0.13 \pm 0.22$ NTU. Both the Agat North and the Adelup sites show slightly elevated turbidity during the periods of large waves ( YD 170-173 and YD 212-220; figs. 5, 15). For the two Agat Central sites, turbidity was essentially zero for the entire study period.

Table 13. Turbidity statistics.

[SD, standard deviation; NTU, Nephelometric Turbidity Units; only data from 2012 Year Days 114.5 to 150.0 are presented for Agat Central 15-m mooring because of vessel damage to mooring; --, no data]

\begin{tabular}{|l|c|c|c|c|}
\hline \multicolumn{1}{|c|}{ Site name } & $\begin{array}{c}\text { Depth } \\
\text { [m] }\end{array}$ & $\begin{array}{c}\text { Mean } \pm \text { 1 SD } \\
\text { [NTU] }\end{array}$ & $\begin{array}{c}\text { Minimum } \\
\text { [NTU] }\end{array}$ & $\begin{array}{c}\text { Maximum } \\
\text { [NTU] }\end{array}$ \\
\hline Adelup 15-m Point MiniProbe & 10 & $0.14 \pm 0.22$ & 0.00 & 3.24 \\
Agat 15-m North Mooring & 14 & $0.06 \pm 0.18$ & 0.00 & 3.32 \\
Agat 15-m North MiniProbe & 12 & $0.47 \pm 0.41$ & -- & -- \\
Agat 7-m North MiniProbe & 7 & -- & 0.00 & 0.00 \\
Agat 15-m Central Mooring* & 14 & $0.00 \pm 0.00$ & 0.00 & 0.00 \\
Agat 15-m Central MiniProbe & 12 & $0.00 \pm 0.00$ & -- & -- \\
Agat 7-m Central MiniProbe & 5 & -- & - & - \\
Agat 15-m South MiniProbe & 13 & -- & & \\
\hline
\end{tabular}

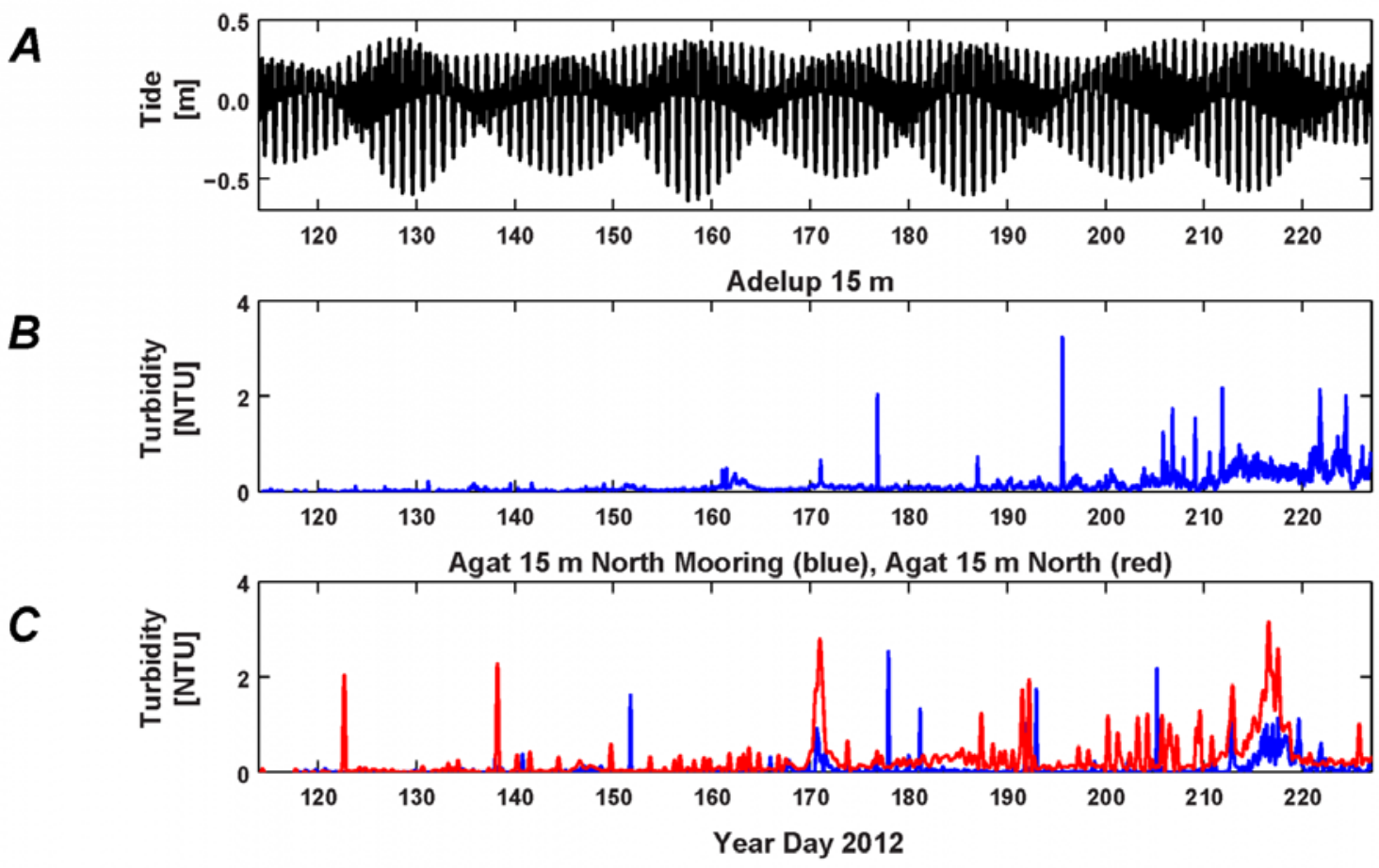

Figure 15. Time-series plots of $(A)$ tide, in meters, and $(B)$ near-bed turbidity, in Nephelometric Turbidity Units (NTU), for Adelup 15-m, as well as (C) near-bed turbidity, in Nephelometric Turbidity Units, for Agat 15-m North Mooring (blue) and MiniProbe (red). 


\section{Spatial Variations in Water-Column Properties}

The water-column properties that were measured by the CTD/OBS profiler included variations in temperature $\left({ }^{\circ} \mathrm{C}\right)$, salinity (PSU), turbidity (NTU), and chlorophyll $\left(\mathrm{mg} / \mathrm{m}^{3}\right)$ with depth.

West-Central Guam.- - Surveys of the water column that spanned the west coast of Guam from Tumon Bay south to Facpi Point were conducted at the beginning and end of the study. These surveys provide insight into the physical structure of the water column along $35 \mathrm{~km}$ of west-central Guam's shoreline and are useful for putting the time-series measurements made in WAPA's Agat Unit into regional context. The first survey, on YD 115 (24 April), showed very uniform depth-averaged salinity and very similar temperature ranges across all casts (fig. 16). During the second survey on YD 229 (16 August), temperatures were warmer and the measured salinity had a much larger range, primarily because of lower-salinity water near the surface (fig. 16). This low-salinity signature in the upper part of the water column was particularly strong in Apra Harbor. Because of this salinity signature in the Apra Harbor surface waters, the depth of the surface mixed layer extended, on average, $4 \mathrm{~m}$ deeper in the August measurements than in those from April. However, for measurements along the coast north and south of Apra Harbor, the mean depth of the surface mixed layer was relatively unchanged between the two surveys. In April, optical backscatter was higher for all casts from Camel Rock (see fig. 1) northward; however, this difference was very small. In general, turbidity was extremely low for all measurements in both surveys (fig. 17). For both surveys, chlorophyll concentrations were very low, though slightly higher chlorophyll concentrations were found in Apra Harbor, and these concentrations were greater in August than in April (fig. 17).

Agat Study Area.- The portion of the profiler casts taken in the Agat study area (Agat Bay to Facpi Point) provide us with greater spatial and vertical resolution than the long-term moored and bottom-mounted instruments, and they serve as quasi-synoptic snapshots of the study area during two different seasons. The YD 115 (24 April) survey took place at the end of the dry trade wind season when both offshore and local winds were consistently out of the northeast, while the YD 229 (16 August) survey occurred during the wet non-trade wind season when winds were slightly weaker and considerably more variable in direction (fig. 5). The contrasts between the surveys taken in these two different seasons match the trends in the mooring data: during the dry trade wind season, waters in this area were cooler, more saline, and had very low turbidity, but after the transition to the wet non-trade wind season, waters warmed by more than $1{ }^{\circ} \mathrm{C}$, less-saline water inhabited the upper water column, and turbidity was higher and also more variable both with depth and between sites (figs. 16-17, appendix 7). The higher turbidity in the August casts may have been caused in part by the large wave event that preceded that survey by approximately one week (fig. 5). For the August survey, the casts in this region that recorded the lowest salinity values were directly offshore from two freshwater sources: Namo River that drains Santa Rita and Agat Harbor. 


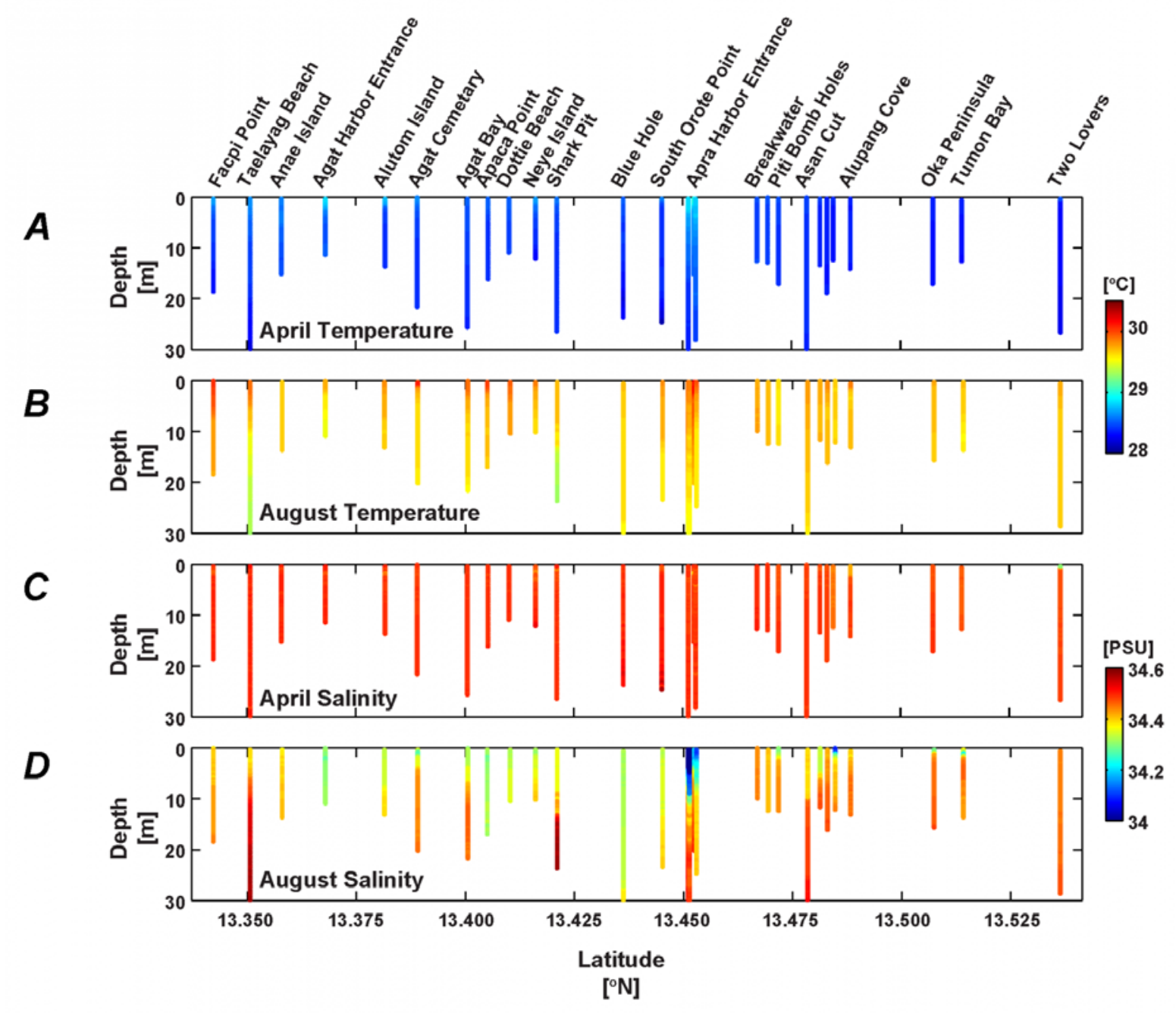

Figure 16. Plots against latitude of water-column profiler measurements of $(A-B)$ temperature, in degrees Celsius, and $(C-D)$ salinity, using the Practical Salinity Units, from April and August surveys. Profiles are plotted from lowest to highest latitude and profile site names are listed at the top of the figure. See appendix 7 for cast locations. 


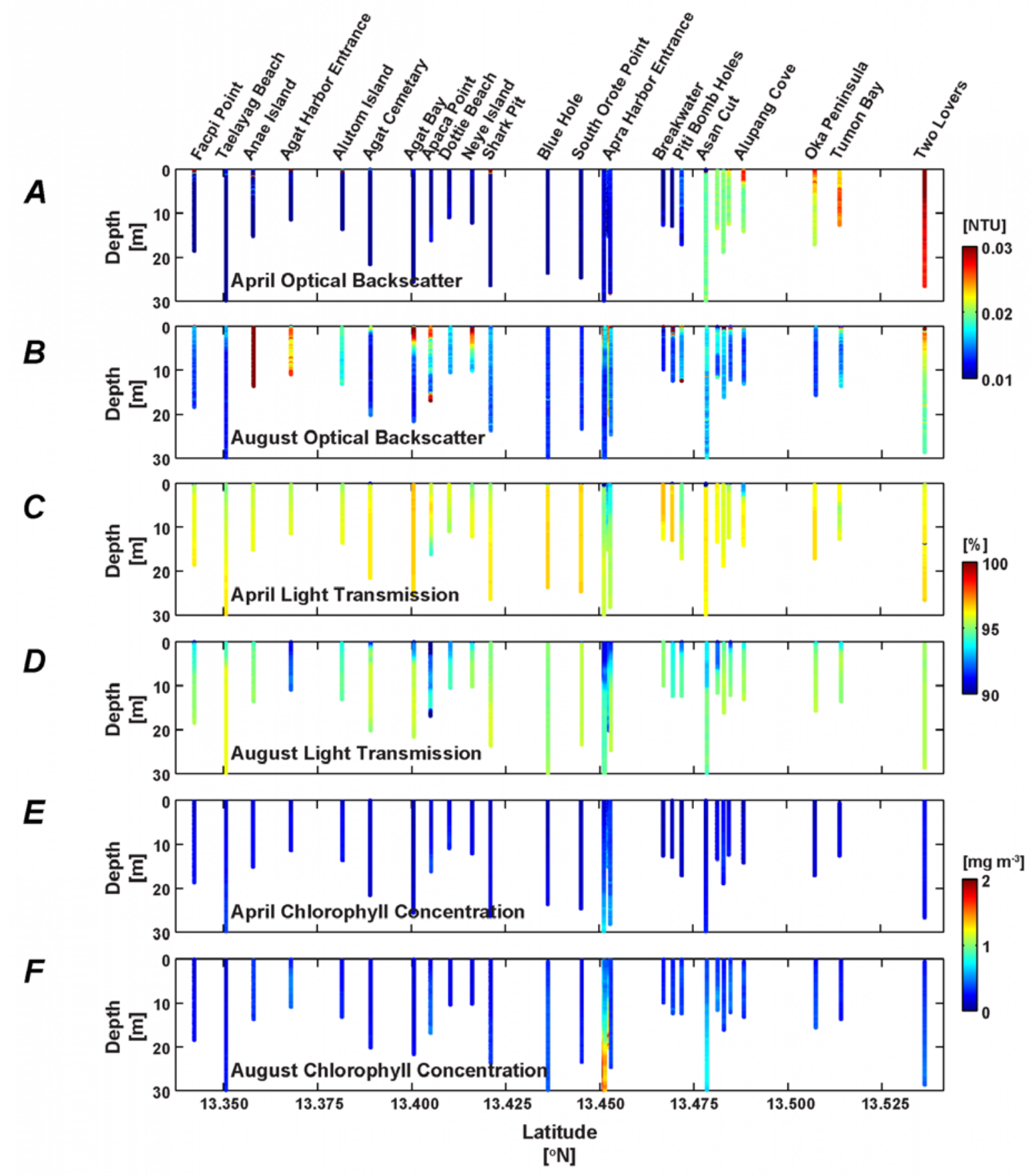

Figure 17. Plots against latitude of water-column profiler measurements of $(A-B)$ optical backscatter, in Nephelometric Turbidity Units, $(C-D)$ light transmission, in percent, and $(E-F)$ chlorophyll concentration, in milligrams per cubic meter, from April and August surveys. Profiles are plotted from lowest to highest latitude and profile site names are listed at the top of the figure. See appendix 7 for cast locations. 


\section{Lagrangian Surface Current Drifters}

LSCDs were deployed over three nights (YD 223-225, 10-12 August 2012; fig. 18) off westcentral Guam following the predicted times of coral spawning in an attempt to track coral larval dispersal. The start and stop dates, times, and locations of each drifter are listed in table 5. The LSCDs were designed so that they floated with the currents either $1.0 \mathrm{~m}$ or $0.1 \mathrm{~m}$ below the surface. Appendix 8 shows the nightly drifter release and recovery locations, as well as timelines showing drifter velocity and direction through each deployment. Each plot also shows the wind velocity and the tidal regime during the deployment, with the gray shaded regions denoting nighttime. Statistics for the LSCD deployments are shown in table 5. During the first night's deployment (YD 223), the LSCDs deployed in Asan Bay off Adelup Point both traveled to the west and were driven on Asan Bay's reef flat; the shallow-drogued unit made it off the reef flat and headed directly offshore, whereas the deeper-drogued unit got stuck on the reef flat. The drifters deployed in Asan Bay during the following nights (YD 224-225), however, all traveled eastward from the deployment site off Adelup Point towards Hagatna and Tamuning. The LSCDs deployed off Agat all traveled alongshore with the tides, slowly moving offshore to the northwest. Compared to observed LSCDs deployed off islands in Hawaii during coral spawning events (for example, Storlazzi and others, 2006; Presto and others, 2012), the measured surface current speeds and net distances traveled were much lower off west-central Guam, apparently because of the weaker wind forcing.

\section{Numerical Circulation Modeling}

\section{Hindcast Test Cases}

The aim of the numerical circulation modeling is not to obtain the best possible correspondence between model and measurements. This would require very detailed (and time-consuming) modeling of both the larger scale ocean circulation as well as the detailed flows on the reef. Such very intensive modeling requires suitable field measurements covering wide time and spatial scales. The circulation model still needs to capture a similar range of values, but it is expected that phase differences in peaks between model and measurement occur because of the relative coarse schematization of the ocean model.

To evaluate the performance of the circulation model, hindcast test cases were run for the summer non-trade wind and winter trade wind seasons from the 2007-2008 and 2012 field experiments. Select time periods of modeled depth-averaged east-west (U) and north-south (V) velocities were compared to those measured by the ADCPs at different sites. Generally, the modeled velocities exhibit a similar range of values and tidally driven fluctuation patterns to those of the in situ records (see appendix 9). However, the phases between the modeled and in situ records are often offset, making the point-to-point correlations between these records poor. 

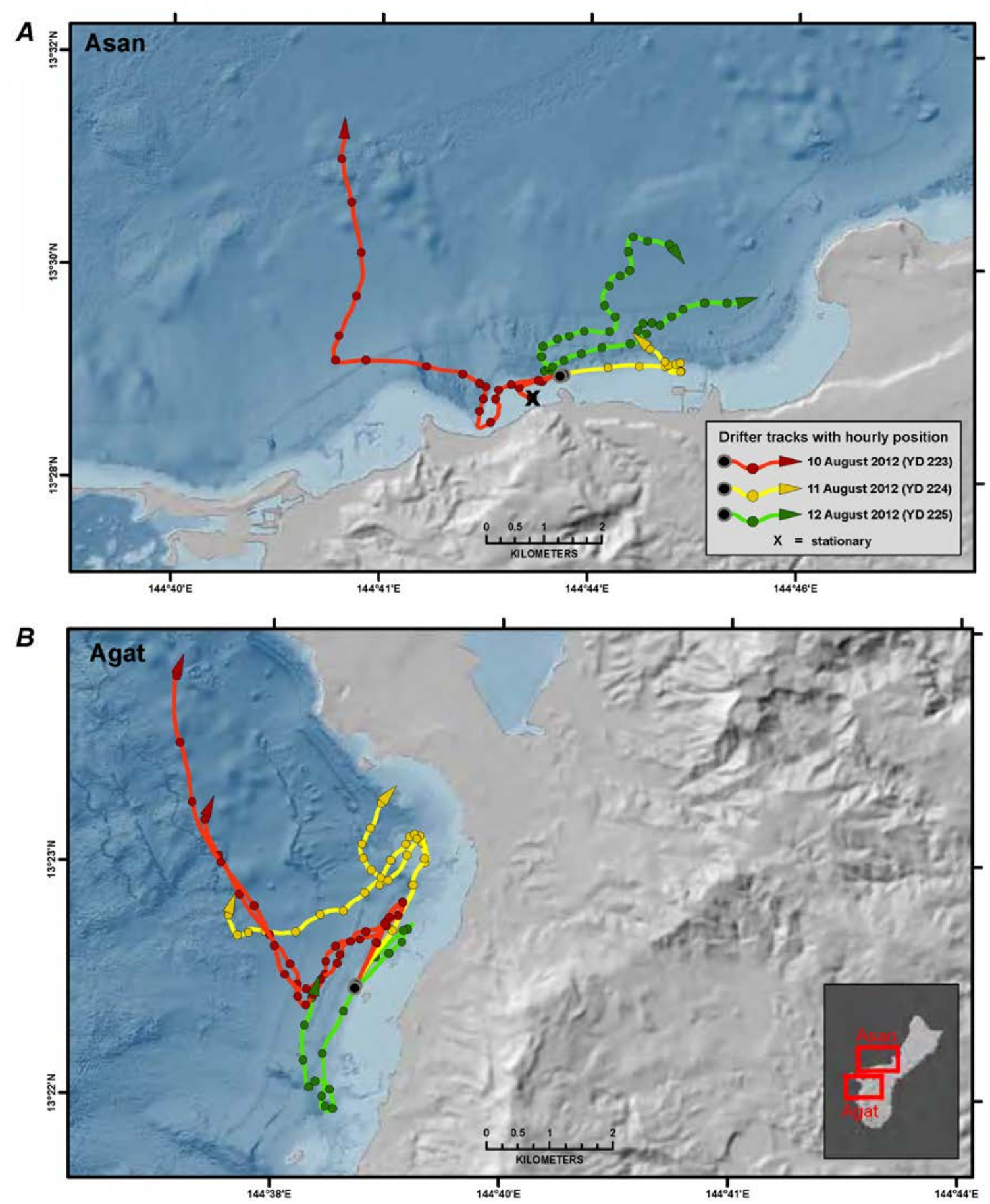

Figure 18. Maps showing all Lagrangian current surface drifter (LCSD) tracks from the (A) Asan and (B) Agat Bays deployed during 2012 Year Days 225-227 (10-12 August 2012). 
Modeled Tide, Wind, and Wave Scenarios

A suite of model runs was conducted to gain insight into the horizontal flow regime under various forcing conditions: (1) tides only (fig. 19), (2) tides and winds (figs. 20-24), and (3) tides and waves (figs. 24-29). Table 7 lists the full suite of modeled tide, wind, and wave scenarios. All simulations were run over the summer 2007 time frame (17 days). For each simulation the average flow over the falling and rising tide were determined. Because of the steep bathymetric gradient along the coast, most wave energy is quickly dissipated on the reef flat when propagating into the nearshore, particularly when coming into an embayment. Consequently, in contrast to the tide and wind scenarios, the resulting effects on currents by the combined tide and wave scenarios (fig. 25-29) are localized to the nearshore regions.

Tides. - The tidal flows are generally weak, with peak flows less than $0.15 \mathrm{~m} / \mathrm{s}$. Under both rising and falling tides, the strongest currents are at the entrance and along the northern perimeter of Apra Harbor (fig. 19). In the region north of the harbor, mean currents are directed alongshore, with flows directed to the south during rising tides and to the northeast during falling tides. In the absence of any other forcing mechanism, mean currents in the region south of Apra Harbor are extremely weak during both tidal phases.

Northerly Winds + Tides. - With winds out of the north, surface flows across the entire model domain were relatively weak and directed along the coast and to the south, regardless of tidal phase (fig. 20). The strongest mean currents were north of Apra Harbor, at the harbor mouth, and close to the Agat shoreline south of the harbor. Current speeds increased with increasing wind speed.

Northwesterly Winds + Tides.-When winds are out of the northwest, flows during both tidal phases are oriented in a more onshore direction (towards the south or southeast; fig. 21). As wind speed increases, current speeds increase across the model domain, with the most vigorous currents found at the harbor mouth and south of the Orote Peninsula.

Westerly Winds + Tides.-With winds out the west, a prominent alongshore current develops along the coast to the north of Apra Harbor (fig. 22). This alongshore current is stronger during a rising tide than a falling tide, and the predicted magnitudes of this current increase with more vigorous winds.

Southwesterly Winds + Tides.-Winds out of the southwest drive currents alongshore to the northeast (fig. 23). This alongshore current occurs along the coastlines both north and south of Apra Harbor. The alongshore current on the north side of the harbor extends further away from the coast than that seen under westerly winds, and it strengthens during falling tides. The alongshore current south of the harbor is more narrowly confined to the coast and does not change in strength with different tidal phases.

Southerly Winds + Tides. - With winds out of the south, currents are directed towards the north or northeast, with considerable sheltering of both the waters within Apra Harbor and the nearshore area north of the harbor (fig. 24). Under weak southerly winds, flows in the northern part of the domain are enhanced (approximately 2-fold) during falling tide (fig. 24A, B). As wind speeds increase, flows become more vigorous just outside the harbor mouth and along the Agat coastline to the south.

Northerly Waves + Tides.- - Under tidal forcing and waves from the north, a shadow zone forms south of Orote Peninsula, resulting in a less energetic wave climate at Agat than at Asan (fig. 25). As wave height increases from 0.5 to $1.5 \mathrm{~m}$, a band of increased alongshore flow forms along the coast north of Apra Harbor.

Northwesterly Waves + Tides.-With waves approaching from the northwest, strong onshore currents develop along the coastlines north of the harbor and south of the Orote Peninsula, with the ocean-facing perimeter of the peninsula remaining sheltered (fig. 26).

Westerly Waves + Tides.-During westerly wave forcing, a small shadow zone forms northeast of Apra Harbor, resulting in a lower energy wave climate at Asan compared to Agat (fig. 27). With 
increased wave heights, nearshore flows north of the harbor are generally along-shore to the northeast while flows south of the harbor are generally alongshore to the south.

Southwesterly Waves + Tides.-With waves from the southwest, nearshore regions of enhanced currents are confined to the coast south of the Orote Peninsula, with weak flows in the northern Asan region (fig. 28). The more vigorous nearshore currents south of the peninsula are directed onshore and to the south/southwest.

Southerly Waves + Tides.-Under southerly wave forcing, very few regions of the coast within the model domain show any enhanced flow, with the entire area north of the harbor being sheltered (fig. 29). A weak, southward, alongshore current develops along the coast south of Apra Harbor.
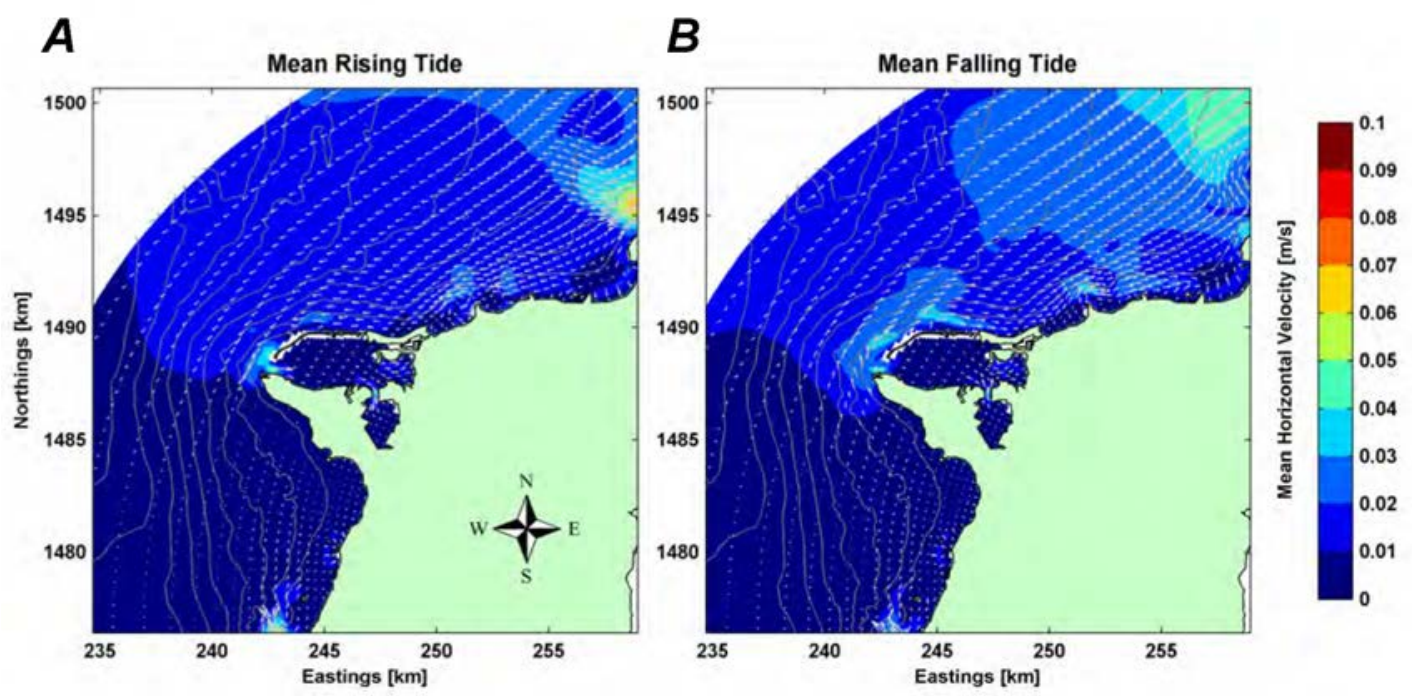

Figure 19. Maps showing desampled Western Guam model average near-surface current speeds, in meters per second, and flow directions, in compass orientation, over mean tidal forcing overlaid on 100-m isobaths. $A$, Flow patterns during mean rising (flood) tides. $B$, Flow patterns during mean falling (ebb) tides. Velocity vectors show magnitude and direction of currents, with speed in meters per second indicated by arrow size and shading color. 

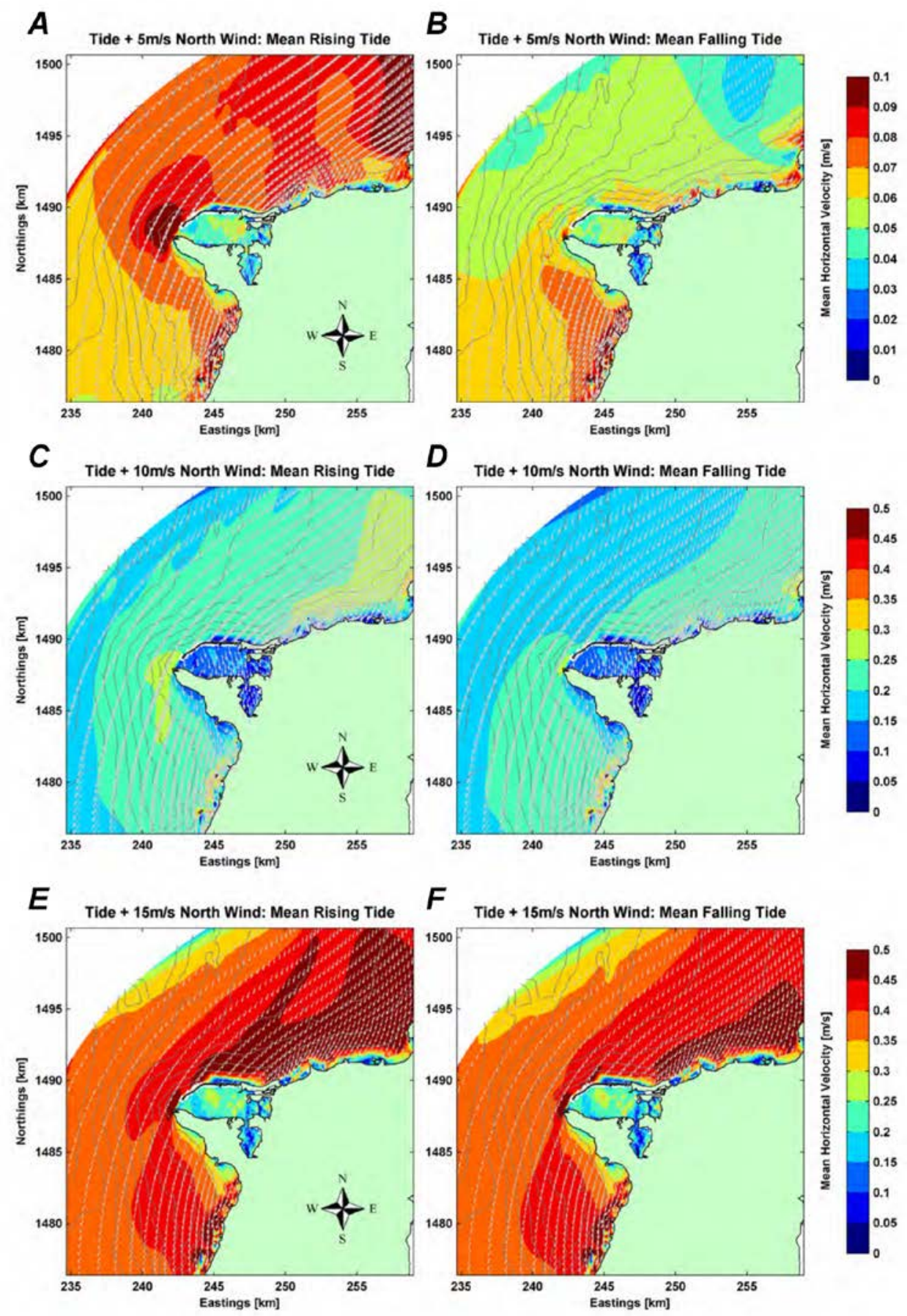

Figure 20. Maps showing desampled Western Guam model average near-surface current speeds, in meters per second, and flow directions, in compass orientation, over mean tidal forcing and winds out of the north overlaid on 100-m isobaths. $A$, Flow patterns during mean rising (flood) tides with the wind blowing at 5 meters per second. $B$, Flow patterns during mean falling (ebb) tides with the wind blowing at 5 meters per second. $C$, Flow patterns during mean rising (flood) tides with the wind blowing at 10 meters per second. $D$, Flow patterns during mean falling (ebb) tides with the wind blowing at 10 meters per second. $E$, Flow patterns during mean rising (flood) tides with the wind blowing at 15 meters per second. $F$, Flow patterns during mean falling (ebb) tides with the wind blowing at 15 meters per second. Velocity vectors show curvilinear magnitude and direction of currents, with speed in meters per second indicated by arrow size and color. Note that color scales for $A-B$ and for $C-F$ are different. 

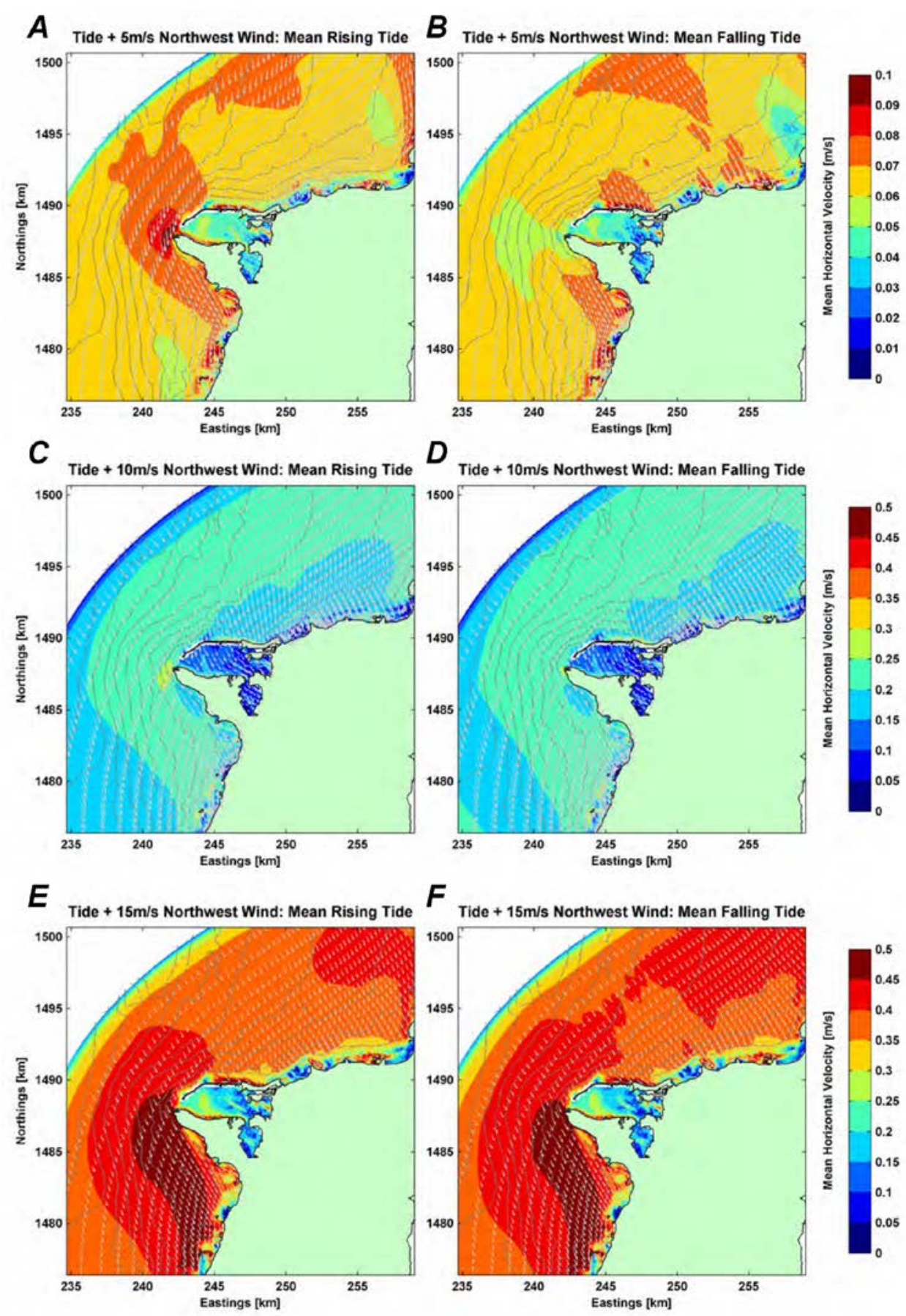

Figure 21. Maps showing desampled Western Guam model average near-surface current speeds, in meters per second, and flow directions, in compass orientation, over mean tidal forcing and winds out of the northwest overlaid on 100-m isobaths. $A$, Flow patterns during mean rising (flood) tides with the wind blowing at 5 meters per second. $B$, Flow patterns during mean falling (ebb) tides with the wind blowing at 5 meters per second. $C$, Flow patterns during mean rising (flood) tides with the wind blowing at 10 meters per second. $D$, Flow patterns during mean falling (ebb) tides with the wind blowing at 10 meters per second. $E$, Flow patterns during mean rising (flood) tides with the wind blowing at 15 meters per second. $F$, Flow patterns during mean falling (ebb) tides with the wind blowing at 15 meters per second. Velocity vectors show curvilinear magnitude and direction of currents, with speed in meters per second indicated by arrow size and color. Note that color scales for $A-B$ and for $C-F$ are different. 

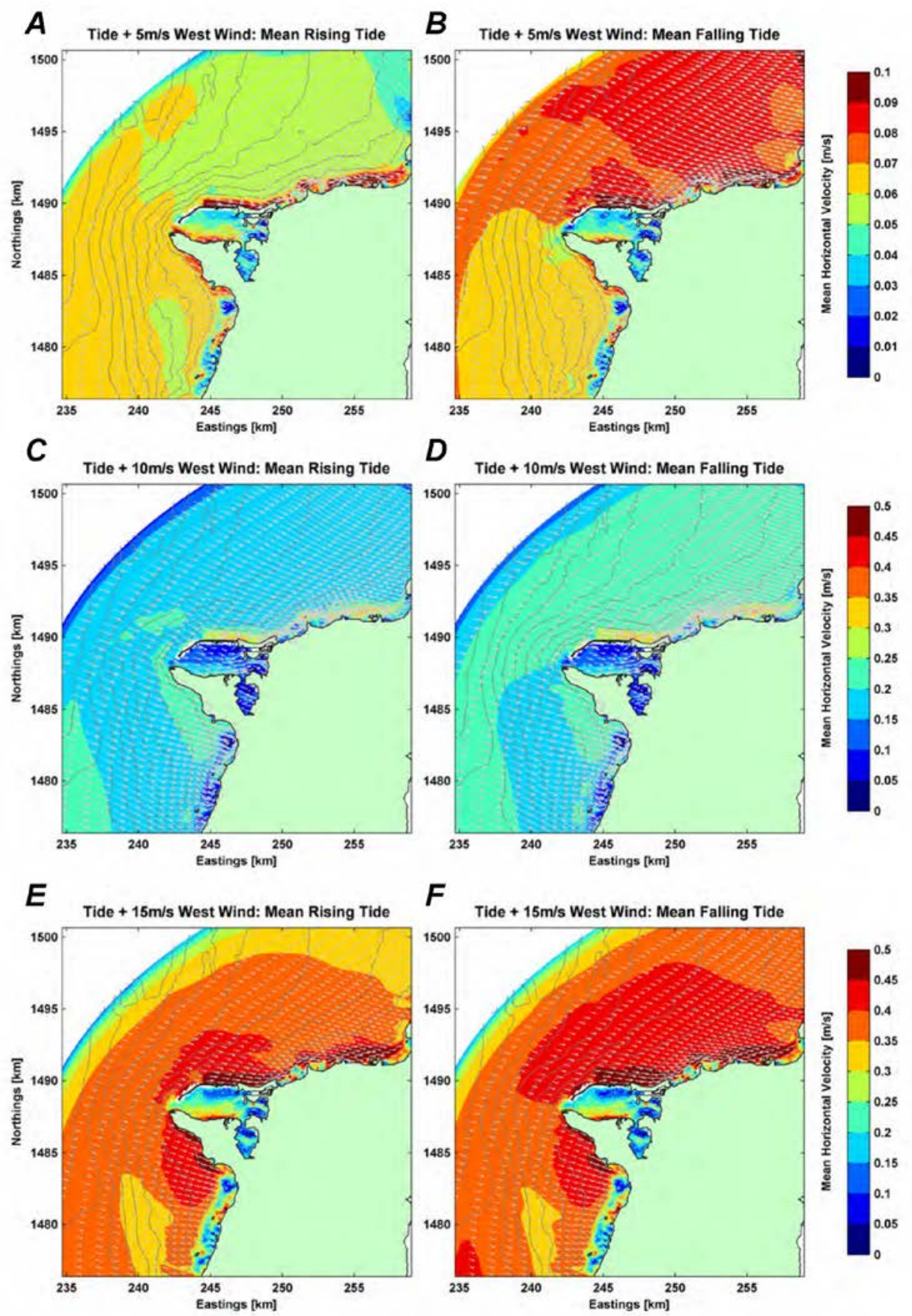

Figure 22. Maps showing desampled Western Guam model average near-surface current speeds, in meters per second, and flow directions, in compass orientation, over mean tidal forcing and winds out of the west overlaid on 100-m isobaths. A, Flow patterns during mean rising (flood) tides with the wind blowing at 5 meters per second. $B$, Flow patterns during mean falling (ebb) tides with the wind blowing at 5 meters per second. $C$, Flow patterns during mean rising (flood) tides with the wind blowing at 10 meters per second. $D$, Flow patterns during mean falling (ebb) tides with the wind blowing at 10 meters per second. $E$, Flow patterns during mean rising (flood) tides with the wind blowing at 15 meters per second. F, Flow patterns during mean falling (ebb) tides with the wind blowing at 15 meters per second. Velocity vectors show curvilinear magnitude and direction of currents, with speed in meters per second indicated by arrow size and color. Note that color scales for $A-B$ and for $C-F$ are different. 

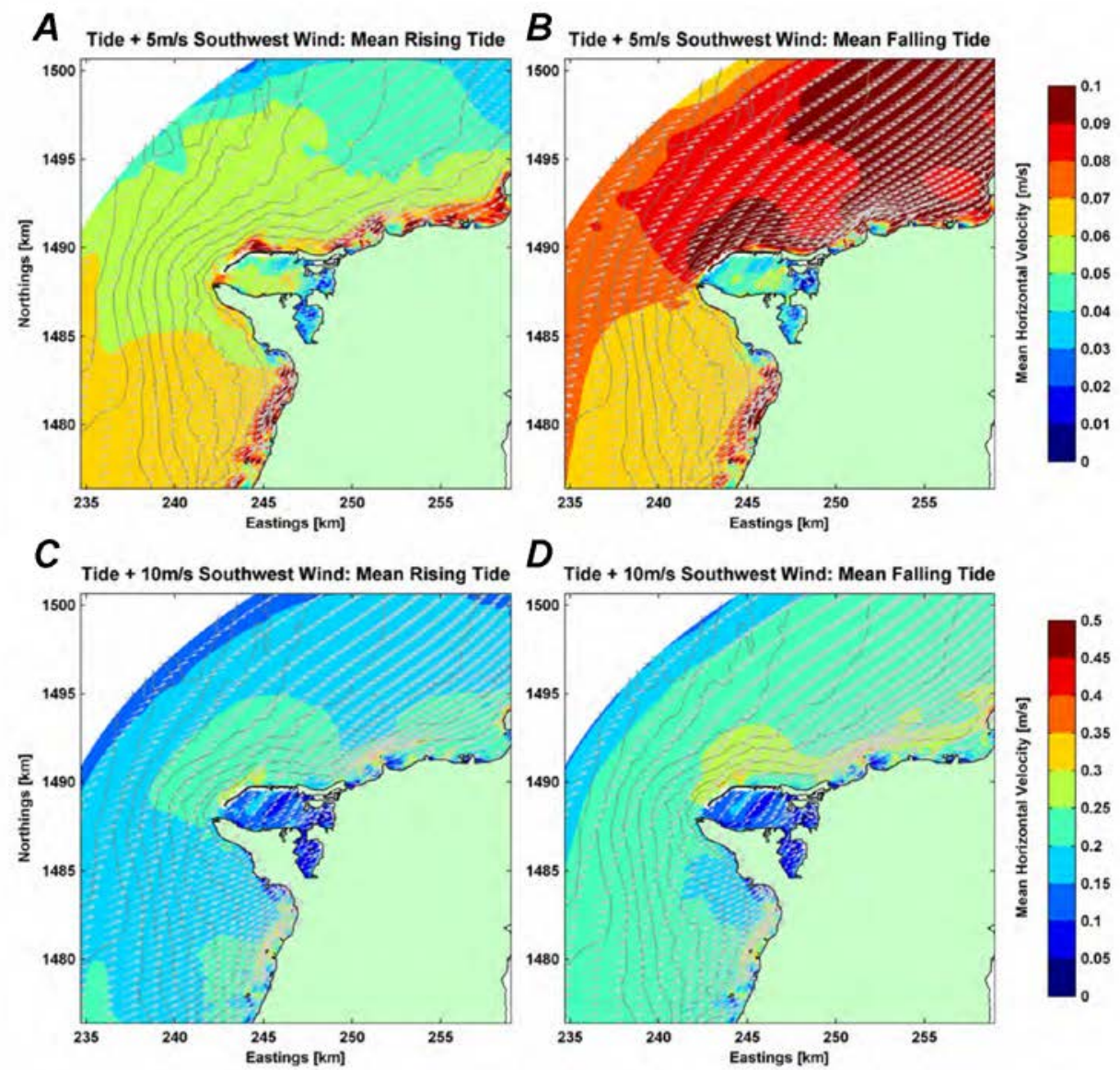

$D_{\text {Tide }+10 \mathrm{~m} / \mathrm{s} \text { Southwest Wind: Mean Falling Tide }}$
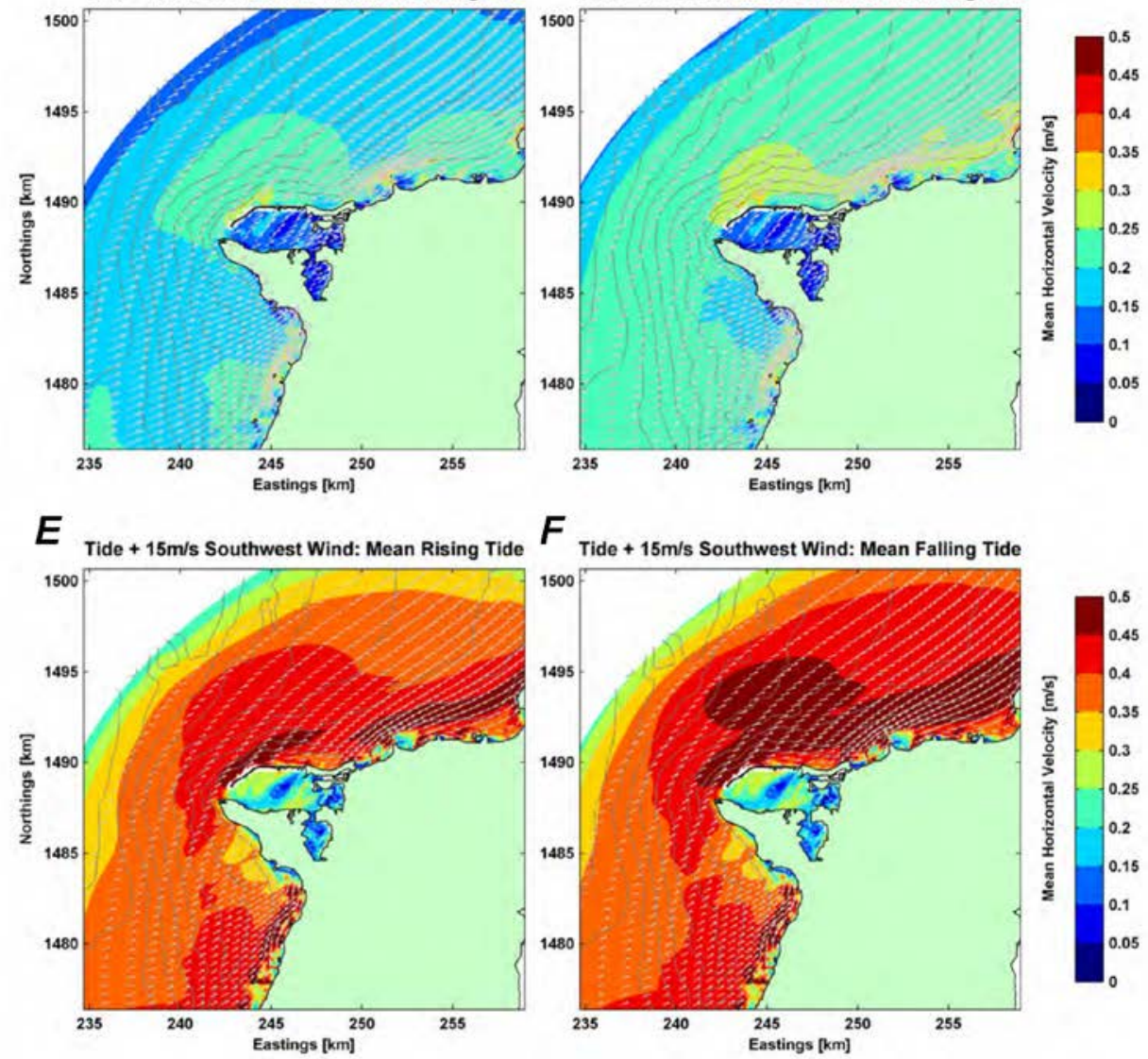

Figure 23. Maps showing desampled Western Guam model average near-surface current speeds, in meters per second, and flow directions, in compass orientation, over mean tidal forcing and winds out of the southwest overlaid on 100-m isobaths. A, Flow patterns during mean rising (flood) tides with the wind blowing at 5 meters per second. $B$, Flow patterns during mean falling (ebb) tides with the wind blowing at 5 meters per second. $C$, Flow patterns during mean rising (flood) tides with the wind blowing at 10 meters per second. $D$, Flow patterns during mean falling (ebb) tides with the wind blowing at 10 meters per second. $E$, Flow patterns during mean rising (flood) tides with the wind blowing at 15 meters per second. F, Flow patterns during mean falling (ebb) tides with the wind blowing at 15 meters per second. Velocity vectors show curvilinear magnitude and direction of currents, with speed in meters per second indicated by arrow size and color. Note that color scales for $A-B$ and for $C-F$ are different. 



Figure 24. Maps showing desampled Western Guam model average near-surface current speeds, in meters per second, and flow directions, in compass orientation, over mean tidal forcing and winds out of the south overlaid on 100-m isobaths. A, Flow patterns during mean rising (flood) tides with the wind blowing at 5 meters per second. $B$, Flow patterns during mean falling (ebb) tides with the wind blowing at 5 meters per second. $C$, Flow patterns during mean rising (flood) tides with the wind blowing at 10 meters per second. $D$, Flow patterns during mean falling (ebb) tides with the wind blowing at 10 meters per second. $E$, Flow patterns during mean rising (flood) tides with the wind blowing at 15 meters per second. F, Flow patterns during mean falling (ebb) tides with the wind blowing at 15 meters per second. Velocity vectors show curvilinear magnitude and direction of currents, with speed in meters per second indicated by arrow size and color. Note that color scales for $A-B$ and for $C-F$ are different. 

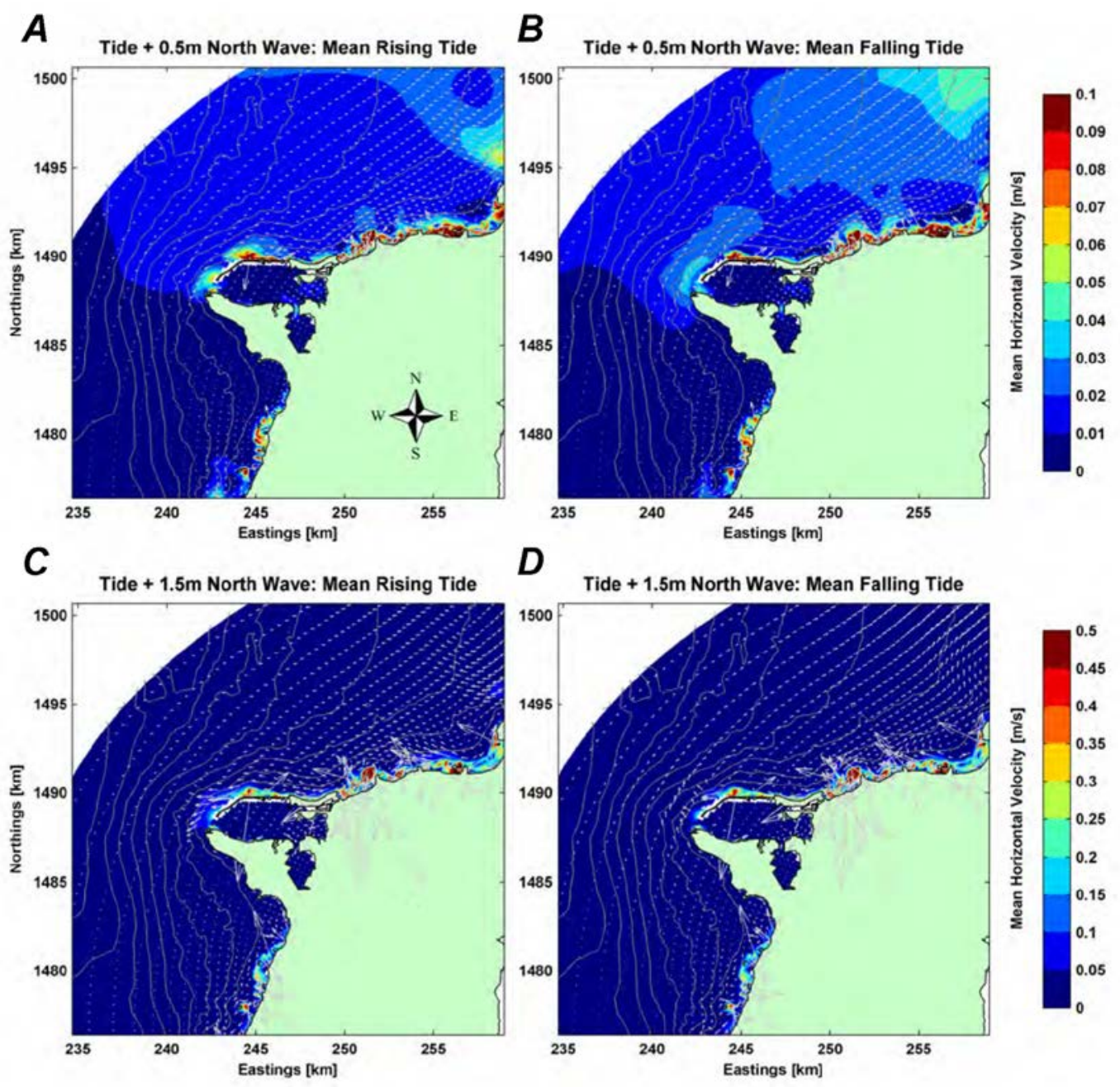

Figure 25. Maps showing desampled Western Guam model average near-surface current speeds, in meters per second, and flow directions, in compass orientation, over mean tidal forcing and waves out of the north overlaid on 100-m isobaths. $A$, Flow patterns during mean rising (flood) tides with 0.5 -meter-high waves. $B$, Flow patterns during mean falling (ebb) tides with 0.5 -meter-high waves. $C$, Flow patterns during mean rising (flood) tides with 1.5-meter-high waves. $D$, Flow patterns during mean falling (ebb) tides with 1.5-meter-high waves. Velocity vectors show curvilinear magnitude and direction of currents, with speed in meters per second indicated by arrow size and color. Note that color scales for $A-B$ and for $C-D$ are different. For more details on the wave fields driving the flow patterns, see appendix 10.3 and 10.4 . 

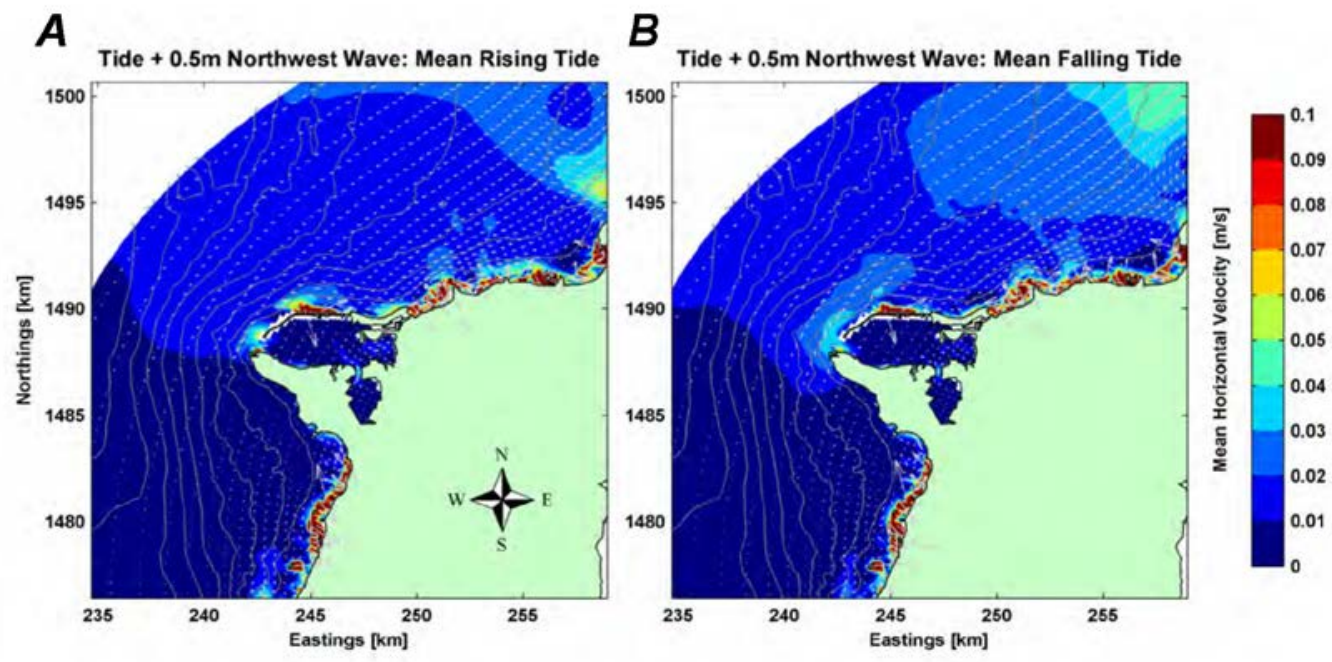

Figure 26. Maps showing desampled Western Guam model average near-surface current speeds, in meters per second, and flow directions, in compass orientation, over mean tidal forcing and waves out of the northwest overlaid on $100-\mathrm{m}$ isobaths. $A$, Flow patterns during mean rising (flood) tides with 0.5 -meter-high waves. $B$, Flow patterns during mean falling (ebb) tides with 0.5 -meter-high waves. Velocity vectors show curvilinear magnitude and direction of currents, with speed in meters per second indicated by arrow size and color. For more details on the wave fields driving the flow patterns, see appendix 10.3 and 10.4. 

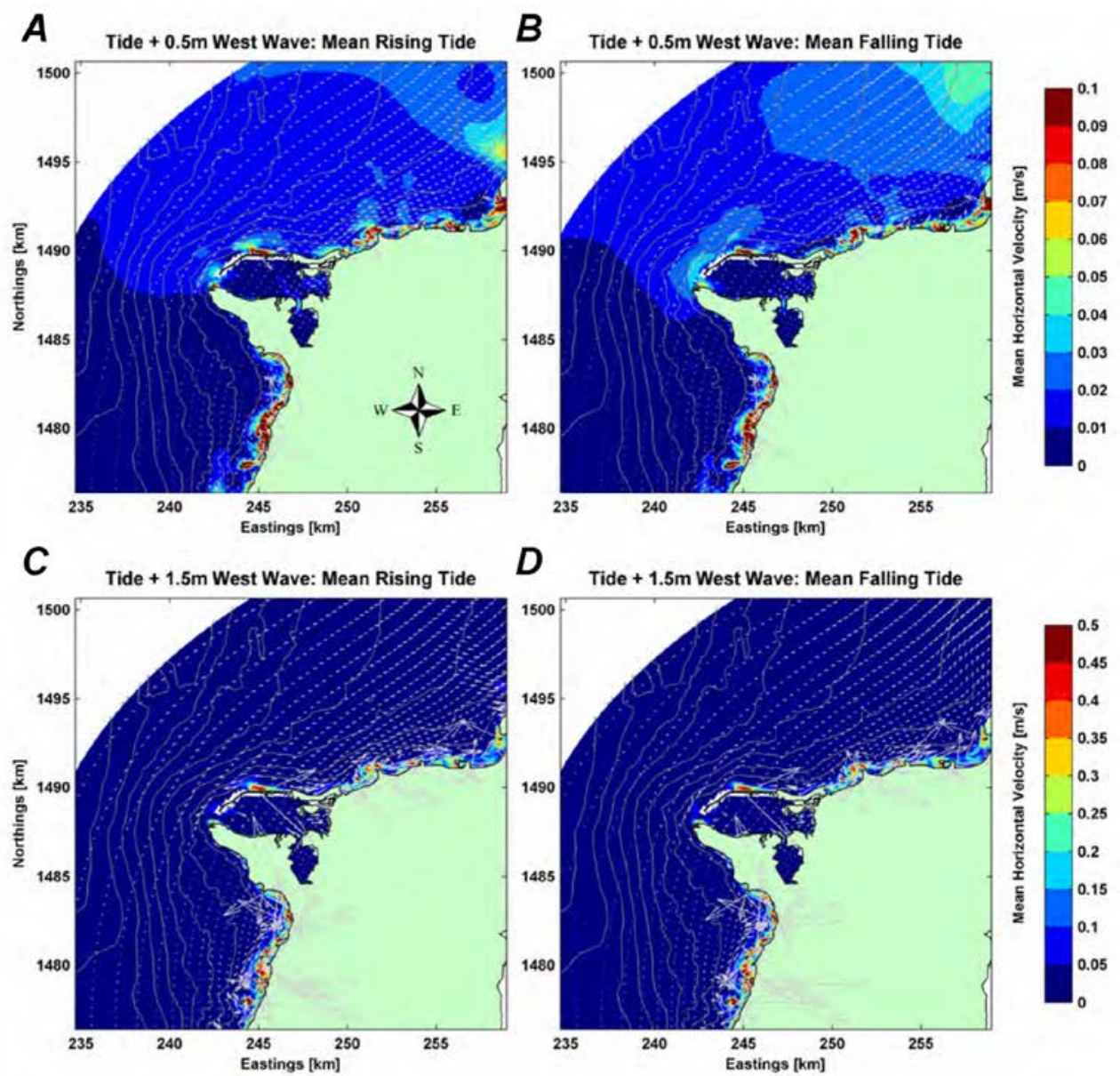

D Tide $+1.5 \mathrm{~m}$ West Wave: Mean Falling Tide
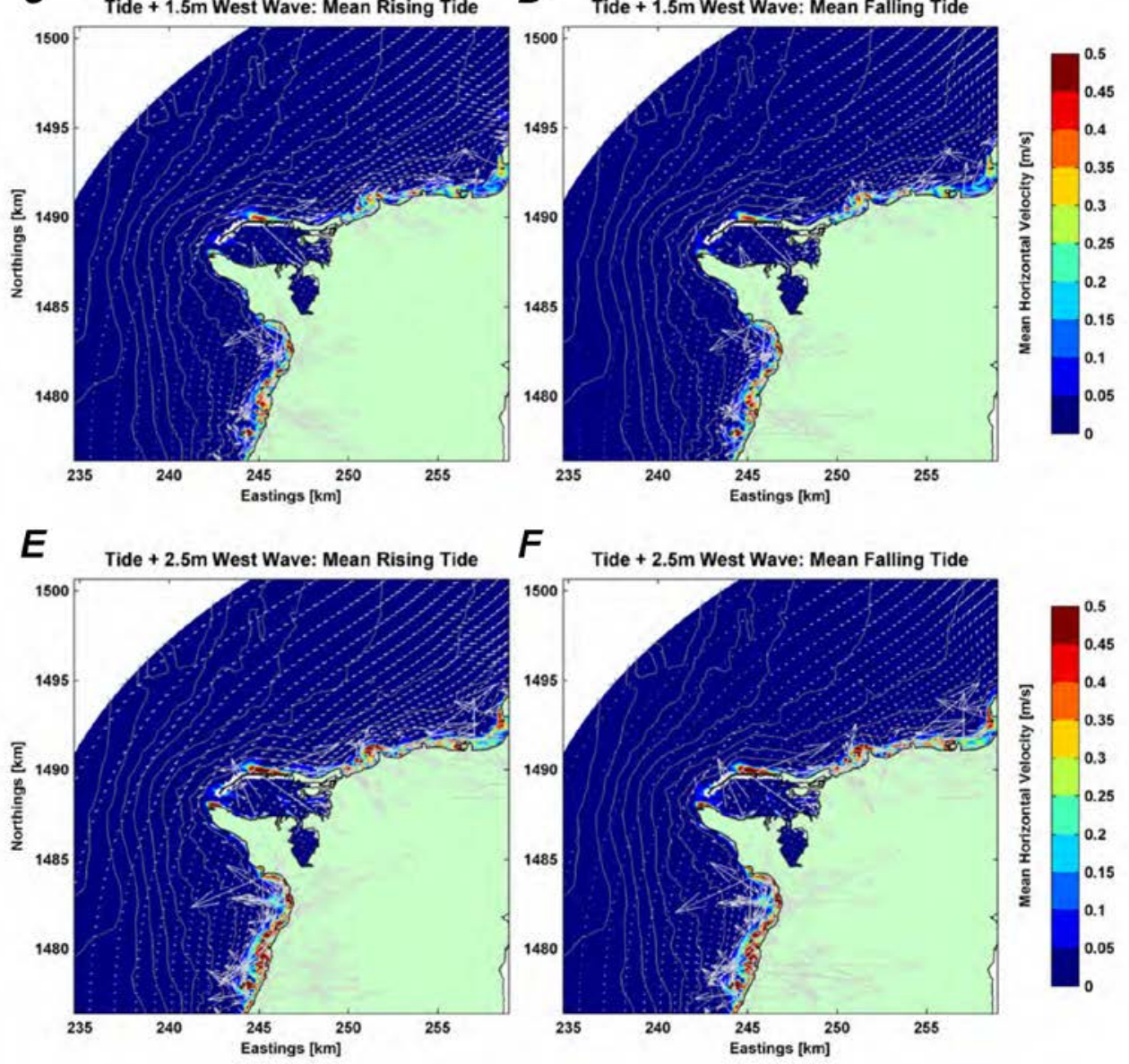

Figure 27. Maps showing desampled Western Guam model average near-surface current speeds, in meters per second, and flow directions, in compass orientation, over mean tidal forcing and waves out of the west overlaid on 100-m isobaths. $A$, Flow patterns during mean rising (flood) tides with 0.5 -meter-high waves. $B$, Flow patterns during mean falling (ebb) tides with 0.5 -meter-high waves. C, Flow patterns during mean rising (flood) tides with 1.5-meter-high waves. $D$, Flow patterns during mean falling (ebb) tides with 1.5-meter-high waves. $E$, Flow patterns during mean rising (flood) tides with 2.5-meter-high waves. F, Flow patterns during mean falling (ebb) tides with 2.5-meter-high waves. Velocity vectors show curvilinear magnitude and direction of currents, with speed in meters per second indicated by arrow size and color. Note that color scales for $A-B$ and for $C-F$ are different. For more details on the wave fields driving the flow patterns, see appendix 10.3 and 10.4. 

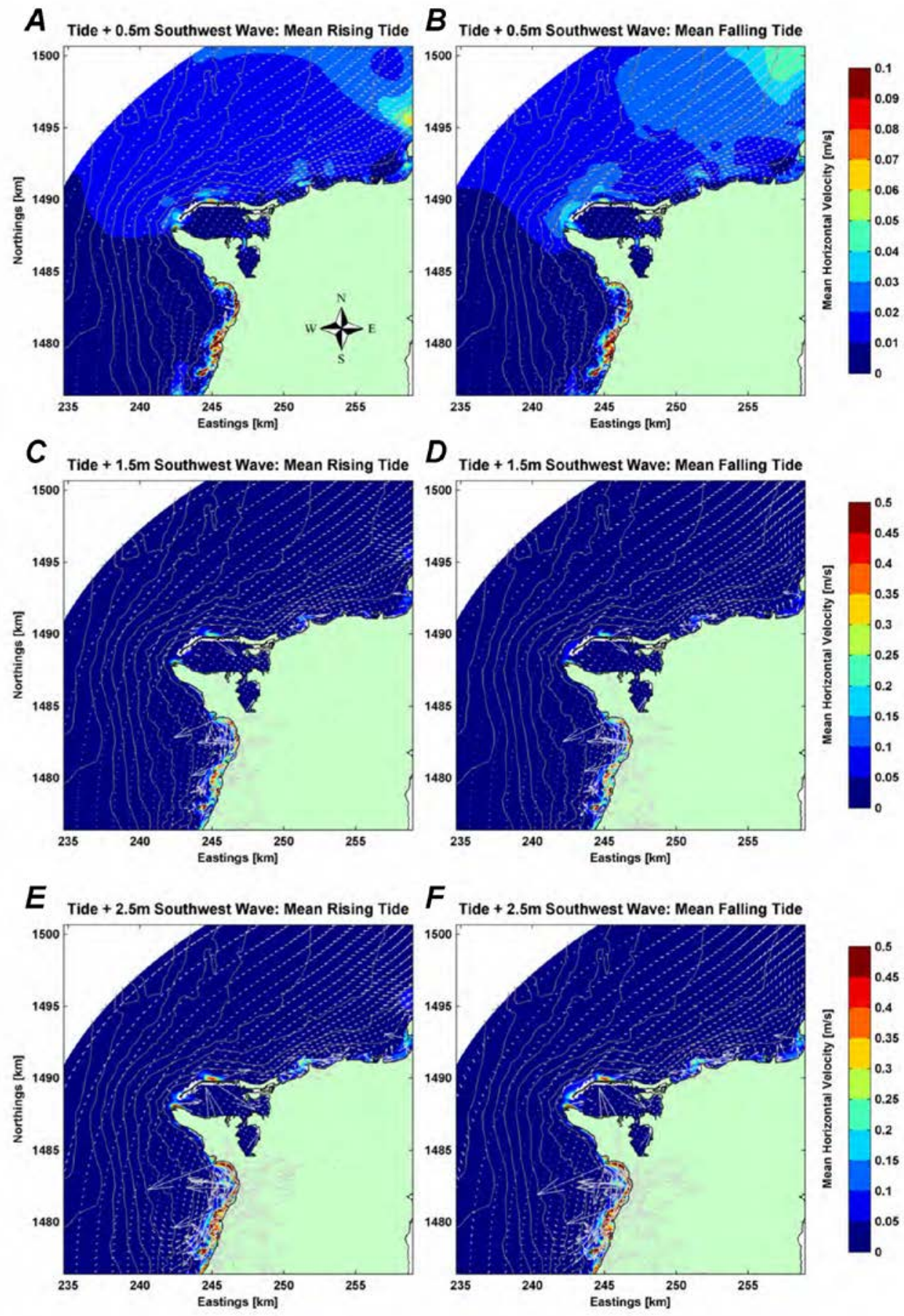

Figure 28. Maps showing desampled Western Guam model average near-surface current speeds, in meters per second, and flow directions, in compass orientation, over mean tidal forcing and waves out of the southwest overlaid on 100-m isobaths. A, Flow patterns during mean rising (flood) tides with 0.5 -meter-high waves. $B$, Flow patterns during mean falling (ebb) tides with 0.5 -meter-high waves. $C$, Flow patterns during mean rising (flood) tides with 1.5-meter-high waves. D, Flow patterns during mean falling (ebb) tides with 1.5-meter-high waves. $E$, Flow patterns during mean rising (flood) tides with 2.5-meter-high waves. $F$, Flow patterns during mean falling (ebb) tides with 2.5-meter-high waves. Velocity vectors show curvilinear magnitude and direction of currents, with speed in meters per second indicated by arrow size and color. Note that color scales for $A-B$ and for $C-F$ are different. For more details on the wave fields driving the flow patterns, see appendix 10.3 and 10.4 . 

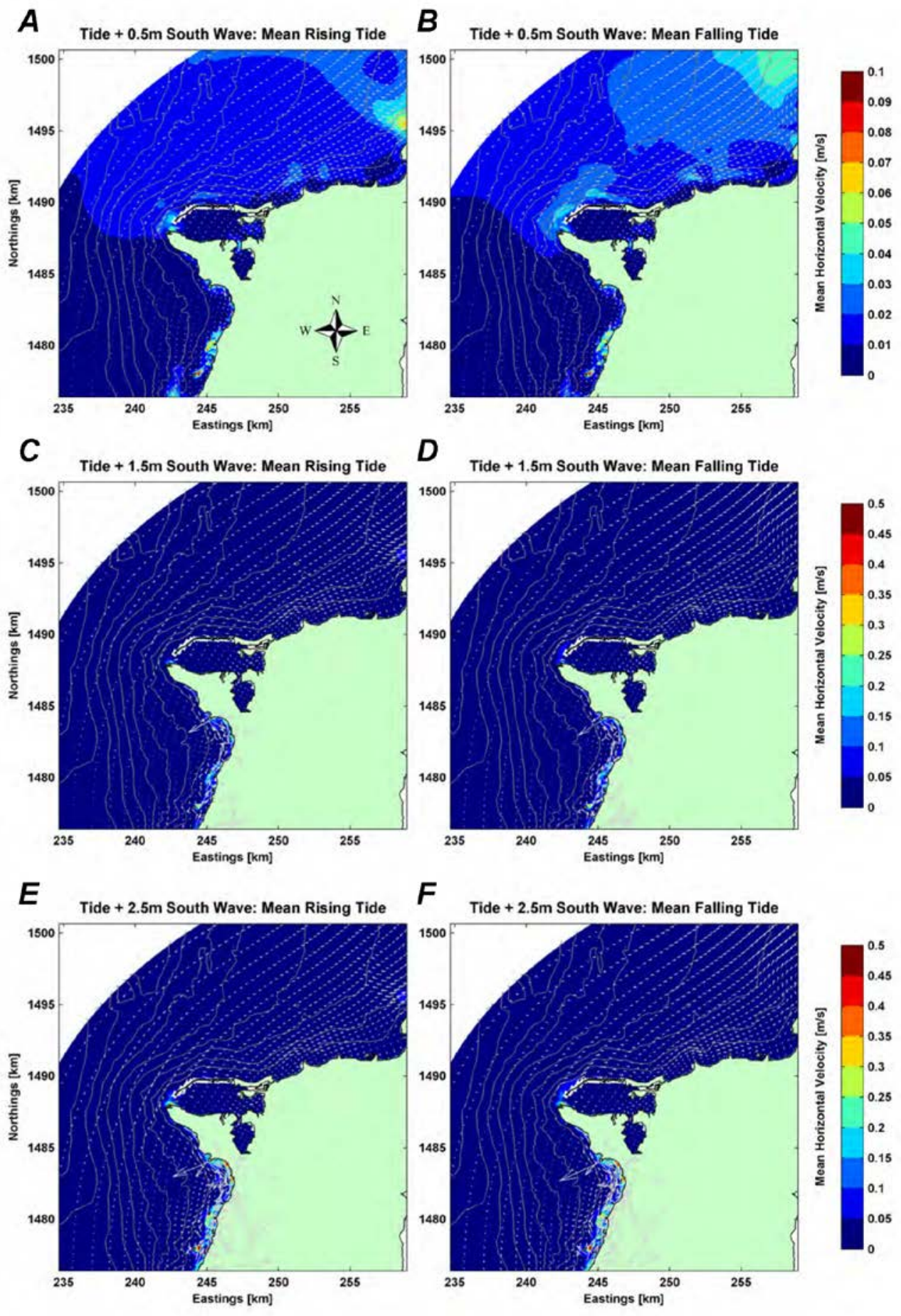

Figure 29. Maps showing desampled Western Guam model average near-surface current speeds, in meters per second, and flow directions, in compass orientation, over mean tidal forcing and waves out of the south overlaid on $100-\mathrm{m}$ isobaths. $A$, Flow patterns during mean rising (flood) tides with 0.5 -meter-high waves. $B$, Flow patterns during mean falling (ebb) tides with 0.5 -meter-high waves. C, Flow patterns during mean rising (flood) tides with 1.5-meter-high waves. $D$, Flow patterns during mean falling (ebb) tides with 1.5-meter-high waves. $E$, Flow patterns during mean rising (flood) tides with 2.5-meter-high waves. F, Flow patterns during mean falling (ebb) tides with 2.5-meter-high waves. Velocity vectors show curvilinear magnitude and direction of currents, with speed in meters per second indicated by arrow size and color. Note that color scales for $A-B$ and for $C-F$ are different. For more details on the wave fields driving the flow patterns, see appendix 10.3 and 10.4. 


\section{Modeled Dispersal Patterns along Western Guam}

The particle-tracking program MDRIFT was employed to investigate the transport pathways from a number of locations along west-central Guam for the period of 10-12 August 2012 (2012 YD 223-225; figs. 30-33). This period was chosen because, out of the three days of Lagrangian Surface Current Drifter (LSCD) releases (10-12 August), the model runs on 11 and 12 August compared favorably to the concurrent LSCD pathways. Twelve release locations were chosen where coral larvae could potentially be released from healthy reefs (figs. 30, 31). An additional 12 release locations were chosen to include areas where terrestrial sediment, nutrients, and (or) contaminants could potentially be released into the coastal zone (figs. 32, 33). In figures 30-33, the particle trajectories are shown with gray lines and the final particles locations 72 hours after release are indicated by black dots. Most of the particles released in the north are transported offshore and to the western and northern model boundaries (figs. 30, 32). In contrast, most of the particles released in Apra Harbor remain within the Harbor, and most of the particles released south of Apra Harbor return to the coast within 72 hours (figs. 31, 33). Thus, it is possible that, under summer non-trade wind conditions, the coral reefs within Apra Harbor and along the south coast could be self-seeded, whereas the corals reefs to the north of Apra Harbor would not. A release point was also positioned on the south side of Orote Peninsula by the large capped landfill, and the majority of these modeled particles reached the model boundaries, indicating they would most likely leave the Western Guam model domain under the summer 2012 forcing conditions.
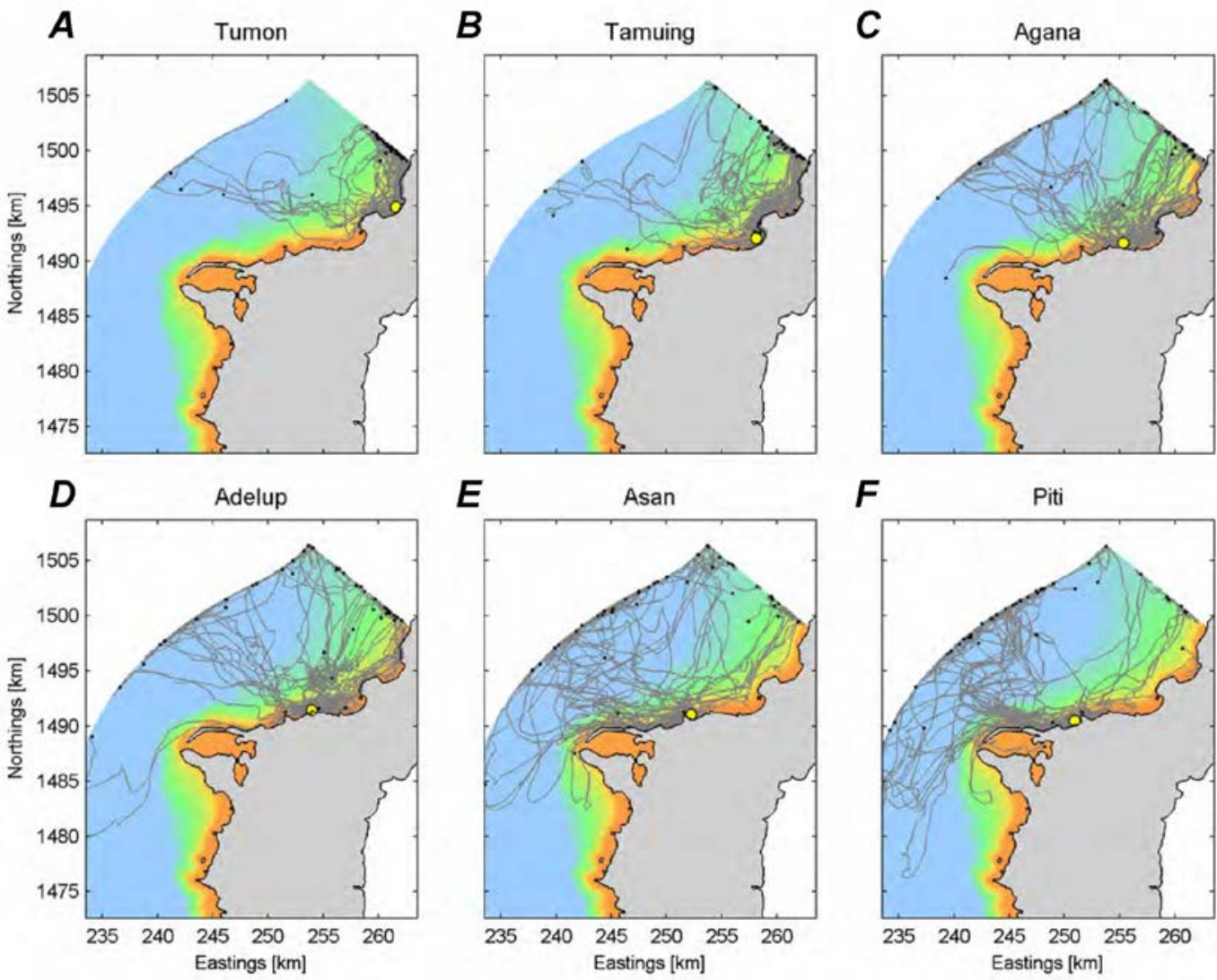

Figure 30. Maps showing modeled surface particle dispersal for 2012 Year Days 223-225 (10-12 August 2012) from six release locations on coral reefs north of Apra Harbor. The large yellow dots represent the particle release location; the black dots represent the final location of the surface particles after 72 hours. $A$, Tumon Bay. B, Off Tamuing. C, Off Agana. D, Off Adelup Point. E, Off Asan, just east of Camel Rock. F, In Piti Bomb Holes. 

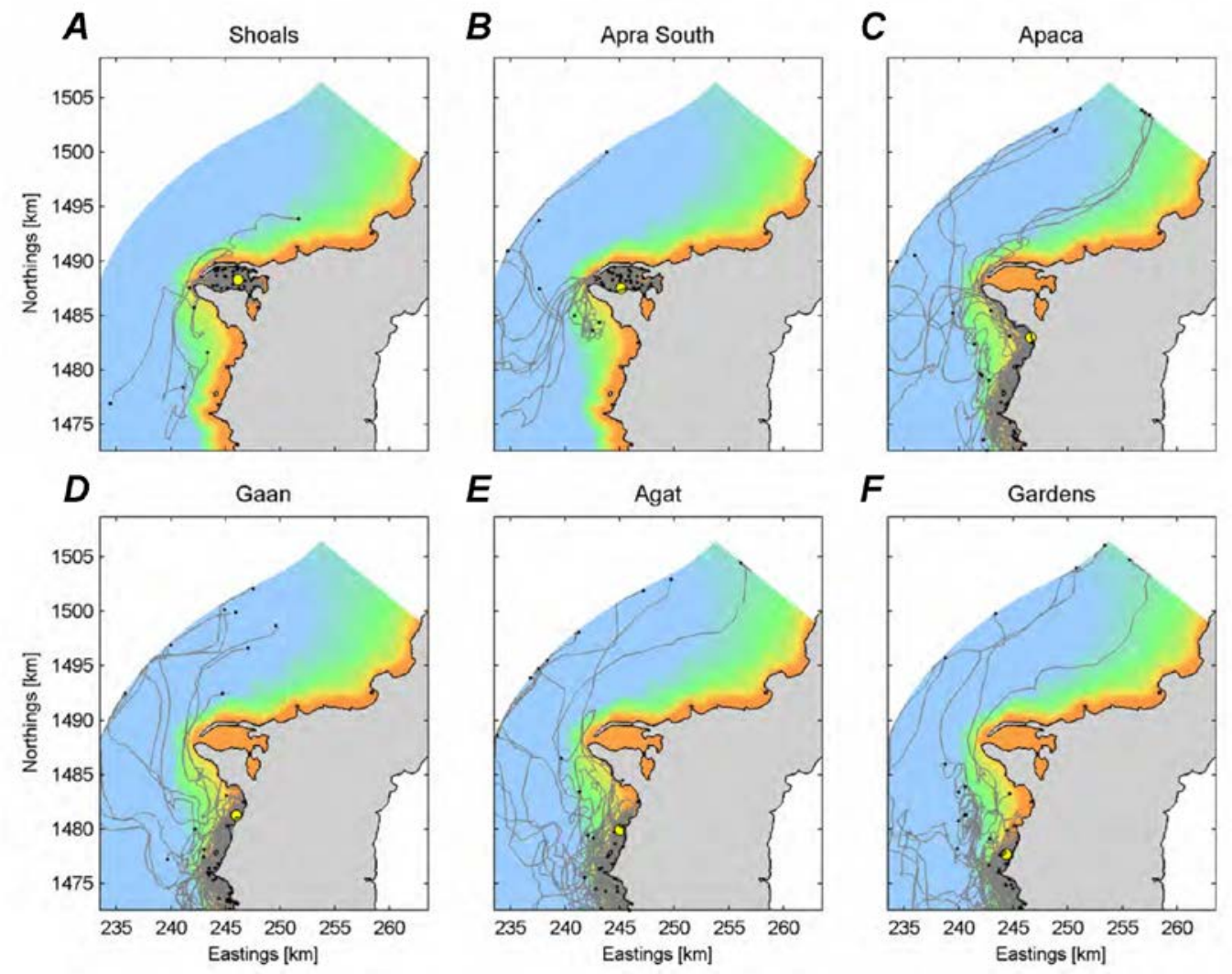

Figure 31. Maps showing modeled surface particle dispersal for 2012 Year Days 223-225 (10-12 August 2012) from six release locations on coral reefs in and south of Apra Harbor. The large yellow dots represent the particle release location; the black dots represent the final location of the surface particles after 72 hours. $A$, Western Shoals. B, Off Gab Gab Beach, southern Apra Harbor. C, Off Apaca Point. D, Off Gaan Point. E, Off Agat. $F$, In Coral Gardens shoreward of Anae Island. 

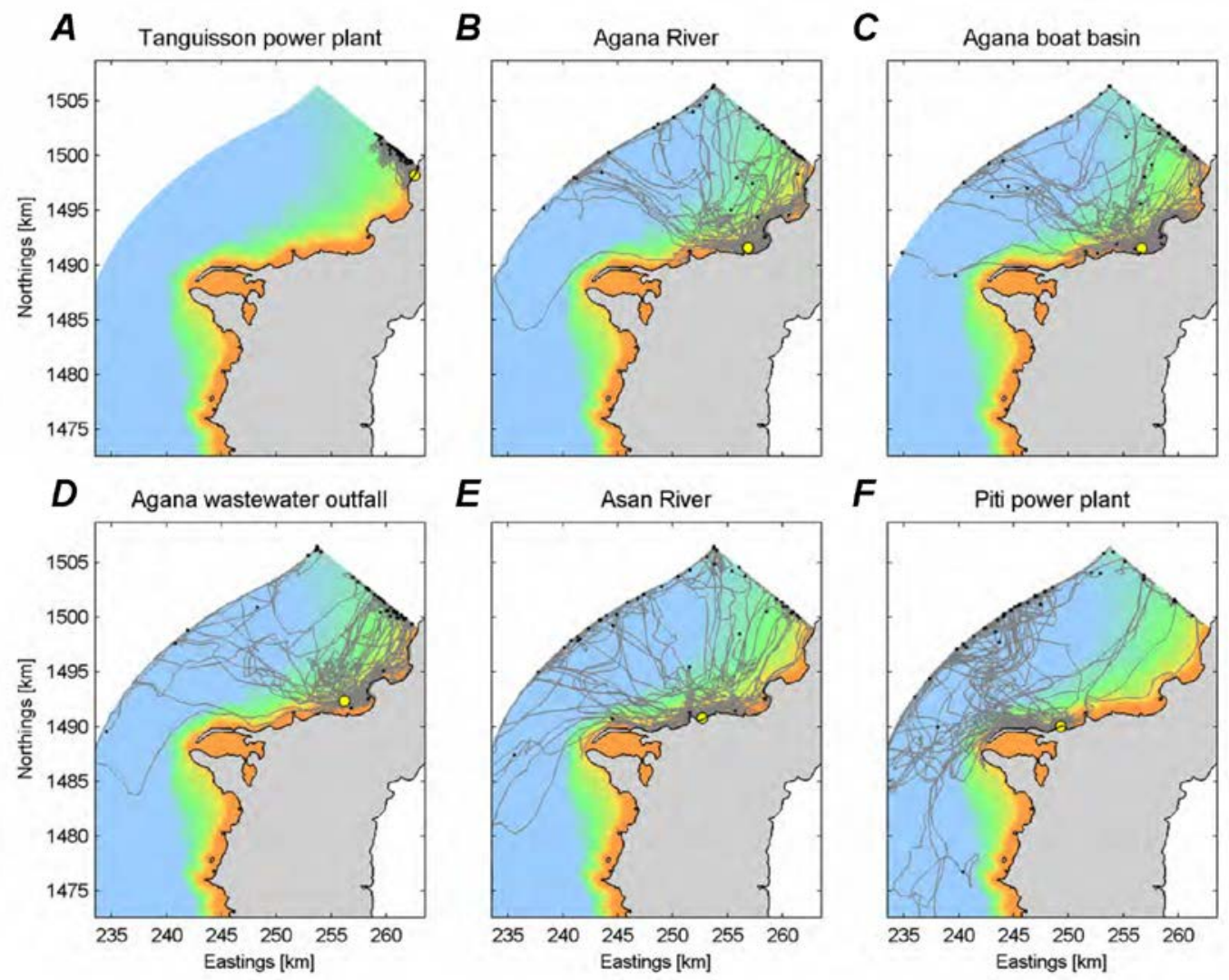

Figure 32. Maps showing modeled surface particle dispersal for 2012 Year Days 223-225 (10-12 August 2012) from six release locations not on coral reefs north of Apra Harbor. The large yellow dots represent the particle release location; the black dots represent the final location of the surface particles after 72 hours. $A$, Tanguisson power plant. $B$, Agana Rivermouth. $C$, Agana boat basin. D, Agana wasterwater outfall. $E$, Asan Rivermouth. $F$, Piti power plant. 

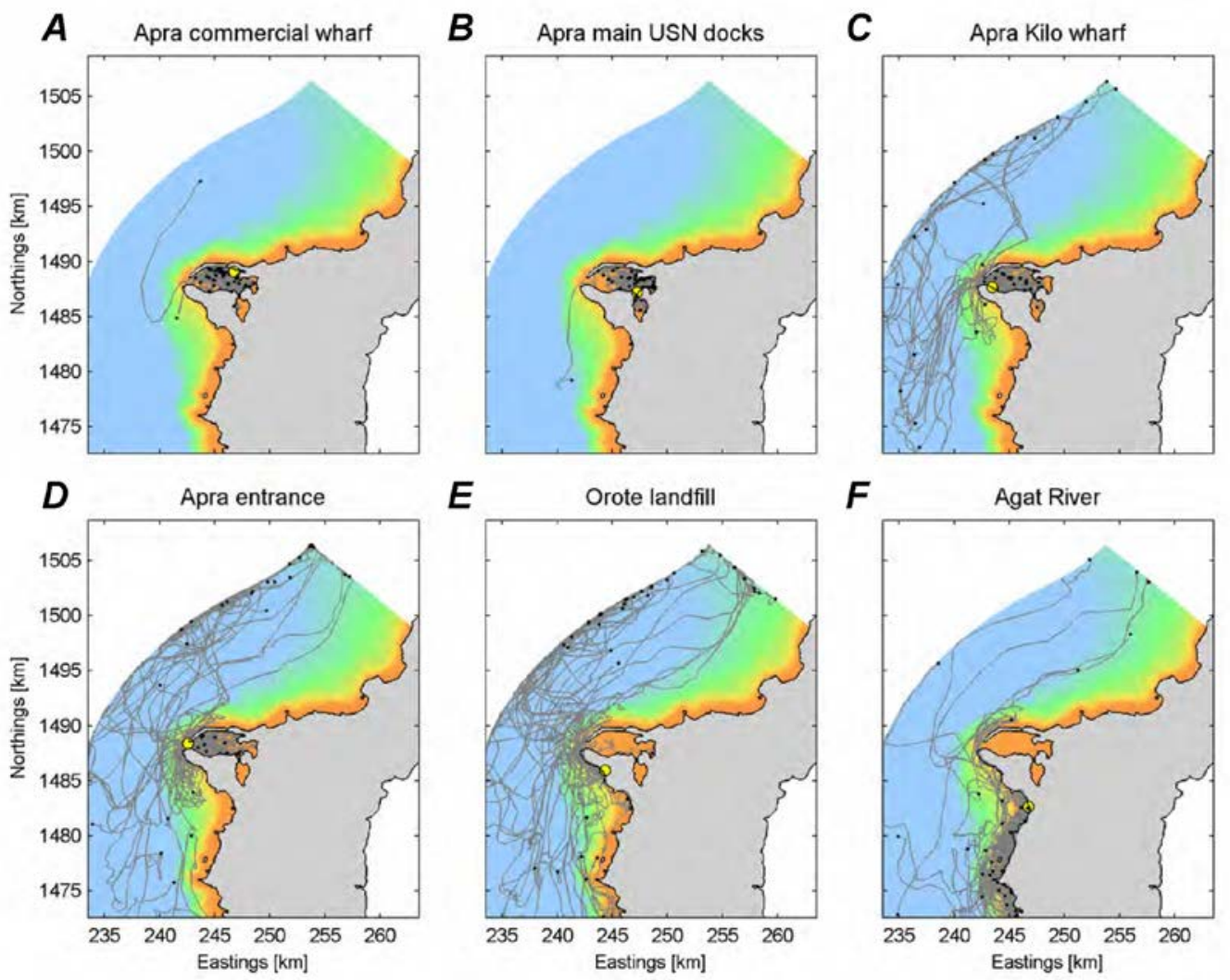

Figure 33. Maps showing modeled surface particle dispersal for 2012 Year Days 223-225 (10-12 August 2012) from release locations not on coral reefs in and south of Apra Harbor. The large yellow dots represent the particle release location; the black dots represent the final location of the surface particles after 72 hours. $A$, Apra Harbor's commercial wharf. B, Entrance to main U.S. Navy (USN) docks in Apra Harbor. C, Kilo wharf in Apra Harbor. D, Apra Harbor entrance. E, Orote landfill. F, Agat Rivermouth.

\section{Discussion}

\section{Spatial and Temporal Variability in Circulation Patterns and Water-Column Properties}

Fluctuations in tides, winds, and waves all occurred on different time scales during the experiment and contributed to the overall circulation in Agat Bay. The resulting circulation patterns and water-column properties are described below for each of these oceanographic forcing processes.

Tides

Most of the daily variability in current speed and direction at the study sites was due to the tides. The magnitude of the tidal currents is driven by the lunar tidal cycle, with the highest tidal current speeds occurring during the spring tides (new and full moons) and the weakest during the neap tides (quarter moons). For all the 15-m sites except for Agat South, the principal axes of tidal flow were oriented approximately parallel to the local isobaths and showed very little asymmetry (figs. 6-7). Mean current flow in Agat Bay was to the northeast (upcoast) under flood/rising surface tides and to the southwest (downcoast) under ebb/falling tides. Flows at the Adelup site were oppositely directed, with flood tide currents directed to the west (downcoast) and ebb tide currents to the east (upcoast). Near-bed temperature also fluctuated according to the tides, with cooling temperatures during flood tide, and warming temperatures during ebb. This temperature differential between major ebb and major flood 
increased as tidal range increased $(r=-0.47, \mathrm{p}<0.05, \mathrm{n}=218)$. No clear relationships were found between tides and salinity.

\section{Winds}

The northeast trade winds form the predominant wind pattern during the winter and spring in Guam. This northeasterly wind pattern was only observed for the first week of deployment (fig. 5C, D). Throughout the remainder of the study, the resulting wind direction measured on the Orote Peninsula was primarily from the east, with a speed of approximately $2 \mathrm{~m} / \mathrm{s}$. The mean subtidal current velocities during the period of northeasterly winds are shown in figure 8. During this initial period, surface currents were primarily directed to the north. The near-surface current flow at the two sites bordering Agat Bay (Agat 15-m North and Agat 15-m South) was alongshore to the north with a mean speed of $0.06 \mathrm{~m} / \mathrm{s}$. Assuming sustained trade-wind forcing and constant alongshore flow, this would result in a total replacement of water along the 7.9-km length of the bay in just over 35 hours. Because oscillatory tidal flows enhance these mean flow speeds, the actual replenishment time would likely be shorter. In contrast, the subtidal currents during a period when winds were variable (and waves were small; YD 185-207) were sluggish and of variable direction (fig. 9). This suggests that without consistent trade wind forcing, waters in Agat Bay may have much longer residence times.

Water-column properties also show a marked shift coinciding with the different wind seasons, with cooler, saline water during the northeasterly trade-wind period, transitioning to warmer, less-saline water during the non-trade wind season (figs. 12-14, 16-17). The increase in temperature may have been due to decreased wind forcing and longer residence times in the Agat Bay region, while the change in salinity was likely driven by the rain events that come with the shift to the non-trade wind season. Overall, there was little thermal stratification in Agat Bay (fig. 13). However, there were three periods of higher stratification (difference in temperature between surface and seabed $>0.5^{\circ} \mathrm{C}$ ), and all three periods coincided with a shift in the winds: (1) during the first major wind shift around YD 133, when northeasterly winds relaxed, (2) during the period of greatest rainfall around YD 147, when wind speeds rapidly increased, and (3) during another major wind shift on approximately YD 218, when strong southerly winds briefly relaxed and reversed direction. In the cases where wind strength decreased, higher stratification may have resulted from increased surface heating. In cases where wind strength suddenly increased or changed direction, the change in stratification may have reflected a shift in watercolumn properties that did not propagate uniformly with depth (for example, cooler, more saline water infiltrated close to the seabed first before reaching the upper-most part of the water column).

\section{Waves}

Although Guam is in the path of many tropical storms and typhoons, excessively large storm waves were not observed during the course of the field experiment. Two larger wave events were observed that had waves originating out of the west with significant wave heights greater than $1 \mathrm{~m}$ and dominant wave periods between 9 and $10 \mathrm{~s}$. The resulting wave-driven near-surface circulation was offshore at the Adelup 15-m and Agat 15-m sites, but onshore at Agat 7-m sites (fig. 10), suggesting a downwelling pattern for water along the coast in Agat Bay during this time. Large waves had little effect on water-column properties. Several of the CT records revealed apparent drops in salinity during large wave events; however, these are most likely due to suspended material fouling the conductivity chambers. At Adelup 15-m and Agat 15-m North sites, turbidity was slightly elevated during the periods of larger waves. 


\section{Modeled Surface Circulation Patterns}

One of the primary utilities of numerical modeling techniques is that, once calibrated and validated, a model can be used to investigate how individual processes (such as tides, winds, or waves) influence resulting circulation patterns in isolation from other forcing mechanisms. The tidal forcing in the Western Guam region results in a mean near-surface current pattern that is extremely weak (fig. 19). This suggests that, solely under tidal forcing, there is high local retention and relatively little net transport of material in the surface layer. The inclusion of wind forcing in the model dramatically increases near-surface current speeds over open (deep) water and the fore reefs (figs. 20-24); furthermore, the current speeds increase approximately linearly with increasing wind speed. Current speeds over the reef flats also increase with increasing wind speed, but the response is much less (as much as half an order of magnitude) than that of deeper water, likely a result of drag caused by the complex bathymetry and the relatively shallow $(0-2 \mathrm{~m})$ depths of these reefs. Conversely, the influence of waves on near-surface currents (figs. 25-29) is primarily constrained to the shallow nearshore areas, with wave-driven currents on the reef flats increasing relatively linearly with increasing wave height, while there is little influence of wave-driven motions on near-surface currents in offshore waters. The flow responses from these different forcing mechanisms over fore reefs versus reef flats are similar to what was observed by Storlazzi and Jaffe (2008) on Hawaiian fringing coral reefs.

\section{Conclusions}

During the 5-month period between April and August 2012, more than 1.4 million measurements of meteorologic and oceanographic parameters were made along west-central Guam and in War in the Pacific National Historical Park (WAPA) to characterize the important physical processes and resulting water-column conditions in this region. Key findings from these measurements and analyses include the following:

1. Circulation in Agat Bay was strongly driven by winds and waves at longer ( $>1$ day) timescales and by the tides at shorter ( $<1$ day) timescales. Flows were primarily directed alongshore to the north and south, with current speeds faster in the northern part of the bay. Large waves resulted in offshore-directed flow at deeper sites in the bay and onshore flow at inshore sites, suggesting a downwelling pattern.

2. Water-column properties exhibit strong seasonality coupled to the shift from the trade wind to the non-trade wind season. During the dry trade-wind season, waters were cooler and more saline. When the winds shifted to a more variable pattern, waters warmed and became less saline because of a combination of increased thermal insolation from lack of wind forcing and higher rainfall.

3. Overall, turbidity was relatively low in Agat Bay and was similar to levels measured elsewhere along west-central Guam. More frequent and intense turbidity fluctuations were recorded in the northern part of the bay, likely a result of the proximity to the Namo River. Because of biofouling of the optical sensors, it was not possible to compare turbidity levels between the 15$\mathrm{m}$ and 7-m sites.

4. The numerical modeling results provide insight into how the field measurements may be extrapolated spatially, as well as what the relative contribution of different forcing mechanisms (tides, winds, and waves) is to the resulting flow patterns along west-central Guam. The model results suggest that near-surface currents in deep water are primarily controlled by the winds, whereas currents on the shallow reef flats are dominated by wave-driven motions. The model results also provide insight into the potential paths of buoyant material released from a series of locations along west-central Guam under summer non-trade wind forcing conditions. This 
information may be useful in evaluating the potential zones of influence/impact resulting from transport by surface currents of material released from these select locations.

Taken together, the field observations and modeling results provide information on the nature of and controls on flow and water-column properties along west-central Guam during nontyphoon conditions. Understanding coastal circulation patterns and water-column properties in Agat Bay and west-central Guam may help to better understand how meteorologic and oceanographic processes, at both the regional and local scales, affect coral reef health and sustainability in this region.

\section{Acknowledgments}

This work was carried out as part of the U.S. Geological Survey (USGS) Pacific Coral Reef Project as part of an effort in the United States and its trust territories to better understand the affect of geologic and oceanographic processes on coral reef systems. This project was funded by the USGS Coastal and Marine Geology Program, the National Park Service (NPS) Pacific West Region Coral Reef Research Program, the NPS Inventory and Monitoring Program, and by NPS-War in the Pacific National Historical Park (WAPA) base funding under Interagency Agreement P11PG80298. Mike Gawel (NPS-WAPA Cultural and Natural Resources Manager) and Barbara Alberti (NPS-WAPA Superintendent) established this cooperative study. Justin Mills and Amanda de Villers of the NPSWAPA Natural Resource Division contributed substantially to this project in innumerable ways, and without their efforts none of this would have been possible. Todd Genereux, Chris Williams, and Monique Genereux expertly captained the F/V Heavy Metal. The NPS maintenance and office staff graciously donated their time, effort, and space during our numerous field operations. The NPS-Pacific Islands Inventory and Monitoring Program provided some of the instruments used in this field experiment. Edwin Elias and Maarten van Ormondt (Deltares) helped with the numerical circulation modeling. Nancy Prouty (USGS) and Andrew Stevens (USGS) contributed numerous excellent suggestions and a timely review of our work.

\section{References Cited}

Booij, N., Ris, R.C., and Holthuijsen, L.H., 1999, A third-generation wave model for coastal regions, Part I-Model description and validation: Journal of Geophysical Research, v. 104, p. 7649-7666.

Center for Operational Oceanographic Products and Services, 2012, Tidal records for Guam: available online at http://tidesandcurrents.noaa.gov, last accessed July 2012.

Chamberlin, C., 2008, A digital elevation model of Guam for tsunami inundation modeling: Seattle, Wash., National Oceanic and Atmospheric Administration Pacific Marine Environmental Laboratory Technical Report, 7 p.

Coastal Hydraulic Laboratory, 2012, Wave hindcast data for Guam: available online at http://chl.erdc.usace.army.mil, last accessed July 2012.

Deines, K.L., 1999, Backscatter estimation using broadband acoustic Doppler current profilers: in Proceedings of the IEEE Sixth Working Conference on Current Measurement, San Diego, Calif., 1113 March 1999, p. 249-253.

Deltares, 2011, Delft3D-FLOW user manual-Simulation of multi-dimensional hydrodynamic flows and transport phenomena, including sediment: Delft, The Netherlands, Deltares (Dutch institute for Delta Technology), Version 3.15, Revision 18392.

Egbert, G.D., Bennett, A.F., and Foreman, M.G.G., 1994, TOPEX/POSEIDON tides estimated using a global inverse model: Journal of Geophysical Research Oceans, v. 99, no. C12, p. 24821-24852.

Egbert, G.D., and Erofeeva, S.Y., 2002, Efficient inverse modeling of barotropic ocean tides, Journal of Atmospheric and Oceanic Technology, v. 19, no. 2, p.183-204. 
Forestry and Soil Resources Division, Guam Department of Agriculture, 1999, Five year plan: Guam, Department of Agriculture.

Holthuijsen, L.H., Booij, N., and Ris, R.C., 1993, A spectral wave model for the coastal zone: New Orleans, 2nd International Symposium on Ocean Wave Measurement and Analysis, Proceedings, p. 630-641.

Intergovernmental Oceanographic Commission and International Hydrographic Organization,, 2003, Centenary edition of the GEBCO digital atlas: Liverpool, U.K., British Oceanographic Data Centre, published on CD-ROM on behalf of the Intergovernmental Oceanographic Commission and the International Hydrographic Organization as part of the General Bathymetric Chart of the Oceans.

Lander, M.A., and Guard, C.P., 2003, Creation of a 50-year rainfall database, annual rainfall climatology, and annual rainfall distribution map for Guam: University of Guam Water and Environmental Research Institute, Technical Report No. 102, 32 p.

Leendertse, J.J., 1987, A 3-dimensional alternating direction implicit model with iterative Fourth order dissipative non-linear advection terms: Rijkswaterstaat, Report WD-3333-NETH.

Minton, D., 2005, Fire, erosion, and sedimentation in the Asan-Piti Watershed and War in the Pacific NHP, Guam: Report prepared for the National Park Service, 99 p.

Minton, D., Lundgren, I., and Pakenham, A., 2007. A two-year study of coral recruitment and sedimentation in Asan Bay, Guam: Final report prepared for the National Park Service, 41 p.

National Oceanic and Atmospheric Administration 2005, Shallow-water benthic habitats of American Samoa, Guam, and the Commonwealth of the Northern Mariana Islands (CD-ROM): Silver Spring, Md., National Oceanic and Atmospheric Administration, National Centers for Coastal Ocean Science (NCCOS), Technical Memorandum NOS NCCOS 8, Biogeography Branch.

National Resource Conservation Service, 1996, Ugam Watershed Management Plan, Territory of Guam: Agana, Guam, U.S. Department of Agriculture, National Resource Conservation Service, Pacific Basin Area.

Pacific Islands Global Climate Observing System, Guam Climate Office, 2012, The weather and climate of Guam: available online at http://pi-gcos.org/guam/default.htm, last accessed July 2013.

Presto, M.K., Storlazzi, C.D., Logan, J.B., Reiss, T.E., and Rosenberger, K.J., 2012, Coastal circulation and potential coral-larval dispersal in Maunalua Bay, O`ahu, Hawaii-Measurements of waves, currents, temperature, and salinity, June-September 2010: U.S. Geological Survey Open-File Report 2012-1040, 67 p., available at http://pubs.usgs.gov/of/2012/1040/.

Porter, V., Leberer, T., Gawel, M., Gutierrez, J., Burdick, D., Torres, V., and Lujan, E., 2005, The state of coral reef ecosystems of Guam, in Waddell, J., ed., The state of coral reef ecosystems of the United States and Pacific Freely Associated State-2005: Silver Spring, Md., National Oceanic and Atmospheric Administration Technical Memorandum, NOS NCCOS 11, NOAA/NCCOS Center for Coastal Monitoring and Assessment Biogeography Team, 533 p.

Richmond, R., and Hunter, C., 1990, Reproduction and recruitment of corals-Comparisons among the Caribbean, tropical Pacific and the Red Sea: Marine Ecology Progress Series, v. 60, p. 185-202.

Ris, R.C., Booij, N., and Holthuijsen, L.H., 1999, A third-generation wave model for coastal regions, Part II-Verification: Journal of Geophysical Research, v. 104, no. 4, p. 7649-7666.

Stelling, G.S., 1984, On the construction of computational methods for shallow water flow problems: The Hague, Netherlands, Rijkswaterstaat, communication series no. 35.

Storlazzi, C.D., Brown, E.K., and Field, M.E., 2006, The application of acoustic Doppler current profilers to measure the timing and patterns of coral larval dispersal: Coral Reefs, v. 25, p. 369-381. Storlazzi, C.D., Field, M.E., Cheriton, O.M., Preston, M.K., and Logan, J.B., 2013, Rapid fluctuations in flow and water-column properties in Asan Bay, Guam-Implications for selective resilience of coral reefs in warming seas: Coral Reefs, v. 32, p. 949-961. 
Storlazzi, C.D., and Jaffe, B.E., 2008, The relative contribution of processes driving variability in flow, shear, and turbidity over a fringing coral reef-West Maui, Hawaii: Estuarine Coastal and Shelf Science, v. 77, no. 4, p. 549-564.

Storlazzi, C.D., Presto, M.K., and Logan, J.B., 2009, Coastal circulation and sediment dynamics in War in the Pacific National Historical Park, Guam-Measurements of waves, currents, temperature, salinity, and turbidity, June 2007-January 2008: U.S. Geological Survey Open-File Report 20091195, 79 p., available at http://pubs.usgs.gov/of/2009/1195/.

Tolman, H.L., 2009, User manual and system documentation of WAVEWATCH III'TM version 3.14:

National Oceanic and Atmospheric Administration / National Weather Service / National Centers for Environmental Prediction / MMAB Technical Note 276, 194 p.

\section{Additional Digital Information}

For additional information on the instrument deployments, please see:

http://walrus.wr.usgs.gov/infobank/b/b0112wp/html/b-01-12-wp.meta.html

http://walrus.wr.usgs.gov/infobank/b/b0312wp/html/b-03-12-wp.meta.html

For an online PDF version of this report, please see:

http://pubs.usgs.gov/of/20141130/

For more information on the U.S. Geological Survey’s Pacific Coastal and Marine Science Center, please see:

http://walrus.wr.usgs.gov/

For more information on the U.S. Geological Survey’s Pacific Coral Reef Project, please see:

http://coralreefs.wr.usgs.gov/

\section{Direct Contact Information}

Regarding this report—Curt D. Storlazzi (USGS Pacific Coral Reef Project Chief): cstorlazzi@usgs.gov

Menlo Park Publishing Service Center

Edited by Peter H. Stauffer

Layout by Cory Hurd

Manuscript approved for publication, June 24, 2014 


\section{Appendix 1. ADCP Information}

RD Instruments $600 \mathrm{kHz}$ Workhorse Monitor upward-looking acoustic Doppler current profiler

\begin{tabular}{|l|l|}
\hline \multicolumn{2}{|c|}{$\mathrm{s} / \mathrm{n}: 2074,2432$, and 3648} \\
\hline Transmitting Frequency: & $614 \mathrm{kHz}$ \\
\hline Depth of Transducer: & $15 \mathrm{~m}$ \\
\hline Blanking Distance: & $1.2 \mathrm{~m}$ \\
\hline Height of First Bin above Bed: & $1.72 \mathrm{~m}$ \\
\hline Bin Size: & $1.0 \mathrm{~m}$ \\
\hline Number of Bins: & 18 \\
\hline Operating Mode: & High resolution, broad bandwidth \\
\hline Sampling Frequency: & $0.08 \mathrm{~Hz}$ \\
\hline Time per Ping: & $00: 12.00$ \\
\hline Pings per Ensemble: & 100 \\
\hline Profile Ensemble Interval: & $0: 12: 00.00$ \\
\hline Wave Ensemble Interval: & $1: 00: 00.00$ \\
\hline Sound Speed Calculation: & Set salinity, updating temperature via sensor \\
\hline
\end{tabular}

Nortek Instruments $2 \mathrm{MHz}$ Aquadopp upward-looking acoustic Doppler current profiler

\begin{tabular}{|l|l|}
\hline \multicolumn{2}{|c|}{ s/n: 1852, 1861} \\
\hline Depth of Transducer: & $7 \mathrm{~m}$ \\
\hline Blanking Distance: & $0.20 \mathrm{~m}$ \\
\hline Height of First Bin above Bed: & $0.83 \mathrm{~m}$ \\
\hline Bin Size: & $0.50 \mathrm{~m}$ \\
\hline Number of Bins: & 20 \\
\hline Average interval: & $0: 15: 00.00$ \\
\hline Profile interval: & $0: 20: 00.00$ \\
\hline Wave interval: & $1: 00: 00.00$ \\
\hline Wave cell size: & $0.50 \mathrm{~m}$ \\
\hline Operating Mode: & High-resolution \\
\hline Sound Speed Calculation: & Set salinity, updating temperature via sensor \\
\hline
\end{tabular}

Nortek Instruments $2 \mathrm{MHz}$ acoustic wave and current profiler (AWAC)

\begin{tabular}{|l|l|}
\hline \multicolumn{2}{|c|}{ s/n: WPR 1519 } \\
\hline Depth of Transducer: & $15 \mathrm{~m}$ \\
\hline Blanking Distance: & $0.50 \mathrm{~m}$ \\
\hline Height of First Bin above Bed: & $1.62 \mathrm{~m}$ \\
\hline Bin Size: & $1.00 \mathrm{~m}$ \\
\hline Number of Bins: & 21 \\
\hline Average interval: & $0: 15: 00.00$ \\
\hline Profile interval: & $0: 20: 00.00$ \\
\hline Wave interval: & $1: 00: 00.00$ \\
\hline Wave cell size: & $1.80 \mathrm{~m}$ \\
\hline Operating Mode: & High-resolution \\
\hline Sound Speed Calculation: & Set salinity, updating temperature via sensor \\
\hline
\end{tabular}

\section{Data Processing:}

The RDI current data were processed using the WinADCP program and the wave data using the WavesMon program. The Nortek current data were processed using the AquaPro program and the wave data were processed using the QuickWave program.

All of the spurious data above the water surface were removed and all of the data in bins where the beam correlation dropped below 80 percent were removed for visualization and analysis. 


\section{Appendix 2. PS, TL, CT, SLOBS, OBS, and WS Information}

Onset HOBO U20-001-01 temperature and pressure sensor (PS)

s/n: 1115706 and 9821212

Sampling Interval: $\quad 15 \mathrm{~min}$

Onset HOBO U22-001 temperature logger (TL) s/n: 9813091, 9813092, 9813094, 9813096, 9813097, and 9816104

Sampling Interval: $\quad 5 \mathrm{~min}$

Seabird Microcat SBE-37SM temperature-conductivity (CT) sensors

s/n: 3800, 3801, 4368, 4369, 7046, and 7047

Sampling Interval: $\quad 5$ min

Number of samples averaged: $\quad 4$

Aquatec 200-TY self-logging optical backscatter sensors (SLOBS)

s/n: 371-026

Aquatec 210-TYT self-logging optical backscatter sensors (SLOBS)

s/n: 24-02, 24-05, 24-06, 24-07, and 24-18

Sampling Frequency: $\quad 1 \mathrm{~Hz}$

Measurements per Burst: $\quad 8$

Time Between Bursts: $\quad$ 00:05:00.00

Seapoint turbidity sensor (OBS)

s/n: 12142 and 12143

Analog input to: $\quad$ Nortek Aquadopp ADCPs

Sampling interval: $20 \mathrm{~min}$

NovaLynx WS-16N-A Marine-grade Weather Station Comp1nts:

Anemometer: $\quad$ 200-05106-MA (marine model)

Temperature \& Relative Humidity: 110-WS-16TH-A w/radiation shield

Barometric Pressure Sensor: $\quad$ 110-WS-16BP

Rain Gauge: $\quad$ 110-WS-16RC

Sampling Frequency: $\quad 1 \mathrm{~Hz}$

Measurements per Burst: 3000

Time Between Bursts: $\quad$ 01:00:00.00

\section{Data Processing:}

The PS pressure and T temperature data were processed using HOBOware. The CT data were processed using the SeaTerm and SBEDataProcessing programs. Further quality control and data analysis was performed on the data using MatLab.

The SLOBS data were postprocessed for visualization and analysis by first smoothing the data using a 19-point Gaussian filter and removing any spikes with a width of three or fewer values. The resulting record was then visually inspected for any remaining outliers, which were also removed from the data. Finally, any biofouling trends were removed and the median value was subtracted from the record. 


\section{Appendix 3. Water Column Profiler (WCP) Information}

Instruments:

Seabird 19plus CTD sensor; s/n:

5250

D\&A Instruments OBS-3 sensor; s/n:

1134

Wet Labs CSTAR transmissometer; s/n:

712

Wet Labs WetStar fluorometer; s/n:

21

Sampling Frequency:

$4 \mathrm{~Hz}$

Position Information:

Garmin GPS-76 GPS; s/n: 80207465; USGS/CRP unit\#1

Data Processing:

The profiler data were processed using the SBEDataProcessing program.

The data were averaged into $0.25-\mathrm{m}$ vertical bins and all of the spurious data marked by a flag in the raw data were removed for visualization and analysis. Stratification was calculated as the difference between the mean of the top three bins (0.5-1.5 m below the surface) and the bottom three bins (0.5-1.5 $\mathrm{m}$ above the bed). 


\section{Appendix 4. Water Column Profiler Log: April 24, 2012}

\begin{tabular}{|c|c|c|c|c|}
\hline Cast \# & $\begin{array}{c}\text { Time } \\
\text { [ChST] }\end{array}$ & $\begin{array}{c}\text { Latitude } \\
\text { [decimal degrees } \mathrm{N}]\end{array}$ & $\begin{array}{c}\text { Longitude } \\
\text { [decimal degrees E] }\end{array}$ & $\begin{array}{c}\text { Depth } \\
{[\mathrm{m}]}\end{array}$ \\
\hline 1 & 0851 & 13.53676 & 144.80072 & 26.6 \\
\hline 2 & 0903 & 13.51401 & 144.79655 & 12.6 \\
\hline 3 & 0911 & 13.50745 & 144.77468 & 17.1 \\
\hline 4 & 0920 & 13.48847 & 144.76433 & 14.1 \\
\hline 5 & 0927 & 13.48458 & 144.74806 & 12.4 \\
\hline 6 & 0934 & 13.48310 & 144.72851 & 18.9 \\
\hline 7 & 0940 & 13.47847 & 144.71503 & 33.1 \\
\hline 8 & 0947 & 13.48148 & 144.70441 & 13.4 \\
\hline 9 & 0954 & 13.47201 & 144.69146 & 17.1 \\
\hline 10 & 1003 & 13.46704 & 144.66377 & 12.6 \\
\hline 11 & 1011 & 13.46947 & 144.63993 & 12.9 \\
\hline 12 & 1026 & 13.45251 & 144.65388 & 15.1 \\
\hline 13 & 1033 & 13.45127 & 144.64429 & 38.9 \\
\hline 14 & 1040 & 13.45135 & 144.63302 & 41.1 \\
\hline 15 & 1048 & 13.45299 & 144.62153 & 28.1 \\
\hline 16 & 1055 & 13.44522 & 144.61834 & 24.6 \\
\hline 17 & 1102 & 13.43634 & 144.62622 & 23.6 \\
\hline 18 & 1110 & 13.42106 & 144.63915 & 26.4 \\
\hline 19 & 1116 & 13.41624 & 144.64472 & 12.1 \\
\hline 20 & 1122 & 13.41010 & 144.65232 & 10.9 \\
\hline 21 & 1129 & 13.40529 & 144.65702 & 16.1 \\
\hline 22 & 1135 & 13.40059 & 144.65172 & 25.6 \\
\hline 23 & 1144 & 13.38904 & 144.64961 & 21.6 \\
\hline 24 & 1150 & 13.38172 & 144.64528 & 13.6 \\
\hline 25 & 1157 & 13.36799 & 144.64225 & 11.4 \\
\hline 26 & 1203 & 13.35789 & 144.63576 & 15.1 \\
\hline 27 & 1210 & 13.34222 & 144.63090 & 18.6 \\
\hline 28 & 1218 & 13.35068 & 144.63704 & 42.6 \\
\hline
\end{tabular}




\section{Appendix 5. Water Column Profiler Log: August 16, 2012}

\begin{tabular}{|c|c|c|c|c|}
\hline Cast \# & $\begin{array}{c}\text { Time } \\
\text { [ChST] }\end{array}$ & $\begin{array}{c}\text { Latitude } \\
\text { [decimal degrees } \mathrm{N} \text { ] }\end{array}$ & $\begin{array}{c}\text { Longitude } \\
\text { [decimal degrees E] }\end{array}$ & $\begin{array}{c}\text { Depth } \\
{[\mathrm{m}]}\end{array}$ \\
\hline 1 & 1134 & 13.53676 & 144.80072 & 28.6 \\
\hline 2 & 1145 & 13.51401 & 144.79655 & 13.6 \\
\hline 3 & 1153 & 13.50745 & 144.77468 & 15.6 \\
\hline 4 & 1202 & 13.48847 & 144.76433 & 13.1 \\
\hline 5 & 1209 & 13.48458 & 144.74806 & 12.1 \\
\hline 6 & 1216 & 13.48310 & 144.72851 & 16.1 \\
\hline 7 & 1223 & 13.47847 & 144.71503 & 30.1 \\
\hline 8 & 1230 & 13.48148 & 144.70441 & 11.6 \\
\hline 9 & 1239 & 13.47201 & 144.69146 & 12.4 \\
\hline 10 & 1248 & 13.46704 & 144.66377 & 9.9 \\
\hline 11 & 1256 & 13.46947 & 144.63993 & 12.4 \\
\hline 12 & 1315 & 13.45251 & 144.65388 & 20.1 \\
\hline 13 & 1321 & 13.45127 & 144.64429 & 36.1 \\
\hline 14 & 1328 & 13.45135 & 144.63302 & 40.1 \\
\hline 15 & 1336 & 13.45299 & 144.62153 & 24.6 \\
\hline 16 & 1342 & 13.44522 & 144.61834 & 23.4 \\
\hline 17 & 1348 & 13.43634 & 144.62622 & 43.9 \\
\hline 18 & 1358 & 13.42106 & 144.63915 & 23.6 \\
\hline 19 & 1404 & 13.41624 & 144.64472 & 10.1 \\
\hline 20 & 1410 & 13.41010 & 144.65232 & 10.4 \\
\hline 21 & 1416 & 13.40529 & 144.65702 & 16.9 \\
\hline 22 & 1421 & 13.40059 & 144.65172 & 21.6 \\
\hline 23 & 1427 & 13.38904 & 144.64961 & 20.1 \\
\hline 24 & 1434 & 13.38172 & 144.64528 & 13.1 \\
\hline 25 & 1440 & 13.36799 & 144.64225 & 10.9 \\
\hline 26 & 1446 & 13.35789 & 144.63576 & 13.6 \\
\hline 27 & 1451 & 13.34222 & 144.63090 & 39.4 \\
\hline 28 & 1458 & 13.35068 & 144.63704 & 18.9 \\
\hline
\end{tabular}




\section{Appendix 6. Time-Series Plots}

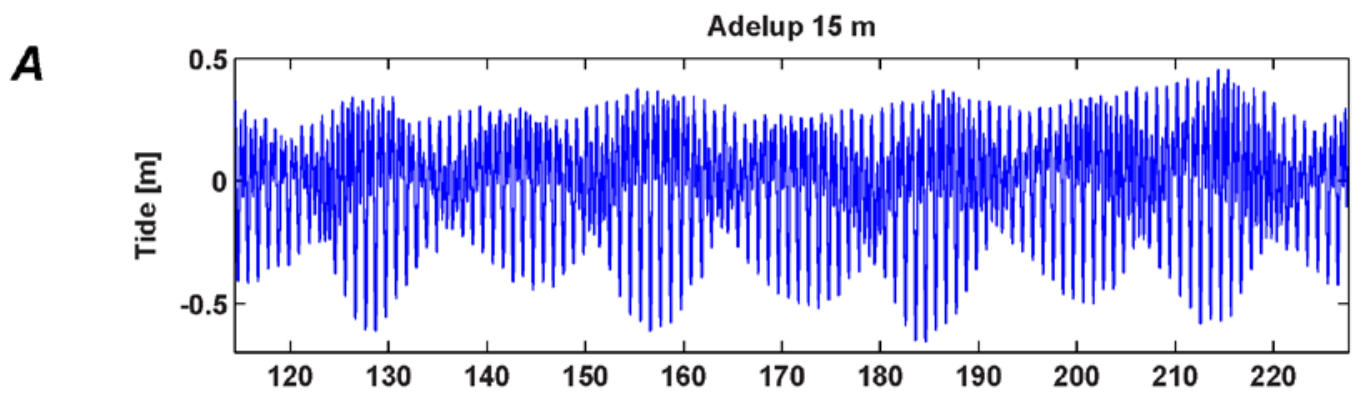

B

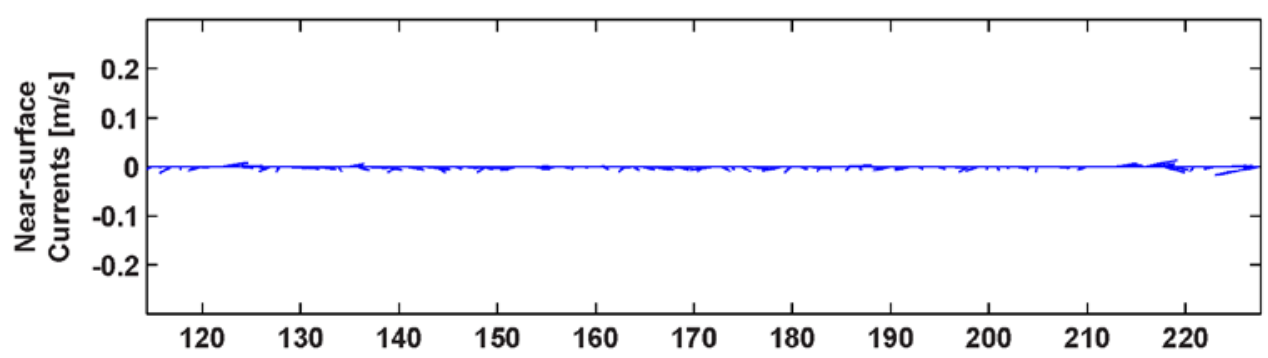

C

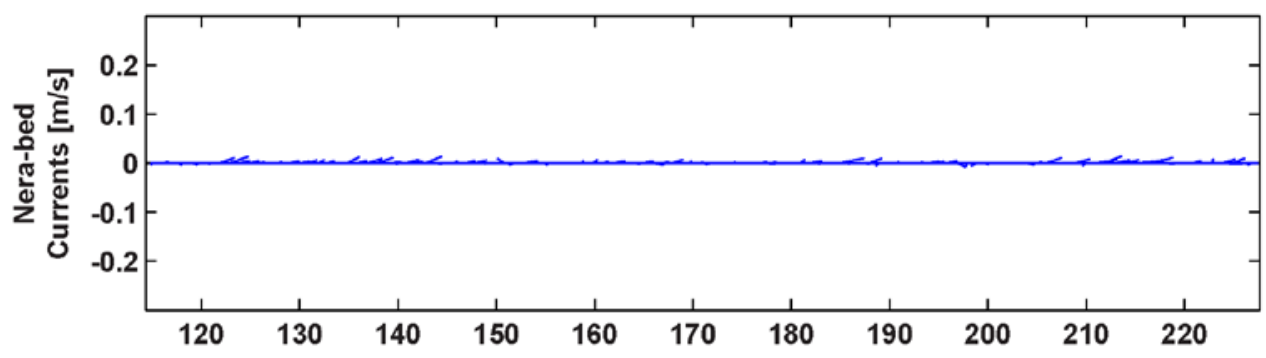

D

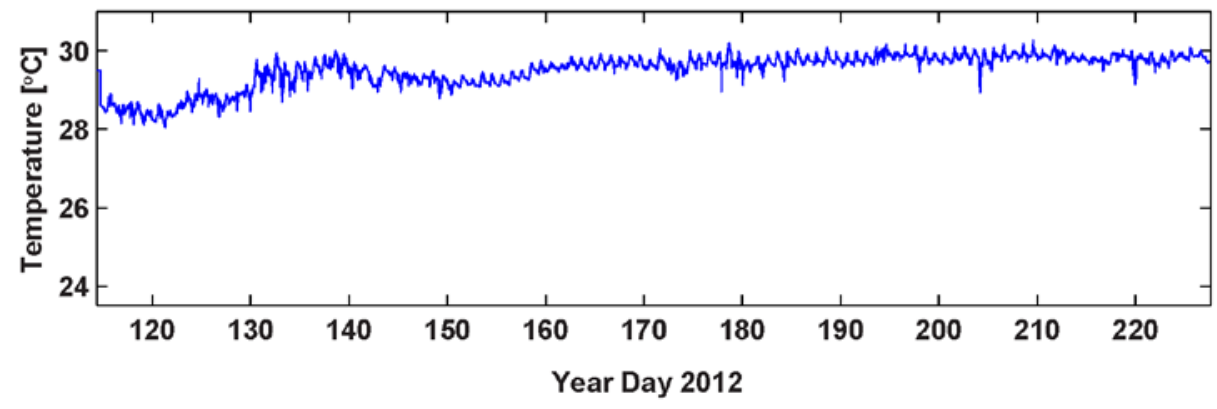

Appendix 6.1. Time-series plot of tide, current, and water temperature data from the ADCP at the Adelup $15-\mathrm{m}$ site. $A$, Tidal height, in meters. $B$, Near-surface current velocity, with direction in degrees from true north and speed in meters per second. $C$, Near-bed current velocity, with direction in degrees from true north and speed in meters per second. $D$, Water temperature, in degrees Celsius. 


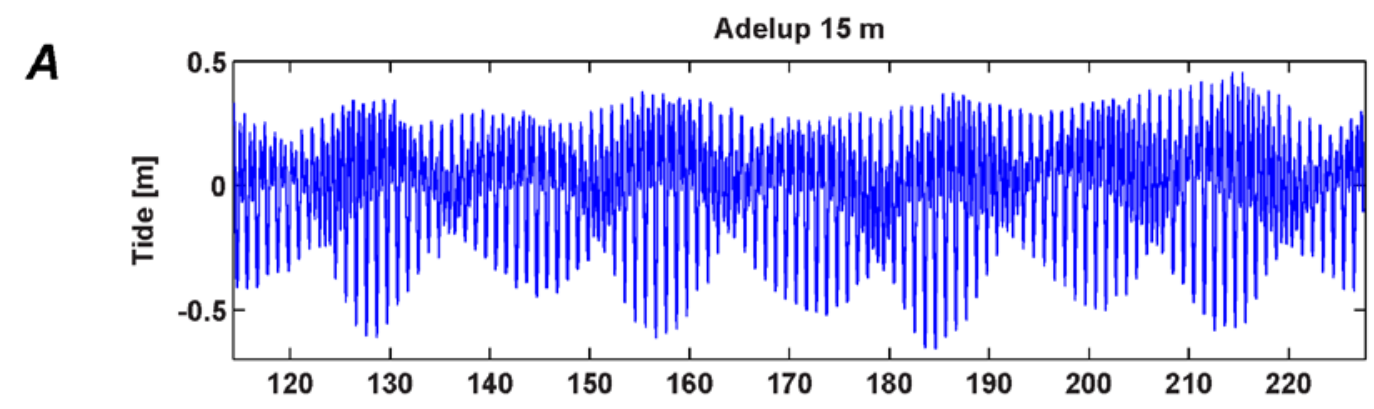

B

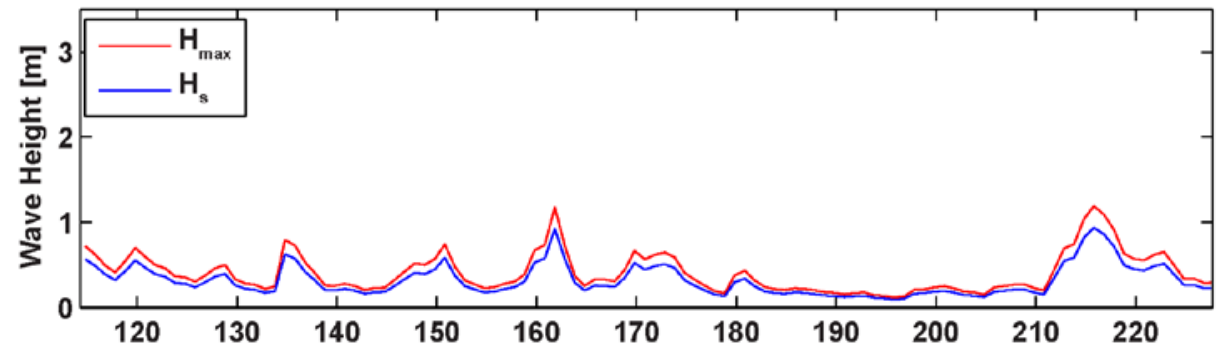

C
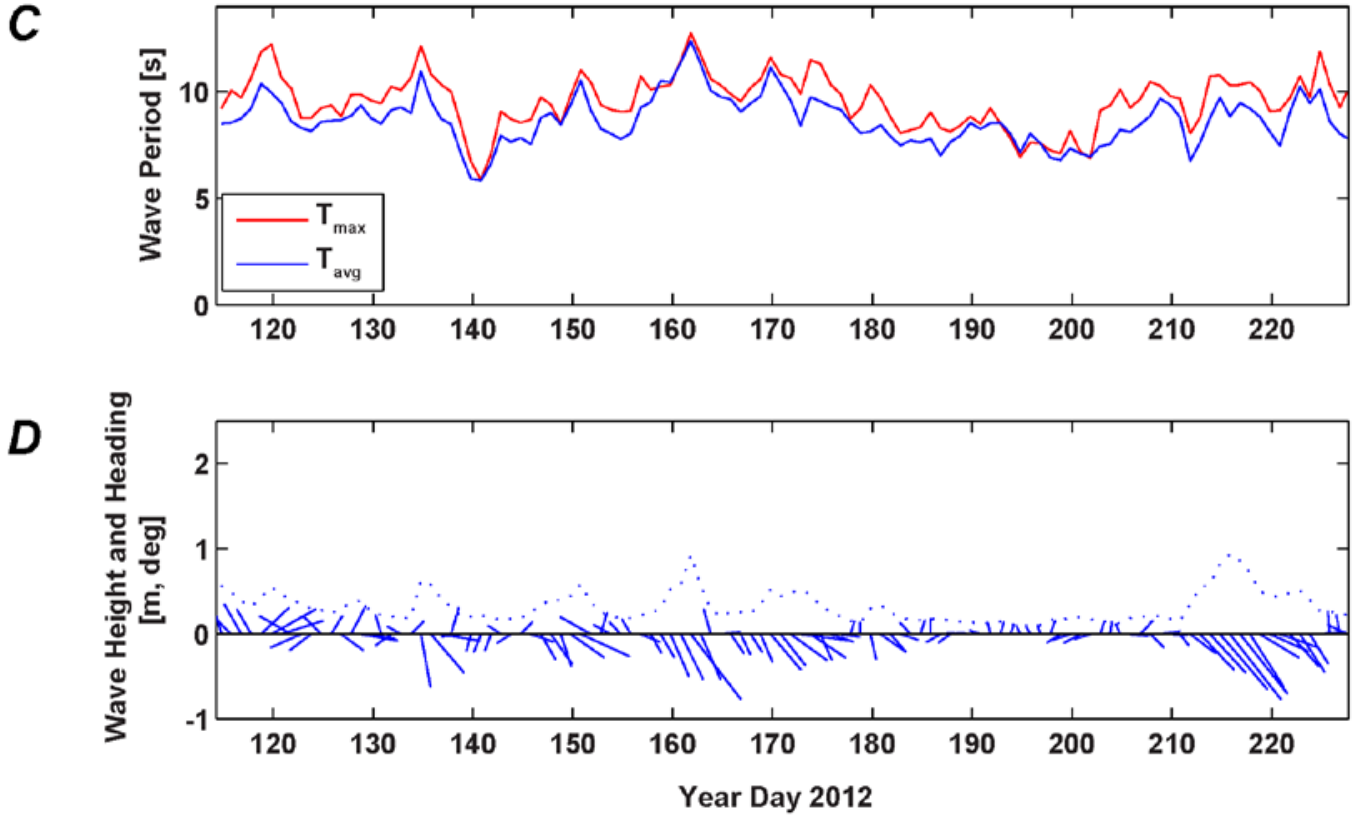

Appendix 6.2. Time-series plot of tide and wave data from the ADCP at the Adelup 15-m site. A, Tidal height, in meters. $B$, Wave height, in meters. $C$, Wave period, in seconds. $D$, Wave height (red), in meters, and wave vectors (blue), with direction given as "going to," measured in degrees clockwise from true north. 


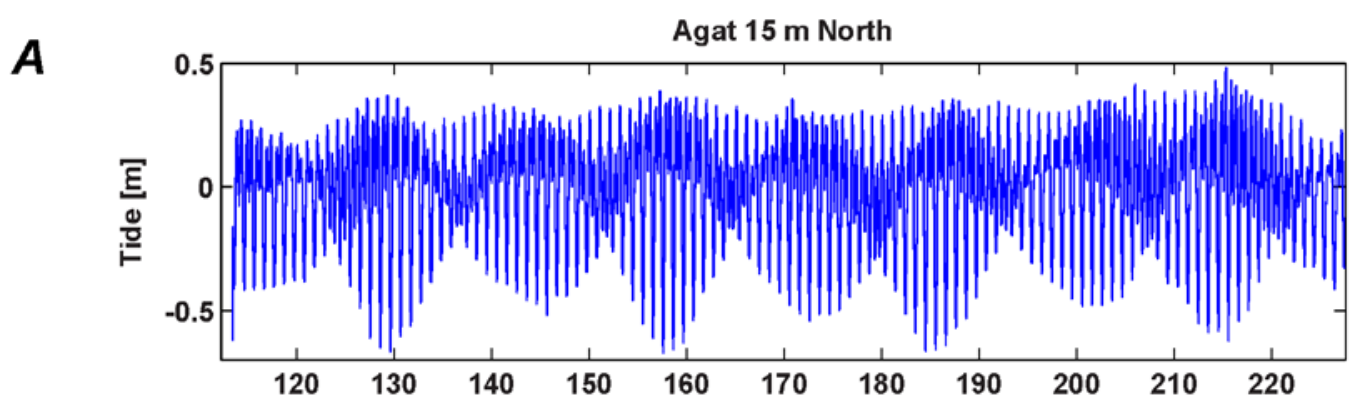

$B$

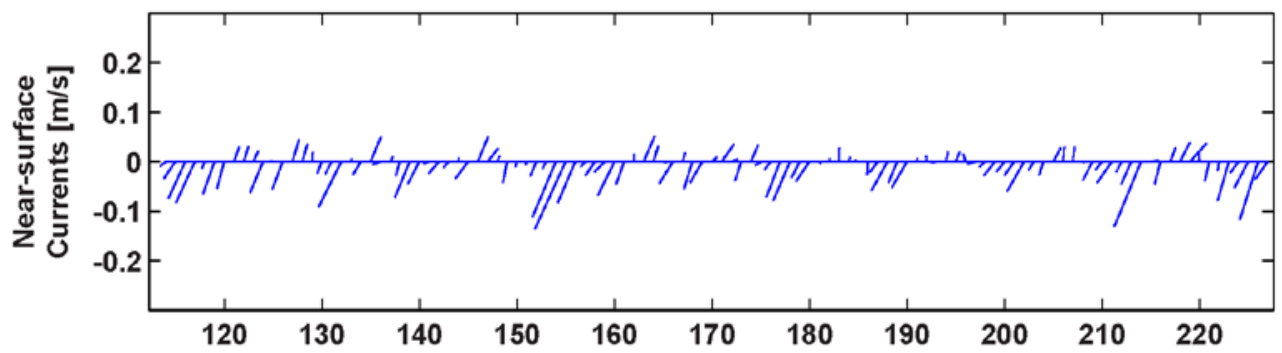

C

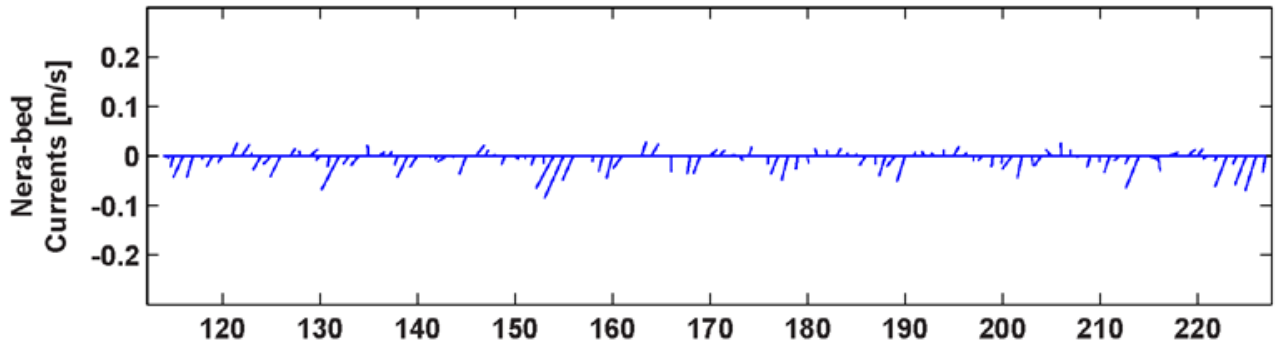

$D$

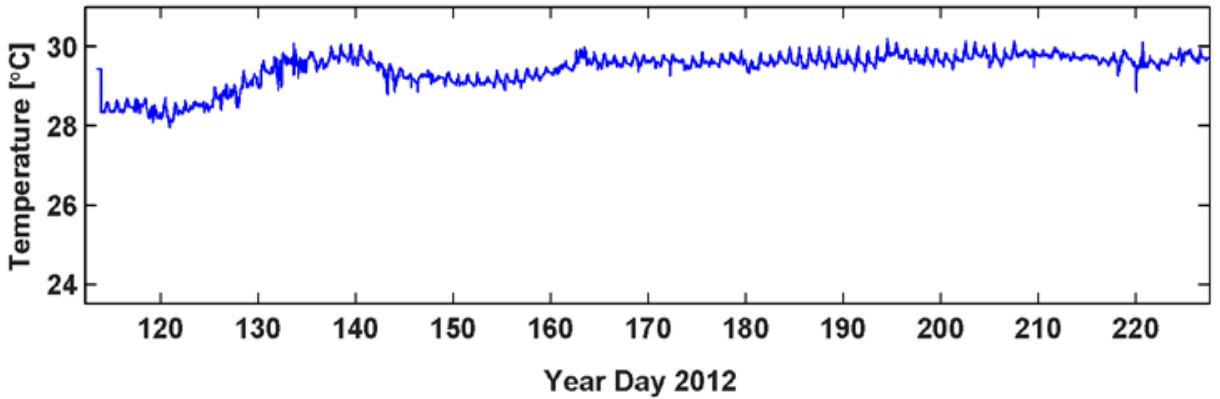

Appendix 6.3. Time-series plot of tide, current, and water temperature data from the ADCP at the Agat $15-\mathrm{m}$ North site. $A$, Tidal height, in meters. $B$, Near-surface current velocity, with direction in degrees from true north and speed in meters per second. $C$, Near-bed current velocity, with direction in degrees from true north and speed in meters per second. $D$, Water temperature, in degrees Celsius. 


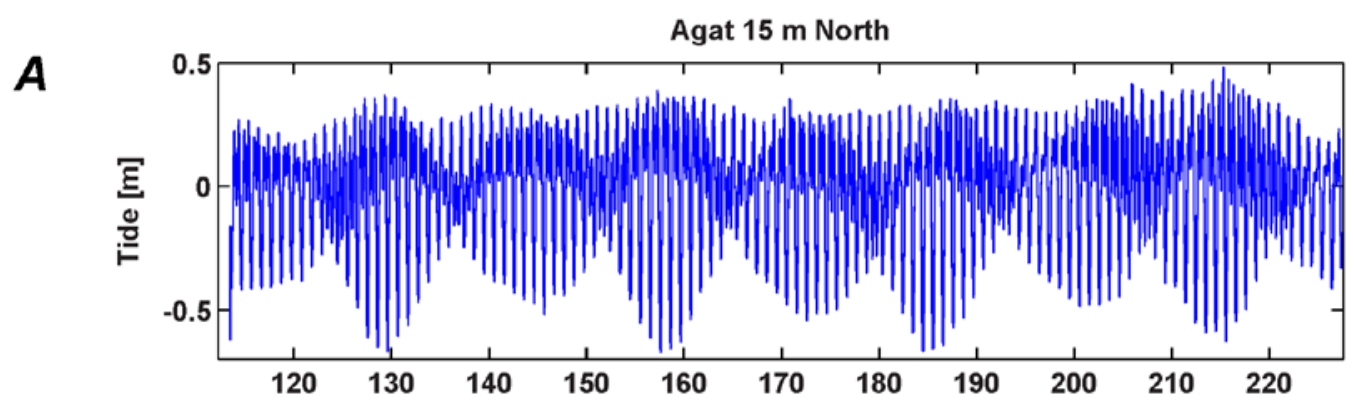

B

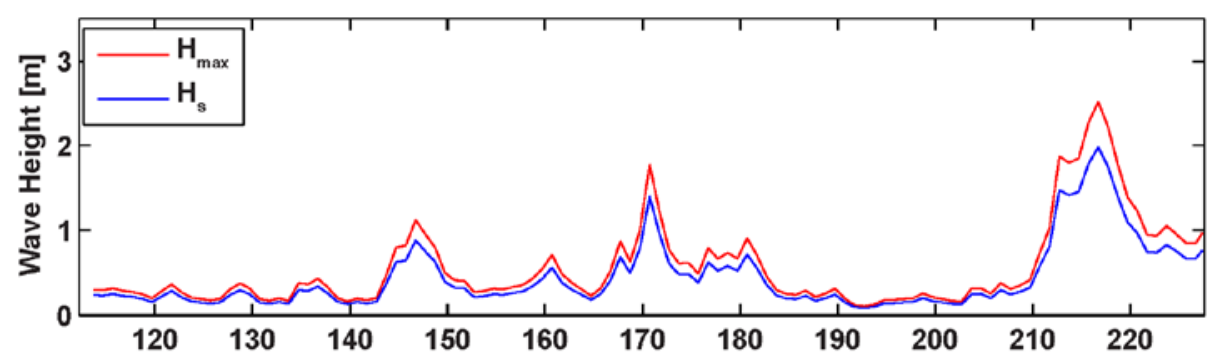

C
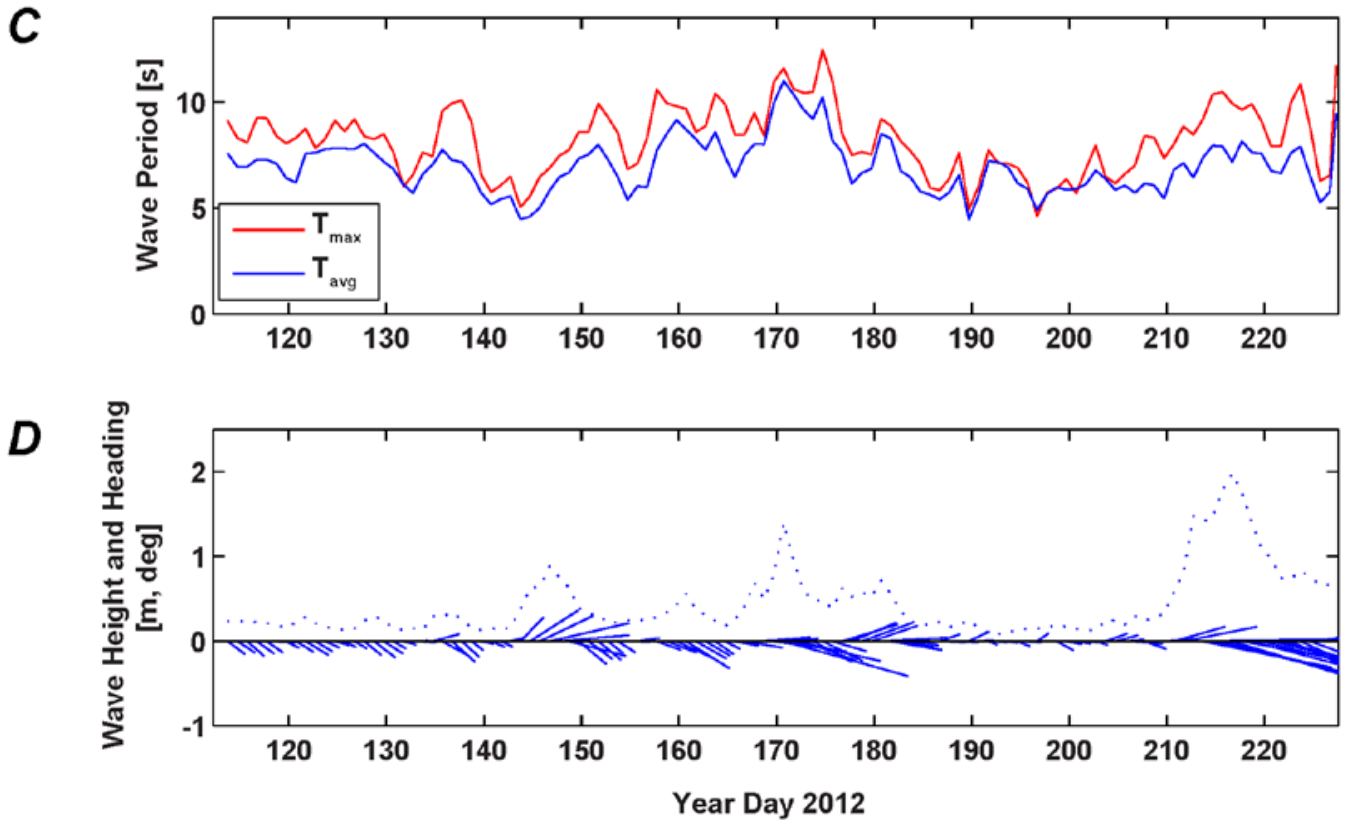

Appendix 6.4. Time-series plot of tide and wave data from the ADCP at the Agat 15-m North site. A, Tidal height, in meters. $B$, Wave height, in meters. $C$, Wave period, in seconds. $D$, Wave height (red), in meters, and wave vectors (blue), with direction given as "going to," measured in degrees clockwise from true north. 


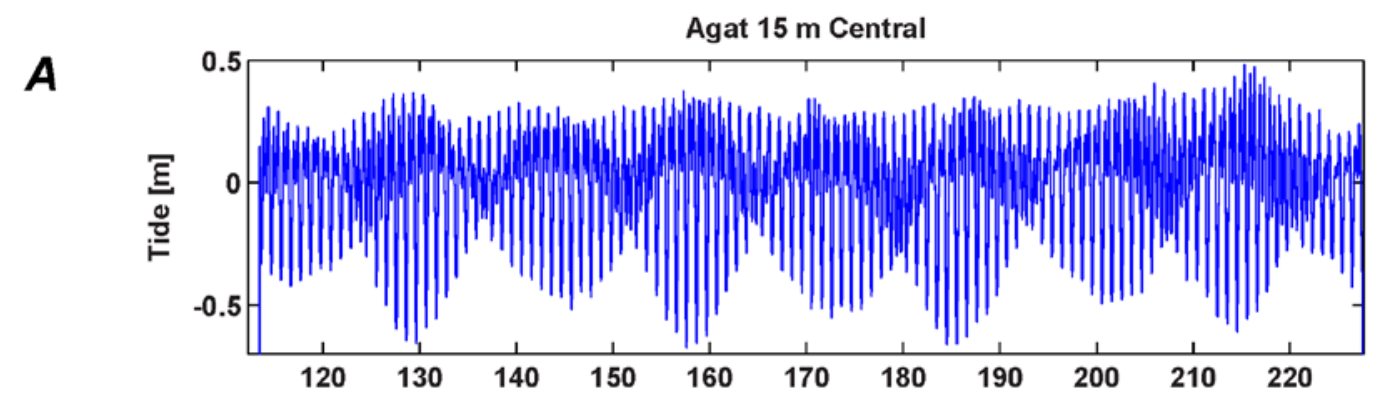

B

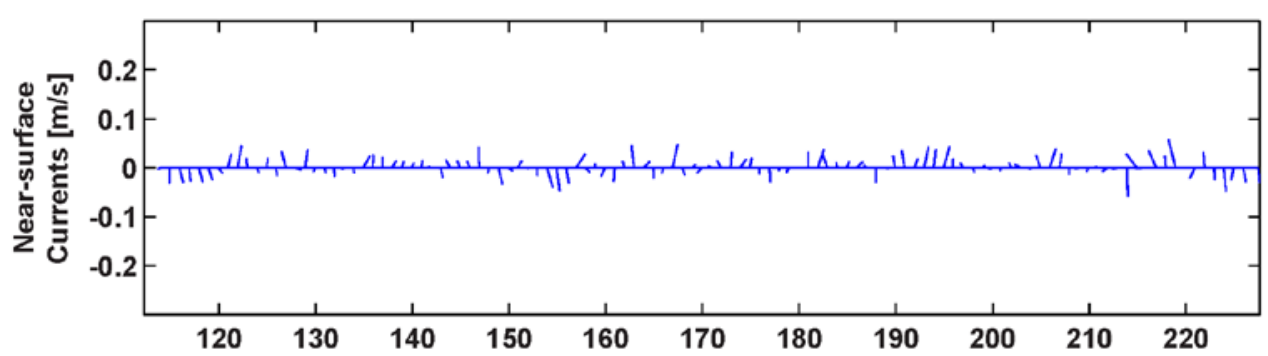

C

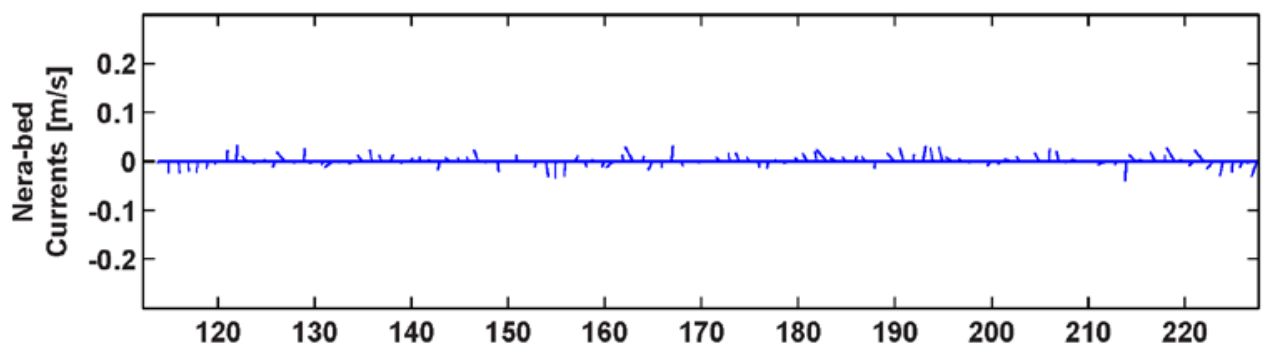

$\boldsymbol{D}$

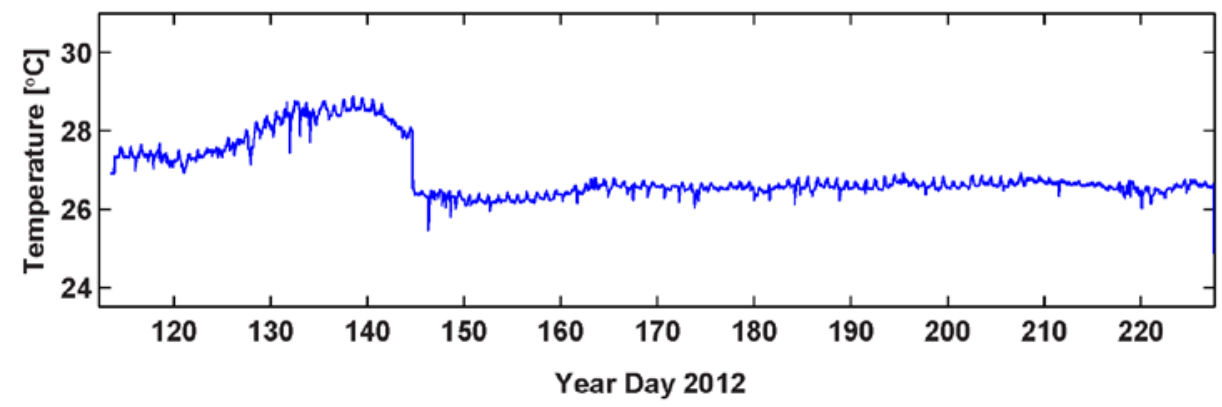

Appendix 6.5. Time-series plot of tide, current, and water temperature data from the ADCP at the Agat 15-m Central site. $A$, Tidal height, in meters. $B$, Near-surface current velocity, with direction in degrees from true north and speed in meters per second. $C$, Near-bed current velocity, with direction in degrees from true north and speed in meters per second. $D$, Water temperature, in degrees Celsius. 


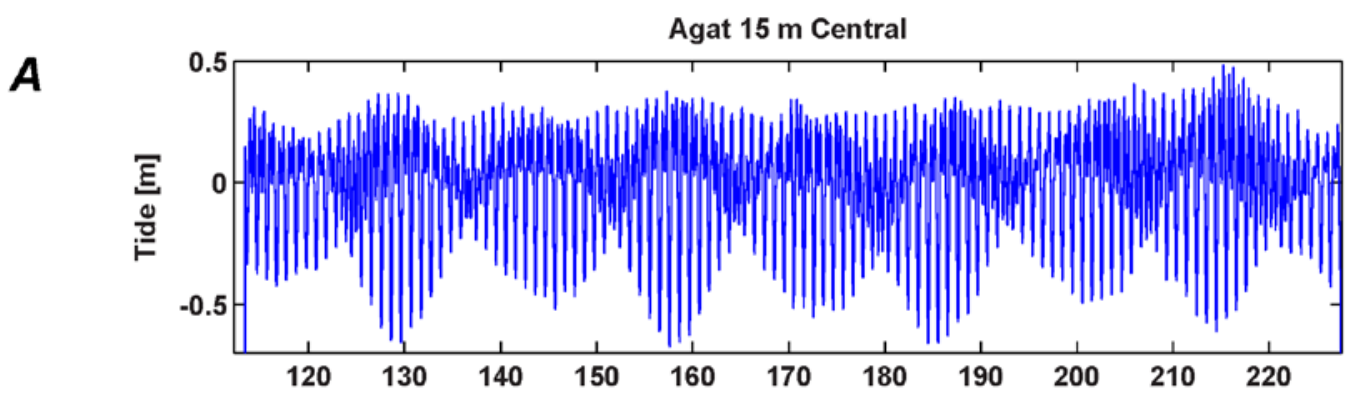

B

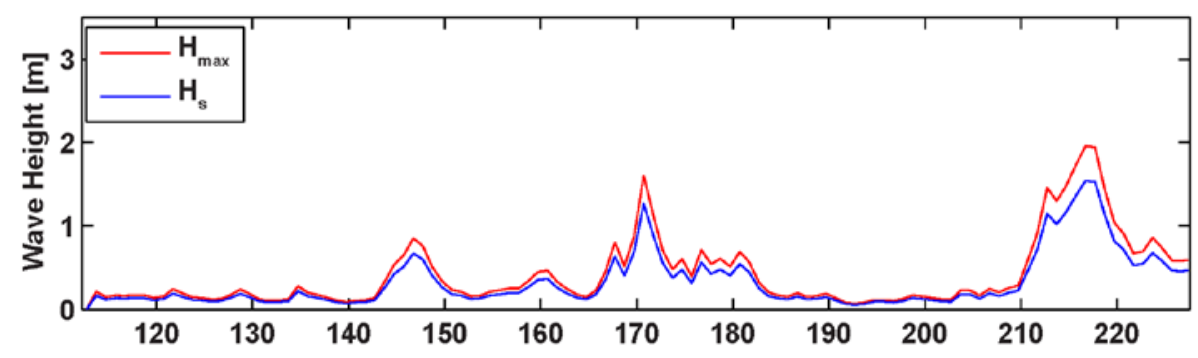

C
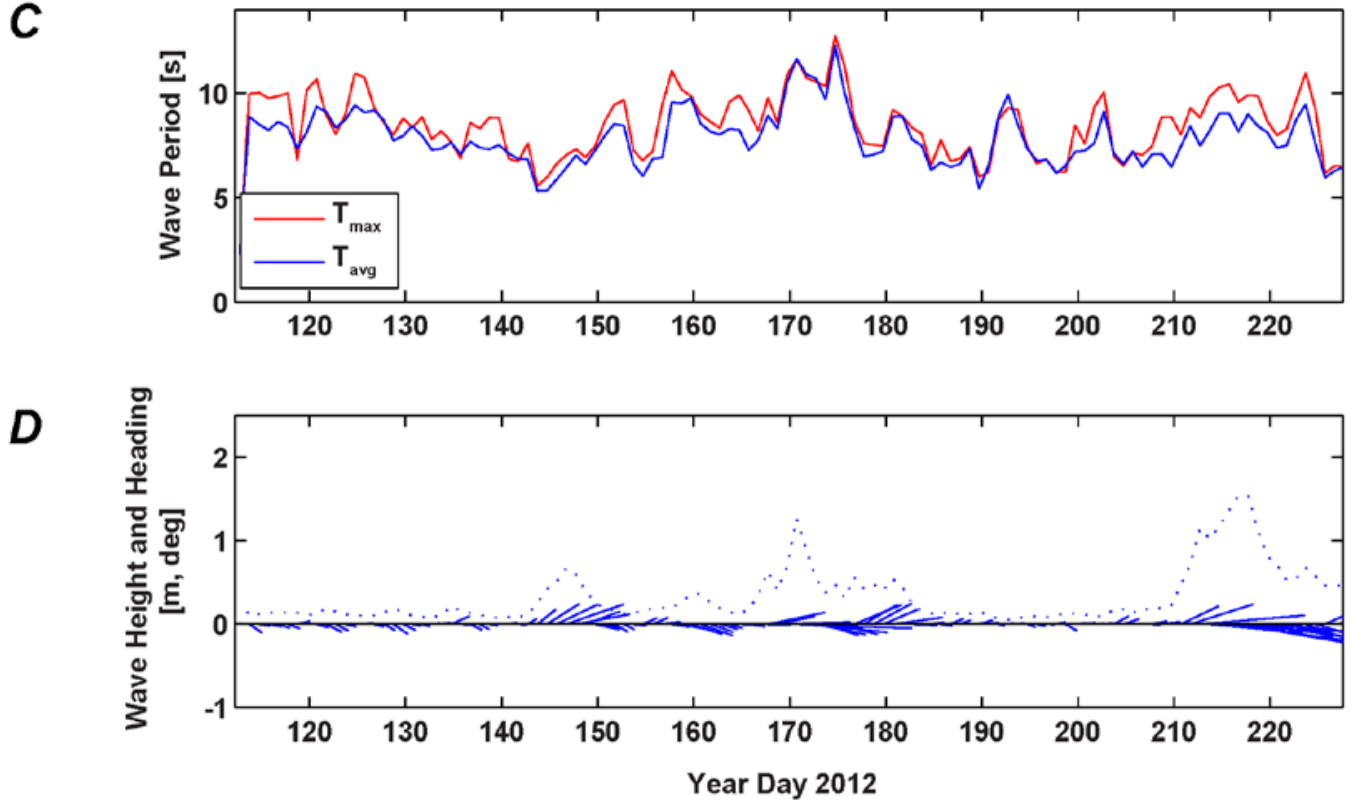

Appendix 6.6. Time-series plot of tide and wave data from the ADCP at the Agat 15-m Central site. A, Tidal height, in meters. $B$, Wave height, in meters. $C$, Wave period, in seconds. $D$, Wave height (red), in meters, and wave vectors (blue), with direction given as "going to," measured in degrees clockwise from true north. 


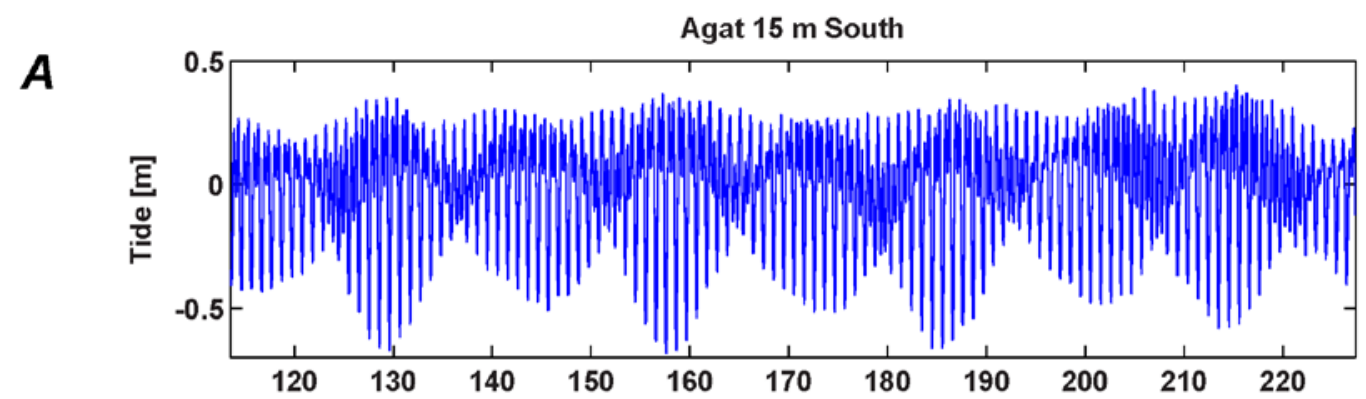

B

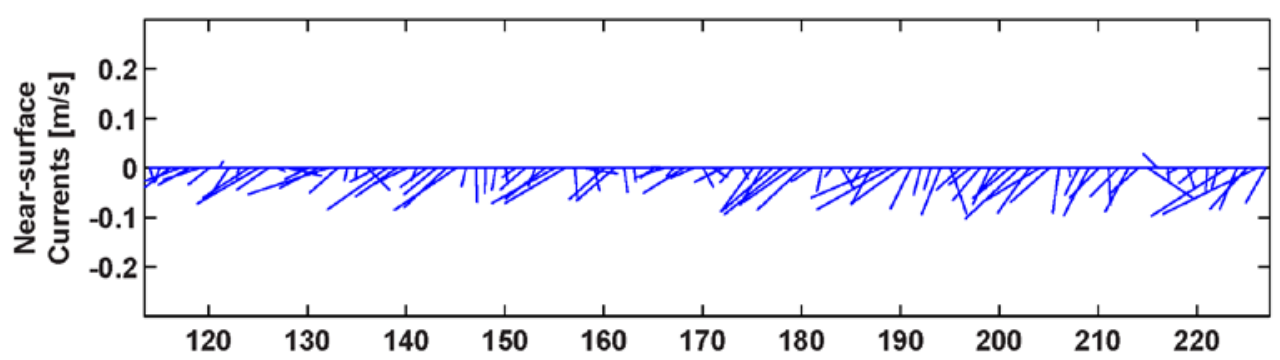

C

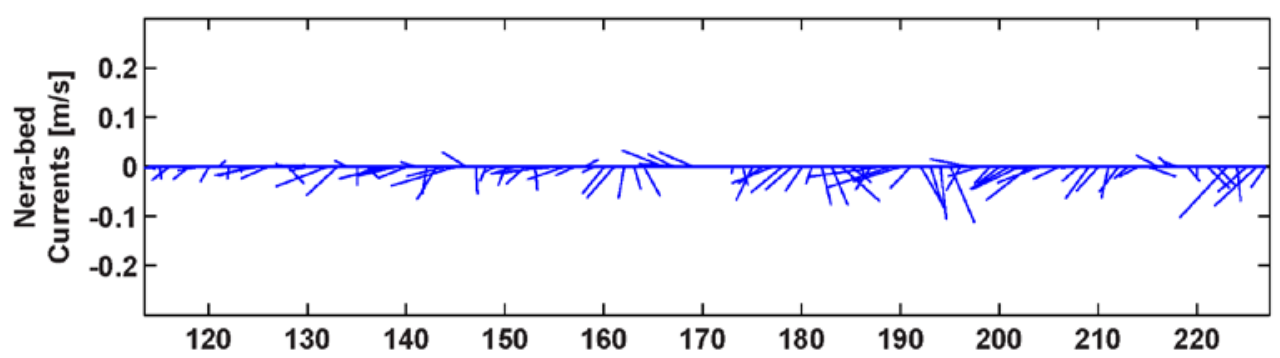

D

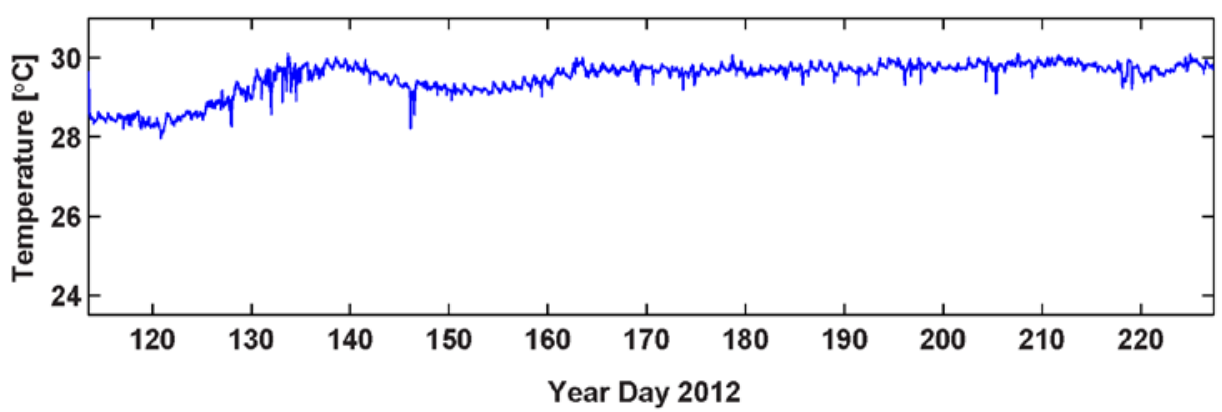

Appendix 6.7. Time-series plot of tide, current, and water temperature data from the ADCP at the Agat 15-m South site. A, Tidal height, in meters. $B$, Near-surface current velocity, with direction in degrees from true north and speed in meters per second. $C$, Near-bed current velocity, with direction in degrees from true north and speed in meters per second. $D$, Water temperature, in degrees Celsius. 


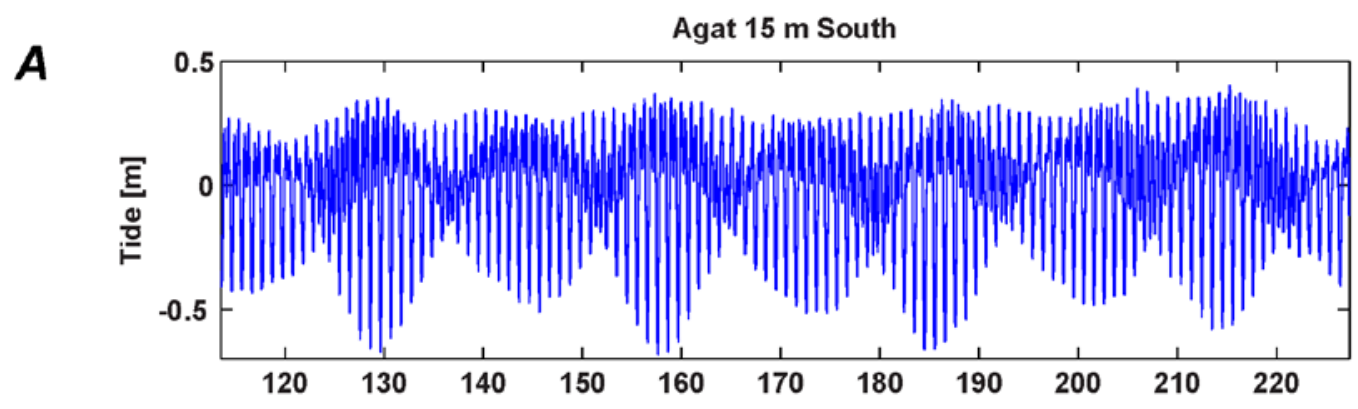

$B$

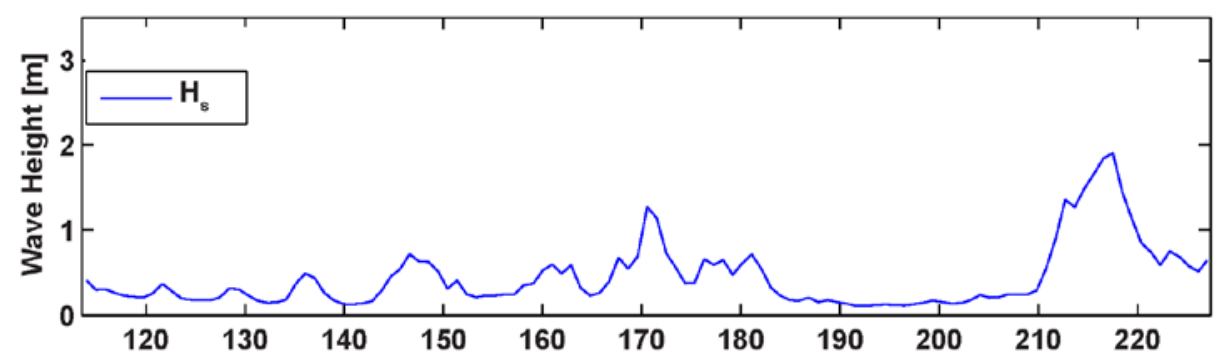

C
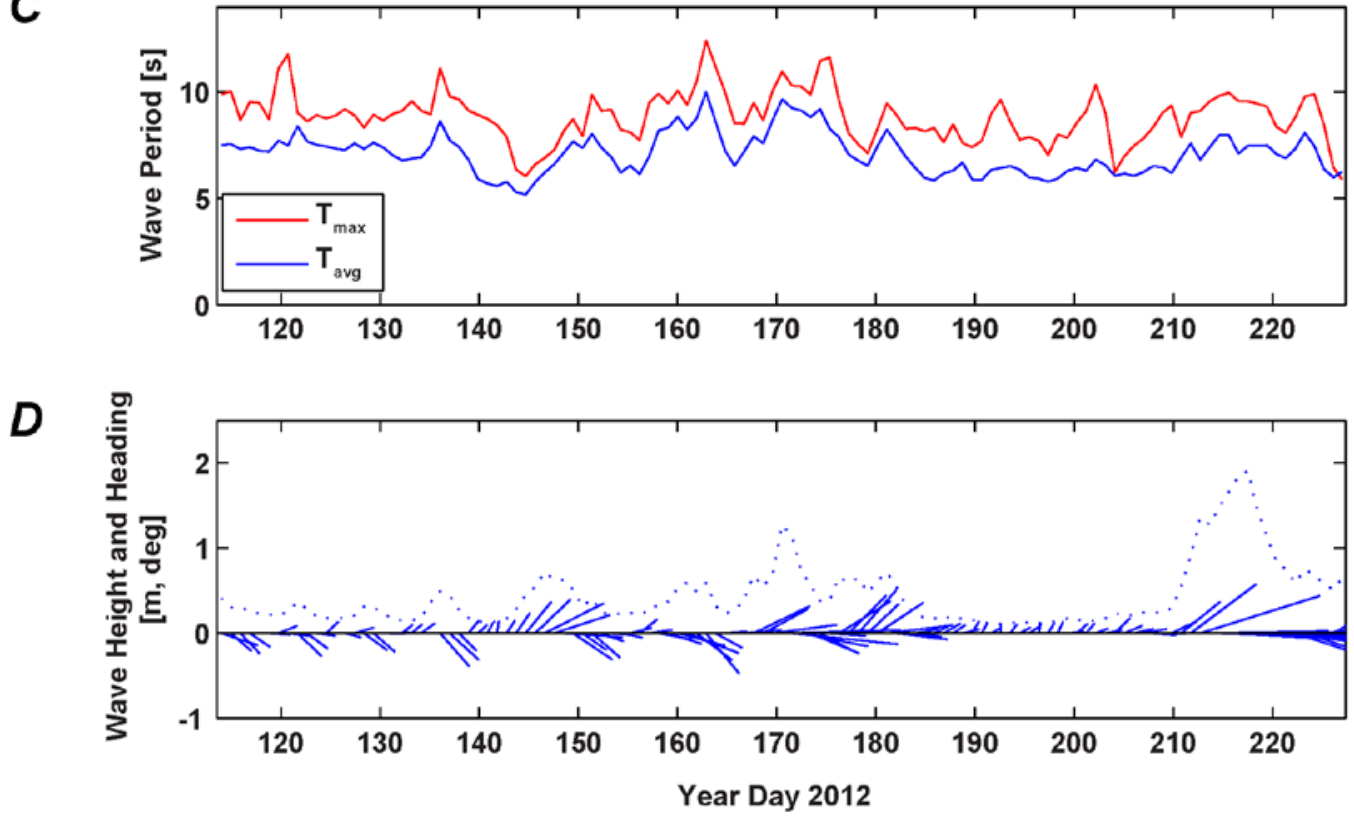

Appendix 6.8. Time-series plot of tide and wave data from the ADCP at the Agat 15-m South site. A, Tidal height, in meters. $B$, Wave height, in meters. $C$, Wave period, in seconds. $D$, Wave height (red), in meters, and wave vectors (blue), with direction given as “going to,” measured in degrees clockwise from true north. 


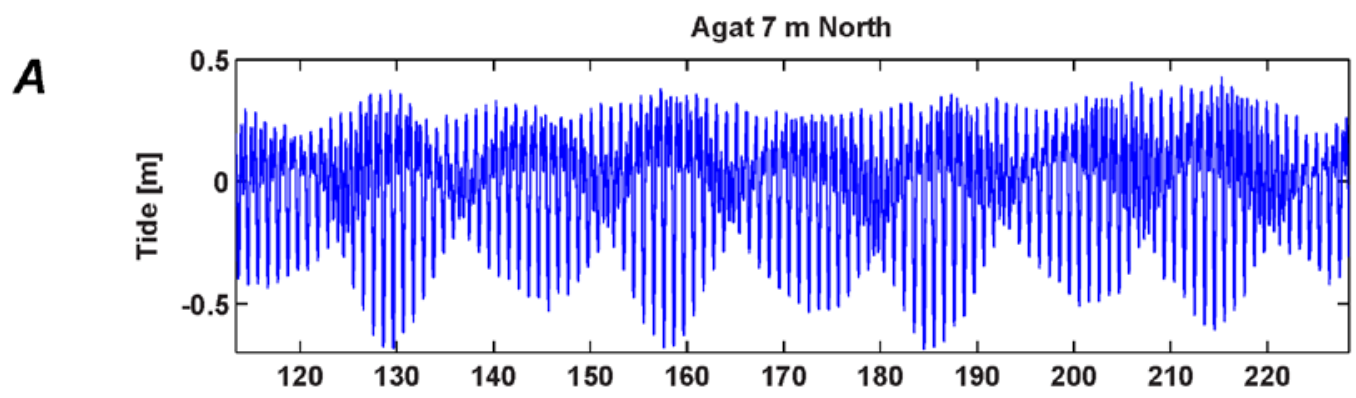

$B$

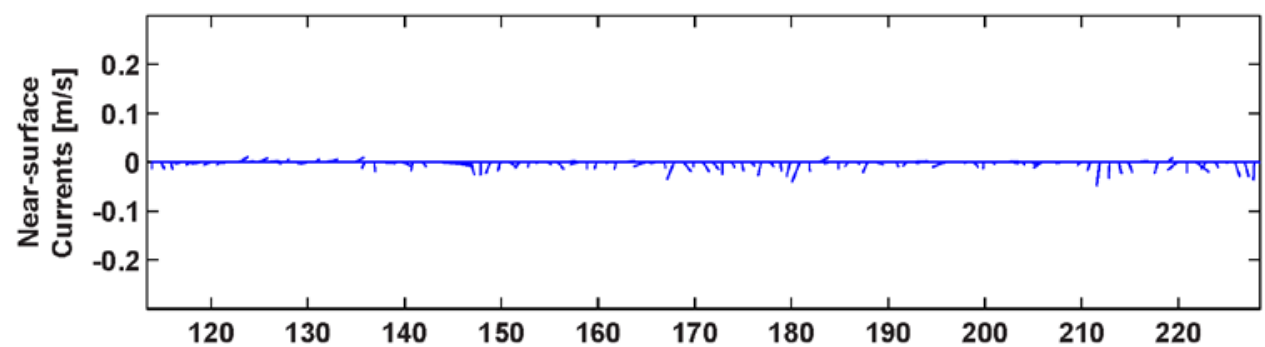

C

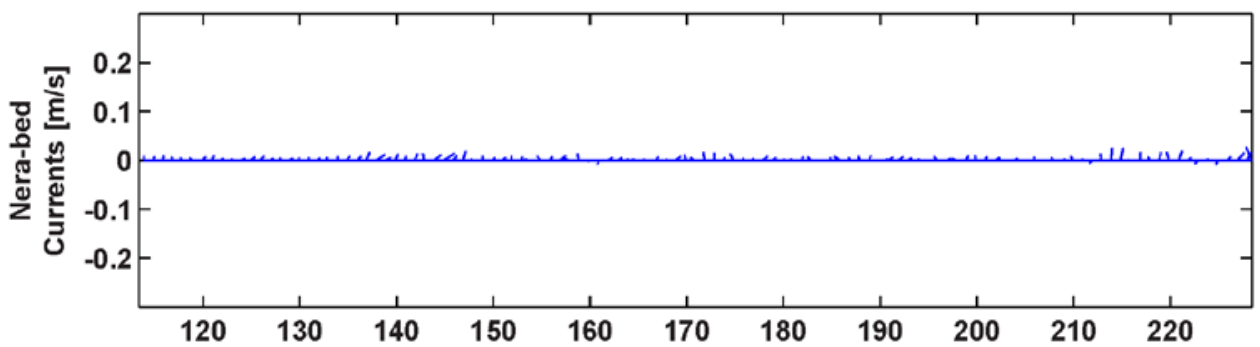

$D$

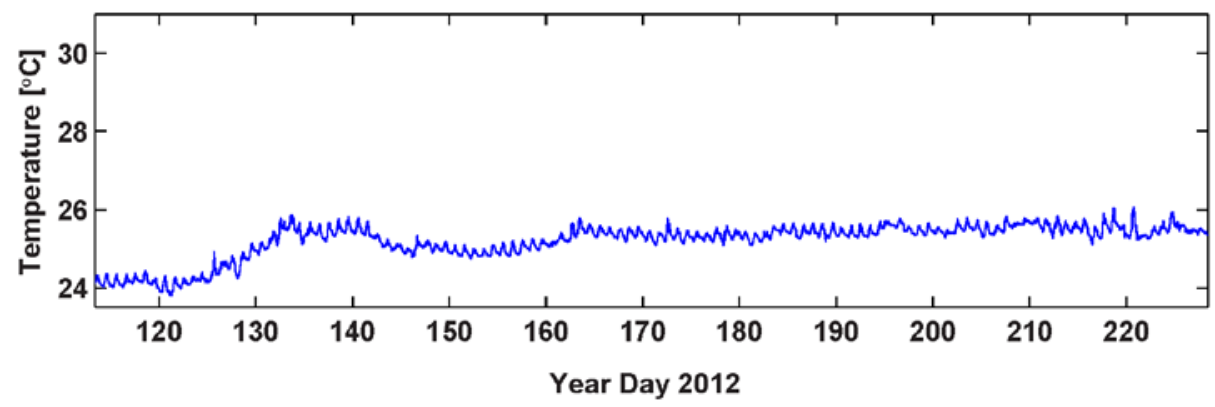

Appendix 6.9. Time-series plot of tide, current, and water temperature data from the ADCP at the Agat 7$\mathrm{m}$ North site. A, Tidal height, in meters. $B$, Near-surface current velocity, with direction in degrees from true north and speed in meters per second. $C$, Near-bed current velocity, with direction in degrees from true north and speed in meters per second. $D$, Water temperature, in degrees Celsius. 

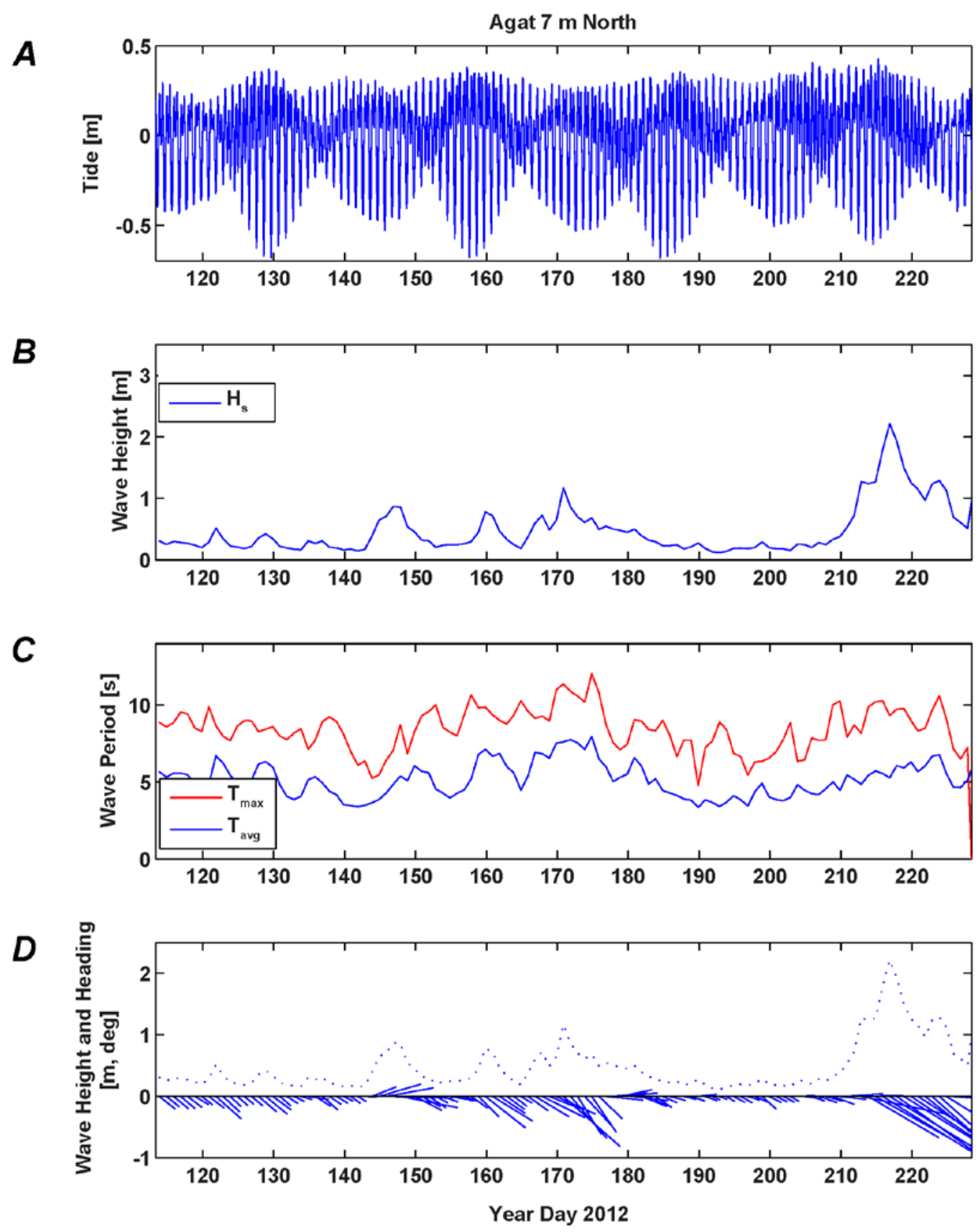

Appendix 6.10. Time-series plot of tide and wave data from the ADCP at the Agat 7-m North site. A, Tidal height, in meters. $B$, Wave height, in meters. $C$, Wave period, in seconds. $D$, Wave height (red), in meters, and wave vectors (blue), with direction given as "going to," measured in degrees clockwise from true north. 
A

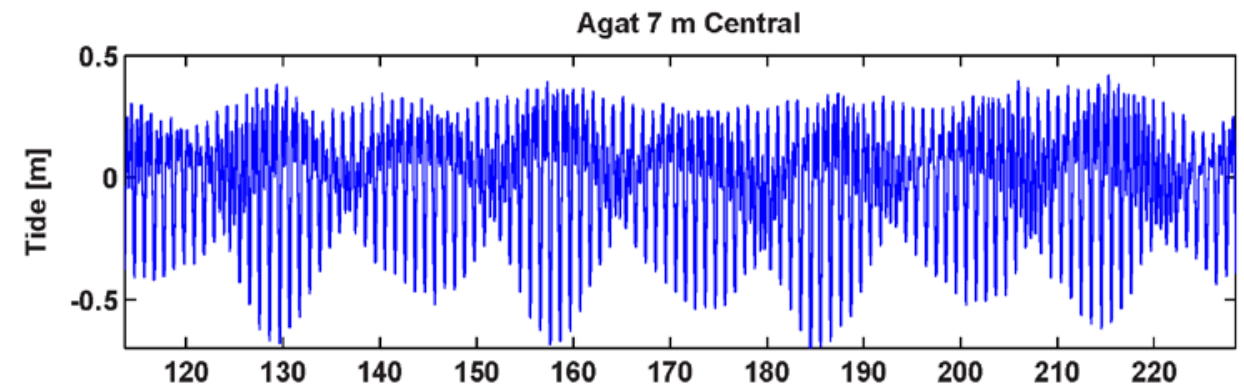

B

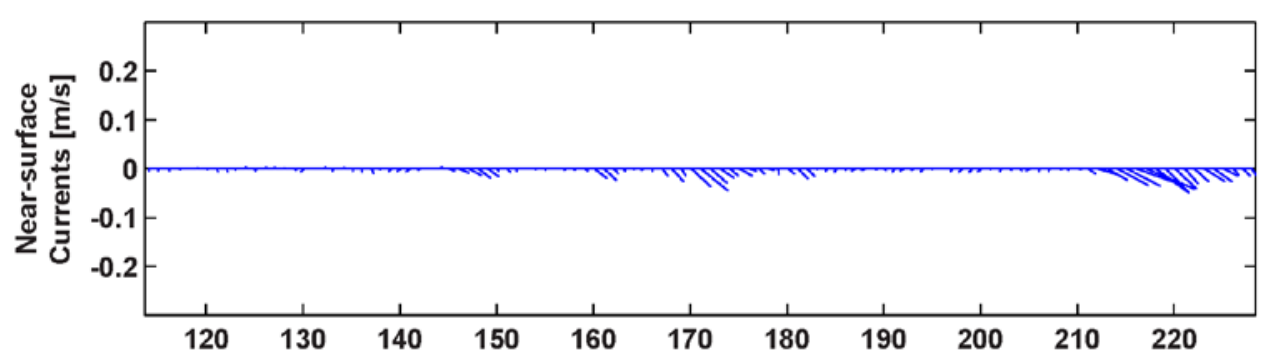

C

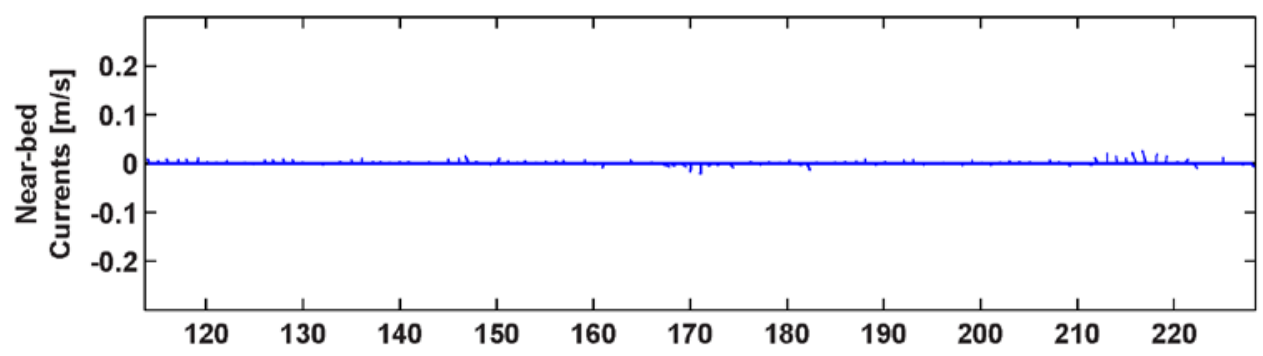

D

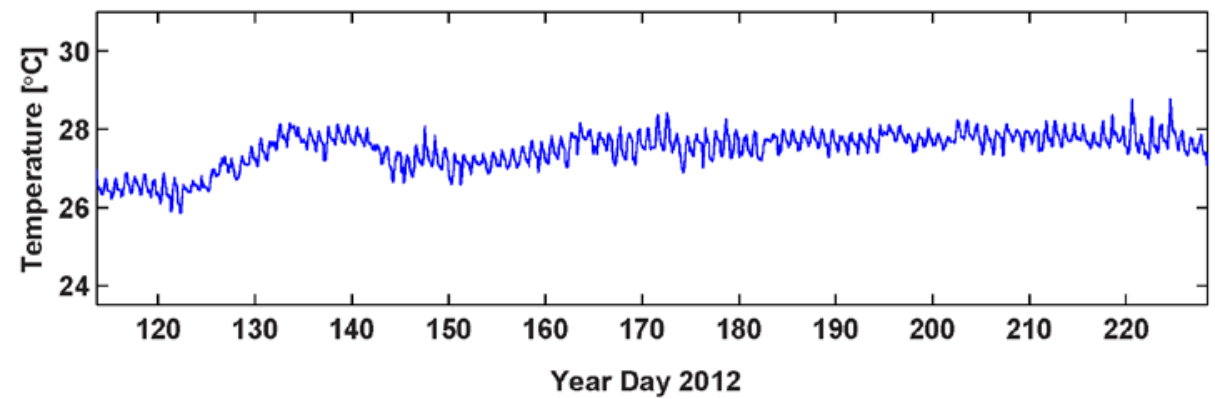

Appendix 6.11. Time-series plot of tide, current, and water temperature data from the ADCP at the Agat 7-m Central site. A, Tidal height, in meters. B, Near-surface current velocity, with direction in degrees from true north and speed in meters per second. $C$, Near-bed current velocity, with direction in degrees from true north and speed in meters per second. $D$, Water temperature, in degrees Celsius. 


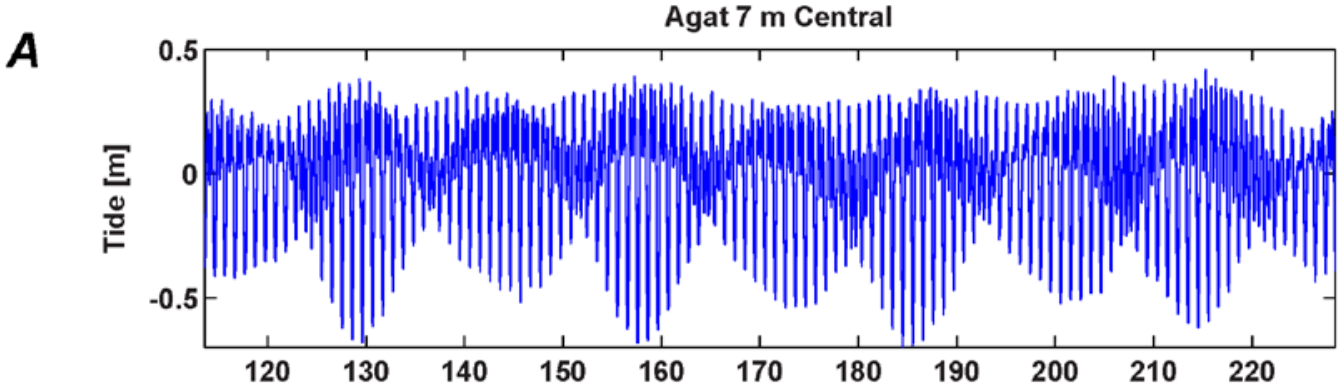

B

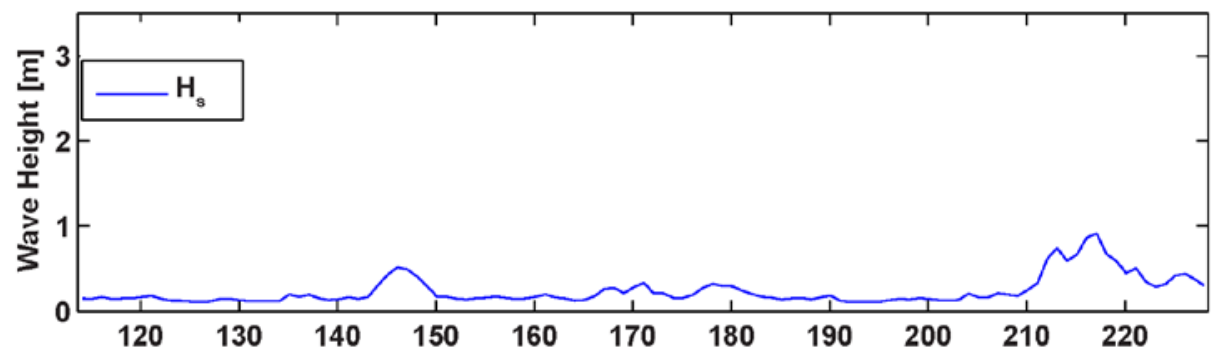

C
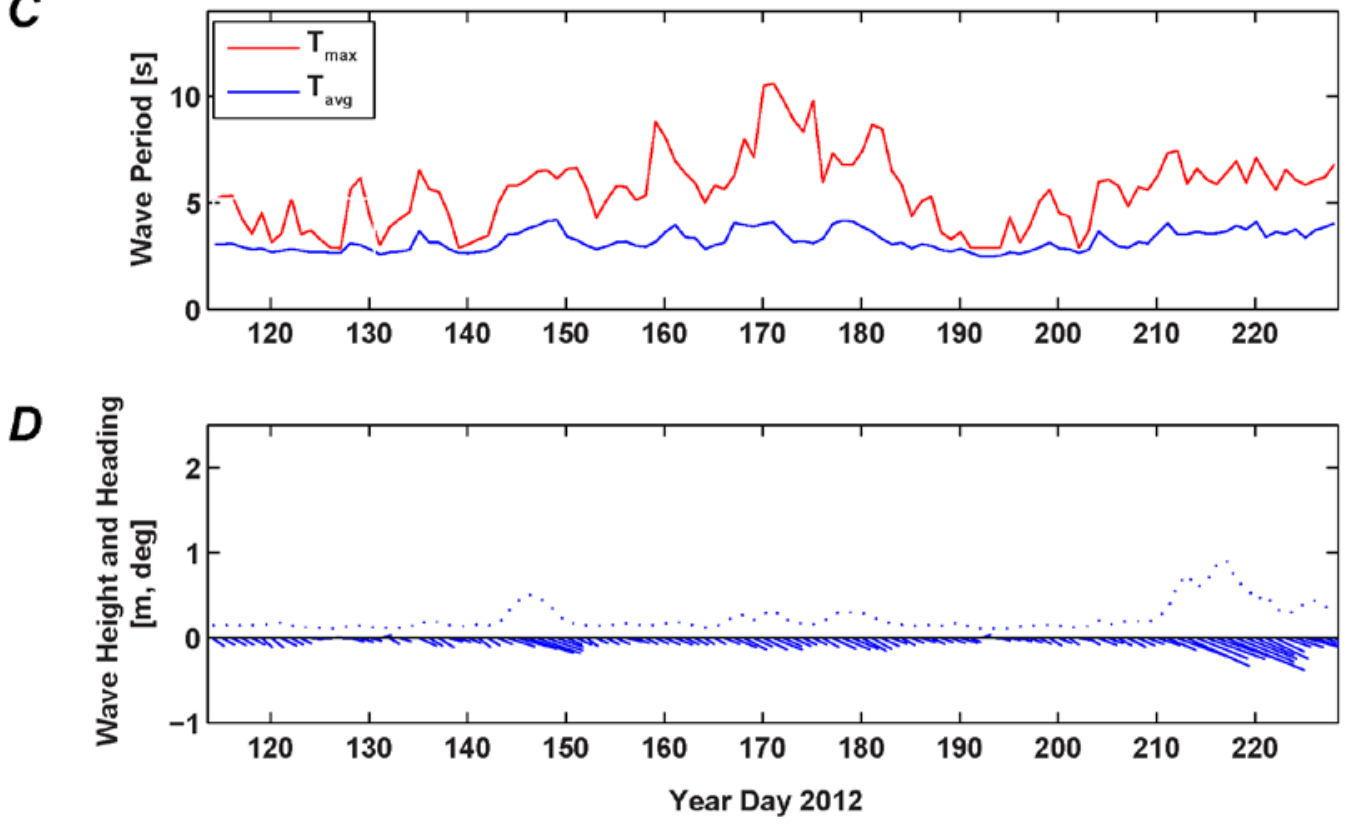

Appendix 6.12. Time-series plot of tide and wave data from the ADCP at the Agat 7-m Central site. A, Tidal height, in meters. $B$, Wave height, in meters. $C$, Wave period, in seconds. $D$, Wave height (red), in meters, and wave vectors (blue), with direction given as "going to," measured in degrees clockwise from true north. 


\section{Appendix 7. Maps Showing Variations of Water-Column Properties}

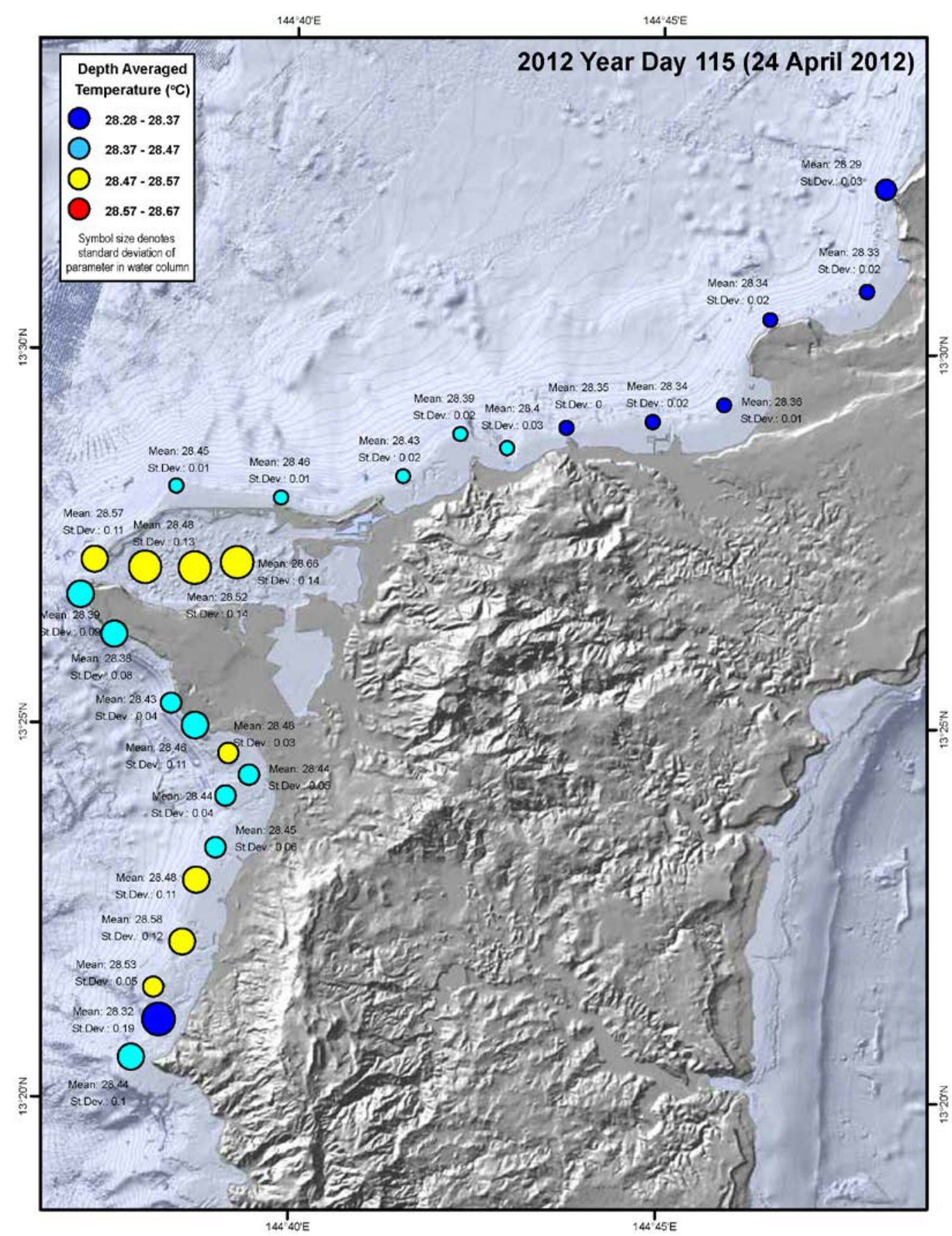

Appendix 7.1. Map showing depth-averaged WCP temperature, in degrees Celsius, from the YD 115 (24 April 2012) survey. 


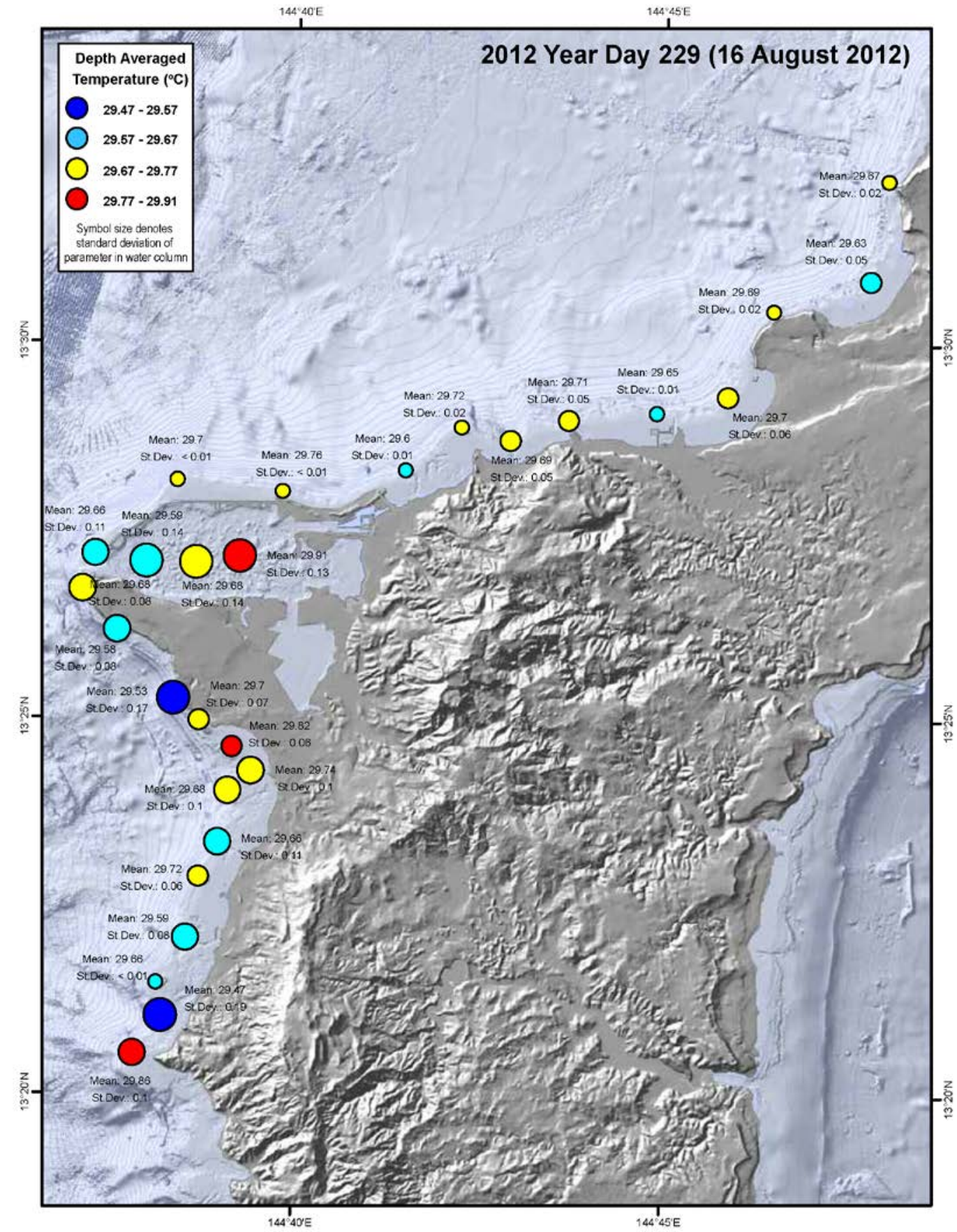

Appendix 7.2. Map showing depth-averaged WCP temperature, in degrees Celsius, from the YD 229 (16 August 2012) survey. 


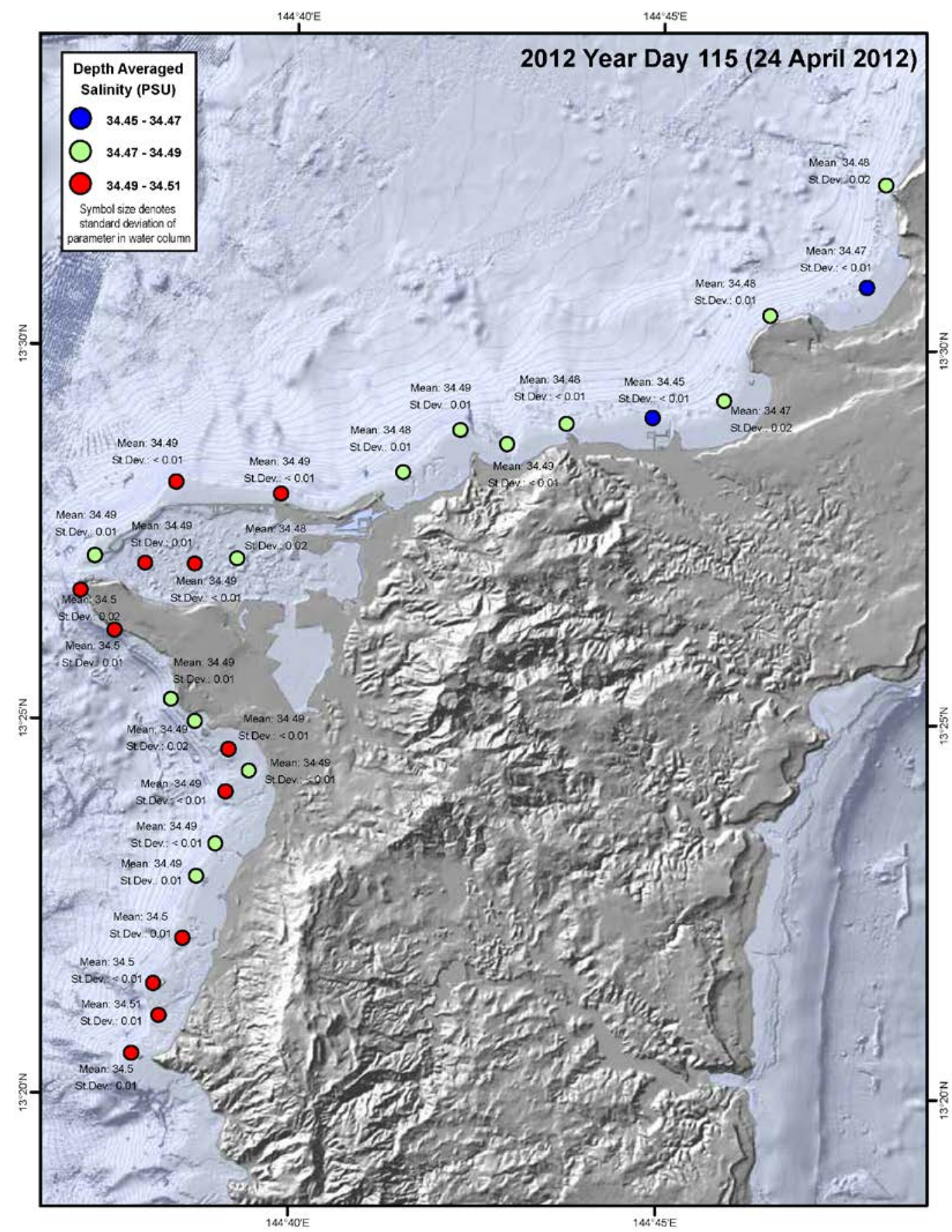

Appendix 7.3. Map showing depth-averaged WCP salinity, in Practical Salinity Units, from the YD 115 (24 April 2012) survey. 


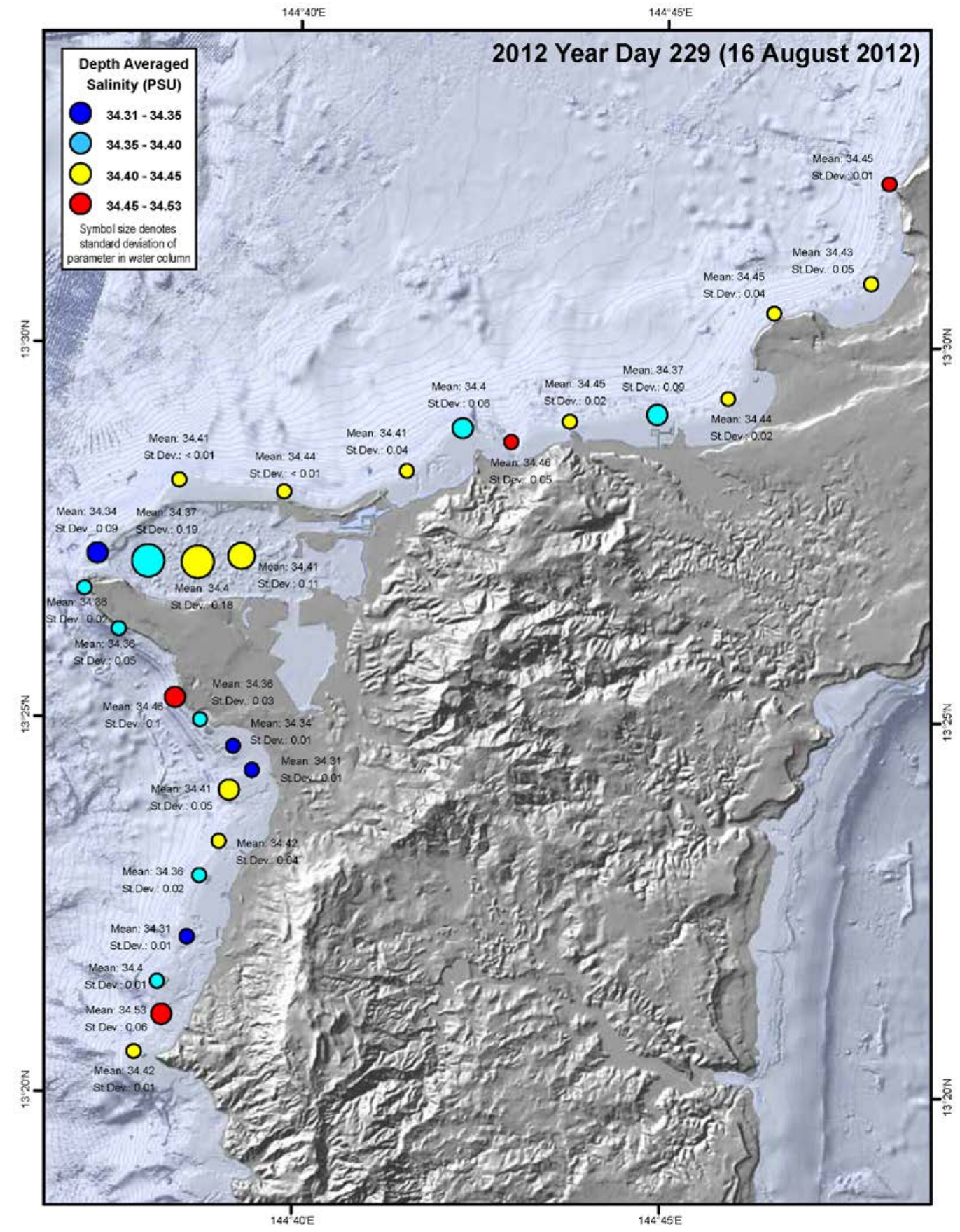

Appendix 7.4. Map showing depth-averaged WCP salinity, in Practical Salinity Units, from the YD 229 (16 August 2012) survey. 


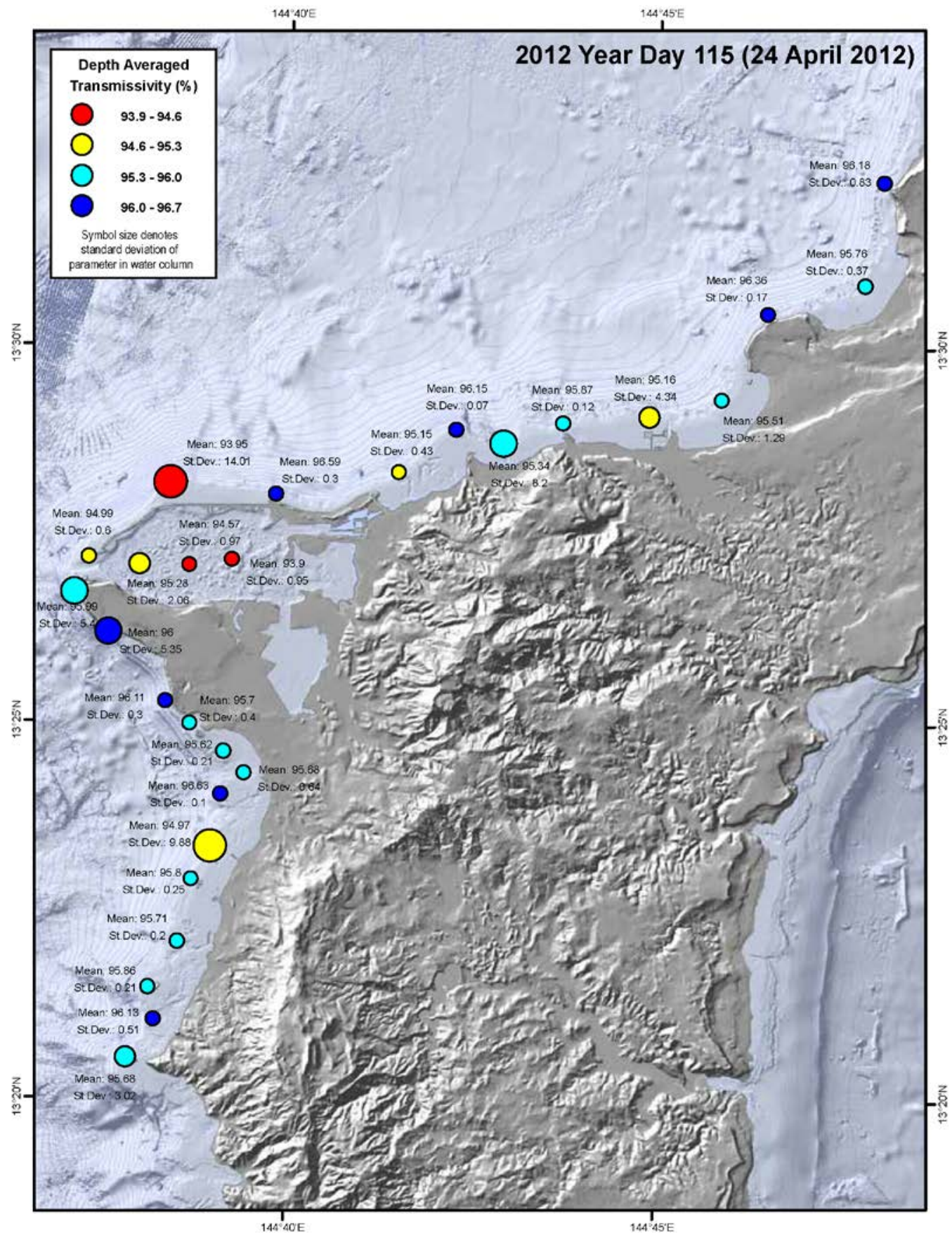

Appendix 7.5. Map showing depth-averaged WCP light transmission, in percent, from the YD 115 (24 April 2012) survey. 


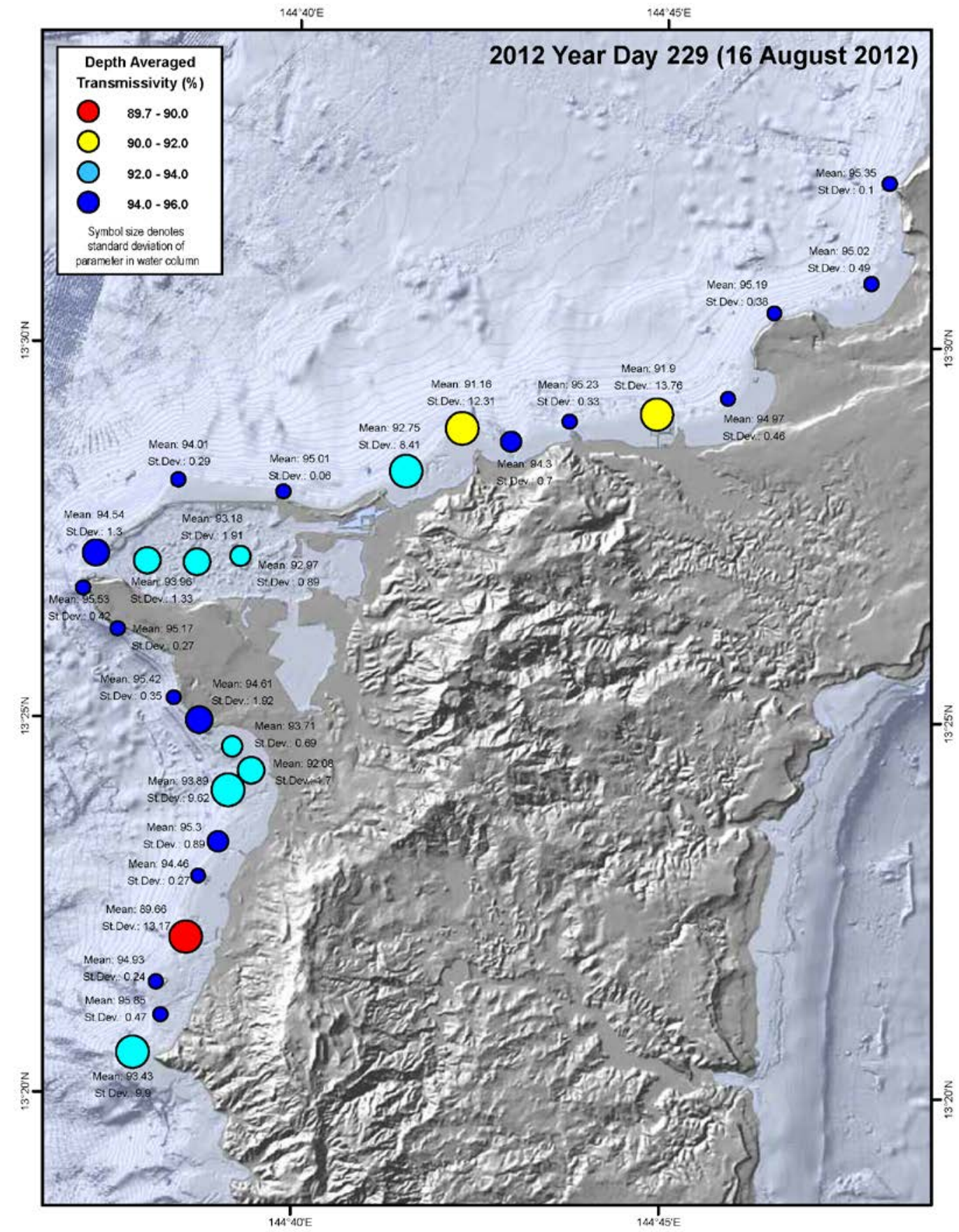

Appendix 7.6. Map showing depth-averaged WCP light transmission, in percent, from the YD 229 (16 August 2012) survey. 


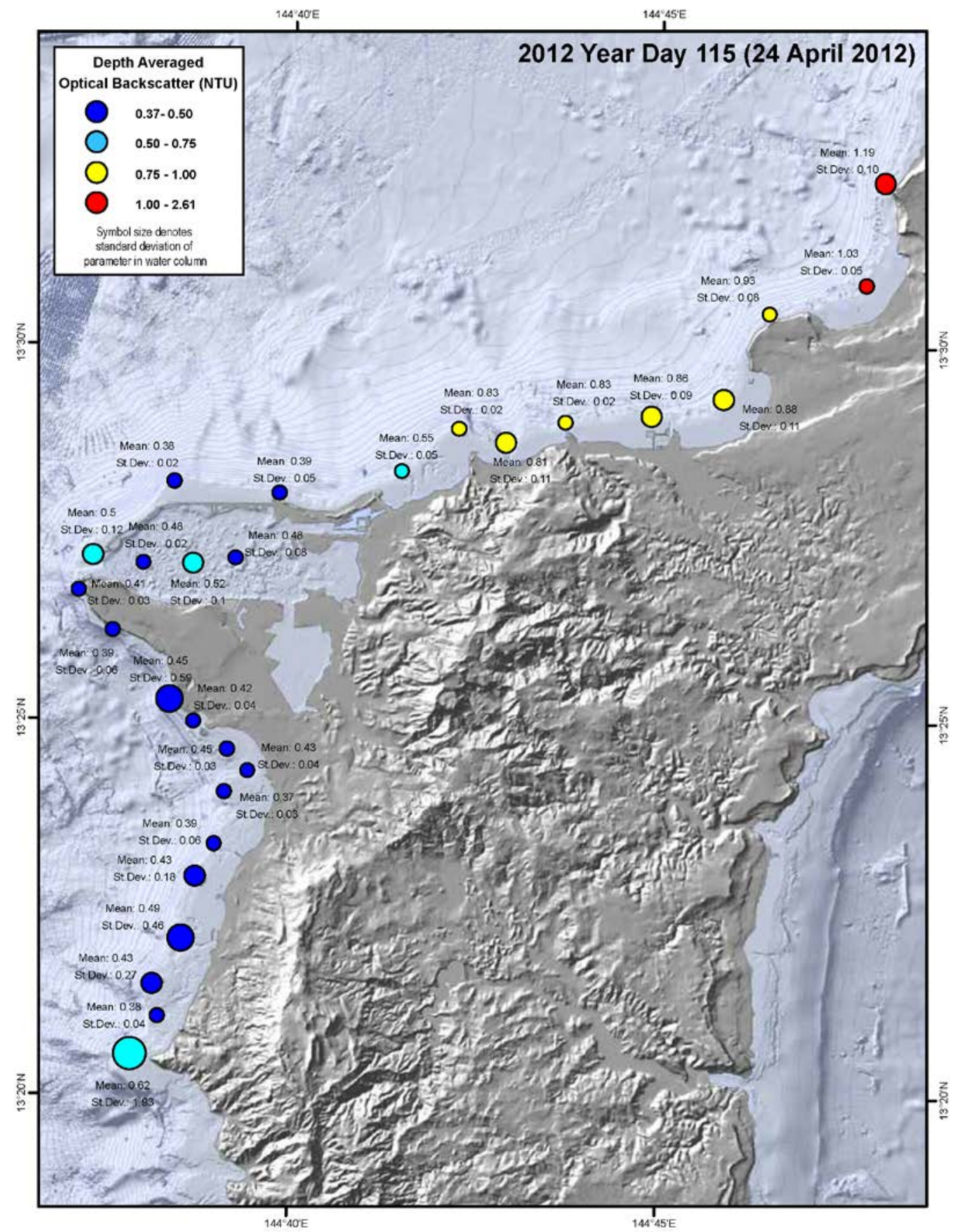

Appendix 7.7. Map showing depth-averaged WCP optical backscatter, in Nephelometric Turbidity Units, from the YD 115 (24 April 2012) survey. 


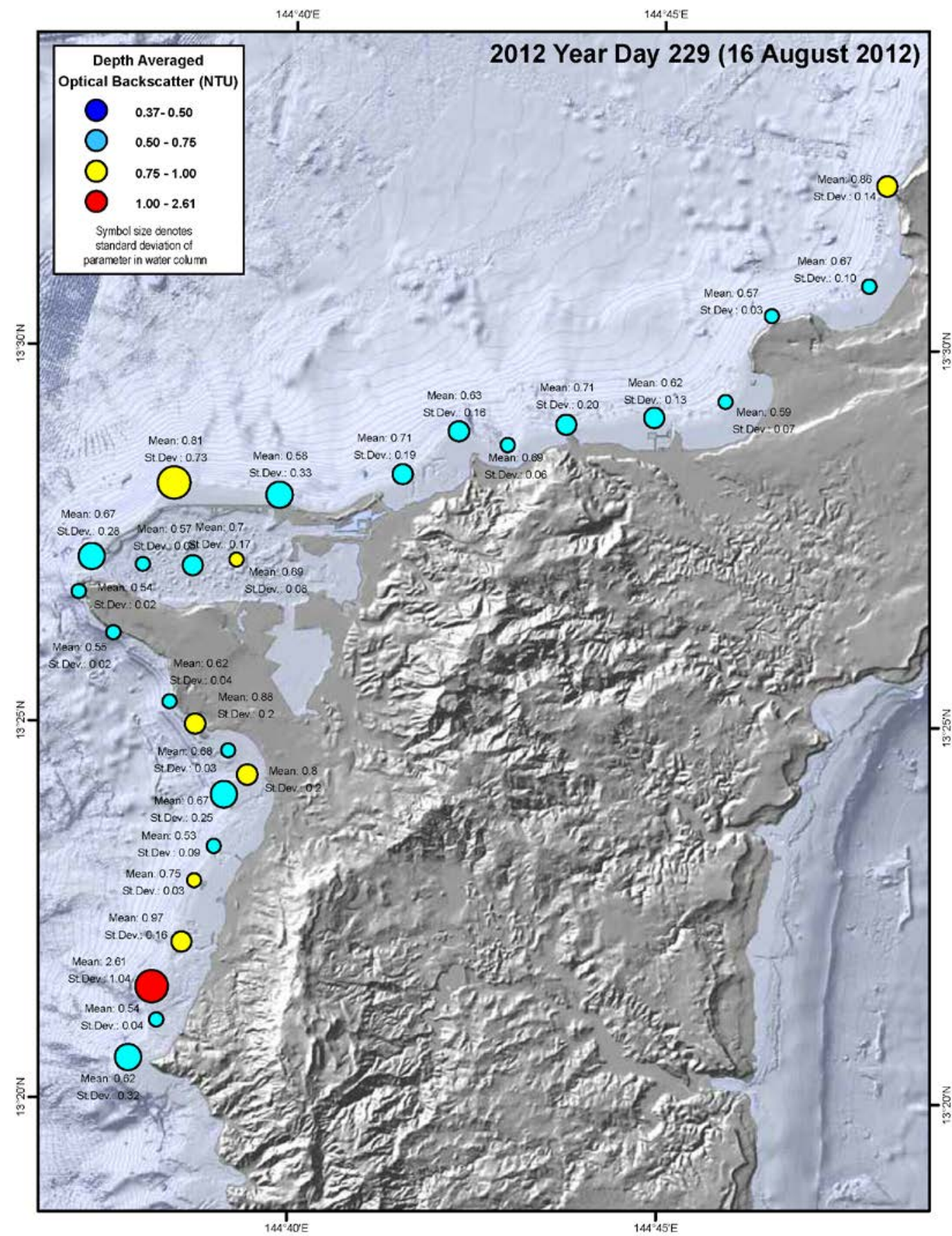

Appendix 7.8. Map showing depth-averaged WCP optical backscatter, in Nephelometric Turbidity Units, from the YD 229 (16 August 2012) survey. 


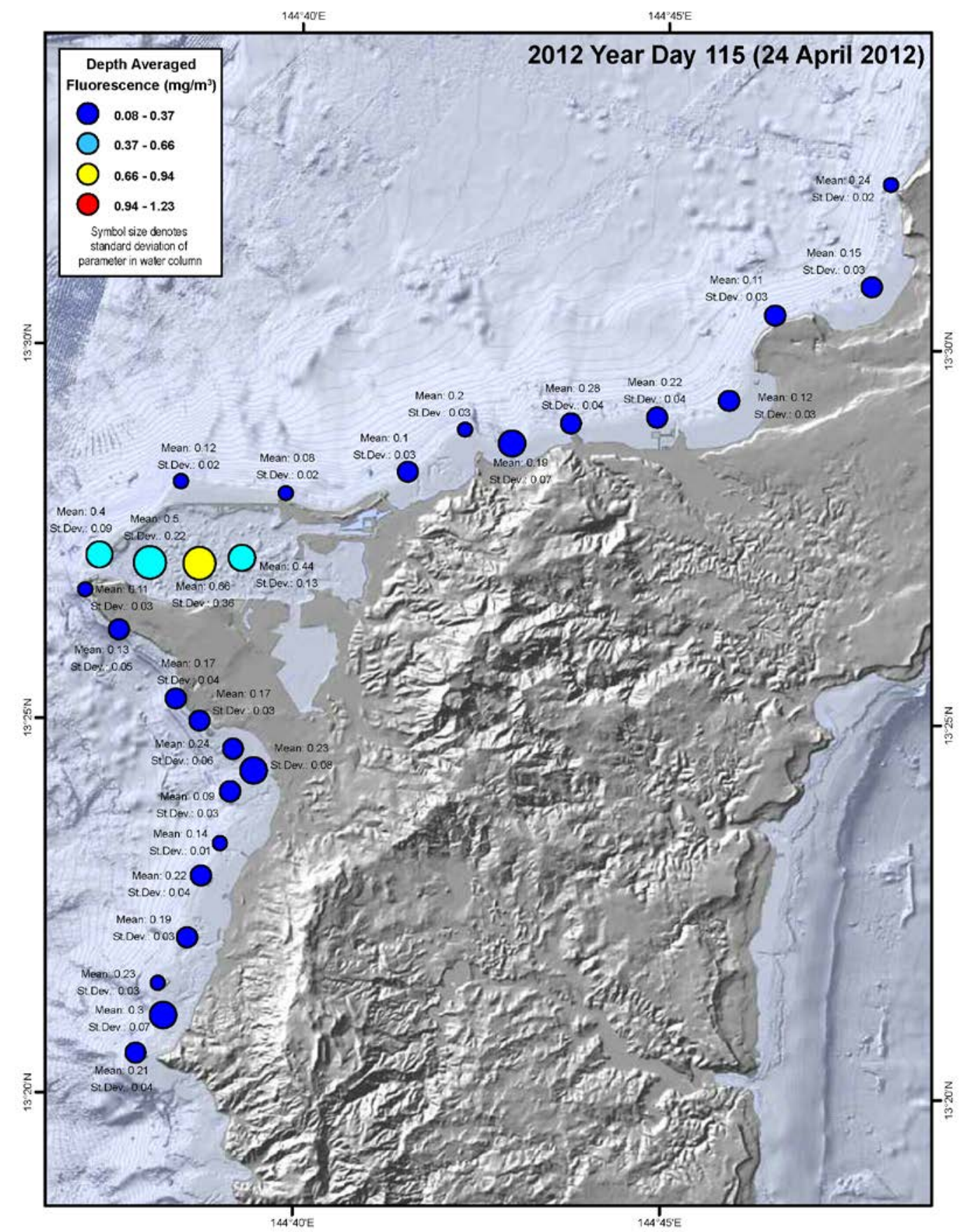

Appendix 7.9. Map showing depth-averaged WCP chlorophyll concentration, in milligrams per cubic meter, from the YD 115 (24 April 2012) survey. 




Appendix 7.10. Map showing depth-averaged WCP chlorophyll concentration, in milligrams per cubic meter, from the YD 229 (16 August 2012) survey. 


\section{Appendix 8. Time-Series Plots and Maps of LCSD Movements}
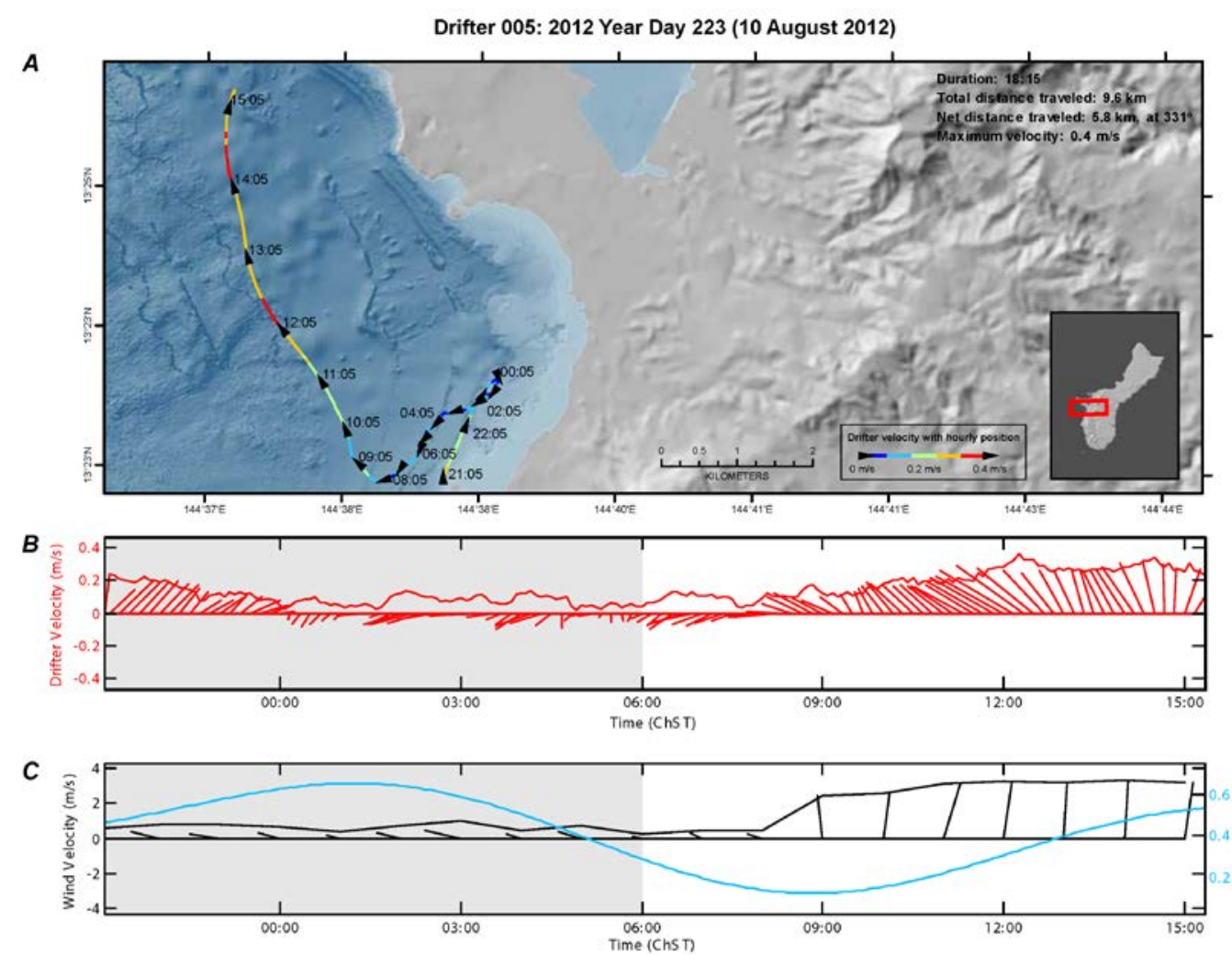

Appendix 8.1. Time series of tide and wind forcing and a map showing the resulting movement of LCSD \#005 on YD 223 (10 August 2012).

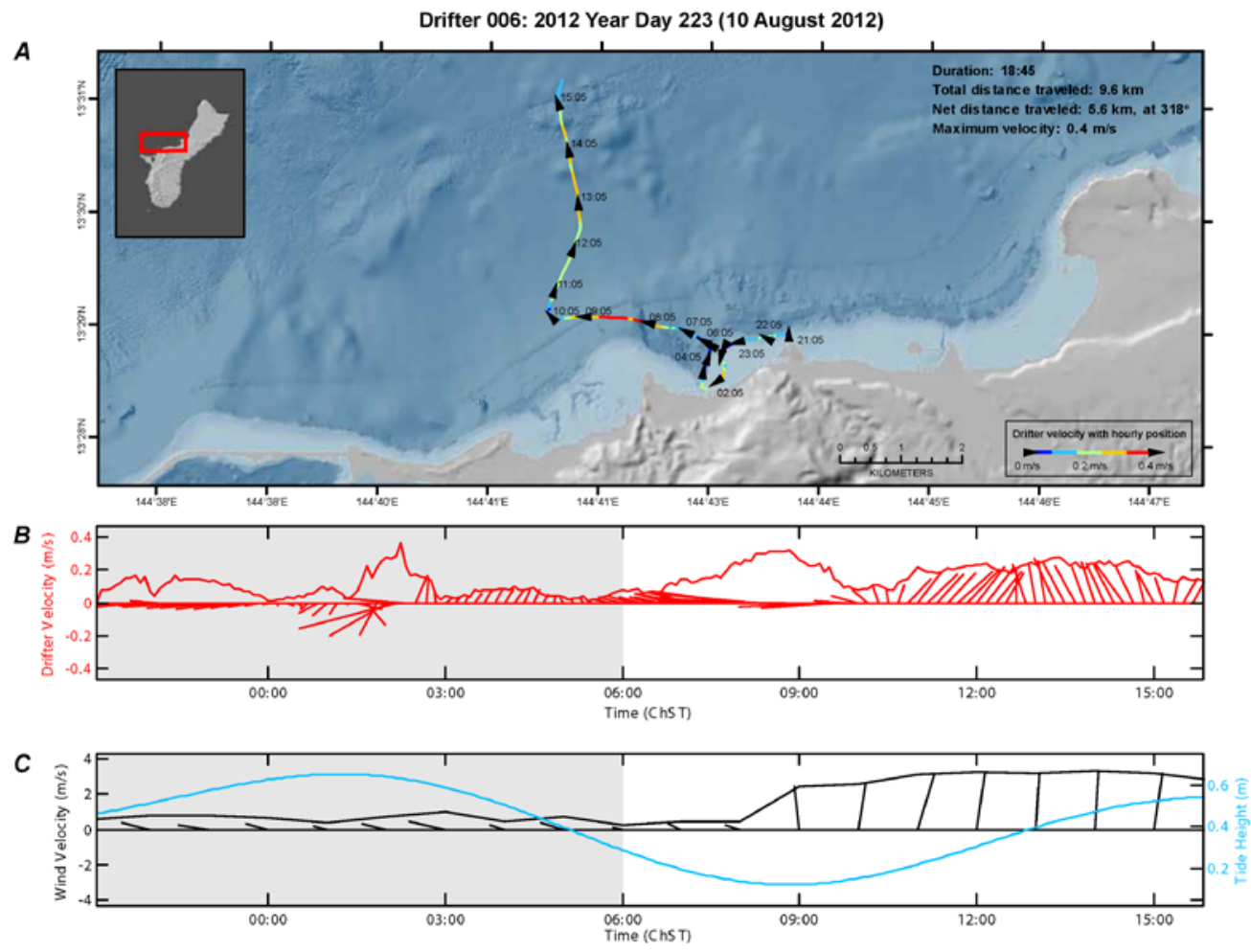

Appendix 8.2. Time series of tide and wind forcing and a map showing the resulting movement of LCSD \#006 on YD 223 (10 August 2012). 

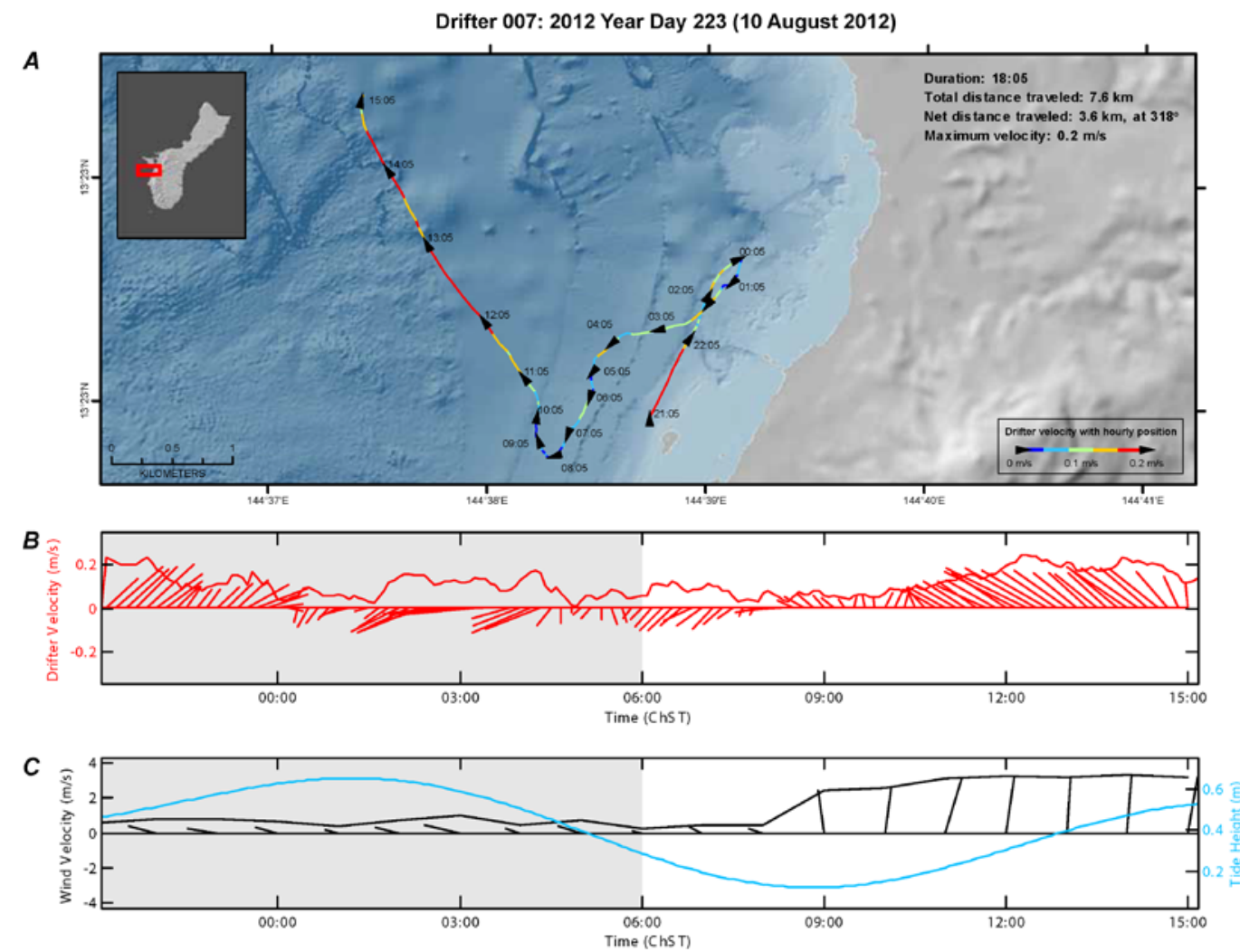

Appendix 8.3. Time series of tide and wind forcing and a map showing the resulting movement of LCSD \#007 on YD 223 (10 August 2012).
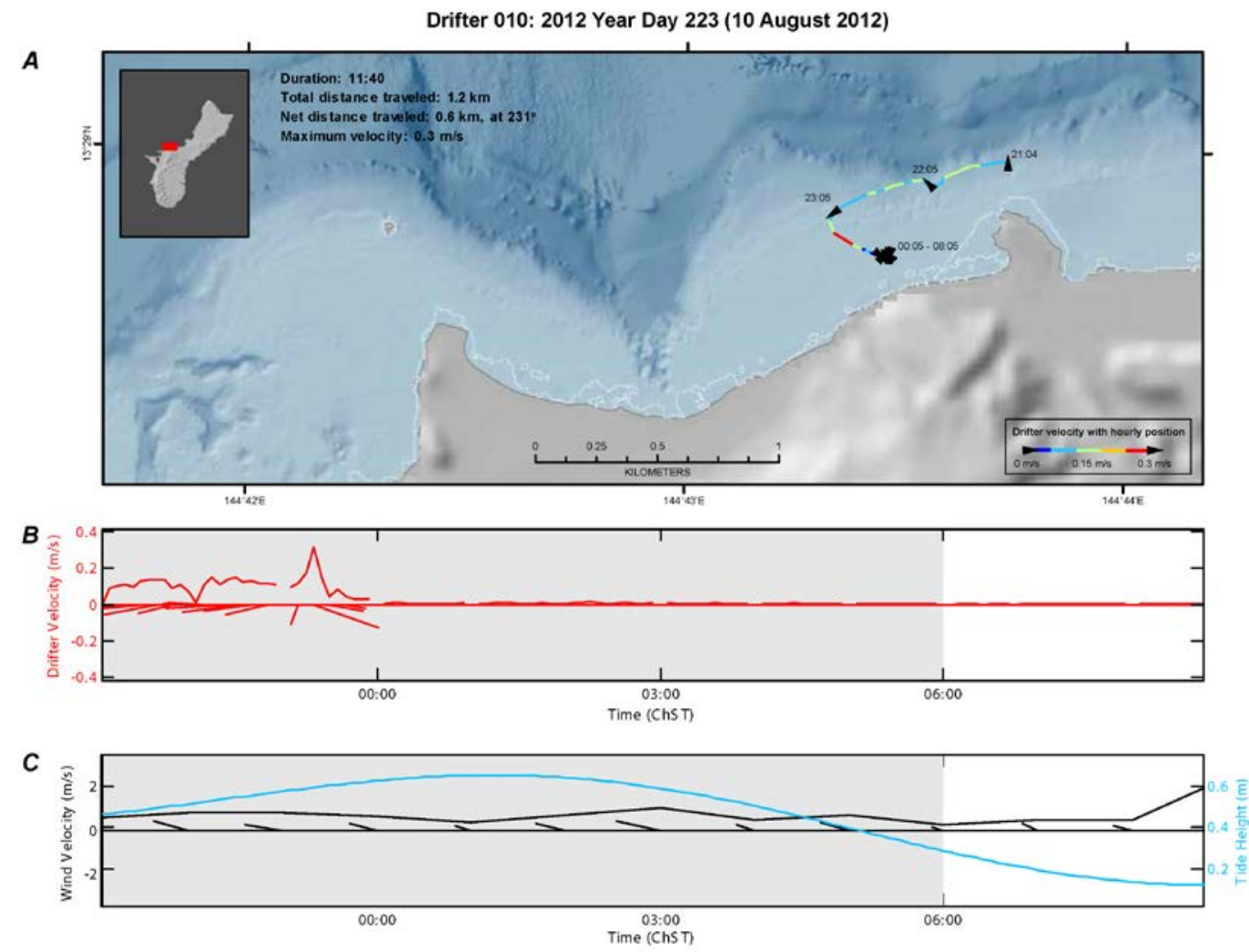

Appendix 8.4. Time series of tide and wind forcing and a map showing the resulting movement of LCSD \#010 on YD 223 (10 August 2012). 

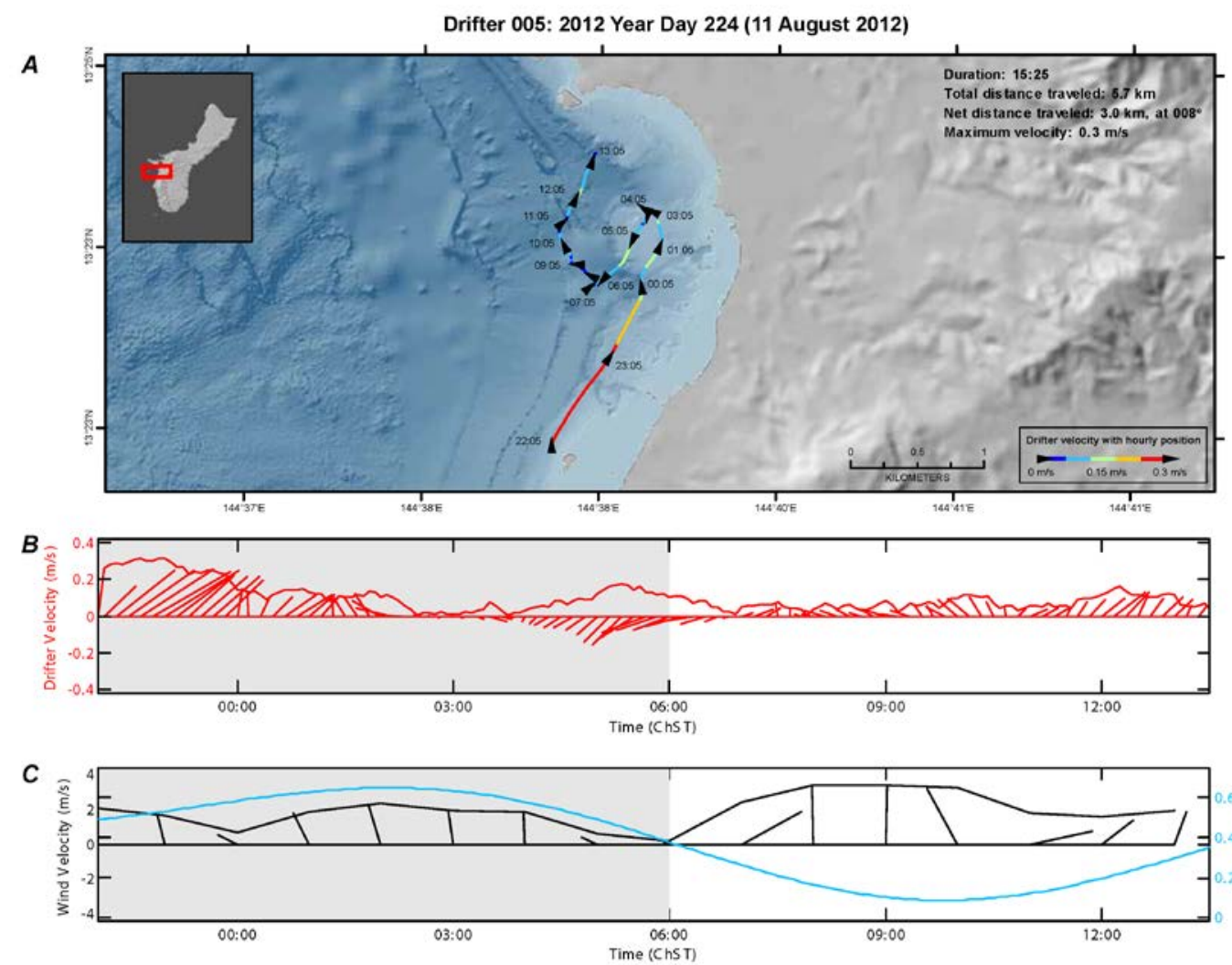

Appendix 8.5. Time series of tide and wind forcing and a map showing the resulting movement of LCSD \#005 on YD 224 (11 August 2012).
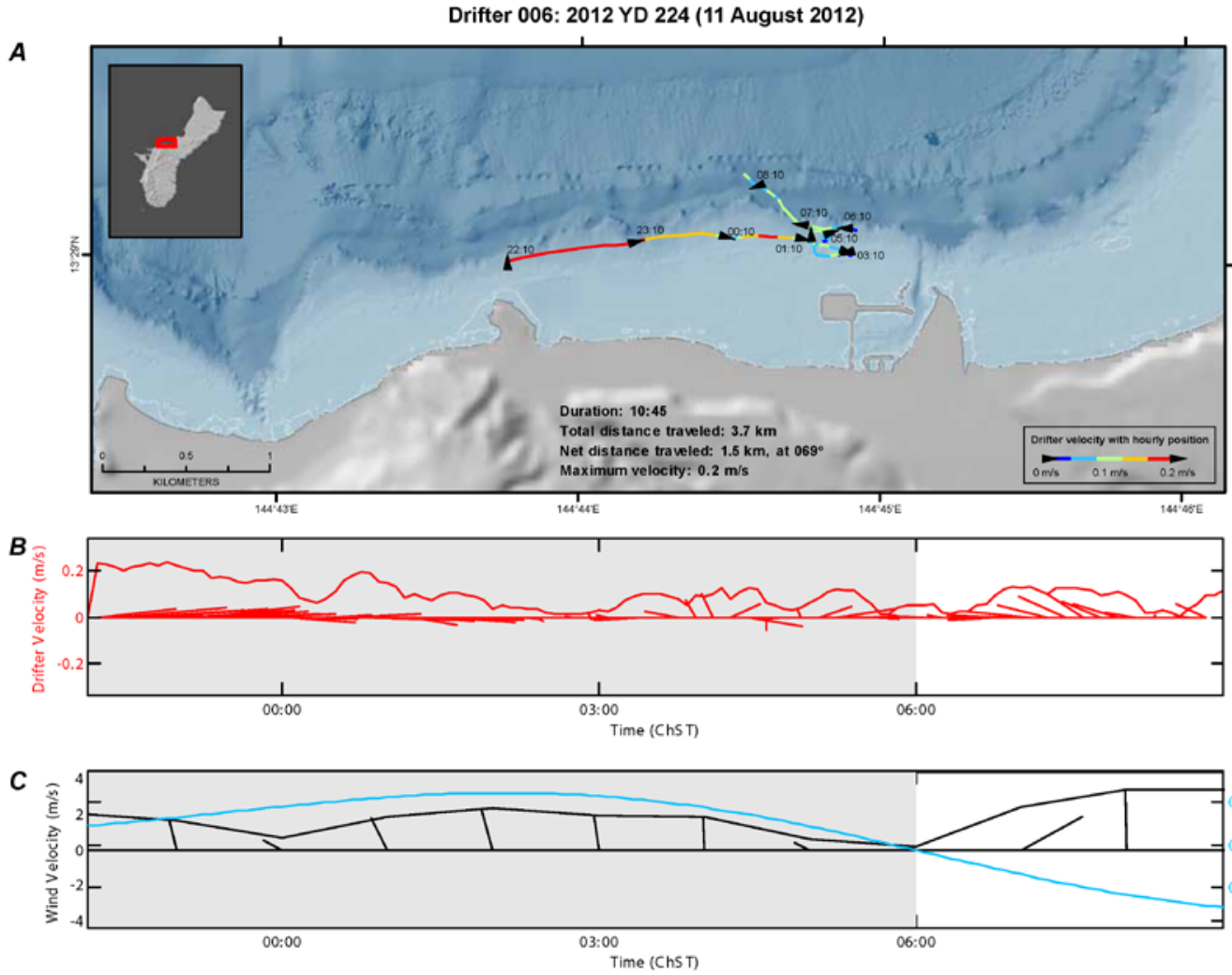

Appendix 8.6. Time series of tide and wind forcing and a map showing the resulting movement of LCSD \#006 on YD 224 (11 August 2012). 

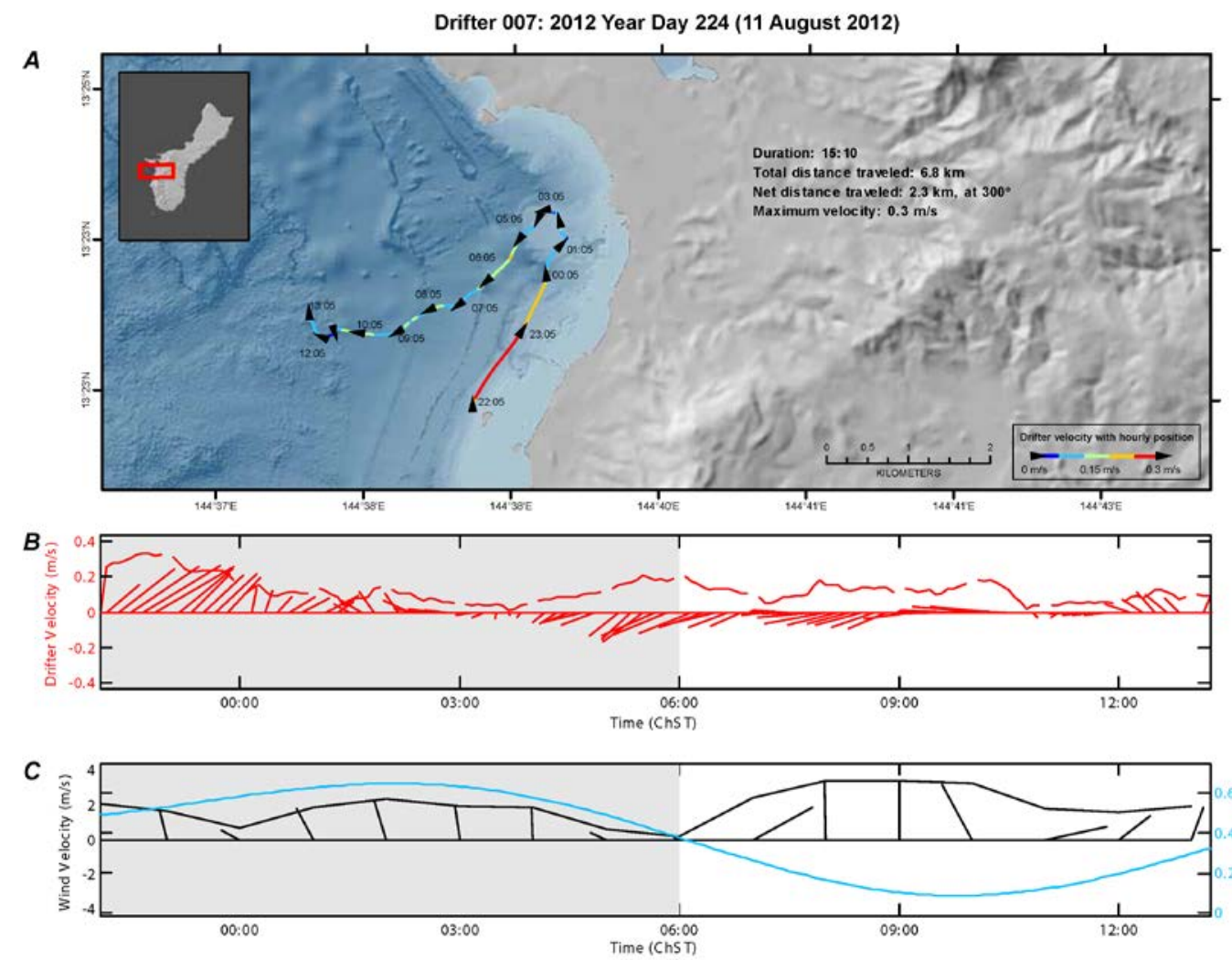

Appendix 8.7. Time series of tide and wind forcing and a map showing the resulting movement of LCSD \#007 on YD 224 (11 August 2012).
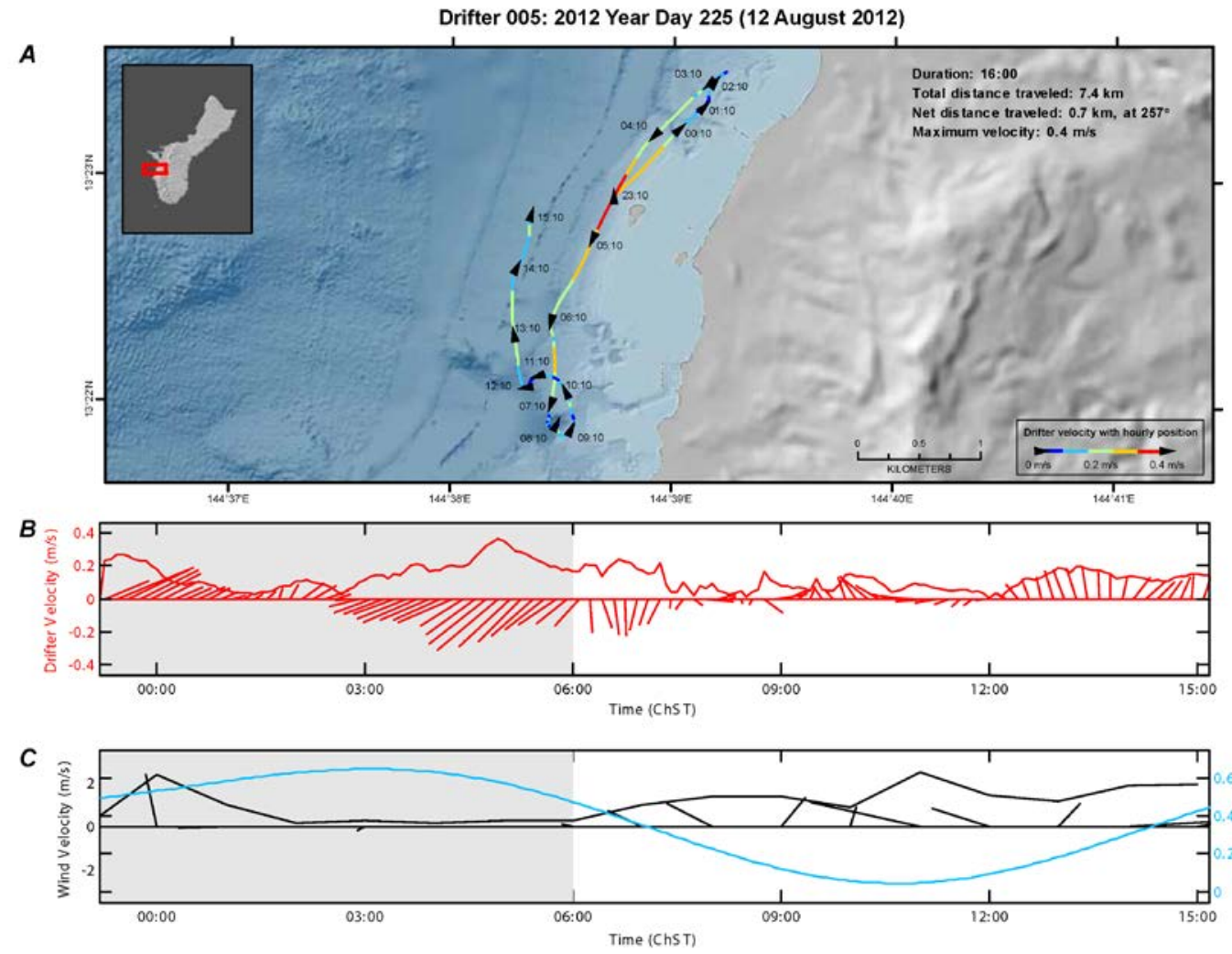

Appendix 8.8. Time series of tide and wind forcing and a map showing the resulting movement of LCSD \#005 on YD 225 (12 August 2012). 

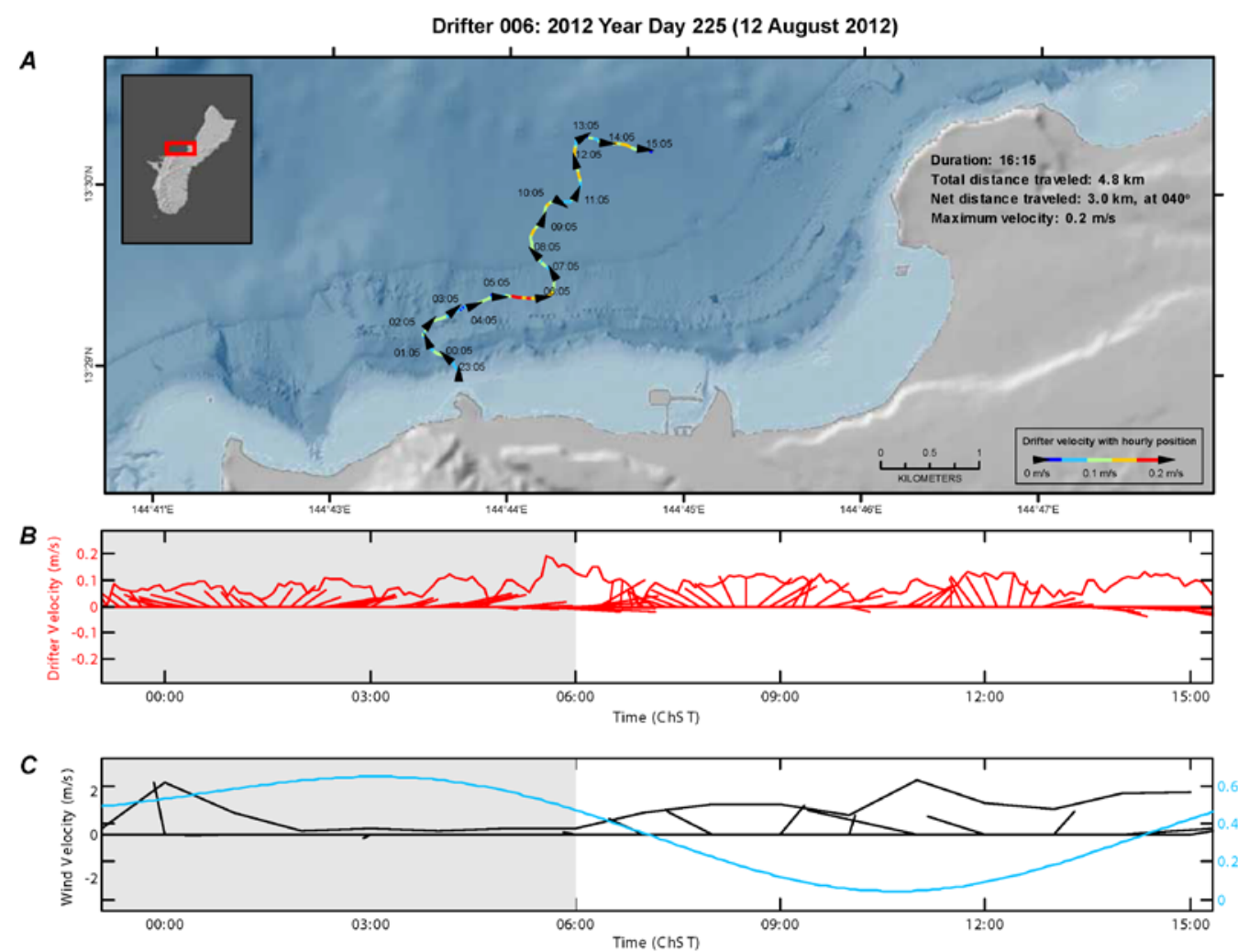

Appendix 8.9. Time series of tide and wind forcing and a map showing the resulting movement of LCSD \#006 on YD 225 (12 August 2012).

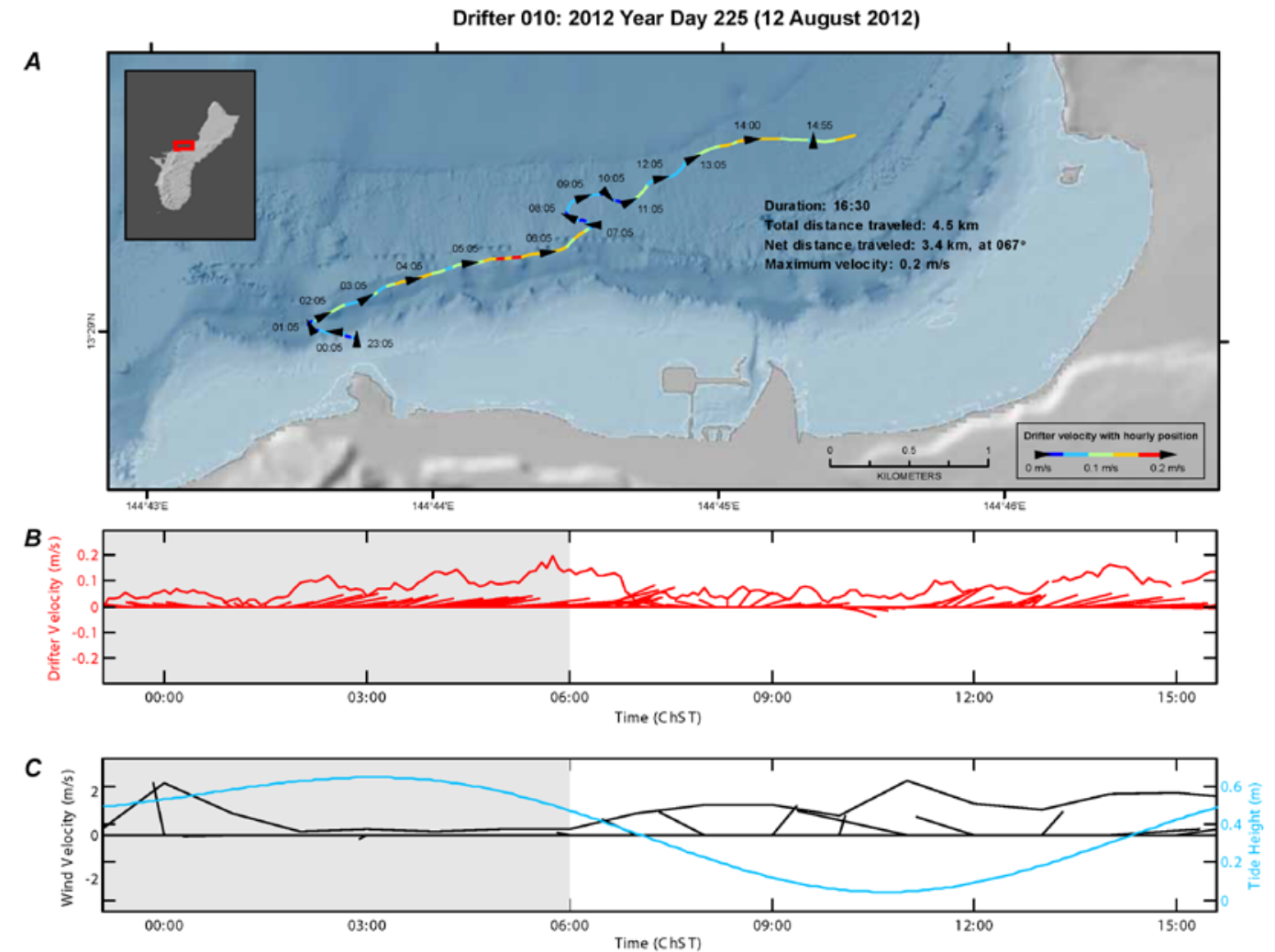

Appendix 8.10. Time series of tide and wind forcing and a map showing the resulting movement of LCSD \#010 on YD 225 (12 August 2012). 


\section{Appendix 9. Plots and Maps of Currents}

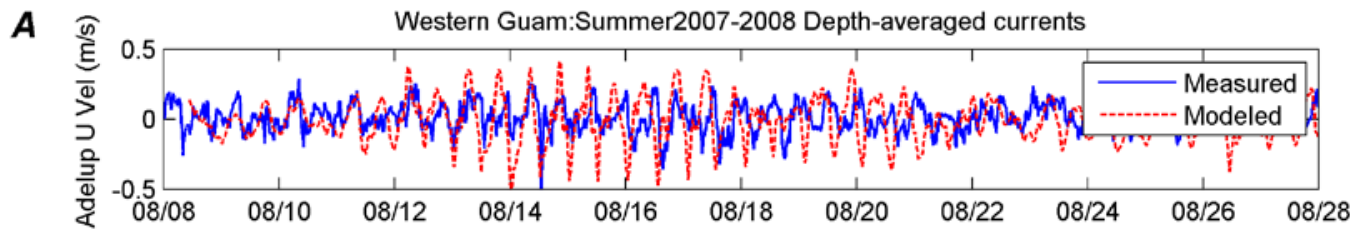

$B$

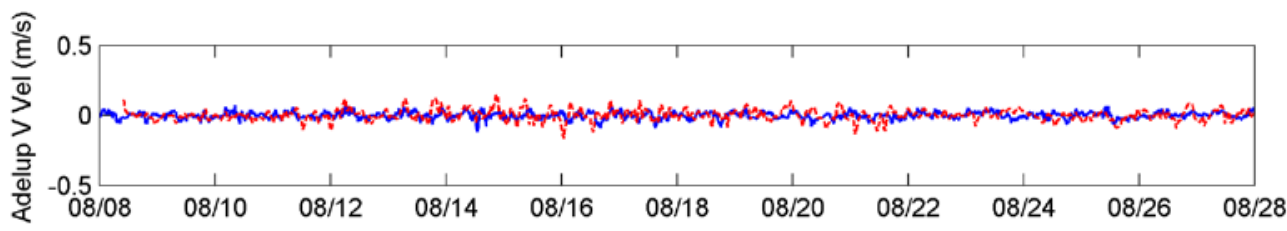

C

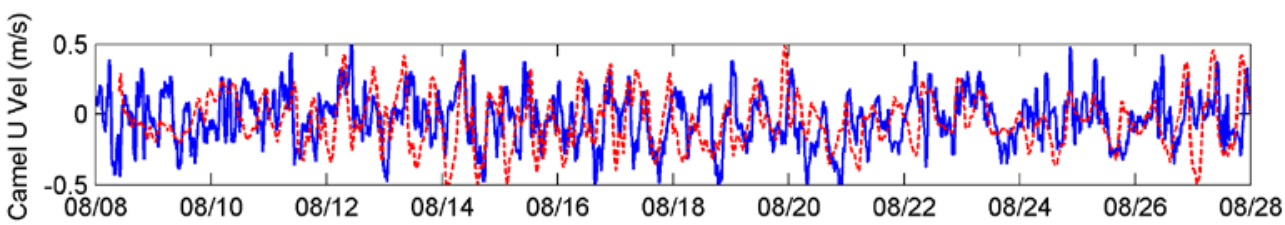

D

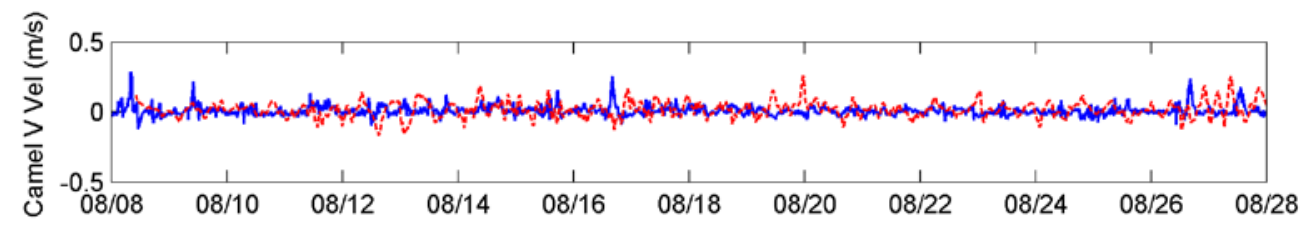

Appendix 9.1. Time series of depth-averaged measured (blue) and modeled (red) current velocities, in meters per second, in August 2007. A, U-velocities off Adelup Point. B, V-velocities off Adelup Point. $C$, U-velocities off Camel Rock. $D$, $\mathrm{V}$-velocities off Camel Rock. $\mathrm{U}$ and $\mathrm{V}$ are eastward and northward current velocities, respectively. 

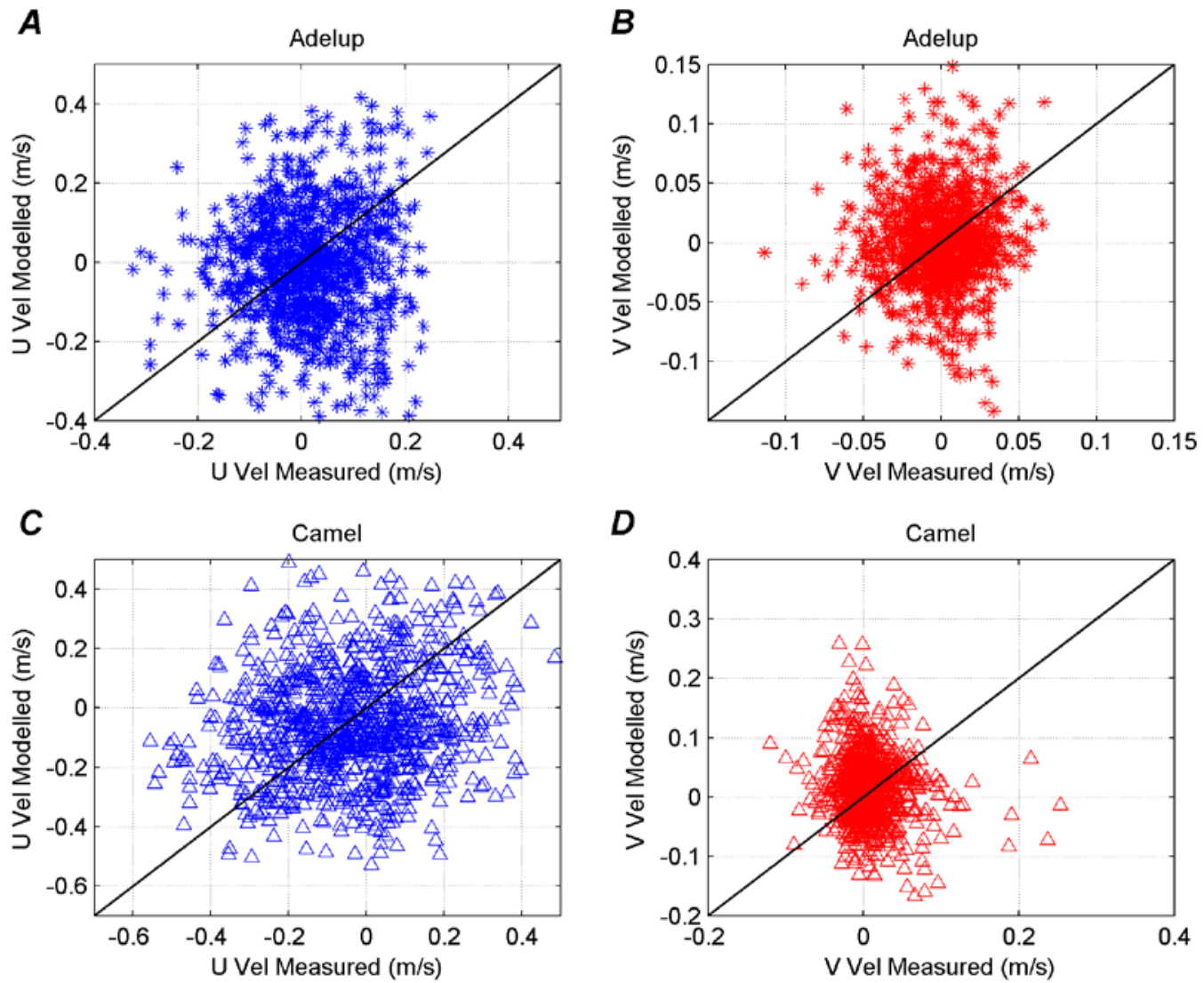

Appendix 9.2. Scatter plots of depth-averaged measured (blue) and modeled (red) current velocities, in meters per second, in August 2007. A, U-velocities off Adelup Point. B, V-velocities off Adelup Point. $C$, U-velocities off Camel Rock. $D$, $\mathrm{V}$-velocities off Camel Rock. $\mathrm{U}$ and $\mathrm{V}$ are eastward and northward current velocities, respectively. 

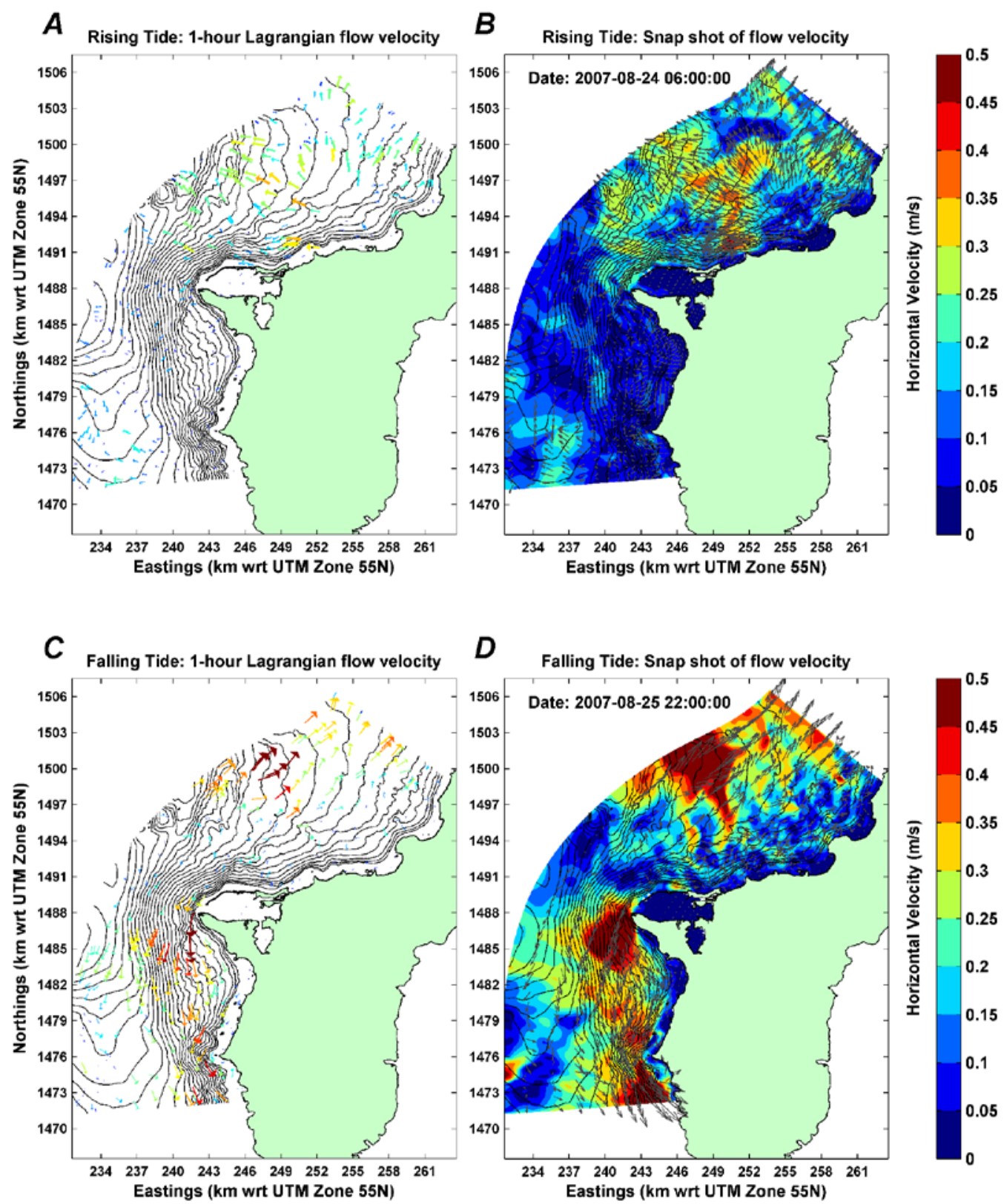

Appendix 9.3. Maps of depth-averaged modeled horizontal currents, with direction in degrees from true north and speed in meters per second, in August 2007. A, Average flow speeds, flow directions, and resulting patterns of net flow over 1 hour during rising (flood) tides. $B$, Current speeds and direction over 1 hour during rising (flood) tides. $C$, Average flow speeds, flow directions, and resulting patterns of net flow over 1 hour during falling (ebb) tides. $D$, Current speeds and directions over 1 hour during falling (ebb) tides. 

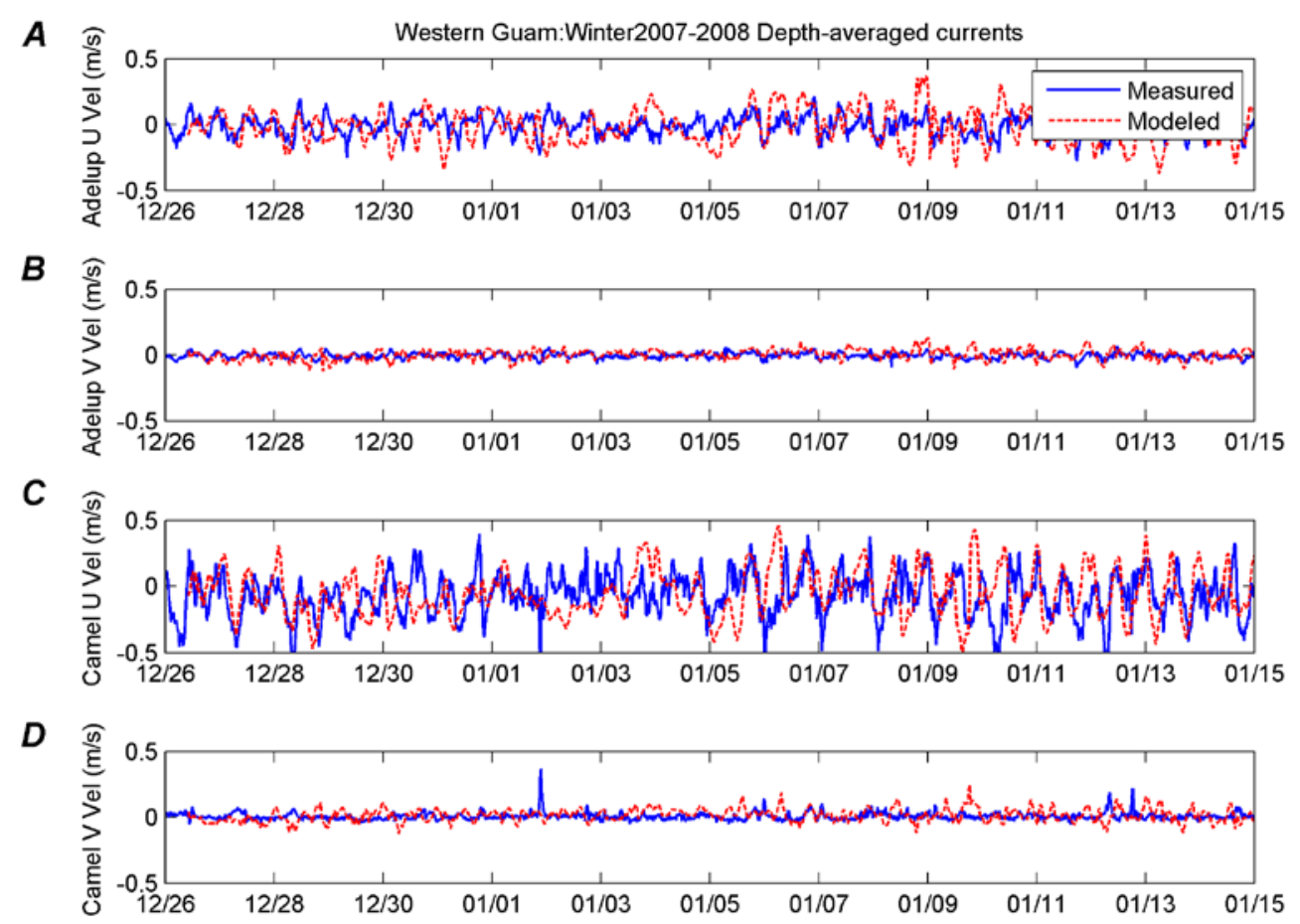

Appendix 9.4. Time series of depth-averaged measured (blue) and modeled (red) current velocities, in meters per second, in December 2007-January 2008. A, U-velocities off Adelup Point. B, V-velocities off Adelup Point. C, U-velocities off Camel Rock. D, V-velocities off Camel Rock. U and V are eastward and northward current velocities, respectively.
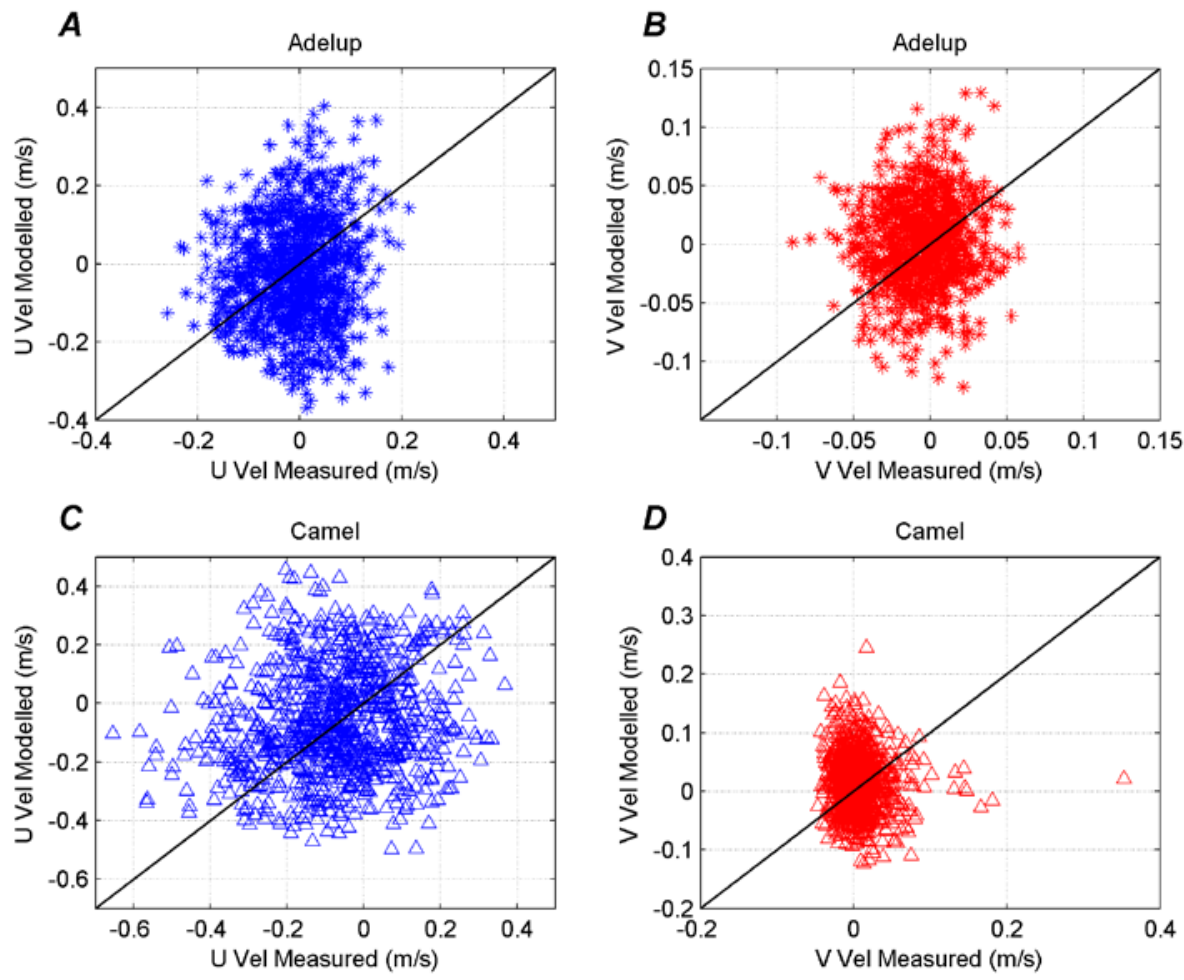

Appendix 9.5. Scatter plots of depth-averaged measured (blue) and modeled (red) current velocities, in meters per second, in December 2007-January 2008. A, U-velocities off Adelup Point. B, V-velocities off Adelup Point. C, U-velocities off Camel Rock. D, V-velocities off Camel Rock. U and V are eastward and northward current velocities, respectively. 

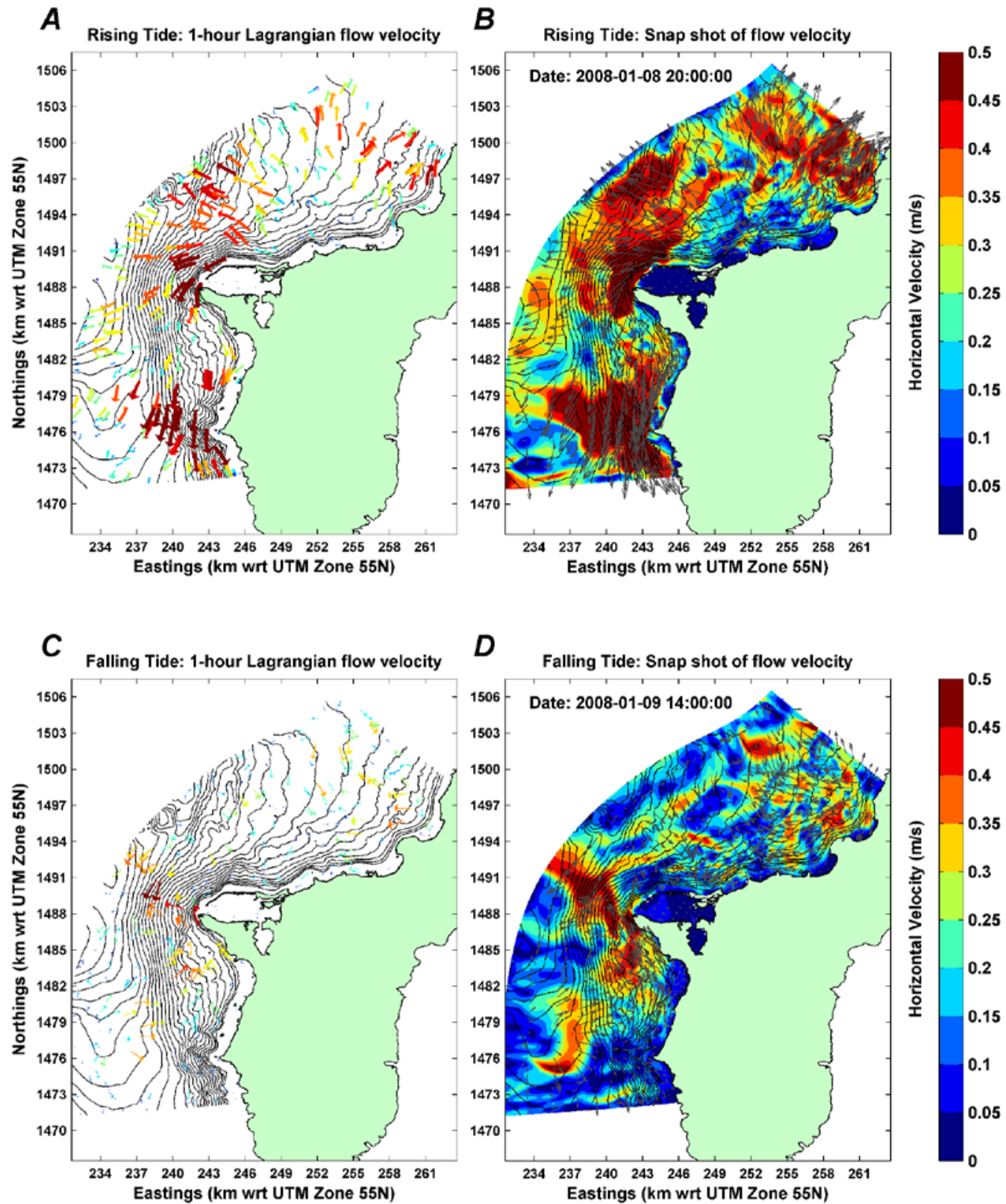

Appendix 9.6. Maps of depth-averaged modeled horizontal currents, with direction in degrees from true north and speed in meters per second, in December 2007-January 2008. A, Average flow speeds, flow directions, and resulting patterns of net flow over 1 hour during rising (flood) tides. $B$, Current speeds and direction over 1 hour during rising (flood) tides. $C$, Average flow speeds, flow directions, and resulting patterns of net flow over 1 hour during falling (ebb) tides. $D$, Current speeds and directions over 1 hour during falling (ebb) tides. 


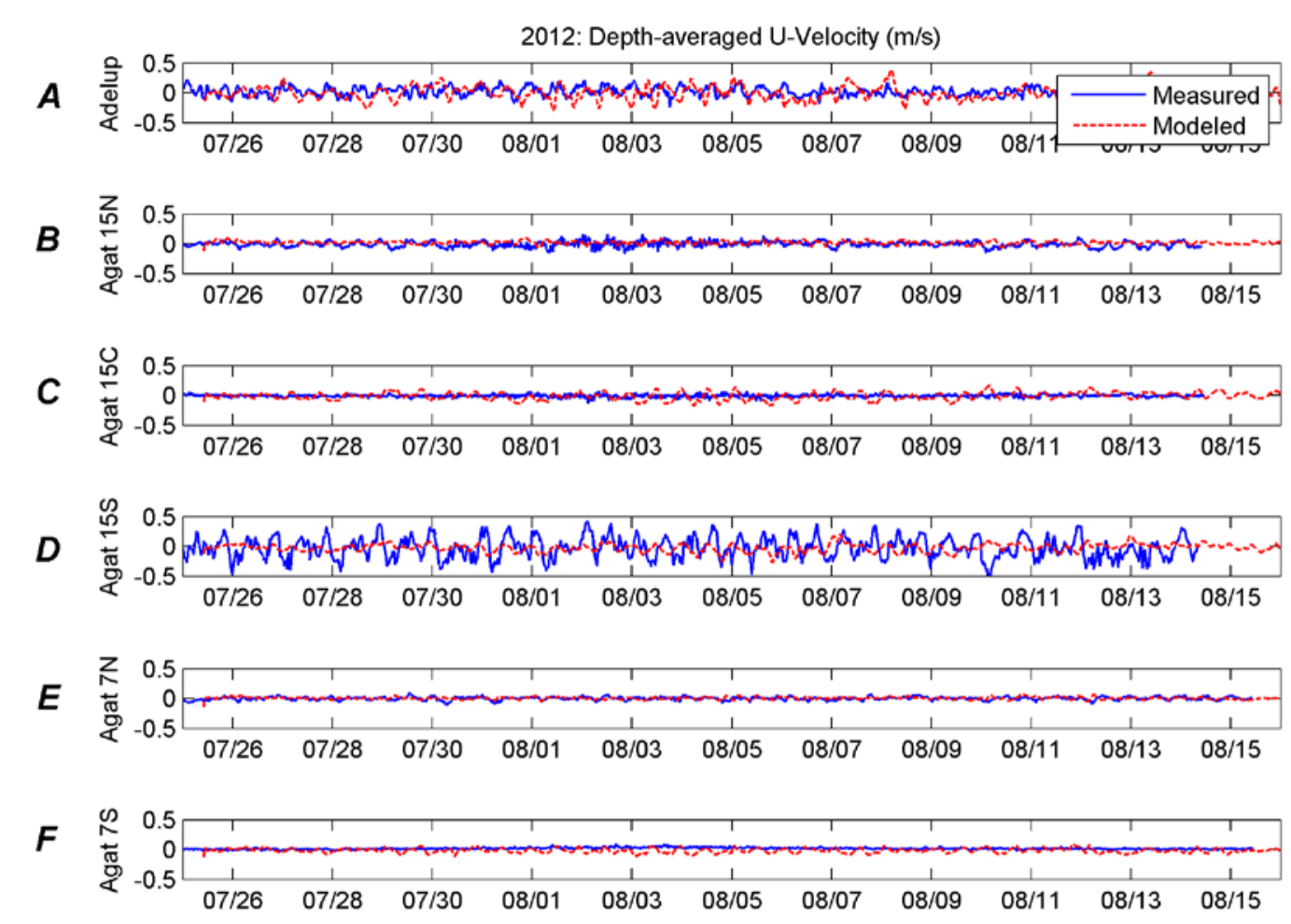

Appendix 9.7. Time series of depth-averaged measured (blue) and modeled (red) U-velocities, in meters per second, in April-May 2012. A, Adelup site. B, Agat 15-m North site. C, Agat 15-m Central site. D, Agat 15-m South site. E, Agat 7-m North site. F, Agat 7-m South site. U are eastward current velocities.

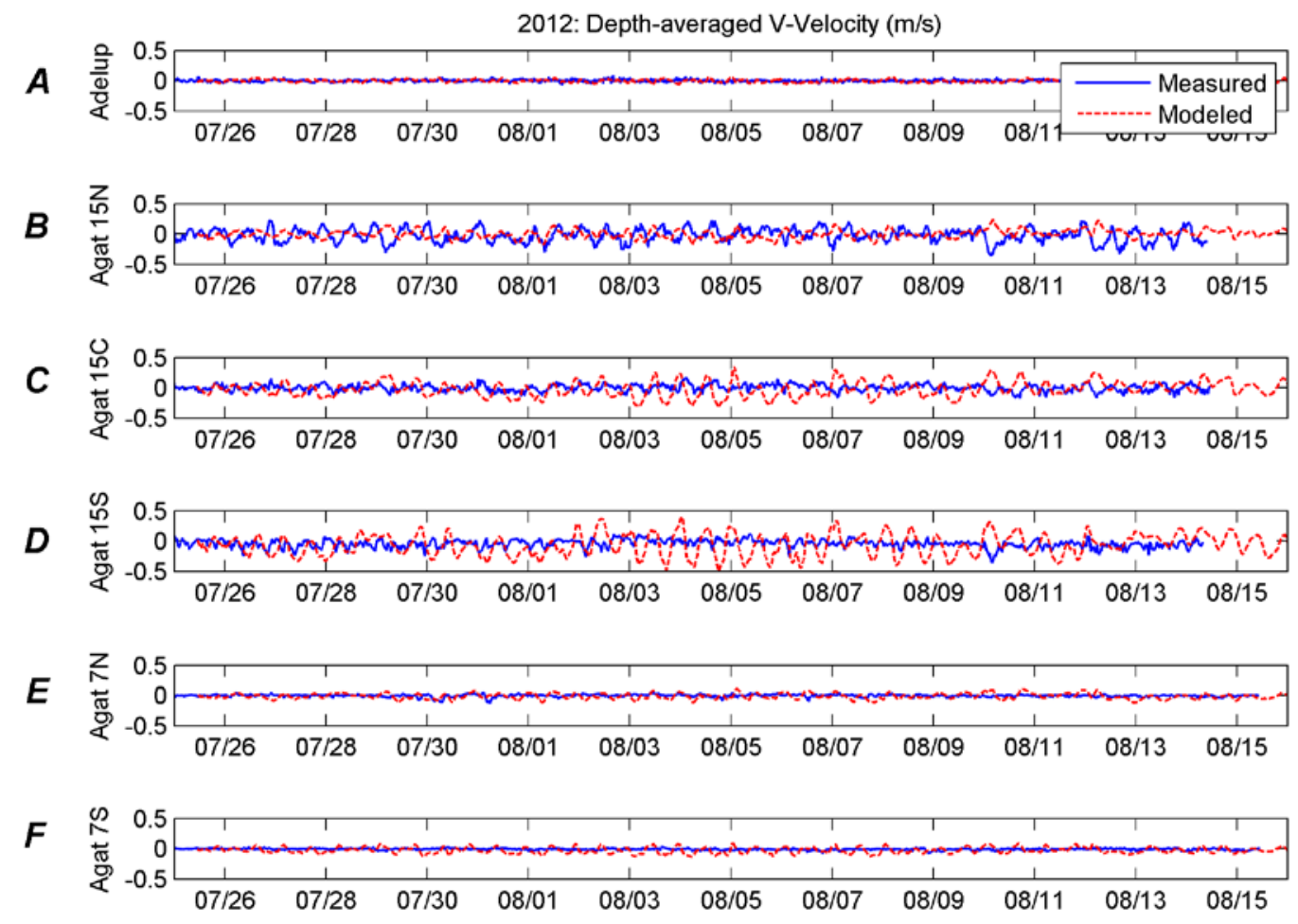

Appendix 9.8. Time series of depth-averaged measured (blue) and modeled (red) V-velocities, in meters per second, in April-May 2012. A, Adelup site. B, Agat 15-m North site. C, Agat 15-m Central site. D, Agat 15-m South site. E, Agat 7-m North site. F, Agat 7-m South site. V are northward current velocities. 

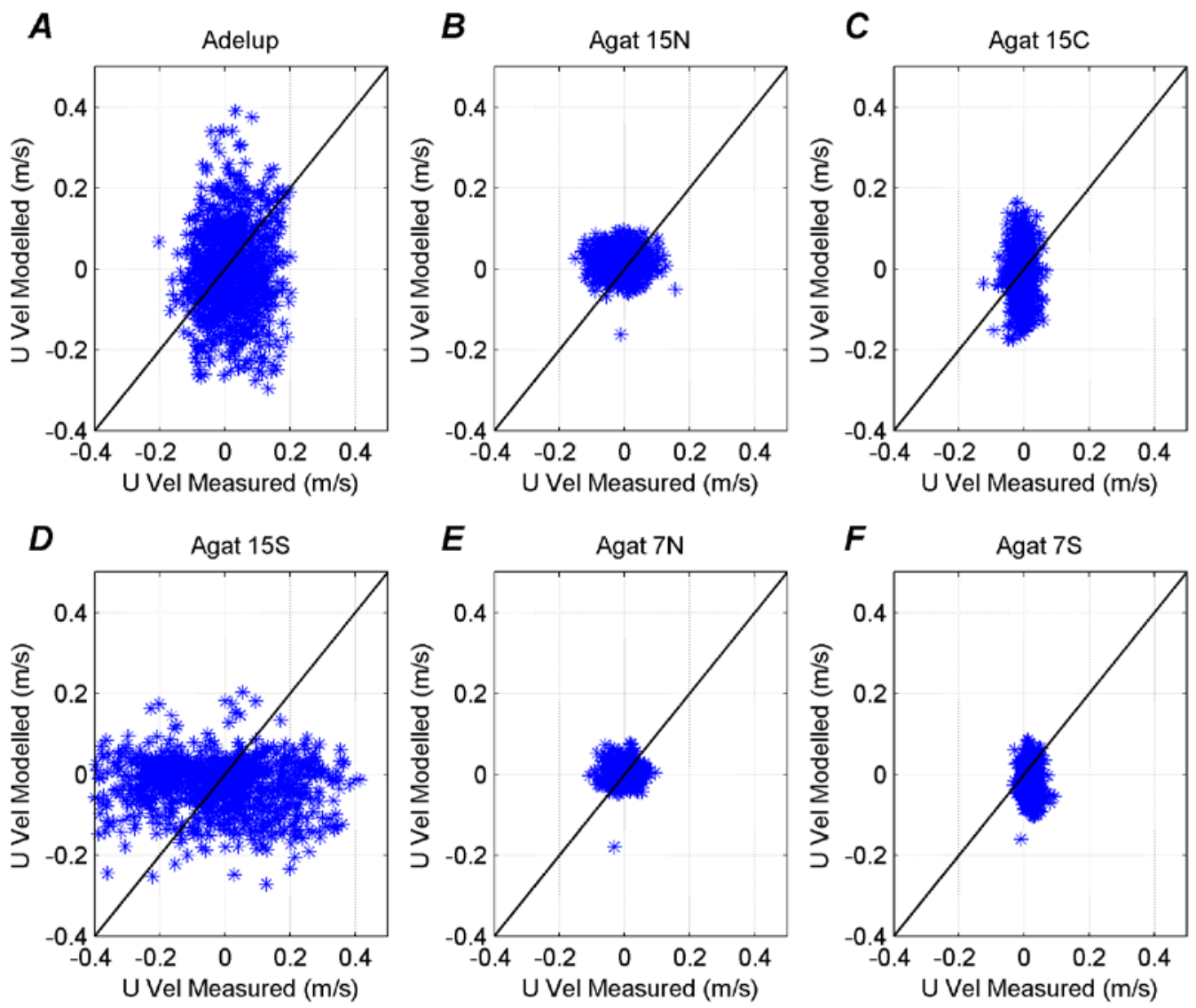

Appendix 9.9. Scatter plots of depth-averaged measured (blue) and modeled (red) U-velocities, in meters per second, in April-May 2012. A, Adelup site. B, Agat 15-m North site. C, Agat 15-m Central site. D, Agat 15-m South site. E, Agat 7-m North site. F, Agat 7-m South site. U are eastward current velocities. 

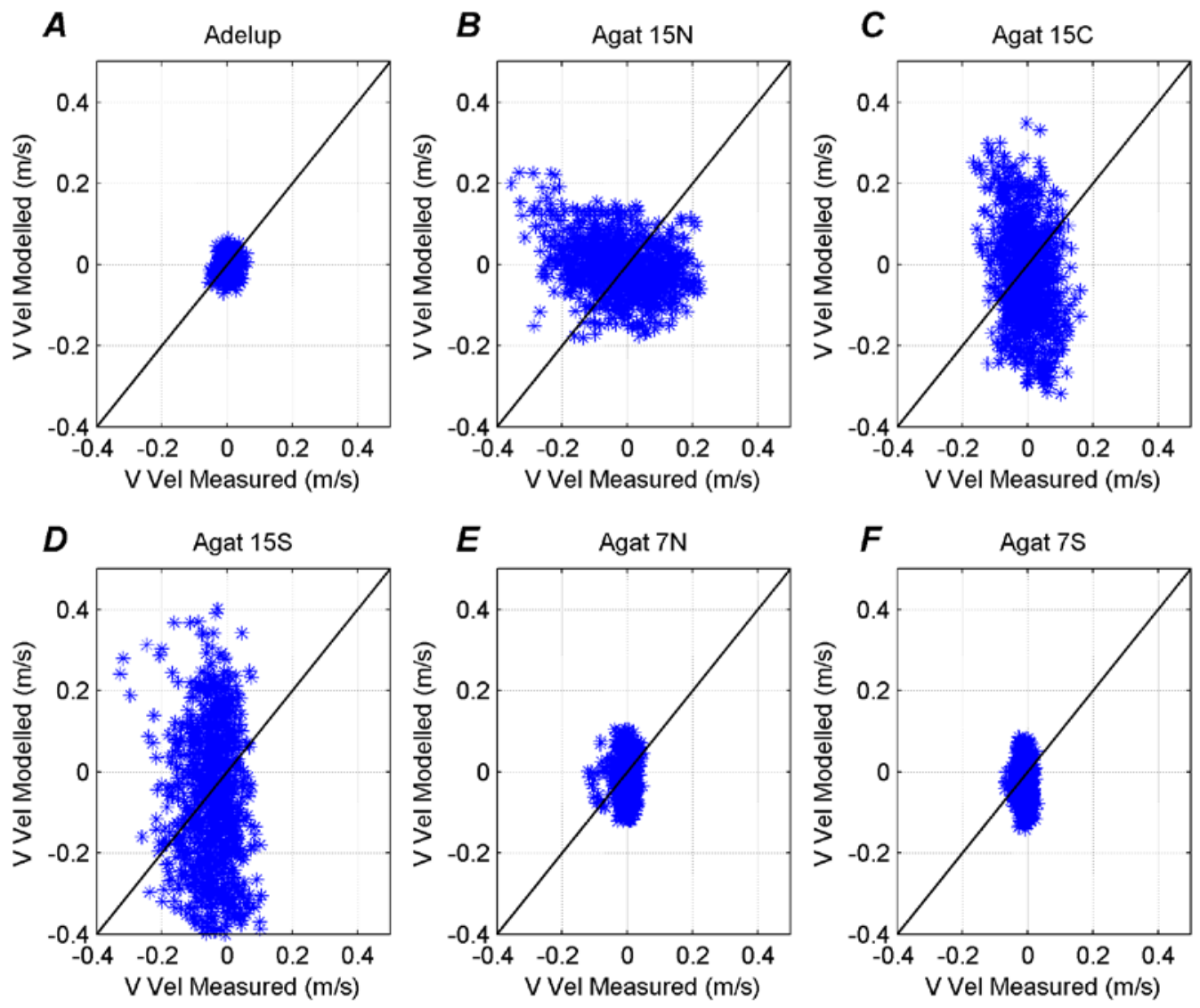

Appendix 9.10. Scatter plots of depth-averaged measured (blue) and modeled (red) V-velocities, in meters per second, in April-May 2012. A, Adelup site. B, Agat 15-m North site. C, Agat 15-m Central site. $D$, Agat 15 -m South site. E, Agat 7-m North site. F, Agat 7-m South site. V are northward current velocities. 

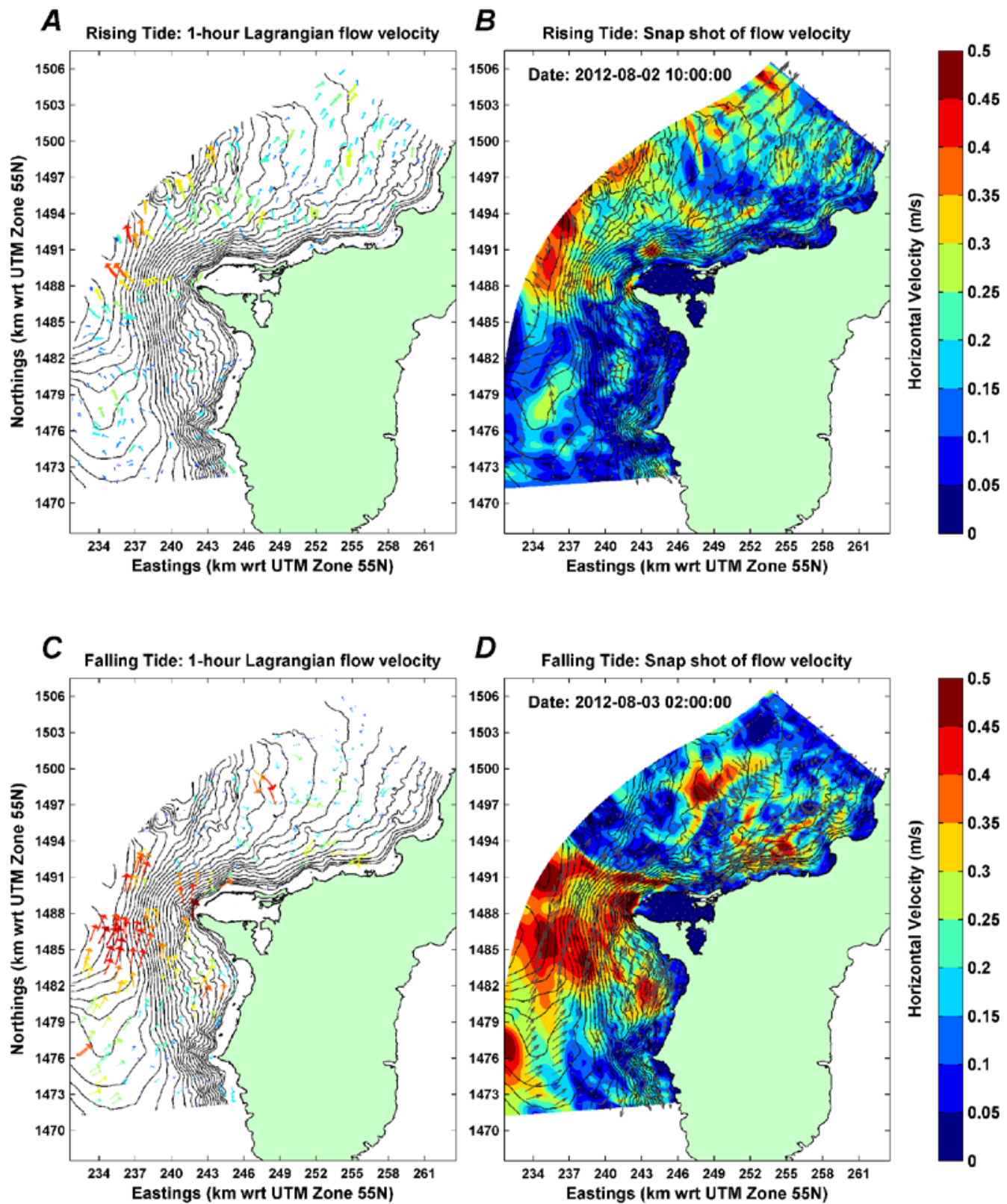

Appendix 9.11. Maps of depth-averaged modeled horizontal currents, with direction in degrees from true north and speed in meters per second, in July-August 2012. A, Average flow speeds, flow directions, and resulting patterns of net flow over 1 hour during rising (flood) tides. $B$, Current speeds and direction over 1 hour during rising (flood) tides. $C$, Average flow speeds, flow directions, and resulting patterns of net flow over 1 hour during falling (ebb) tides. $D$, Current speeds and directions over 1 hour during falling (ebb) tides. 


\section{Appendix 10. Plots and Table of Wind and Wave Data}

A

Station PGBP7 - 1631428 - Pago Bay, Guam: 2009-2011 Wind Speed (m/s)

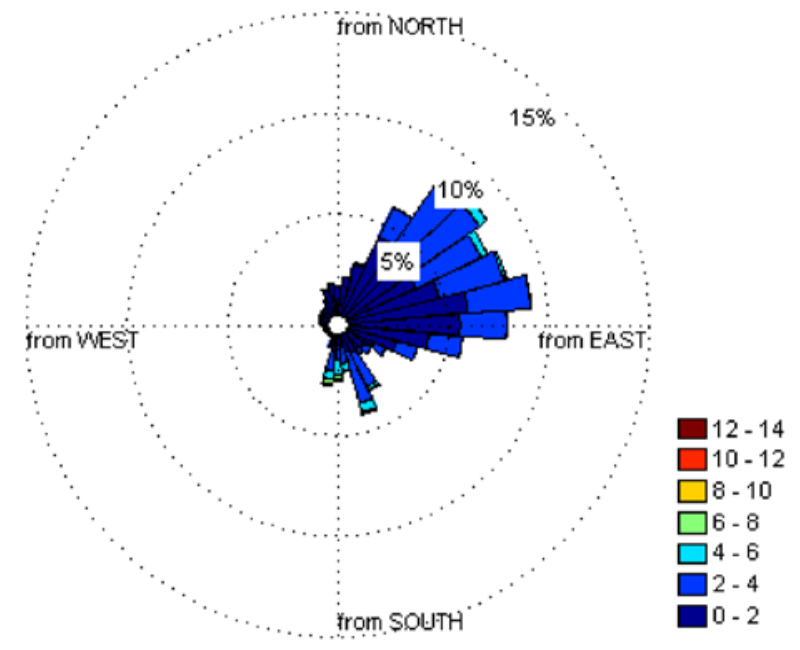

B

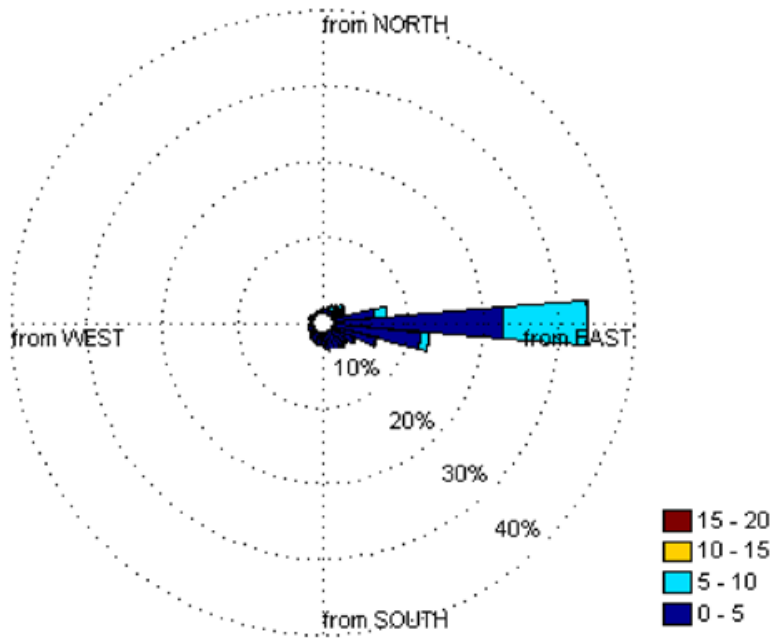

Appendix 10.1. Directional plots of variations in wind speed, in meters per second, by wind direction, in compass orientation, based on NCDC (2013) data for the years 2009-2011. A, Data from station PGBP7 at Pago Bay, Guam. B, Data from station APRP7 at Apra Harbor, Guam. Radial axis, frequency of occurrence, in percent, increase outward from the center of the plot. 

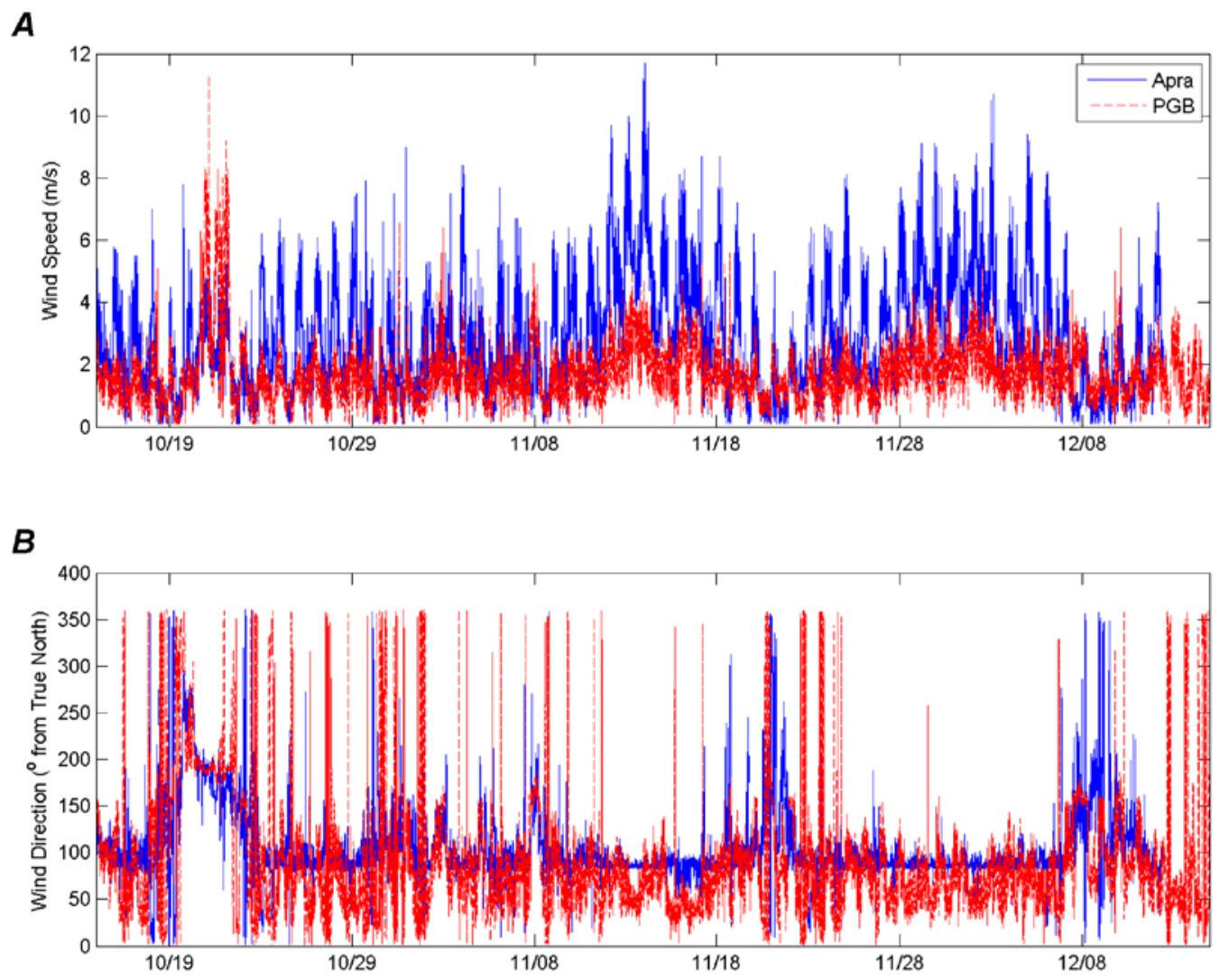

Appendix 10.2. Time series wind data from NCDC (2013) stations PGBP7 at Pago Bay, Guam (red), and APRP7 at Apra Harbor, Guam (blue) from October-December 2012. A, Wind speed, in meters per second. $B$, Wind direction, in degrees from true north. 
A

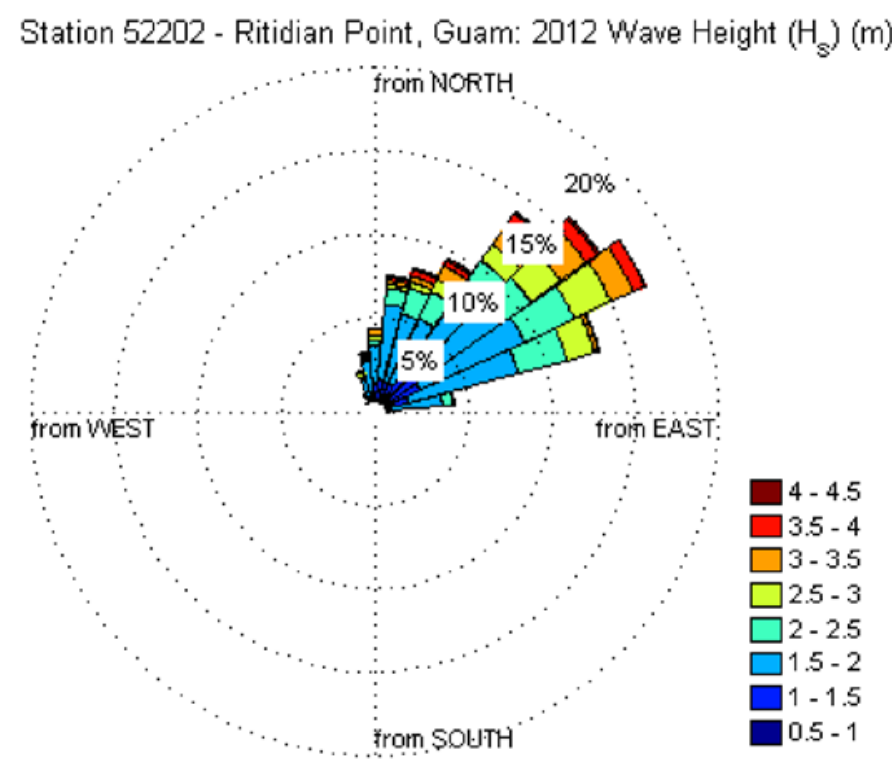

B

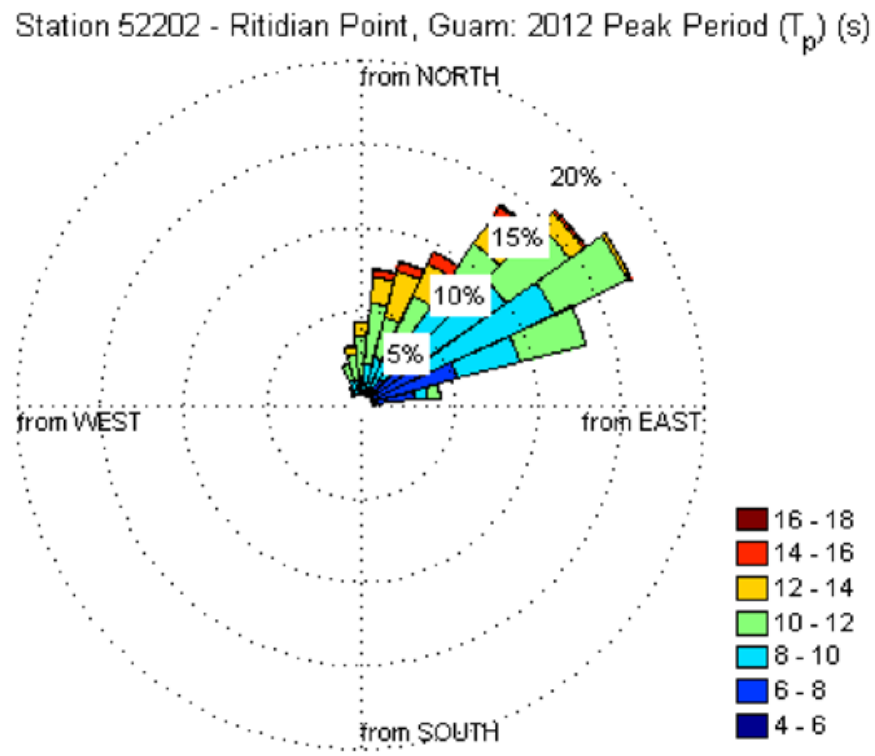

Appendix 10.3. Directional plots of variations in wave parameters, by wave direction, in compass orientation, based on NDBC (2013) station 52202 at Ritidian Point, Guam, for October-December, 2012. A, Wave height, in meters. $B$, Wave period, in seconds. Radial axis, frequency of occurrence, in percent, increases outward from the center of the plot. 
Appendix 10.4. Table summarizing wave data from NDBC (2013) station 52202 at Ritidian Point, Guam, for October-December, 2012, including the number of sample points, minimum, maximum, and average wave period, in seconds, per wave height range, in meters.

\begin{tabular}{|ccccc|}
\hline $\begin{array}{c}\text { Wave height range } \\
(\mathbf{m})\end{array}$ & Number of data points & $\begin{array}{c}\text { Minimum wave period } \\
(\mathbf{s})\end{array}$ & $\begin{array}{c}\text { Maximum wave period } \\
(\mathbf{s})\end{array}$ & $\begin{array}{c}\text { Average wave period } \\
(\mathbf{s})\end{array}$ \\
\hline$<1$ & 365 & 7.7 & 12.5 & 9.8 \\
$1-2$ & 836 & 5.6 & 16.7 & 9.9 \\
$2-3$ & 1968 & 5.0 & 16.7 & 10.2 \\
$>3$ & 11 & 8.3 & 9.9 & 9.2 \\
\hline
\end{tabular}

